Universidade Federal de Juiz de Fora

Instituto de CiênCias Exatas

Pós-graduaÇÃo EM Física

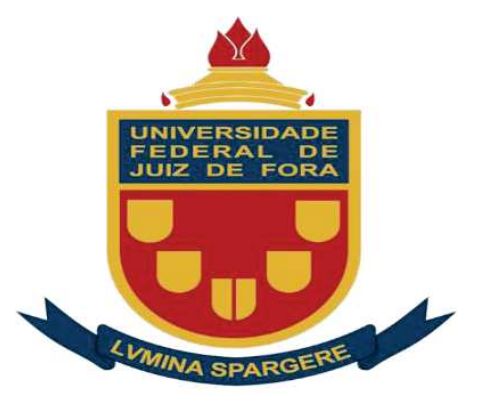

\title{
Engineering of Semiconductor Nanocrystals and Metal Ions in Amorphous Materials
}

\author{
RADHA MADA
}

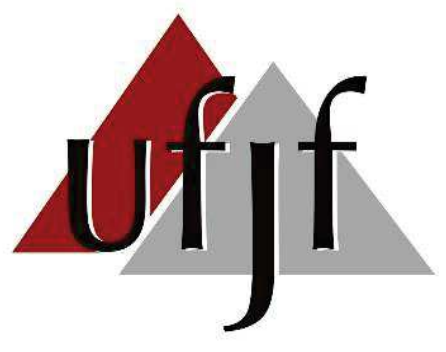

JUIZ DE FORA

MAY 2021 


\title{
Engineering of Semiconductor Nanocrystals and Metal Ions in Amorphous Materials
}

\author{
RADHA MADA
}

Universidade Federal de Juiz de Fora

Instituto de Ciências Exatas

Departamento de Física

Doutorado em Física

Orientador: Prof. Dr. Virgílio de Carvalho dos Anjos

JUIZ DE FORA

MAY, 2021 


\section{Radha Mada}

\section{"Engineering of semiconductor nanocrystals and metal ions in amorphous materials"}

Tese apresentada ao Programa de Pósgraduação em Física, da Universidade Federal de Juiz de Fora como requisito parcial a obtenção do grau de Doutor em Física. Área de Concentração: Física.

Aprovada em 06 de maio de 2021.

BANCA EXAMINADORA

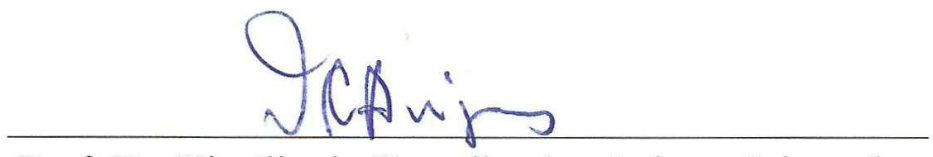

Prof. Dr. Virgílio de Carvalho dos Anjos - Orientador Universidade Federal de Juiz de Fora

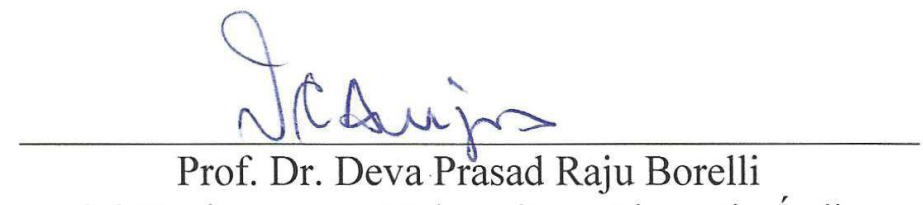

Sri Venkateswara University - Tirupati - Índia

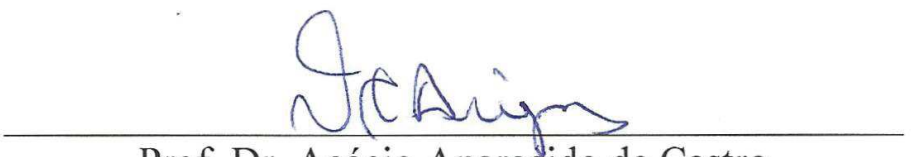

Prof. Dr. Acácio Aparecido de Castro

Universidade Federal de Uberlândia

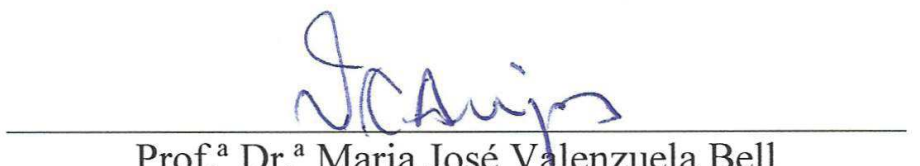

Prof. ${ }^{a}$ Dr. ${ }^{a}$ Maria José Valenzuela Bell

Universidade Federal de Juiz de Fora

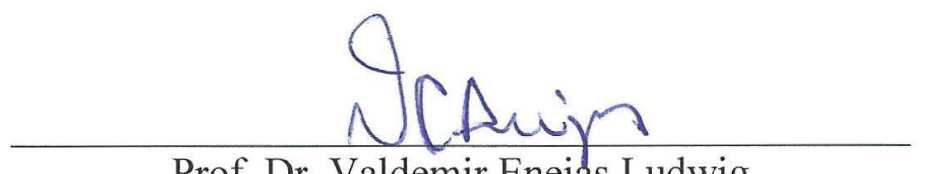

Prof. Dr. Valdemir Eneias Ludwig

Universidade Federal de Juiz de Fora 
PRÓ-REITORIA DE PÓS-GRADUAÇÃO E PESQUISA (PROPP)

Rua José Lourenço Kelmer, s/n - Campus Universitário

Bairro São Pedro - CEP: 36036-900 - Juiz de Fora - MG

(32) 2102-3785/bancas.propp@ufjf.edu.br

PROGRAMA DE PÓS-GRADUAÇÃO EM FÍSICA (BANCA VIRTUAL - CF. RESOLUÇÃO Nº 01/2020 - CSPP)

\section{ATA DE DEFESA DE TRABALHO DE CONCLUSÃO \\ DE PÓS-GRADUAÇÃO STRICTO SENSU}

N $^{\circ}$ PROPP: 239.6052021.21-D

No PPG: 070

Ata da sessão pública referente à defesa da tese intitulada "Engineering of semiconductor nanocrystals and metal ions in amorphous materials", para fins de obtenção do título de doutor em Física, área de concentração Física, pelo(a) discente

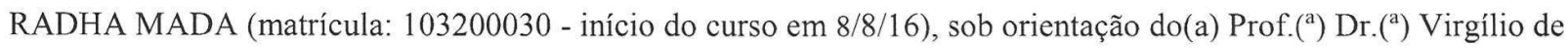
Carvalho dos Anjos

Aos 6 dias do mês de maio do ano de 2021, às 10:00 horas, no(a) "por webconferência, conforme Resolução n 001/2020CSPP" da Universidade Federal de Juiz de Fora (UFJF), reuniu-se a Banca Examinadora da Tese em epígrafe, aprovada pelo Colegiado do Programa de Pós-Graduação conforme a seguinte composição:

Prof.(a) Dr.(a) Virgílio de Carvalho dos Anjos - Orientador(a) e Presidente da Banca

Prof.(a) Dr.(a) Deva Prasad Raju Borelli - Membro titular externo

Prof.(a) Dr.(a) Noelio de Oliveira Dantas - Membro titular externo

Prof.(a) Dr.(a) Acácio Aparecido de Castro - Membro titular externo

Prof.(a) Dr.(a) Maria José Valenzuela Bell - Membro titular interno

Prof.(a) Dr.(a) Valdemir Eneias Ludwig - Membro titular interno

Prof.(a) Dr.(a) Luciana Reyes Pires Kassab - Suplente externo

Prof.(a) Dr.(a) Viviane Pilla - Suplente externo

Prof.(a) Dr.(a) Zélia Maria da Costa Ludwig - Suplente interno

Prof.(a) Dr.(a) Eduardo Ferreira da Silva - Suplente interno

Tendo o(a) senhor(a) Presidente declarado aberta a sessão, mediante o prévio exame do referido trabalho por parte de cada membro da Banca, o(a) discente procedeu a apresentação de seu Trabalho de Conclusão de Curso de Pós-graduação stricto sensu e foi submetido(a) à arguição pela Banca Examinadora que, em seguida, deliberou sobre o seguinte resultado:

\section{Х APROVADO (Conceito A).}

APROVADO CONDICIONALMENTE (Conceito B), mediante o atendimento das alterações sugeridas pela Banca Examinadora, constantes do campo Observações desta Ata e/ou do parecer em anexo.

REPROVADO (Conceito C), conforme parecer circunstanciado, registrado no campo Observações desta Ata e/ou em documento anexo, elaborado pela Banca Examinadora. 
PRÓ-REITORIA DE PÓS-GRADUAÇ̃̃O E PESQUISA (PROPP)

Rua José Lourenço Kelmer, s/n - Campus Universitário Bairro São Pedro - CEP: 36036-900 - Juiz de Fora - MG (32) 2102-3785/propg@ufjf.edu.br

Observações da Banca Examinadora (caso inexistam, anular o campo):

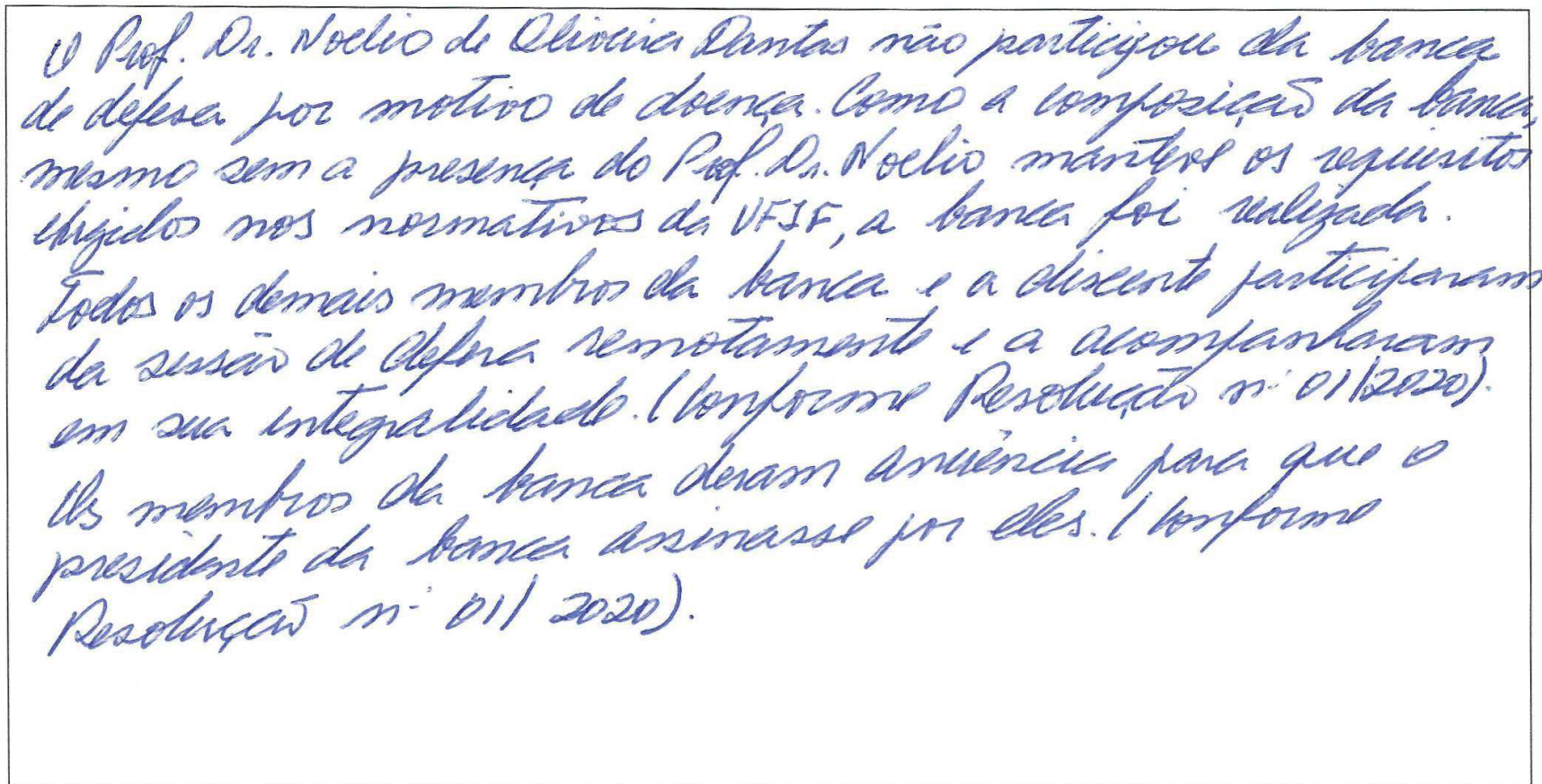

Nada mais havendo a tratar, o(a) senhor(a) Presidente declarou encerrada a sessão de Defesa, sendo a presente Ata lavrada e assinada pelos(as) senhores(as) membros da Banca Examinadora e pelo(a) discente, atestando ciência do que nela consta.

\section{INFORMAÇÕES:}

- Para fazer jus ao título de mestre(a)/doutor(a), a versão final da dissertação/tese, considerada Aprovada, devidamente conferida pela Secretaria do Programa de PósGraduação, deverá ser tramitada para a PROPP, em Processo de Homologação de Dissertação/Tese, dentro do prazo regulamentar de 90 dias a partir da data da defesa. Após a entrega dos dois exemplares definitivos, o processo deverá receber homologação e, então, ser encaminhado à CDARA.

- Esta Ata de Defesa é um documento padronizado pela Pró-Reitoria de Pós-Graduação e Pesquisa. Observações excepcionais feitas pela Banca Examinadora poderão ser registradas no campo disponível acima ou em documento anexo, desde que assinadas pelo(a) Presidente.

- Esta Ata de Defesa somente poderá ser utilizada como comprovante de titulação se apresentada junto à Certidão da Coordenadoria de Assuntos e Registros Acadêmicos da UFJF (CDARA) atestando que o processo de confecção e registro do diploma está em andamento.

Tranim

Prof.(a) Dr.(a) Virgílio de Carvalho dos

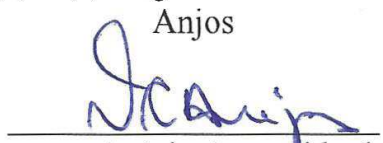

Prof.(a) Dr.(a) Acácio Aparecido de Castro
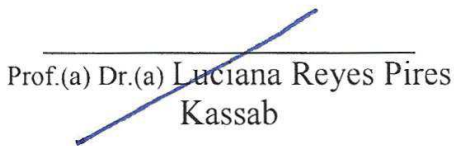

Prof.(a) Dr.(a) Eduardo Ferreira da Silva

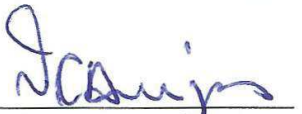

Prof.(a) Dr.(a) Deva Prasad Raju Borelli

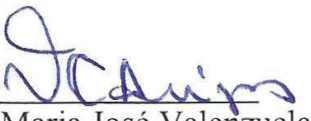

Prof.(a) Dr.(a) Maria José Valenzuela Bell

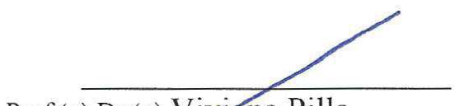

Prof.(a) Dr.(a) Viviane Pilla

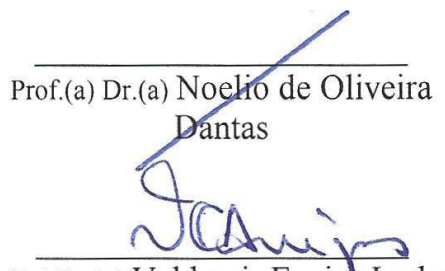

Prof.(a) Dr.(a) Valdemir Eneias Ludwig

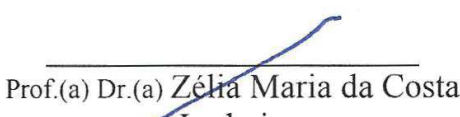

Ludwig

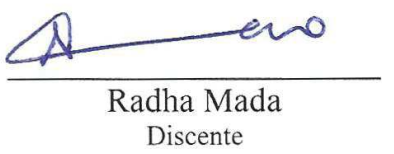




\section{Acknowledgements}

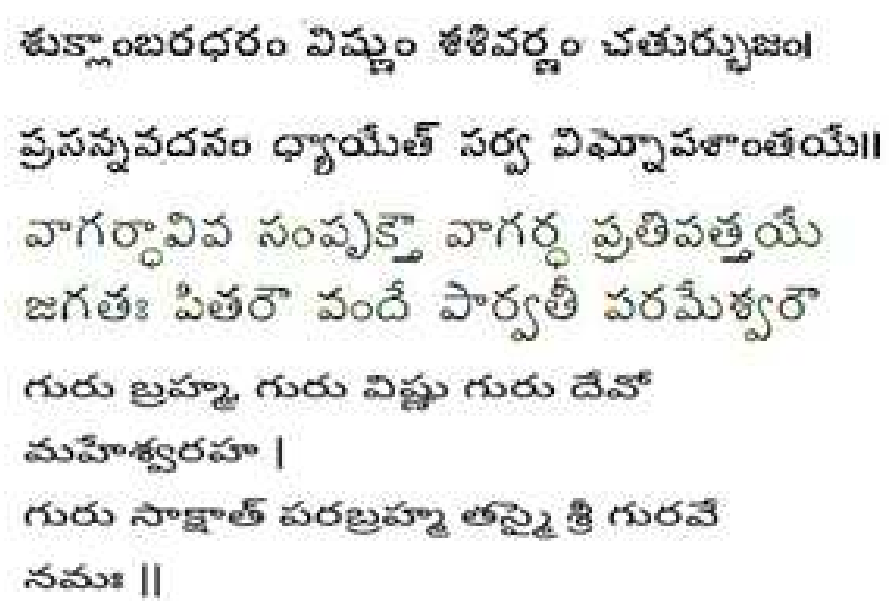

I would like to take this opportunity to thank Prof. Dr. Virgílio de Carvalho dos Anjos, who gave me opportunity to work in the Group of Engineering and Spectroscopic materials (GE2M)-ICE. I am deeply thankful to Prof. Dr. Virgílio de Carvalho dos Anjos who is patient teacher, a great friend and mentor throughout research work. His discussions, suggestions, help, humanity and caring makes me inspired in this unknown Brazilian world especially in difficult times. I have no words to express my thankfulness towards my master. I met one of the Great person in the journey of my life. Thanks to the Lord Sri Krishna who gave me great Opportunity to work with him.

I would like to express my sincere gratitude to Prof. Dr. Maria José Valenzuela Bell and Prof. Sergio Makler for their helpful advices and suggestions during my study and research.

I am also very thankful to my Master's Supervisors Prof. Y.C. Ratnakaram, Professor of Physic, S.V. University, Tirupati and Prof. K. Ravindra Prasad (Rted), Professor of Physics, S.V. University, Tirupati, for providing the reference letters \& support for joining in my doctoral program at the Federal University of Juiz de Fora, Brazil.

I would like to extend my sincere thanks to Prof. N.O. Dantas, Dept. of Physics, Laboratório de Novos Materiais Isolantes e Semicondutores, Federal University of Uberlândia, who provided a set of samples for this research work. I would like to 
express my sincere gratitude to Prof. Virgilio de Carvalho dos Anjos (Condensed matter Physics \& Quantum Electronics), Prof. Zélia Maria Da Costa ludwig (Material Science and Engineering \& Graduate labs), Prof. Gil de Oliveira Neto (Quantum Mechanics) and Prof. Pablo Zimmerman Coura (Seminars), Prof. Roberto (Graduate Lab) and Prof. Denise (Portuguese) who offered course works for finishing Doctorate. I would also like to thank the big family of research group GE2M members, Ilza, Icaro, Claudio, Cassiano, Josiane, Leisa, Renata, Leandro, Hamid, Geissy, Thamiris and others of our group and technical staff of department of physics helped me directly and indirectly. Special thanks goes to Dr. Seshadri for his constant support and useful discussions.

I convey my thanks to Brazillain funding agencies: CAPES, CNPq, FAPEMIG and Universidade Federal de Juiz de Fora (UFJF) for the financial supports as well as the physics Department and the post-graduation coordinator, Prof. Welber Gianini Quirino, and the former coordinator Prof. Pablo Zimmemann Coura for their comprehensive support. Also, my sincere thanks to Mr. Domingos Souza, Secretary of post-graduation Department of Physics-ICE.

Last but not least, I have no words to express my gratitude to my parents Smt M. Malleswari and Sri M.Venkata Ramana, and My Sister Prof. Sridevi and Brothers Prof. Mohan, Dr. Ramesh, Dr. Bhaskar and especially to my husband, soulmate, friend, Dr. Seshadri Meruva, my Loving Son master Sandeep Krishna Meruva who are my love, joy \& life and to My Mother in Law, late Smt. Bhagyamma Meruva who gave lots of energy during stay in Brazil and inexhaustible support and their indefinitely patience for the betterment of my future. Without their love, patience, help, constant support and encouragement, I could have not fulfilled my education and present position.

A special thanks to my loving friend Smt. Vinoda Sree, her suggestions, talks, lectures about meditation and soul gave lots of joy \& strength and to neighbours and friends Karthik, Deepak, Ilza Tenorio Cavalcante Santos, Rosiline, Margareth their fun talks and suggestions helped me greatly, and to Noeme Alves Pereira, Stephane Alves Pereira who gave love and taking care of my son during my study.

Finally, I would like to thank my mother land India, Nature and natural, beautiful and friendly Latin American nation Brazil gave me great opportunity to pursue my 
Doctorate \& to observe beauty of nature. I thank to everyone who supports me directly and indirectly to fulfil my childhood dream.

I dedicated this work to my Lord Sri Krishna. 


\section{Resumo}

Nanocristais semicondutores (NCs), íons metálicos contidos em materiais à base de vidro, podem ter aplicações em projetos de engenharia e resolver muitos problemas tecnológicos. Composições de vidro à base de $\mathrm{P}_{2} \mathrm{O}_{5}$ constituem uma classe importante de materiais para diversas aplicações, especialmente para aplicações de laser de alta potência. Recentemente, a produção de materiais de vidro fosfato à base de NCs semicondutores tem se mostrado de fundamental importância para aplicações em várias áreas tais como, fotovoltaica, LEDs, lasers e spintrônica. Os principais desafios são a inserção intencional de dopantes nos NCs semicondutores de forma a expandir suas funcionalidades intrínsecas e a incorporação de NCs em hospedeiros livres de hidroxila e espécies orgânicas para estabilizar e integrar seus desempenhos. Por outro lado, o índice de refração pequeno dos vidros fosfato pode ser ajustado pela adição de $\mathrm{TeO}_{2}$ que possui alto índice de refração, permitindo assim o controle da dispersão cromática que é útil para projetos de materiais fotônicos. O foco da tese é a caracterização de semicondutores ZnNiTe crescidos em materiais vitro-cerâmicos transparentes a base de fosfato e o efeito de $\mathrm{TeO}_{2}$ em vidro fosfatos dopados com $\mathrm{Nd}^{3+}$ para aplicações optoeletrônicas e de lasers de estado sólido. As características estruturais desses materiais foram determinadas por técnicas espectroscópicas de XRD, FT-IR e Raman. As propriedades ópticas foram caracterizadas pelo uso de técnicas espectroscópicas de absorção de UV-Vis-NIR e fluorescência. Os resultados foram usados para estimar parâmetros de interação de cristal, estado de coordenação de íons $\mathrm{Ni}^{2+}$, parâmetros de Judd-Ofelt para íons $\mathrm{Nd}^{3+}$ e propriedades radiativas de íons metálicos em vidros. A difusividade térmica (D) e a condutividade térmica (K) dos NCs de ZnNiTe em vidros foram determinadas pelas técnicas de lente térmica (TL) e de relaxamento térmico (TR). Os resultados revelaram que os comportamentos de D e $\mathrm{K}$ nas amostras estudadas são semelhantes. As propriedades ópticas não lineares de NCs de ZnNiTe em vidros também foram estudadas usando a técnica de Z-scan. A propriedade de refração não linear foi observada apenas em amostras contendo $5 \%$ de $\mathrm{Ni}$. 
Outras amostras, contendo de 1,0\% a 10\% de Ni apresentaram natureza de absorção não linear. Isto sugere que o coeficiente de absorção, não muda significativamente em função do comprimento de onda, mas sim devido ao aumento da concentração de $\mathrm{Ni}$, efeitos de confinamento eletrônico e processos de absorção de dois fótons (TPA).

Palavras-chave: Nanocristais semicondutores, íons metálicos, vidros fosfatos, fotoluminescência, propriedades não lineares, propriedades termo-ópticas. 


\begin{abstract}
Semiconductor nanocrystals (NCs), metal ions containing glass based materials have applications in design engineering, and may solve many technological problems. $\mathrm{P}_{2} \mathrm{O}_{5}$ based glasses are an important class of materials for several applications, especially for high power laser. Recently, the construction of semiconductor NCs-based phosphate glass materials has been shown to be of high importance for various applications, like in photovoltaics, LEDs, lasers and spintronics. The major challenges are the intentional insertion of dopants into semiconductor NCs aiming expanding their intrinsic functionalities and the scalable incorporation of NCs into host free of hydroxyl and organic species for stabilizing and integrating their performances. On the other hand, the low refractive index of phosphate glass can be adjusted by the addition of a high index of $\mathrm{TeO}_{2}$ content. These hybrid materials fulfil the requirement of refractive index contrast for chromatic dispersion control and are useful for the design of photonic materials. The thesis focus on the design of ZnNiTe semiconductors in transparent phosphate glass-ceramics, and the effect of $\mathrm{TeO}_{2}$ environment in $\mathrm{Nd}^{3+}$ doped phosphate glass for optoelectronic and solid-state laser applications. The structural features of these materials have been determined by XRD, FT-IR and Raman spectroscopic techniques. Optical properties were characterized by using UV-Vis-NIR absorption and fluorescence spectroscopic techniques. The findings were used to estimate crystal field interaction parameters, coordinate state of $\mathrm{Ni}^{2+}$ ions, Judd-Ofelt intensity parameters for $\mathrm{Nd}^{3+}$ ions and radiative properties of metal ions in glasses. Thermal diffusivity (D) and thermal conductivity (K) of ZnNiTe NCs in glasses were determined using thermal lens (TL) and thermal relaxation (TR) techniques. The results revealed that the behaviors of $\mathrm{D}$ and $\mathrm{K}$ for the studied samples are similar. Nonlinear optical properties of ZnNiTe NCs glasses were also studied using Z-scan technique. The nonlinear refractive property is observed only in the sample containing $5 \% \mathrm{Ni}$. Other samples with $1.0 \%$ to $10 \%$ of Ni content presented nonlinear absorption nature. This suggests that the absorption coefficient, $\beta$ does not change significantly with the wavelength,
\end{abstract}


but increase with Ni concentration, with confinement effects and two-photon absorption (TPA).

Keywords: Semiconductor, nanocrystals, metal ions, phosphate glass, photoluminescence, non linear properties, thermal-optical properties. 


\section{Contents}

$\begin{array}{ll}\text { List of Figures } & 11\end{array}$

List of Tables $\quad 14$

$\begin{array}{ll}\text { List of Abbreviations } & 15\end{array}$

1 Introduction $\quad 16$

1.1 Motivation . . . . . . . . . . . . . . . . . . 16

1.2 Organisation of the thesis . . . . . . . . . . . 18

2 Basic Concepts 20

2.1 Glass, an amorphous material . . . . . . . . . . . . . . . 20

2.1.1 Definition of amorphous (or glass) material . . . . . . . . . . . 21

2.1.2 Glass formation: Enthalpy Vs Temperature . . . . . . . . . . . 22

2.2 Semiconductors . . . . . . . . . . . . . . . . . . . . 24

2.2.1 Semiconductor nanocrystals (NCS) . . . . . . . . . . . . . 26

2.2.2 Quantum confinement effects . . . . . . . . . . . . 27

2.2.3 Crystalline structure of ZnTe NCs . . . . . . . . . . . . . . . . . 29

2.3 Metal ions . . . . . . . . . . . . . . . . . . . . . . . . 31

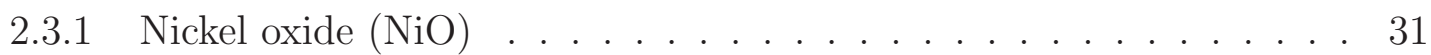

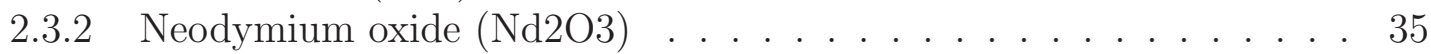

2.4 Host material used in this work: Phosphate glasses and their structure . . 43

2.5 State of the art of semiconductor nanocrystals (NCs) in glasses . . . . . . . 45

2.6 State of the art of metal $(\mathrm{TM} / \mathrm{RE})$ ions in glasses . . . . . . . . . . . 48

3 Engineering properties of amorphous materials $\quad 51$

3.1 Optical properties . . . . . . . . . . . . . . . 51

3.1 .1 Refractive index . . . . . . . . . . . . . . 51

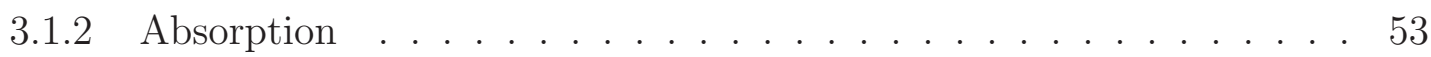

3.1 .3 Color . . . . . . . . . . . . . . . . . . . 54

3.2 Chemical properties . . . . . . . . . . . . . . . . 55

3.3 Mechanical properties . . . . . . . . . . . . . . . 56

3.3 .1 Elasticity . . . . . . . . . . . . . . . 56

3.3 .2 Hardness . . . . . . . . . . . . . . . . . . . . . . 57

3.4 Thermal properties . . . . . . . . . . . . . . . . . . 58

3.4.1 Viscosity . . . . . . . . . . . . . . . . . 58

3.4 .2 Thermal Expansion . . . . . . . . . . . . . . . . 59

3.4.3 Heat Transfer . . . . . . . . . . . . . . . . . . . . 60

4 Materials and characterization techniques $\quad 61$

4.1 Preparation of glass materials . . . . . . . . . . . . . . . . . . 61

4.2 Physical parameters . . . . . . . . . . . . . . . . . . . 62

4.3 Characterization techniques and specifications . . . . . . . . . . 63

4.3.1 X-ray diffraction spectrometer . . . . . . . . . . . . . . . 64

4.3.2 Fourier Transform Infrared spectrometer . . . . . . . . . . . . . . 64 
4.3.3 Micro-Raman spectrometer . . . . . . . . . . . . . . 65

4.3.4 UV-Vis-NIR absorption spectrometer . . . . . . . . . . . . . . 65

4.3.5 Emission spectral analysis . . . . . . . . . . . . . . . . 66

4.3.6 Thermal Lens (TL) Technique . . . . . . . . . . . . . . . . 68

4.3.7 Thermal Relaxation (TR) Technique . . . . . . . . . . . . . . . 70

4.3.8 Nonlinear optical spectroscopy (Z-scan) . . . . . . . . . . . . 73

5 Results and Discussions $\quad \mathbf{7 6}$

5.1 ZnNiTe semiconductor NCs in PZABP phosphate glasses for optoelectronics 76

5.1.1 Structural analysis: XRD, FT-IR, Raman spectra . . . . . . . . . . 77

5.1 .2 Optical absorption spectra . . . . . . . . . . . . . . . 82

5.1.3 Emission spectra and cross-sections . . . . . . . . . . . . 85

5.1.4 Photo-thermal spectroscopy . . . . . . . . . . . . . . . . 88

5.1.5 Nonlinear optical spectroscopy: Z-scan . . . . . . . . . . . . . 93

5.1 .6 Conclusions . . . . . . . . . . . . . . . . . . 96

5.2 Effect of $\mathrm{TeO}_{2}$ environment in $\mathrm{Nd}^{3+}$ doped PZN phosphate glasses for high power lasers . . . . . . . . . . . . . . . . . . . . . . . . 997 97

5.2.1 Structural analysis: XRD, FT-IR and Raman spectra . . . . . . . . 98

5.2 .2 Optical absorption spectra . . . . . . . . . . . . . . . . 101

5.2.3 Emission spectra and radiative properties . . . . . . . . . . 108

5.2 .4 Conclusions . . . . . . . . . . . . . . . . . . 112

6 Summary 114

$\begin{array}{lr}\text { Appendices } & 120\end{array}$

A List of Published and submitted articles 121

$\begin{array}{ll}\text { Bibliography } & 122\end{array}$ 


\section{List of Figures}

1.1 Grand Engineering challenges for 21st century (Adapted from [9]) . . . . . 17

2.1 Atomic structure of crystal (left) and glass (right) natures of $\mathrm{SiO}_{2} \ldots \ldots$. . 21

2.2 Effect of temperature on the enthalpy of a glass melt. . . . . . . . . . . . 22

2.3 Bandgap energies (solid line for direct bandgap/ dash line for indirect bandgap) of semiconductors as a function of lattice constants [15] . . . . 25

2.4 Schematic illustration of the density of electrons for various dimensionalities, 1D, 2D and 3D confined materials (adopted from Ref.[19]). . . . . . . 27

2.5 Variation of the energy gap of nanocrystals with $\mathrm{NC}$ size effects due to quantum confinement $[20,21] \ldots \ldots$. . . . . . . . . . . . . 29

2.6 a) Zinc-blende crystal elementary cell for ZnTe semiconductor, b) Bonding and anti-bonding state arising from the hybridization of $\mathrm{s}$ and $\mathrm{p}$ orbitals [19]. 30

2.7 Periodic table of chemical elements [24]. . . . . . . . . . . . . . . . . 31

2.8 The crystal structure and band diagram for $\mathrm{NiO}[25] \ldots \ldots$. . . . . . . . . . 32

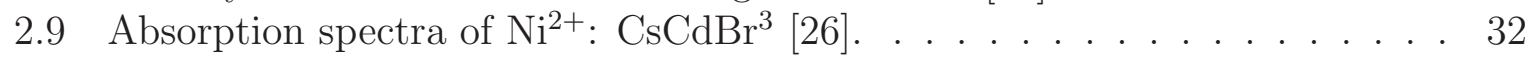

2.10 Sugano-Tanabe diagram for a $3 \mathrm{~d}^{8}$ configuration [28] . . . . . . . . . . . 34

2.11 Square of the radial wavefunctions for the 4f, 5s, 5p and 6s energy levels from Hartree-Fock. It was a calculation for $\mathrm{Gd}^{3+}$ [29]. Picture inset schematically shows that the $4 \mathrm{f}$ orbital is within the $6 \mathrm{~s}, 5 \mathrm{p}$ and $5 \mathrm{~s}$ levels. . 36

2.12 The Dieke diagram for elements of the lanthanide series in $\mathrm{LaCl}_{3}$, based on theoretical free-ion and crystal-field splittings [30]. . . . . . . . . .

2.13 On the left: energy levels for $\mathrm{Nd}^{3+}$ originated from the splitting of the $4 \mathrm{f}^{3}$ configuration under the effect of Coulombic $\left(\mathrm{H}_{\text {coul }}\right)$, spin-orbit coupling $\left(\mathrm{H}_{S O}\right)$ and crystal field $\left(\mathrm{H}_{C F}\right)$ interactions. The laser transition of interest $(1053 \mathrm{~nm})$ is from the metastable ${ }^{4} \mathrm{~F}_{3 / 2}$ state to the ${ }^{4} \mathrm{I}_{11 / 2}$ final level. The wavy lines denote rapid non-radiative (multi-phonon) transitions. On the right: typical Nd-absorption cross-section in metaphosphate glass host. Relative output intensity for a xenon flash lamp and laser diode pump source are also shown. The energies reported are relative to the ${ }^{4} \mathrm{I}_{9 / 2}$ ground

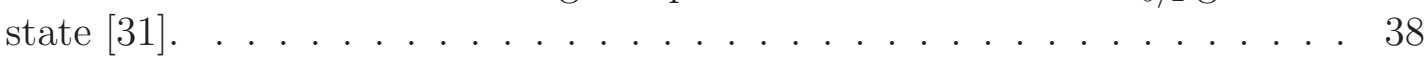

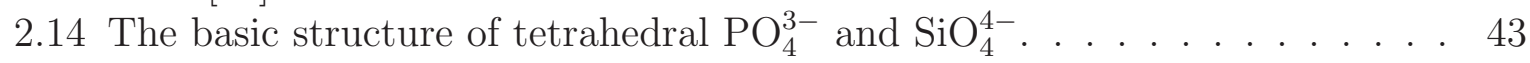

2.15 Phosphate based glass tetrahedral in $\mathrm{Q}^{n}$ terminology. . . . . . . . . . . . . 44

2.16 Schematic phosphate structures as a function of composition, note that linear phosphates are also known as polyphosphates [43] . . . . . . . . . 45

2.17 Commission Internationale de l'Eclairage (CIE) color coordinates of LEDs mounted with CdSe/CdS QDs-embedded silicate glasses of various thickness heat-treated for $5,10,15$, and $20 \mathrm{~h}$ at $500{ }^{\circ} \mathrm{C}$. The inset presents the electroluminescence and PL spectra of the wLED, which had coordinates of (0.3277, 0.3458) and a CRI (Color Rendering Index) of 90. Actual photos of the LEDs with CdSe/CdS QDs-embedded silicate glasses of the same thickness $(1.2 \mathrm{~mm})$ with varying heat treatment duration are presented at the right of the figure. (Adapted from Ref.[1]). . . . . . . . . . . . 
3.1 a) Complex refractive index (n, k), b) absorption coefficient, c) reflection coefficient as a function of wavelength for a silica $\mathrm{SiO}_{2}$; and d) reflection (R) and transmission $(\mathrm{T})$ coefficients for a normal incidence of light from one medium to another medium as a function of the refractive index. Figures adapted from ref. [80].

3.2 Variation of chemical resistance between commercial silicate glasses and optical glasses [81]

3.3 The effect of temperature on the viscosity of glass [82] • Melting point (at 10 Pa.s): At this point the glass becomes fluid enough to be considered as a liquid. - Working point (at $10^{3}$ Pa.s): Glass is easily deformed at this viscosity and this is the reason why the glass fabrication operations are carried out at this point. - Softening point $\left(4 \times 10^{6}\right.$ Pa.s $)$ : Represents the maximum temperature at which a glass piece may be handled without resulting in significant dimensional changes. At this point the glass can flow under its own weight. . . . . . . . . . . . . . . . .

4.1 Photograph of D8 ADVANCE BRUKER x-ray diffractometer. . . . . . . . 64

4.2 Photograph of FT-IR VERTEX 70 (BRUKER) spectrometer. . . . . . . . 64

4.3 Micro-Raman HORIBA JOBIN IVON T64000 spectrometer. . . . . . . . . 65

4.4 Photographs shows UV-Vis-NIR absorption spectrometers (Left: UV 2550 and Right: MPA-FT-NIR). . . . . . . . . . . . . . . . . 66

4.5 FLS920 spectrofluorimeter for visible emission with Hydrogen lamp as an excitation source (EDINBURG PHOTONICS). . . . . . . . . . . . 66

4.6 Emission experimental setup. Lens (LA, LB, L1, L2, L3); Gratings (G1, G2, G3).

4.7 (a) Schematic diagram of the mode-mismatched thermal lens experimental apparatus, where M1, M2 and M3 are mirrors, and P1 and P2 are detectors; (b) geometric position of excitation and probe beams. . . . . . . . . . . 68

4.8 Schematic illustrations for thermal relaxation method. . . . . . . . . . . . 71

4.9 Cooling curve data for specific heat measurement using a) Sensor and b) Thermocouple as a data acquisition, c) and d) are the variation of heat capacity $(\rho \mathrm{c})$ as a function of thickness of sample, and laser power $(\lambda=$

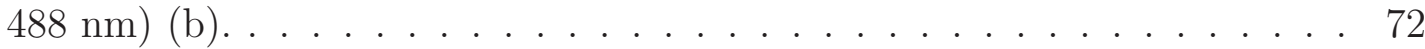

4.10 Single beam Z-scan experimental setup. . . . . . . . . . . . . . . 74

5.1 XRD pattern of samples. a) Glass (G) and glass-ceramic (GC2) samples. TEM image of sample contain ZnTe NCs, which is adapted from our col-

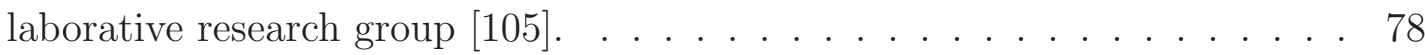

5.2 Raman spectra of $\mathrm{Ni}^{2+}$ doped glass and glass-ceramics. . . . . . . . . . . . 80

5.3 IR absorption spectra of $\mathrm{Ni}^{2+}$ doped glass and glass-ceramics. . . . . . . . 81

5.4 (a) Optical absorption spectra of $\mathrm{Ni}^{2+}$ ions doped glass and glass-ceramics; (b) Energy level diagram for octahedral of $\mathrm{Ni}^{2+}$ ions. . . . . . . . . . . . . 83

5.5 Plots of $(\alpha \mathrm{h} \nu)^{2}$ and $(\alpha \mathrm{h} \nu)^{1 / 2}$ as a function of photon energy $(\mathrm{h} \nu)$ for $\mathrm{Ni}^{2+}$ doped glass and glass-ceramics. . . . . . . . . . . . . . . 84

5.6 a) UV-excitation and Visible emission spectra for $\mathrm{Ni}^{2+}$ ions, and b) schematic representation of emission levels of $\mathrm{Ni}^{2+}$ ions in ZnTe NCs contain system.

5.7 Variation of emission intensity and FWHM with $\mathrm{Ni}^{2+}$ ions in GC samples.

5.8 Decay curves for $\mathrm{Ni}^{2+}$ ions doped glass and glass-ceramics. Inset figure shows a variation of lifetime with $\mathrm{Ni}^{2+}$ ions. . . . . . . . . . . . . . . 87

5.9 Typical normalized TL signal for ZnNiTe contain samples. . . . . . . . . . 89 
5.10 Cooling curve of the specific heat capacity measurements for for $5 \% \mathrm{Ni}$. . 90

5.11 Variation of $\mathrm{D}$ and $\mathrm{K}$ with $\mathrm{Ni}^{2+}$ ions in samples . . . . . . . . . . . . . 91

5.12 Z-scan results in the close-aperture mode for the sample $5 \% \mathrm{Ni}$ at $800 \mathrm{~nm} . \quad 93$

$5.13 \mathrm{Z}$-scan results in the open-aperture mode for sample $1.0 \%$ and $10 \% \mathrm{Ni}$ at $750 \mathrm{~nm}, 800$ and $850 \mathrm{~nm}$. . . . . . . . . . . . . . . . 94

5.14 XRD patterns of $\mathrm{Nd}^{3+}$ doped glasses . . . . . . . . . . . . . . . . . 99

5.15 Raman and IR absorption spectra of $\mathrm{Nd} 3+$ doped glasses. . . . . . . . . . 100

5.16 Optical absorption spectra of $\mathrm{Nd}^{3+}$ doped glasses. . . . . . . . . . . . . . 102

5.17 Plots of $(\alpha \mathrm{h} \nu)^{2}$ and $(\alpha \mathrm{h} \nu)^{1 / 2}$ as a function of photon energy $(\mathrm{h} \nu)$ for $\mathrm{Nd}^{3+}$ doped glasses . . . . . . . . . . . . . . . . . . . . 103

5.18 Plots of (a) optical band gap, and b) density and molar volume as a function of $\mathrm{x} \mathrm{mol} \% \mathrm{TeO}_{2}$ in glasses. . . . . . . . . . . . . . . . . . . 104

5.19 (a) Refractive index (n), (b) oxygen polarizability $\alpha_{O^{2-}}$, (c) oxygen packing density $\mathrm{P}_{\mathrm{O}^{2-}}$ and $(\mathrm{d})$ ion concentration $(\mathrm{N})$ as a function of $\mathrm{x}$ mol\% $\mathrm{TeO}_{2}$ in glass. . . . . . . . . . . . . . . . . . . . . . 105

5.20 (a) Emission spectra and (b) schematic energy levels of $\mathrm{Nd}^{3+}$ ions. Inset shows decay of ${ }^{4} \mathrm{~F}_{3 / 2}$ level. . . . . . . . . . . . . . . . . . . 108

5.21 (a) Nonradiative relaxation rate $\left(\mathrm{W}_{N R}\right)$, (b) quantum efficiency $(\eta)$, (c) emission cross-section $\left(\lambda_{p} @ 1057 \mathrm{~nm}\right)$ and $(\mathrm{d})$ optical gain $\left(\lambda_{p} \times_{\exp } @ 1057\right.$ $\mathrm{nm})$ as a function of $\mathrm{x}$ in glass. . . . . . . . . . . . . . . . . . 110

5.22 Comparative analysis of laser properties: a) Laser emission wavelength, b) stimulated emission cross-section $\left(\sigma_{p} @ 1057 \mathrm{~nm}\right)$ and (c) effective line width $\left(\Delta \lambda_{e f f} @ 1057 \mathrm{~nm}\right)$ in glasses. . . . . . . . . . . . . . . . 112 


\section{List of Tables}

2.1 Density of states for the dimensionality of the materials. . . . . . . . . . 27

2.2 Key parameters of $\mathrm{Nd}$ doped commercial laser glasses [7] . . . . . . . . . . 50

5.1 Physical properties of $\mathrm{Ni}^{2+}$ ions in samples . . . . . . . . . . . . . 77

5.2 Raman and Infrared vibrational bands with assignments. . . . . . . . . . 79

5.3 Absorption band energies $(\nu)$, crystal field splitting $\left(D_{q}\right)$, Racah parameter (B), nephelauxetic ratio $(\beta)$ and optical band gaps $\left(E_{\text {opt }}\right)$ of our glasses. . . 83

5.4 Emission properties of samples (* from McCumber's theory) . . . . . . . . . 87

5.5 Thermo-optical properties of samples. . . . . . . . . . . . . . . 89

5.6 Thermal diffusivity (D) and thermal conductivity $(\mathrm{K})$ of materials. . . . . 92

5.7 Laser excitation $(\lambda)$, nolinear absorption $(\beta)$ and nolinear refractive index $\left(\mathrm{n}_{2}\right)$ in materials. . . . . . . . . . . . . . . . . . . . 95

5.8 Physical properties of $\mathrm{Nd}^{3+}$ doped glasses . . . . . . . . . . . . . . . 98

5.9 Raman and Infrared vibrational bands with assignments. . . . . . . . . . . 99

5.10 Molar volume, cation polarizability, $\alpha_{\text {cat. }}$, (b) number of oxide ions, $\mathrm{N}_{O^{2-}}$, (c) oxygen polarizability, $\alpha_{O^{2-}}$, (c) oxygen packing density, $\mathrm{P}_{O^{2-}}$, and optical basicity $(\Lambda)$ in glasses. . . . . . . . . . . . . . . 105

5.11 The wavenumber $\left(\nu, \mathrm{cm}^{-1}\right)$ and experimental oscillator strength $\left(f_{\exp } \times\right.$ $\left.10^{-6}\right)$ for the absorption transition of $\mathrm{Nd}^{3+}$. . . . . . . . . . . 106

$5.12 \mathrm{~J}$-O parameters $\left(\Omega_{\lambda}\right)\left(\times 10^{-20} \mathrm{~cm}^{2}\right)$ and spectroscopic quality factor $(\chi)$ in $\mathrm{Nd}^{3+}$ doped glasses. . . . . . . . . . . . . . . . . . . . . . . . . . . . . . . . . . . . . . . . . . .

5.13 Emission properties of $\mathrm{Nd}$ samples. . . . . . . . . . . . . 107

5.14 Radiative lifetime $(\tau)$, radiative energy transfer rate $\left(\mathrm{W}_{E T}\right)$ and quantum efficiency $(\eta)$ for $\mathrm{Nd}^{3+}$ doped glasses. . . . . . . . . . . . . . . . 109

5.15 Effective linewidth $\left(\Delta \lambda_{e f f}\right)$, emission cross-section $\left(\sigma_{p}\right)$ and optical gain $\left(\sigma_{p} \times \tau_{\text {exp }}\right)$ for the $1057 \mathrm{~nm}$ emission of $\mathrm{Nd}^{3+}$ in glasses. . . . . . . . 111 


\section{List of Abbreviations}

NCs Nanocrystals

XRD x-ray diffraction

FT-IR Fourier transform-infrared

TL Thermal lens

TR Thermal relaxation

TPA Two-photon absorption

TM Transition metal

RE Rare earth

LEDs Light emitting diodes

QD Quantum Dot

MPR Multi-phonon relaxation rate

BO Bridging oxygen

NBO Non-bridging oxygen 


\section{Introduction}

\subsection{Motivation}

A central theme in photonics is the design and fabrication of optical materials with controlled optical properties and new functionalities. Semiconductor nanocrystals (NCs), metal (Transition metals $(\mathrm{TM})$ and rare-earth $(\mathrm{RE})$ ) ions contain materials that are a growing class of functional materials that have attracted considerable attention in photonics due to their unique optical properties. Impurity doping plays a crucial role in defining the optical properties of a particular material. For instance, glasses containing nanocrystals, transition metals and rare earth ions are important materials in optoelectronic devices such as light emitting diodes (LEDs), solid-state lasers, display technology and photovoltaics $[1,2,3,4]$. Special attention should be paid to the incorporation of active dopants, like $\mathrm{Ni}^{2+}, \mathrm{Mn}^{2+}, \mathrm{Cr}^{2+}$, and $\mathrm{In}^{3+}$ into semiconducting NCs which can effectively tune their luminescence while simultaneously reducing the toxic problems due to the use of cadmium and lead in the materials [1, 2].

An intentional introduction of carriers into semiconductor nanocrystals may lead to the reduction of the lasing threshold, thus greatly enhancing their optical behavior [5]. Growing semiconductor NCs still remains a great challenge during the nano-crystallization process, as the host matrix on the nanoscale, energetically drives the dopants towards the surface through the commonly assumed "intrinsic self-purification" mechanism [6]. Since the discovery of nanocrystals embedded in glasses in the early 1980s, their growth in several host glassy materials have been extensively studied for sustainable increasing energy demand and environmental concerns. Additionally, quantum confinement effects at nanoscale in semiconductor helps effectively the materials control of their optical and electrical properties [6].

On the other hand, rare earth (RE) doped glasses are well suited for solid state lasers due to the f-shell electrons shield by the outer $5 \mathrm{~s}$ and $5 \mathrm{p}$ electrons which avoid interaction with the environment surrounding the ions. In spectroscopic terms, this leads to 
exceptionally narrow homogeneous linewidths and correspondingly long coherence times for transitions between states of the $4 \mathrm{f}^{N}$ configuration. Among the $\mathrm{RE}$ doping, the $\mathrm{Nd}^{3+}$ ion was chosen because is one of the most important activators for crystalline and bulk glass lasers, thanks to the power and efficiency available from the transition around 1.06 $\mu \mathrm{m}\left({ }^{4} F_{3 / 2} \rightarrow{ }^{4} I_{11 / 2}\right)$. Upon $800 \mathrm{~nm}$ excitation, $\mathrm{Nd}^{3+}$ doped laser operation behaves like a four-level laser system. Nevertheless, a positive internal gain is possible even for very small pump power, which allows that a very low threshold can be achieved. Recently, three Nd:phosphate laser glasses, LHG-8 (Hoya), LG-770 (Schott), and N31 (Shanghai Institute of Optics and Fine Mechanics, SIOM), have been developed for high power laser inertial confinement fusion (ICF) technology demonstration and application and are currently used by National Ignition Facility (NIF) in the United States, Laser Megajoule (LMJ) in France, and Shen Guang in China, respectively [7].

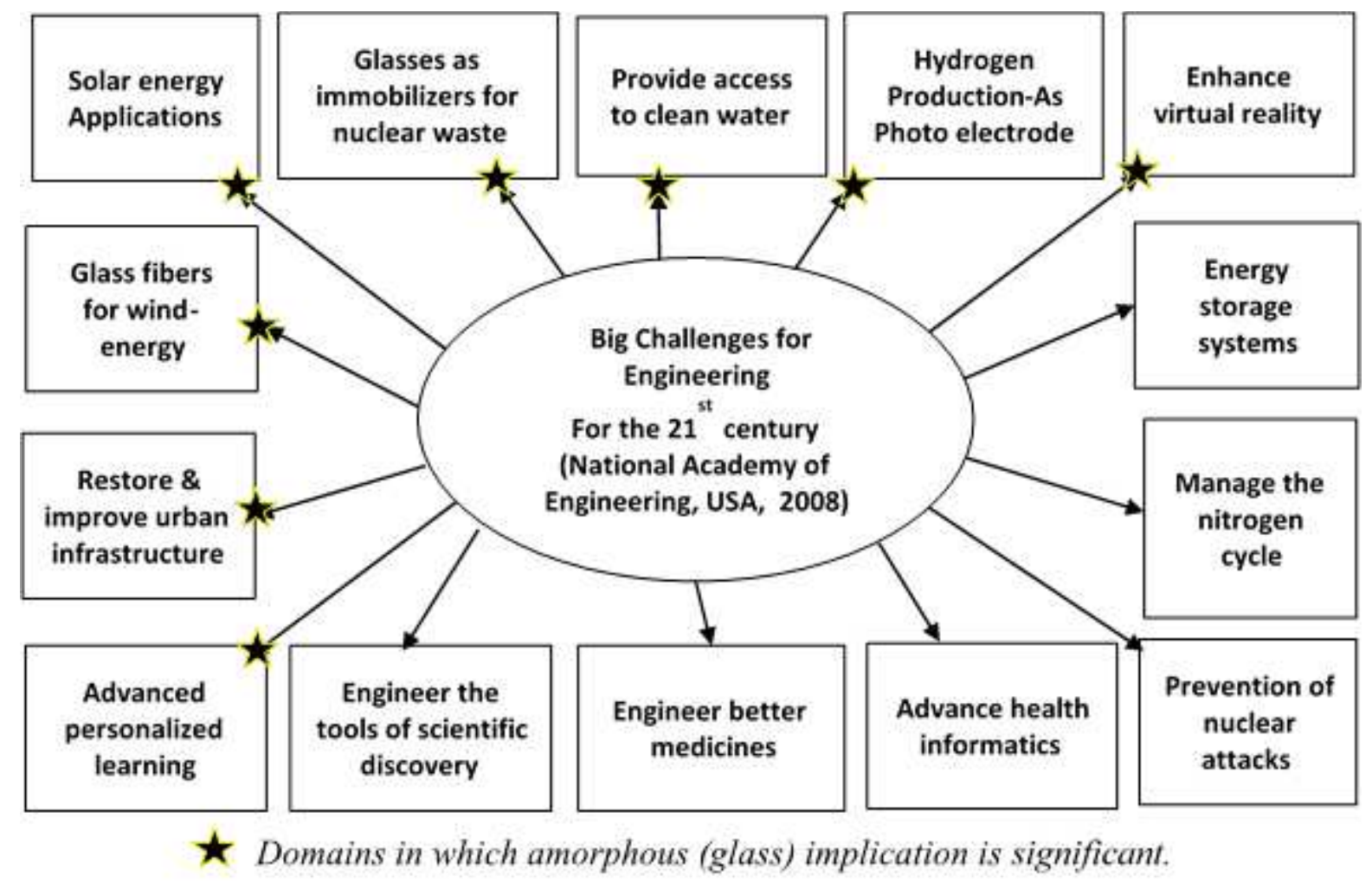

Figure 1.1: Grand Engineering challenges for 21st century (Adapted from [9]).

Recently, National Academy of Engineering (NAE, Washington, DC) identified that glasses and glasses-ceramics played an important role to many of the engineering achievements of the 20th century, as development of solid-state lasers, optical glass fibers, 
bioimaging technologies, biomaterials, and microelectronic devices. In 2008, NAE also found that glasses may have a major role in the Grand Engineering challenges for 21st century $[8,9]$, as shown in figure 1.1 . The reason is that glasses seem to be preferable for optical devices because of their ease of fabrication in desirable shapes and sizes, high transparency, good chemical and thermal durability, threshold to optical damage, and so forth [10]. This confers them as promising matrices for loading different nanocrystals, transition metal ions and rare earth ions. Glasses, therefore, may fulfil the required conditions in the modern engineering materials.

The subject of the current thesis is focused on the fabrication and characterization of $\mathrm{Ni}^{2+}$ ions as an interstitial dopant into ZnTe NCs phosphate glasses; and an influence of $\mathrm{TeO}_{2}$ as a second glass network former in $\mathrm{Nd}^{3+}$ doped phosphate glass. ZnTe with a direct bandgap at $2.26 \mathrm{eV}(548.67 \mathrm{~nm})$ corresponds to the green wavelength region which is the maximum sensitivity of the human eye. This makes ZnTe an appealing material for green LEDs. Here, the results of optical, thermal and nonlinear optical properties of Ni containing ZnTe NCs phosphate glasses suggest that these materials are potential candidate for optoelectronics. Moreover, $\mathrm{TeO}_{2}$ based glasses exhibit the higher nonlinear refractive indexes and the wider transmission window. The typical refractive index of tellurite glass is $\sim 2.0$ near the infrared wavelength, which is really high compared to that of phosphate glass. By adjusting contents of glass network modifiers, the refractive index can be tailored in the scale of $\sim 0.1$, which is really small compared with the requirement of refractive index contrast for chromatic dispersion tailoring. Therefore, introducing glass network formers instead of glass network modifiers can tune the refractive index in larger scale which greatly influence materials optical properties. We present the optical and luminescence properties of $\mathrm{Nd}^{3+}$ ions in phosphate glasses with addition of $\mathrm{TeO}_{2}$ content.

\subsection{Organisation of the thesis}

This thesis is organized as follows:

In Chapter 2, we introduce the basic concepts and physics required to realize this thesis with amorphous materials, semiconductors, quantum confinement effects, transition metals, rare earth ions and their significant features. In chapter 3, we give a short 
discussion on required engineering conditions for an amorphous material such as optical, chemical, mechanical, and thermal properties.

Chapter 4 presents the sample preparation method and characterization techniques used throughout the research work. Preparation of samples by melt-quenching method is explained. XRD, FT-IR, Raman, optical absorption and emission spectrophotometers are used to characterize the studied samples and their used parameters are reported. Also, Thermal lens (TL), thermal relaxation (TR) and nonlinear spectroscopic experimental setups are discussed with useful theoretical expressions that are used to determine the thermal-optical and nonlinear optical properties.

In Chapter 5, we presented our results and discussions. Section 5.1, deals on ZnNiTe nanocrystals phosphate glasses. Structural and optical properties are reported. Particularly on thermal diffusivity, thermal conductivity and nonlinear optical properties, and their comparison with those ones reported in the literature.

In 5.2 section, we presented our results and discussions about the role of $\mathrm{TeO}_{2}$ in $\mathrm{Nd}^{3+}$ doped phosphate glasses for high power lasers. Optical properties of $\mathrm{Nd}^{3+}$ doped phosphate glasses are determined using Judd-Ofelt formalism and detailed results are reported and discussed.

Finally, Chapter 6 holds the concluding remarks of this thesis. 


\section{Basic Concepts}

The recent research progress in the development and fabrication of amorphous materials containing semiconductor nanocrystals (NCs), and various types of efficient gain matrix activated with rare-earth and transition metal ions have been witnessed for usage in optoelectronics. The reason is anchored in their excellent plasticity, extremely low loss, and unique tuneable optical properties. In this chapter, we will give a short conceptual explanation of the physics and chemistry behind the research work presented in this thesis. To understand the physicochemical properties of the non-crystalline solids, first we define what noncrystalline solid is and discuss its transformation conditions thermodynamically. Then we will overview the structure of phosphate glasses which are used as host material in the present research work. Doping/formation of semiconductor nanocrystals and metal ions into the phosphate matrix, and their optical properties are, as already explained, the primary focus of the thesis. Herein, we will give a simple quantum mechanical treatment of the optical processes and the information of how to treat quantum confinement within the effective mass approximation. This chapter provides the importance of transition/rare earth metal ions and discuss the benefits of their electronic transitions, particularly, Nickle oxide ( $\mathrm{NiO}$ ) and Neodymium $\mathrm{Nd}_{2} \mathrm{O}_{3}$ oxide ions. Finally, an overview of the state of art in semiconductor nanocrystals and metal (transition/rare earth) ions in amorphous materials is given.

\subsection{Glass, an amorphous material}

Glass being a non-crystalline solid is widely used in everyday life. In fact it is difficult to imagine our life without the products arising from glasses. Glass making is not new and the first glass was made around 5000 BC by Phoenician merchants (from ancient Roman history). According to the archaeological evidence, the first men made glass were from Eastern Mesopotamia and Egypt around 3500 BC and the first glass vessels were made about 1500 BC in Egypt and Mesopotamia. From onwards, glass industry 
increased rapidly and the revolutionary float glass technique was invented by Sir Alastair Pilkington in 1959 [11]. Today's 90\% of the manufacturing technologies (Corning, SaintGobain, Pilkington, Asahi Glass Co. etc) used float glass techniques for the production of large quantity of glass windows, shower screens, technological applications, and etc.

\subsubsection{Definition of amorphous (or glass) material}

Any material, inorganic, organic or metal formed by any processing technique presenting a glass transition behaviour is a glass. So, there are many definitions proposed by scientists for glassy materials. In 1990, Elliot said that glasses do not present long range order of atoms in lattice like crystals and are an amorphous solids exhibiting the glass transition [10]. In 1991, Zarzycki proposed that a glass is a non-crystalline solid exhibiting the phenomena of glass transition [12]. Recently, in 1997, Shelby said that glass is an amorphous solid lacking completely long range periodic atomic structure and exhibiting a region of glass transformation behaviour [13].

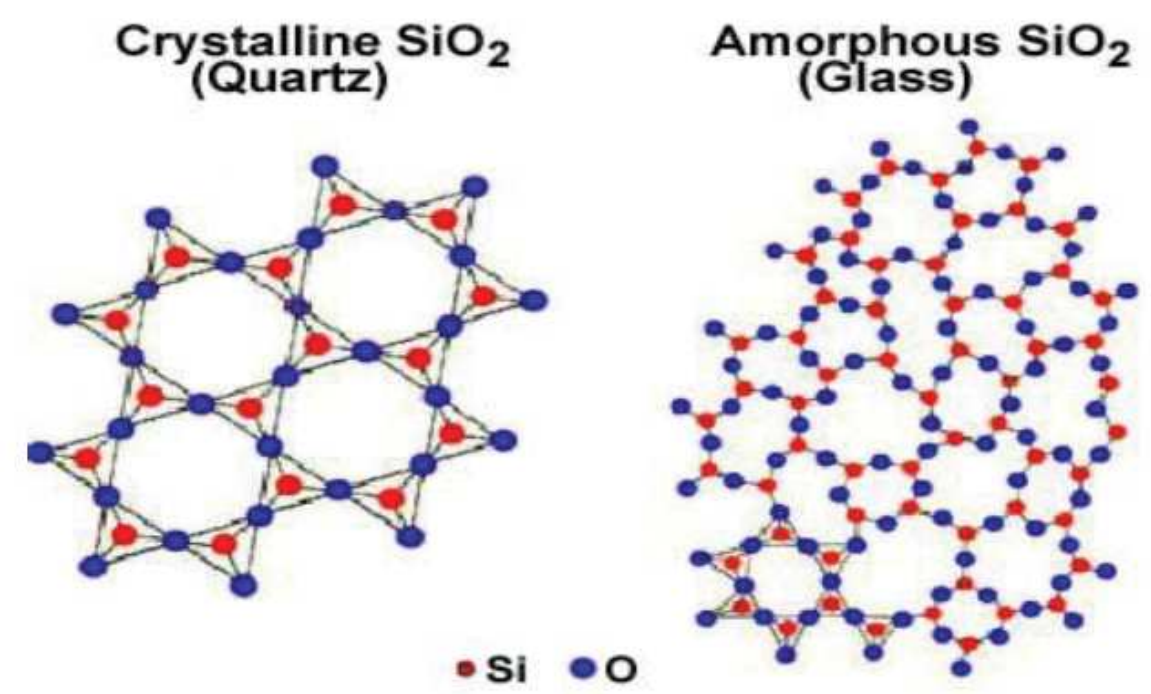

Figure 2.1: Atomic structure of crystal (left) and glass (right) natures of $\mathrm{SiO}_{2}$.

Eventually, we also describe glass as an inorganic product of melting which has been cooled to a solid without crystallization. It means that glass looks like an undercooled liquid at glass transition zone. According to Zachariasen's model [14], glass is an extended network of corner sharing oxygen polyhedra which lacks periodicity and whose energy is comparable to that of the corresponding ordered crystalline network. Figure 2.1 shows 
compared atomic structure of crystal and amorphous nature of $\mathrm{SiO}_{2}$.

\subsubsection{Glass formation: Enthalpy Vs Temperature}

Zachariasen [12] proposed that the structure of glass was similar to that of a crystal, but with a larger lattice energy resulting from the disordered arrangements of polyhedral units, to possess a random network lacking long-range periodicity. With regard to structure, the favorable conditions for glass formation are:

(1) an oxygen or anion must not be linked to more than two cations;

(2) the number of oxygens or anions coordinated to the cations must be small, typically three or four;

(3) the cation-anion polyhedra must share corners rather than edges or faces;

(4) at least three corners must be shared.

These conditions lead to the open structures that can accommodate a distribution of inter polyhedral bond angles that are associated with the loss of long-range structural order when a crystal forms a glass. The thermodynamic phase transition graph presented in Figure 2.2 shows the way of glass or non-crystalline solids differ from their crystalline counterparts.

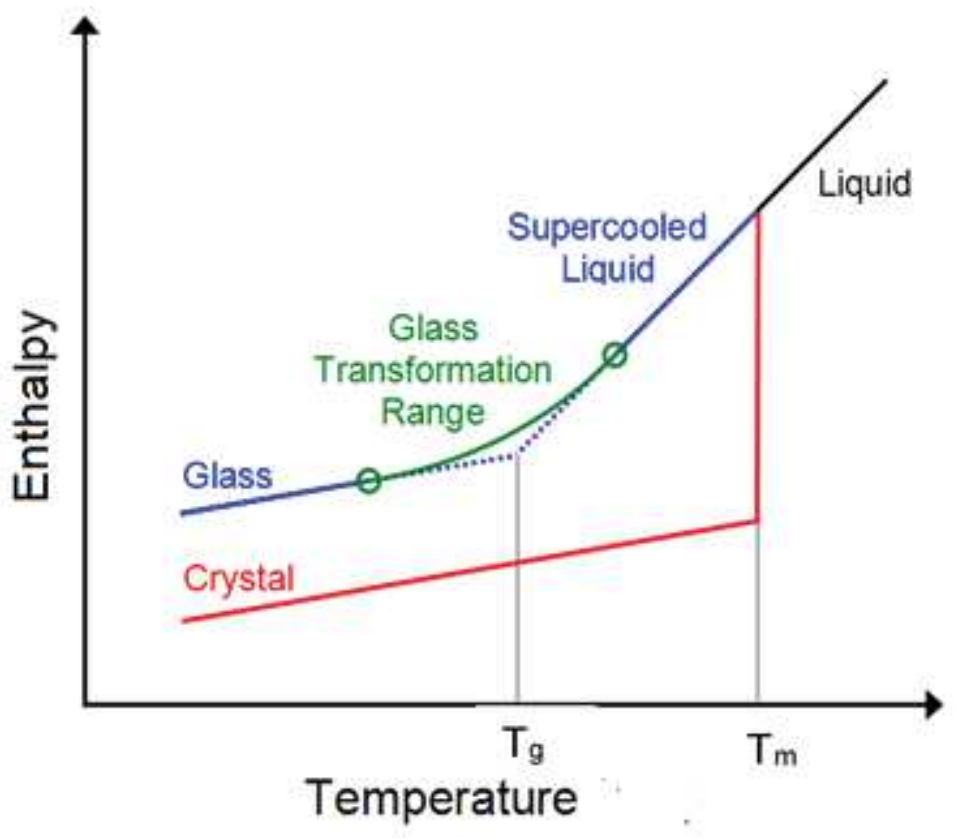

Figure 2.2: Effect of temperature on the enthalpy of a glass melt.

The right side of Figure 2.2, for a chemical substance, is constituted of a small 
volume of liquid with temperature well above the melting temperature (represented as the black path in the figure). As we cool the liquid, the atomic structure of the melt will gradually change until the exact temperature at which the melt is held. But, there is no definite temperature for a glassy material at which the liquid transforms into a solid, unless their viscosity becomes greater as the temperature decreases in a continuous manner. If the enthalpy decreases abruptly down (red path) and at the melting temperature $\mathrm{T}_{m}$, they form a long range, periodic atomic arrangements of crystals. If the liquid can be cooled below the melting temperature, a supercooled liquid may be obtained (the blue path) with no abrupt decrease in enthalpy. The continuous decrease of temperature of a liquid begins to deviate the enthalpy from the equilibrium line (black). This leads to gradually increase of the viscosity of the melt and arrangements of ions begin to form in the typical glassy disorder. The process is gradual and at some point the viscosity becomes so great that the structure of the liquid becomes fixed and no longer is temperature dependent. Thus, the frozen liquid becomes a glass at a temperature range over which is called glass transformation region [13]. The temperature where the glass start to form is called glass transition temperature $\left(\mathrm{T}_{g}\right)$.

Enthalpy dynamics is strongly composition dependent. The quenching has to be fast enough to avoid the crystallization of the composition, whereas slow enough not to generate strains and internal stresses in the glass compound. It is noted that crystals can also be formed in a glass by the growth and nucleation kinetics during the supercooled liquid phase. Decreasing the temperature from $\mathrm{T}_{m}$ the material passes the first grow process, and then the nucleation one. If the passage is fast enough, nucleation happens when very little crystals have been formed thereby favouring the glassy state. The crystallization tendencies vary widely between various glass systems. The difference between the onset-temperature for crystallization and $T_{g}, \Delta \mathrm{T}=T_{x}-T_{g}$, is related to a stability of a particular glass. The high stability ( $\Delta \mathrm{T}$ high) against devitrification of silicate glasses is one of numerous reasons that they have traditionally dominated glass technology. In the present research work, phosphate glass is used as host which has lower stability against devitrification than silicate glass. Therefore, making these glasses for technological applications poses a greater challenge. 


\subsection{Semiconductors}

Most of the materials exhibit electrical properties that are directly related to the behaviour of electrons in crystal lattice. According to quantum mechanical Bohr postulates, the electrons of an isolated atom occupy atomic orbitals which form a discrete energy levels (i.e., the electron may occupy one of the orbitals). Whereas, if several atoms are brought together in a crystal, the interaction between the outermost electrons in neighbouring atoms causes the atomic orbitals split but with very small energy difference. Thus, in crystals the levels form a quasi continuum bands of energy rather than the discrete energy levels of the isolated atoms. However, some intervals of energy contain no orbitals, forming band gaps. This concept becomes more important in the context of semiconductors and insulators.

The highest allowed energy band in semiconductor and insulators in which all energy states are occupied by electrons at $0 \mathrm{~K}$, is called the valence band (bands with lower energies), $\mathrm{E}_{V B}$. The next band is called the conduction band (or bands with higher energy), $\mathrm{E}_{C B}$. In the case of metals, the conduction band is the highest half filled band occupied by electrons at $0 \mathrm{~K}$ (the conduction carriers may be electrons or holes). It is by the relative position of these bands that all solids are divided into three major groups: conductors, insulators, and semiconductors. In the conductor material where the highest band is partially filled there is no bandgap and the resistivity is very low. On the contrary, in an insulator the bands are not overlapped and the energy distance between them is so large (typically, $\mathrm{E}_{g}>5 \mathrm{eV}$ ) that the conduction band is empty at room temperature, which result in no electric conduction.

We call semiconductors those materials exhibiting the properties between insulators and conductors. In a typical semiconductor, the bands are not overlapped and the distance between them $\mathrm{E}_{g}$ is in the range from 0.5 to $3 \mathrm{eV}$. At room temperature, transfer of electron from valence band into the conduction band requires less energy than insulators. The width of the "forbidden" band (the energy gap between the valence and conduction bands) is the key variable in the band theory; it defines the electrical and optical properties of the material. Elemental semiconductors such as silicon ( $\mathrm{Si}$ ), germanium (Ge) lie in group IV of periodic table, having the properties intermediate to the metals 
and non-metals. The combination of elemental semiconductors, III-V (GaAs, InP, GaN, etc.,) and II-VI ( CdSe, ZnTe, HgTe, ZnO, etc.,) can also be formed.

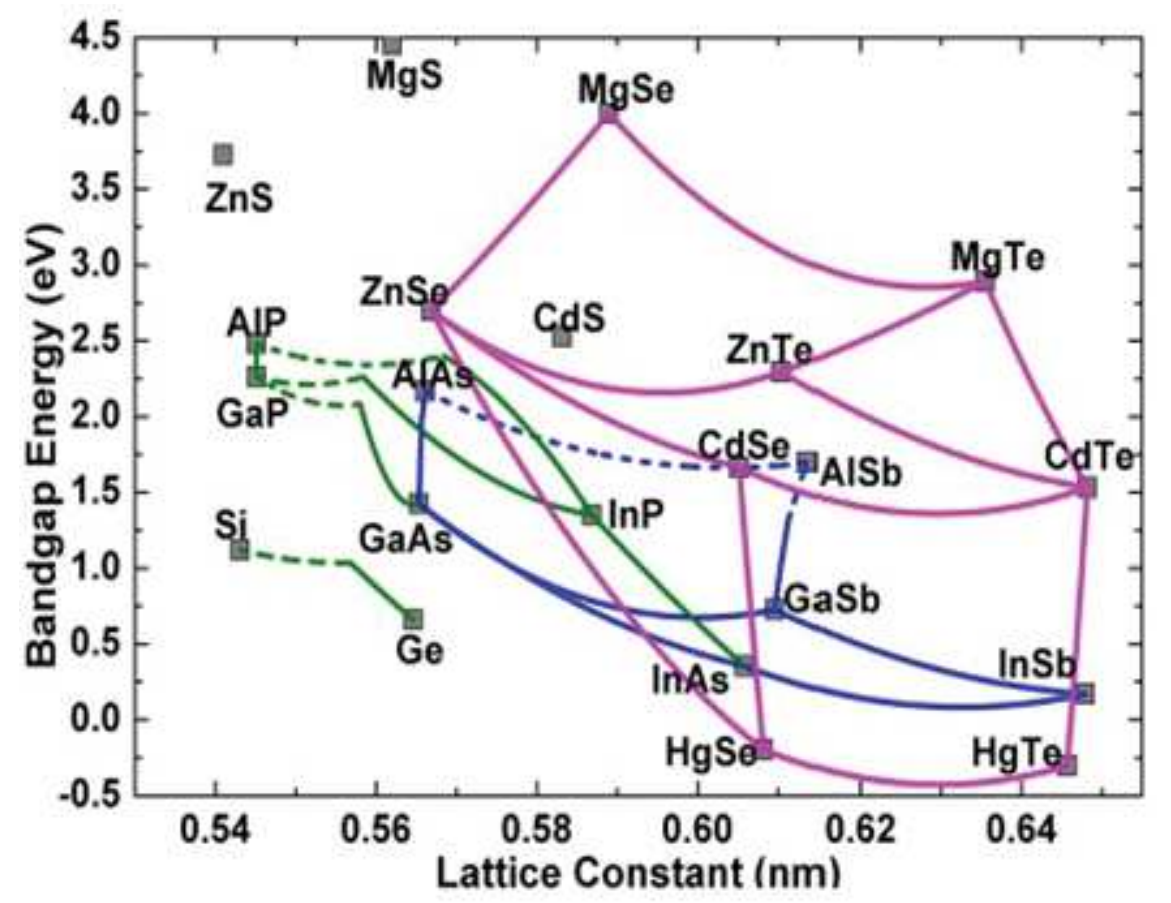

Figure 2.3: Bandgap energies (solid line for direct bandgap/ dash line for indirect bandgap) of semiconductors as a function of lattice constants [15]

Figure 2.3 shows the direct and indirect band gap energies as a function of lattice constant [15]. For the electron transition from the valence band edge to conduction band edge, the energy and momentum conservation should be required. If the electron at the maximum energy of the valence band has the same crystal momentum as the hole at the minimum energy of conduction band, the electron could be excited directly by a photon, and the corresponding semiconductors are direct semiconductors. If the electron at the maximum energy of the valence band has a different crystal momentum as the hole at the minimum energy of the conduction band, the electron can only be excited indirectly by a photon. The assistance of a phonon will be required, and the corresponding semiconductors are called indirect semiconductors.

Usually, the optical absorption edge is connected with theory of electronic structure of amorphous materials and can be used to determine the optical band gaps for direct and indirect transitions. Davis and Mott [16] proposed an expression for the optical ab- 
sorption coefficient $(\alpha)$ as a function of photon energy $(\mathrm{h} \nu)$ as follows,

$$
\alpha(\nu)=\frac{B}{h \nu}\left(h \nu-E_{g}\right)^{n}
$$

where $\mathrm{B}$ is a constant and $E_{g}$ is the band gap energy. $\mathrm{n}$ is the power factor of the optical transition mode, $\mathrm{n}=1 / 2$ for allowed direct transition and $\mathrm{n}=2$ for allowed indirect transition. Therefore, equation (2.1) can be written as,

$$
\begin{gathered}
(\alpha h \nu)^{2}=B\left(h \nu-E_{g}\right) \quad(\text { Direct allowed transition }) \\
(\alpha h \nu)^{1 / 2}=B\left(h \nu-E_{g}\right) \quad(\text { Indirect allowed transition })
\end{gathered}
$$

One can estimate optical gaps by extrapolation from the linear region of the plots of $(\alpha h \nu)^{2}$ and $(\alpha h \nu)^{1 / 2}$ as a function of $\mathrm{h} \nu$ for the direct and indirect material bandgaps.

\subsubsection{Semiconductor nanocrystals (NCS)}

Generally, when the size of semiconductor materials is reduced to nanoscale, is defined as semiconductor nanocrystal (NC) or quantum dot (QD). Physical and chemical properties of NCs change drastically, resulting in unique properties due to their large surface area in relation to their volume or quantum size effects. In nanocrystalline materials, the electrons are confined to regions having one, two or three dimensions, as shown in figure 2.4, when the relative dimension is comparable with the de Broglie wavelength. The density $\rho(\mathrm{E})$ of electronic states varies with energy as [17],

$$
\rho(E) \propto E^{\frac{d}{2}-1}, \quad d=1,2,3
$$

where $\mathrm{d}$ is the dimensionality. As can been in figure 2.4, in the case of 3D material, $\rho(\mathrm{E})$ is a smooth function of square root of energy. In the case of $d=1(1 \mathrm{D})$ and $\mathrm{d}=2(2 \mathrm{D})$ systems, a number of discrete subbands appear due to quantum confinement effect and the density of states obeys equation 2.4 within every subband. In these cases, the carriers are confined in one and two-dimensions respectively.

In the $(0 \mathrm{D})$ nanocrystals the carriers are confined in all dimensions. Due to the 


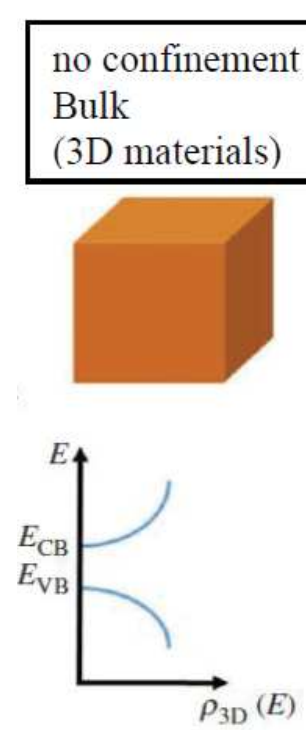

Bulk
1D confinement Q-well

(2D materials)
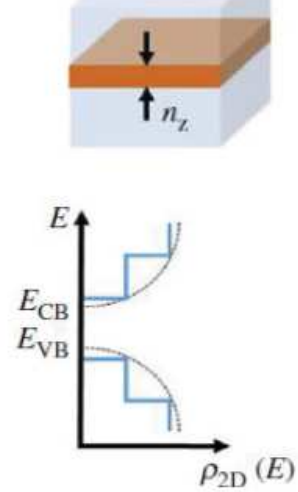

Quantum well

\begin{tabular}{|l|}
\hline 2D confinement \\
Q-wire \\
(1D materials) \\
\hline
\end{tabular}

3D confinement

Q-dot

(0D materials)
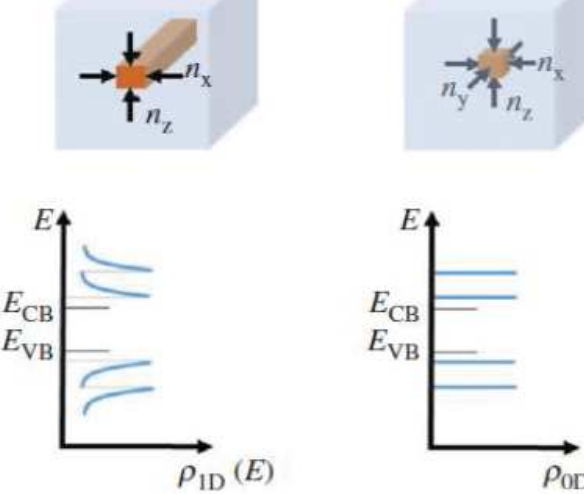

Quantum wire

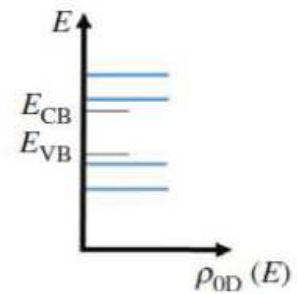

Quantum dot

Figure 2.4: Schematic illustration of the density of electrons for various dimensionalities, 1D, 2D and 3D confined materials (adopted from Ref.[19]).

Table 2.1: Density of states for the dimensionality of the materials.

\begin{tabular}{|l|c|}
\hline \multicolumn{1}{|c|}{ Degree of freedom } & Density of states \\
\hline 3D (Bulk) & $\rho_{3 D}=\left(\frac{L^{3} m}{2 \pi^{2} \hbar^{3}}\right) \sqrt{2 m E}$ \\
\hline 2D (film) & $\rho_{2 D}=\frac{L^{2} m}{2 \pi \hbar^{2}} E^{0}$ \\
\hline 1D (Wire) & $\rho_{1 D}=\left(\frac{m L}{\pi \hbar^{2} \sqrt{2 m E}}\right)$ \\
\hline QD (dot) & $\rho_{0 D}=2 \delta(E)$ \\
\hline
\end{tabular}

finite size of the NCs, the continuous bands of the bulk crystal transforms into a series of discrete states resulting in widening of effective bandgap. An overview of density of states for the dimensionality of the materials is given in table 2.1.

\subsubsection{Quantum confinement effects}

The effect of quantum confinement on electronic states were investigated theoretically by Efros and Efros [18]. According to classical quantum model, the energy of particle in a box can be written as [19],

$$
E_{n}=\frac{h^{2}}{8 m} \frac{n^{2}}{L^{2}}
$$


where $\mathrm{E}$ is the particle energy with quantum number $\mathrm{n}, \mathrm{h}$ is the Planck constant, $\mathrm{m}$ is the particle mass, and L is the box size. One can define that the smaller the box, the higher the particle energy. By considering the effective mass approximation, the energy change for semiconductor nanocrystals was proposed as follows [19],

$$
E=E_{g}+\frac{n^{2} \hbar^{2} \pi^{2}}{8 R^{2}}\left(\frac{1}{m_{e}^{*}}+\frac{1}{m_{h}^{*}}\right)-\frac{1.8 e^{2}}{\varepsilon R}
$$

where $\mathrm{E}_{g}$ is bulk semiconductor bandgap, $\mathrm{n}$ is interband transition number, $\mathrm{R}$ is the crystal size, $m_{e}^{*}$ and $m_{h}^{*}$ are the effective mass of the electron and hole, e is the charge of the electron, and $\varepsilon$ is the dielectric constant of the solid. The middle term of the right side of equation 2.6 describes the quantum confinement, in which the increased kinetic energy from the localization of the electron-hole pair inside a sphere with radius $\mathrm{R}$ and scales as $R^{-2}$. The term of the right side of equation 2.6 is the potential energy related to Coulomb interaction between electron and hole, and scales as $R^{-1}$. The general trend obeyed by equation 2.6 is that the decrease of particle size will induce higher energy states.

Efros and Efros [18] theoretically classified the size effects into three regimes: weak, intermediate and strong, by comparing the radio $(\mathrm{R})$ of the nanocrystal to the exciton Bohr radius. The Bohr radius is defined as,

$$
a_{B}=\frac{4 \pi \varepsilon(\infty) \hbar}{e^{2}}\left(\frac{1}{m_{e}^{*}}+\frac{1}{m_{h}^{*}}\right)
$$

where, $\varepsilon(\infty)$ is the optical frequency of dielectric constant. In the case of weak confinement $\left(\mathrm{R}>a_{B}\right)$, the electron and hole retain their bulk-like character as an electron-hole pair bound by the Coulomb interaction (an exciton) and are virtually unaffected by the quantum confinement. In the intermediate regime $\left(a_{e}>R>a_{h}\right)$, where $a_{e}\left(a_{h}\right)$ are the electron (hole) Bohr radius. In this case the electron is quantized and as a result, experiences an increase in its energy (confinement energy). The hole is still unaffected by confinement and remains influenced by the Coulomb attraction to the confined electron. However, when the confinement is strong $\left(a_{B}>R\right)$, both energies are significantly increased due to the quantum confinement. In fact, the energy of the strongly-confined charge carriers is quite larger than the energy of the Coulomb interaction. In this case, 
Coulomb effects are typically ignored.

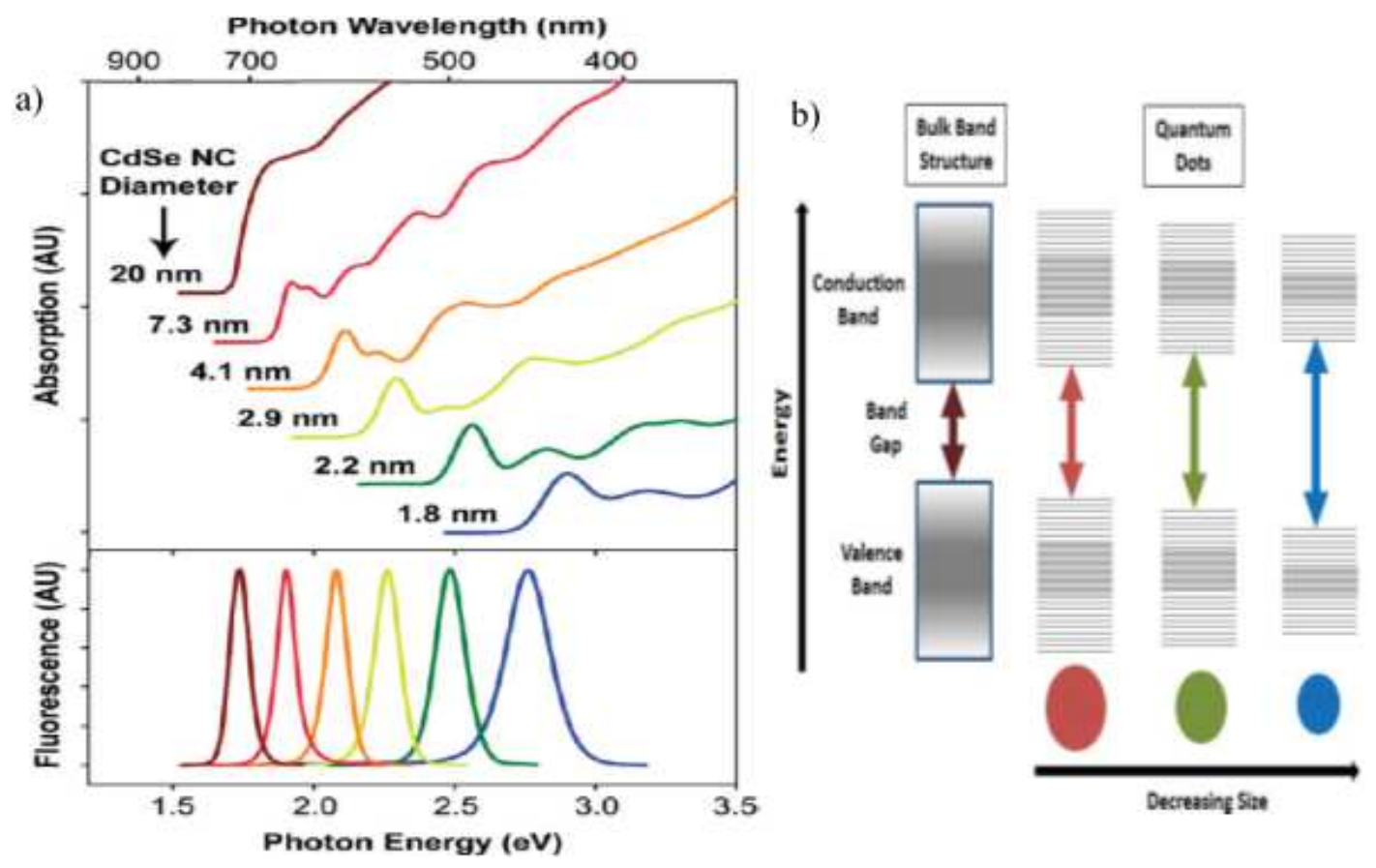

Figure 2.5: Variation of the energy gap of nanocrystals with NC size effects due to quantum confinement [20,21].

The quantum confinement effect increases the excitonic transition energy thus a blue shift in the absorption and luminescence bandgap energy is observed (Figure 2.5a). Also, it leads to a collapse of the continuous energy bands of the bulk semiconductor into discrete, atomic like energy levels (Figure 2.5b). Therefore, the semiconductor nanocrystals in the strong confinement limit have the potential for tuning the optical properties and motivate the study of semiconductor nanocrystals or quantum dots in this limit[20, 21].

\subsubsection{Crystalline structure of ZnTe NCs}

The absorption can easily be correlated with the energy states of the system, and generally the absorption energy of semiconductors varies between $0.5-3.0 \mathrm{eV}$, which is between the infrared to the ultraviolet range. Among different semiconductor nanocrystals, II-VI semiconductor (CdTe, ZnTe, CdSe and CdS) nanocrystals types are thoroughly investigated for different applications. The most commonly used Cd based NCs are toxic and are not environment friendly. Therefore, in this research work, we are going to deal with ZnTe (II-VI) semiconductor nanocrystals in amorphous materials. ZnTe NCs does not 
contain harmful elements. Unfortunately, very few investigations are found in the literature on ZnTe NCs because the size controlled synthesis of ZnTe quantum dots is very difficult, and have poor chemical stability due to Te oxidation.

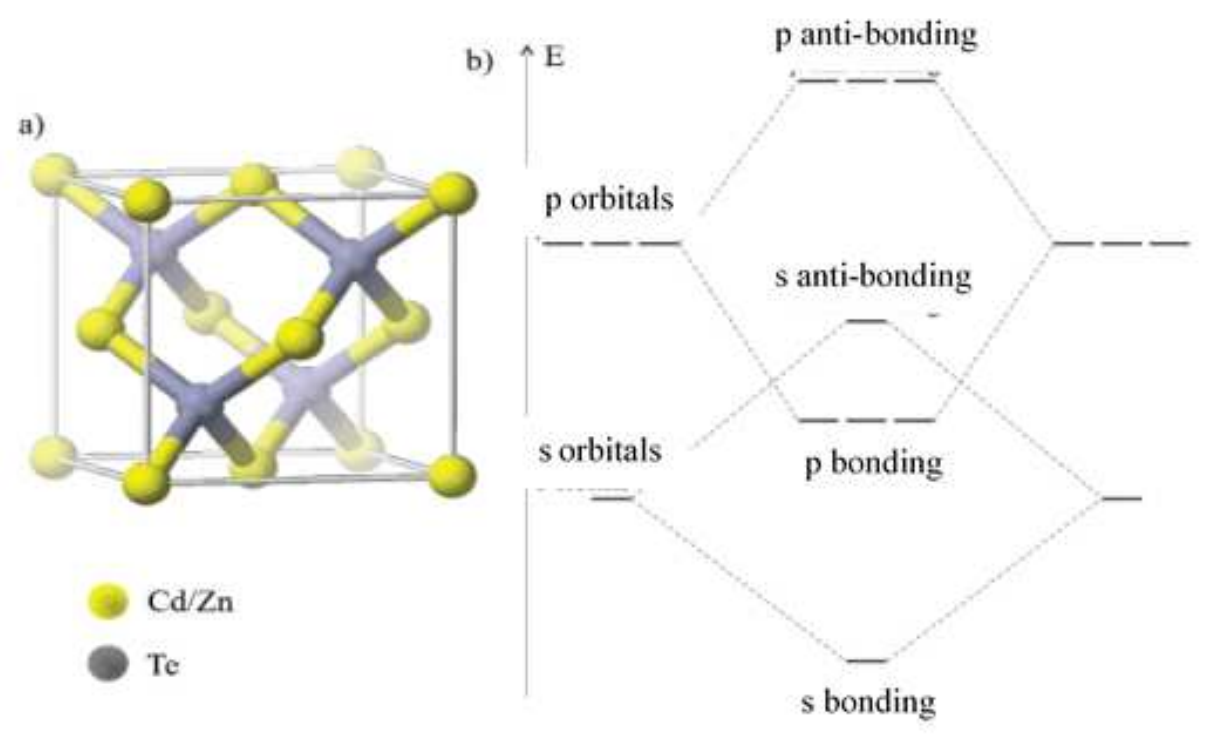

Figure 2.6: a) Zinc-blende crystal elementary cell for ZnTe semiconductor, b) Bonding and anti-bonding state arising from the hybridization of $\mathrm{s}$ and $\mathrm{p}$ orbitals [19].

The crystal structure shows the simple coordination of the $\mathrm{Zn}$ and Te atoms, in which one $\mathrm{Zn}$ atom is coordinated to $4 \mathrm{Te}$ atoms with tetragonal environment. On the other hand, one Te atom is coordinated with $4 \mathrm{Zn}$ atoms with the same symmetry, as shown in Figure 2.6a. The interatomic distances between the $\mathrm{Zn}$ and Te atoms are very small, around $2.671 \AA$. Therefore, the structure can have several $\mathrm{Zn}-\mathrm{Zn}$ and $\mathrm{Te}-\mathrm{Te}$ metallic bonds as edge-sharing dimeric units oriented at 180 degrees with respect to their neighbours. The external orbitals for the cations are $\mathrm{s}\left(3 \mathrm{~d}^{10} 4 \mathrm{~s}^{2}\right.$ for $\left.\mathrm{Zn}\right)$ and $\mathrm{p}$ for the anion $\left(4 \mathrm{~d}^{10} 5 \mathrm{~s}^{2} 5 \mathrm{p}^{4}\right.$ for $\left.\mathrm{Te}\right)$, and their hybridization form the conduction band and the valence band of the semiconductor, as shown in figure 2.6b. The lowest band of the bonding levels, coming from s orbitals, will be filled by two valence electrons. Six will be taken to fill the three bonding bands of higher energy, formed by the hybridization of p orbitals. Those bonding states form the valence band. At higher energy, the anti-bonding states form the conduction band. Since all the available electrons are used to fill the valence band, the conduction band is empty in the ground state. The lower energy band of the conduction band is formed by the anti-symmetric combination of the s orbitals. At higher energy, the 
anti-symmetric hybridization of p orbitals form three other bands. The energy needed to excite one electron from the higher energy state of the valence band to the lower energy state of the conduction band is the gap. ZnTe is a direct bandgap semiconductor with a bandgap of $2.26 \mathrm{eV}$ which corresponds to a wavelength of $548.67 \mathrm{~nm}$. So, this is an important material for optoelectronic devices such as light emitting diodes (LEDs), laser diodes (LDs) and solar cells [22, 23].

\subsection{Metal ions}

Most of the elements of the periodic table as shown in figure 2.7 [24] can be incorporated in host materials. Few of them have been used as optically active centers and few of them can be incorporated in ionic form that may gives rise to energy levels within a gap separated by optical energies. For technological applications, the most useful ions chosen are those from transition metals and rare earth series of the periodic table. In this work, we will focus our attention on Nickle $(\mathrm{Ni})$ and Neodymium Oxide $\left(\mathrm{Nd}_{2} \mathrm{O}_{3}\right)$ ions that are used as dopants in amorphous materials.

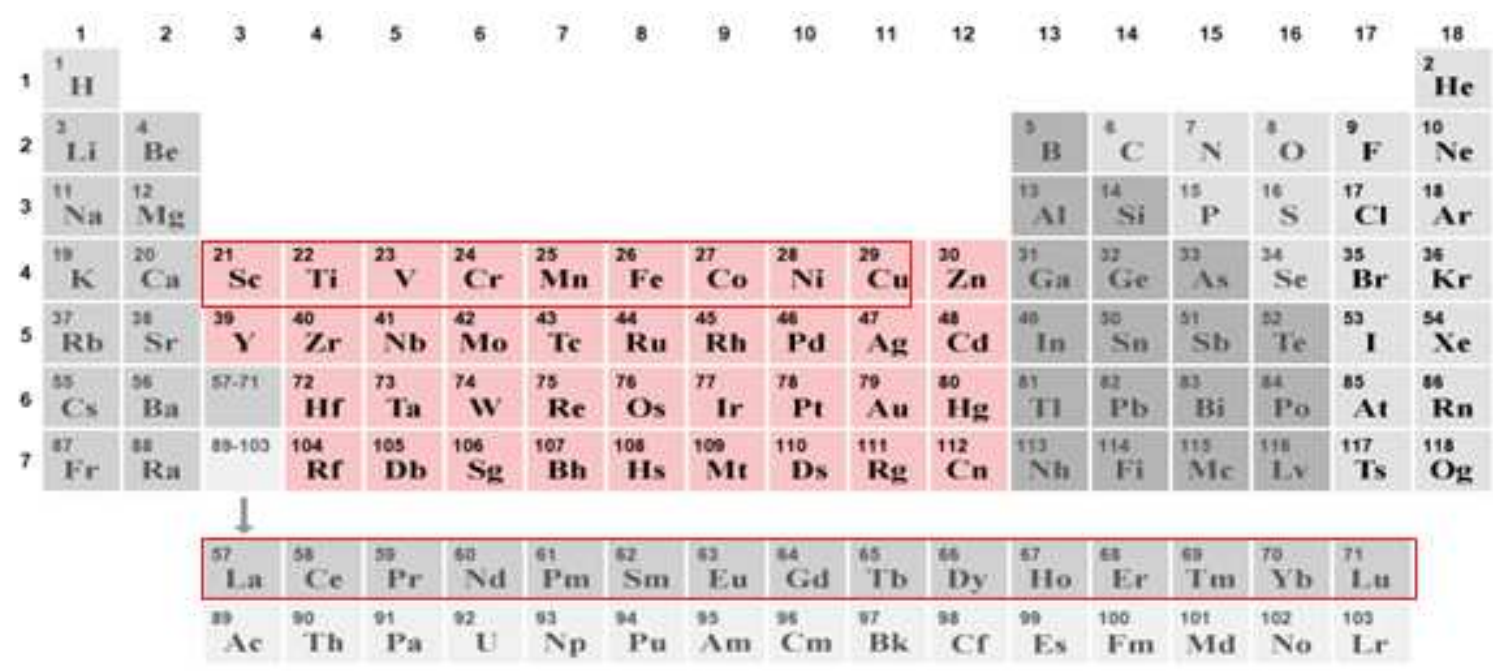

Figure 2.7: Periodic table of chemical elements [24].

\subsubsection{Nickel oxide $(\mathrm{NiO})$}

Generally, transition metals (TM) ions are formed from atoms in the fourth period of the periodic table; from beyond the calcium atom (element 20 in the periodic table), 
with electronic configuration (Ar) $4 s^{2}$, up to the zinc atom (element 30), with electronic configuration (Ar) $4 \mathrm{~s}^{2} 3 \mathrm{~d}^{1} 0$. TM atoms tend to lose the outer 4 s electrons, and in some

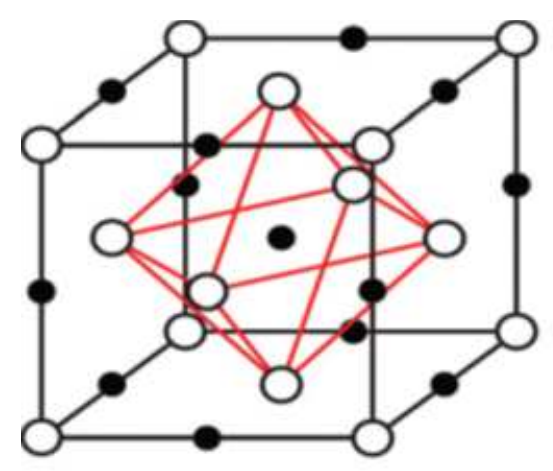

- Nickel $\bigcirc$ Oxygen

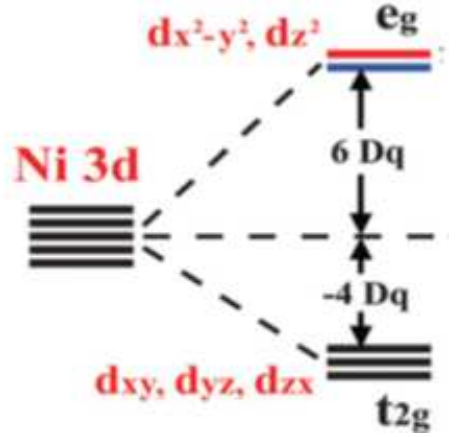

Figure 2.8: The crystal structure and band diagram for $\mathrm{NiO}$ [25].

cases lose or gain 3d electrons, to form different kinds of stable cations. Thus, TM ions have an electronic configuration $1 \mathrm{~s}^{2} 2 \mathrm{~s}^{2} 2 \mathrm{p}^{6} 3 \mathrm{~s}^{2} 3 \mathrm{p}^{6} 3 \mathrm{~d}^{n}$, where $\mathrm{n}=1$ to 10 denotes the number of $3 \mathrm{~d}$ electrons. These electrons are responsible for the optical transitions (i.e., they are valence electrons). The $3 \mathrm{~d}$ orbitals in TM ions have a relatively large radius and are unshielded by outer shells, so that strong ion-lattice coupling tend to occur in TM ions. As a result, the spectra of TM ions present both broad and sharp optical bands.

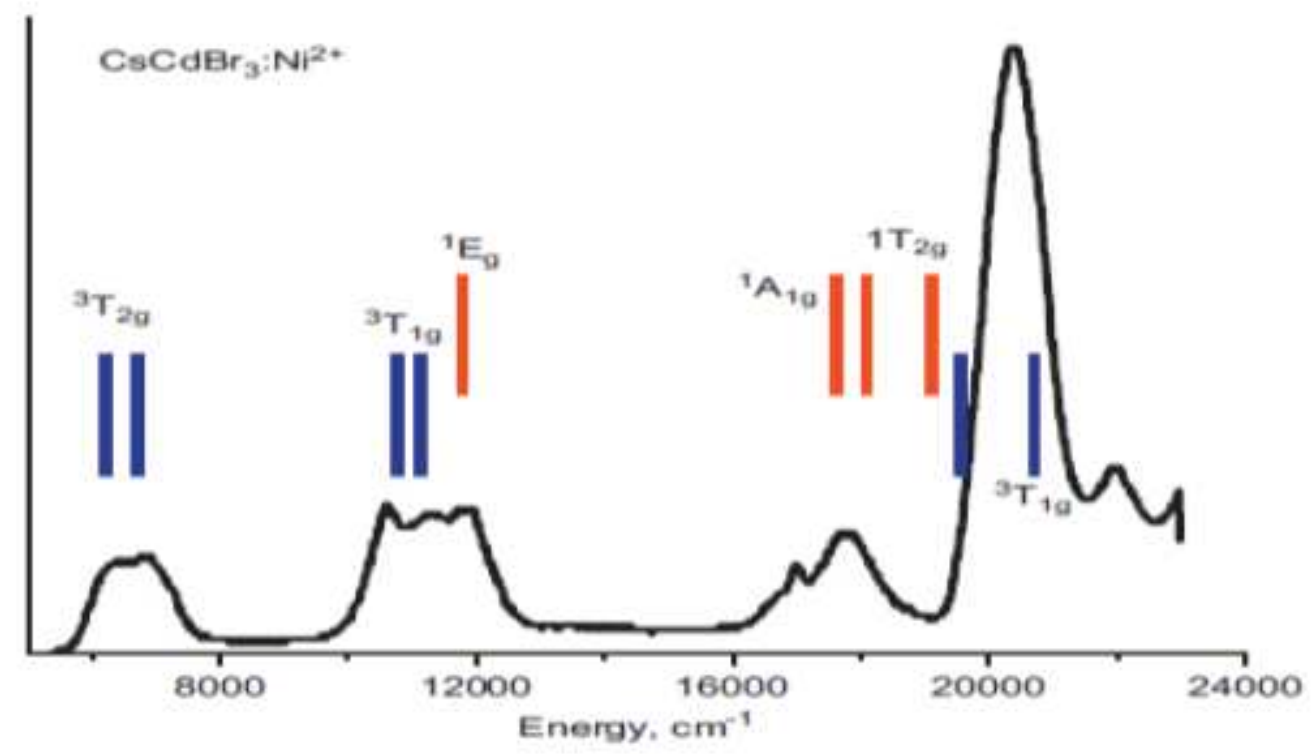

Figure 2.9: Absorption spectra of $\mathrm{Ni}^{2+}$ : $\mathrm{CsCdBr}^{3}[26]$.

The electronic configuration of nickel is $[\operatorname{Ar}] 4 \mathrm{~S}^{2} 3 \mathrm{~d}^{8}$. Nickel occurs in nature as 
oxide, silicate and sulphide. Nickel exhibits +1 to +4 oxidation states, but divalent state is the most stable. The $3 \mathrm{~d}$ band of $\mathrm{Ni}^{2+}$ will be split by the octahedral ligand field to give $e_{g}$ and $t_{2 g}$ subbands, as shown in Figure 2.8. There is no degeneracy for high spin and low spin states in $3 \mathrm{~d}^{8}$, because both of them give $e_{g}^{2} t_{2} g^{6}$. Therefore, $\mathrm{Ni}^{2+}$ exhibits three spin allowed transitions: ${ }^{3} \mathrm{~A}_{2 g}(\mathrm{~F}) \rightarrow{ }^{3} \mathrm{~T}_{1 g}(\mathrm{P}),{ }^{3} \mathrm{~A}_{2 g}(\mathrm{~F}) \rightarrow{ }^{3} \mathrm{~T}_{1} g(\mathrm{~F})$ and ${ }^{3} \mathrm{~A}_{2 g}(\mathrm{~F}) \rightarrow{ }^{3} \mathrm{~T}_{2 g}(\mathrm{~F})$; and other are spin forbidden transitions, ${ }^{3} \mathrm{~A}_{2 g}(\mathrm{~F}) \rightarrow{ }^{1} \mathrm{~T}_{1 g}(\mathrm{G}),{ }^{3} \mathrm{~A}_{2 g}(\mathrm{~F}) \rightarrow{ }^{1} \mathrm{~T}_{1 g}(\mathrm{D}),{ }^{3} \mathrm{~A}_{2 g}(\mathrm{~F}) \rightarrow$ ${ }^{1} \mathrm{E}_{g}(\mathrm{D}),{ }^{3} \mathrm{~A}_{2 g}(\mathrm{~F}) \rightarrow{ }^{1} \mathrm{~T}_{2 g}(\mathrm{D})$ and ${ }^{3} \mathrm{~A}_{2 g}(\mathrm{~F}) \rightarrow{ }^{1} \mathrm{~T}_{2 g}(\mathrm{G})$ [25]. Figure 2.9 shows absorption spectra of $\mathrm{Ni}^{2+}$ : $\mathrm{CsCdBr}^{3}[26]$.

The free ion states of transition metal ions are governed by the electron-electron interaction and so are labelled by ${ }^{2 S+1} \mathrm{~L}$ states, in which $\mathrm{S}$ is the total spin and $\mathrm{L}$ is the total angular momentum. The energy separation between the various ${ }^{2 S+1} \mathrm{~L}$ states is usually given in terms of the Racah parameters (A, B and $\mathrm{C}$ ). These parameters describe the strength of the electrostatic interaction between the electrons [27]. Sugano and Tanabe have estimated the energy of the states derived from the $3 \mathrm{~d}^{n}$ ions (from $\mathrm{n}=2$ to 8 ) as a function of the octahedral crystal field strength. These calculations are represented in the so-called Sugano-Tanabe diagrams, which are extremely useful in the interpretation of the spectra of TM ions in a variety of host materials. Sugano-Tanabe diagrams show how the ${ }^{2 S+1} \mathrm{~L}$ free ion levels split up as the ratio between the crystal-field strength and the inter-electronic interaction (a ratio measured in units of $\mathrm{D}_{q} / \mathrm{B}$ ) increases. The crystal field splitting energy parameter, $\mathrm{D}_{q}$ and the Racah parameter, $\mathrm{B}$ for octahedral nickel ions are given by the following expressions [27],

$$
\begin{gathered}
D_{q}=\frac{\nu_{1}}{10} \\
B=\frac{\nu_{3}+\nu_{2}-3 \nu_{1}}{15}
\end{gathered}
$$

where $\nu_{1}, \nu_{2}$ and $\nu_{3}$ are the absorption band positions of octahedral nickel ions.

Figure 2.10 shows the Sugano-Tanabe diagram for a $3 \mathrm{~d}^{8}$ transition metal ion, $\mathrm{Ni}^{2+}$. The free ion energy levels, 3F, $1 \mathrm{D}, 3 \mathrm{P}$ and $1 \mathrm{G}$ are shown on the left-hand side the figure, measured in E/B energy units. The split components (identified by group theory labels) of each free ion energy level in an increasing octahedral crystal field are shown on 


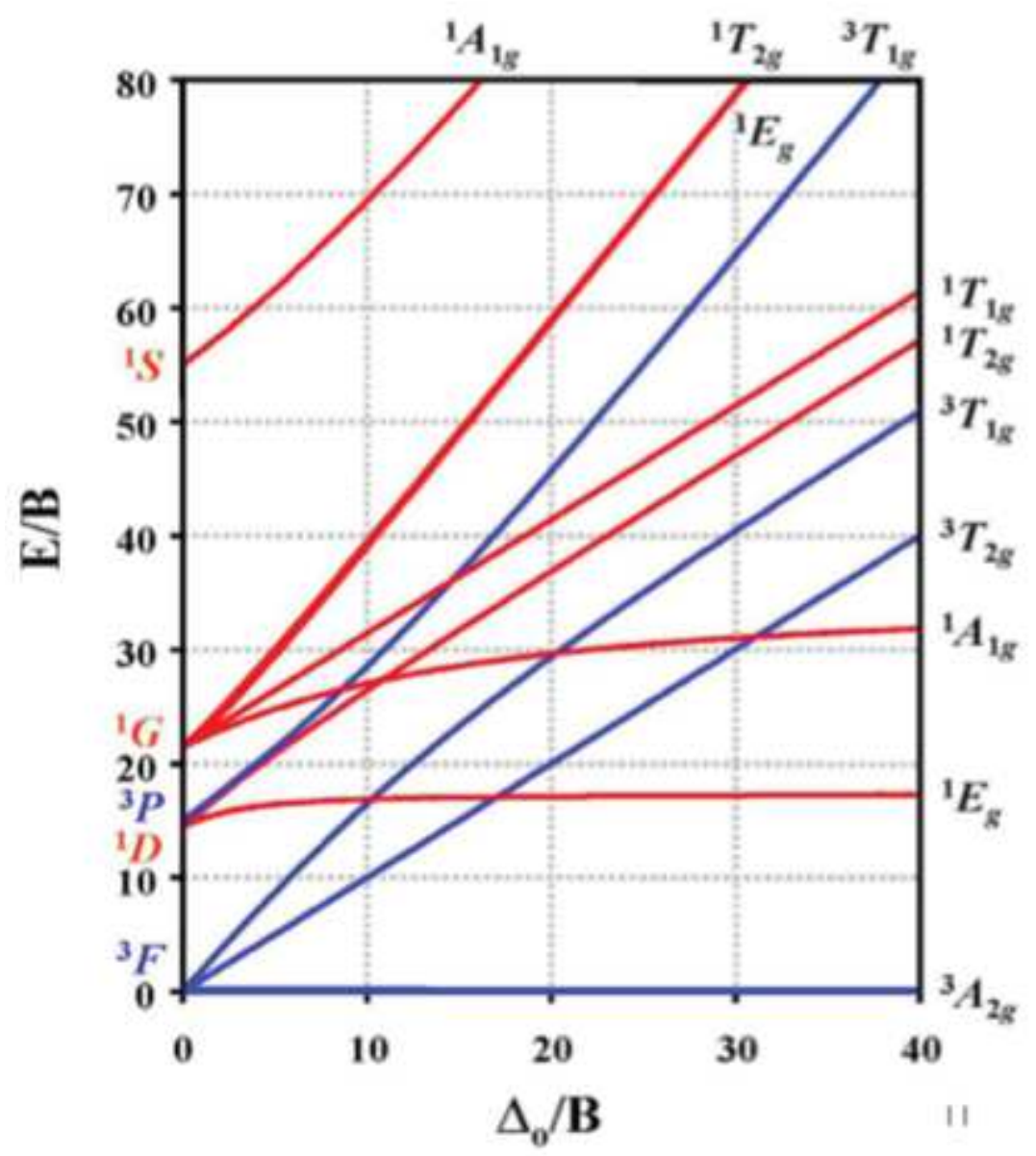

Figure 2.10: Sugano-Tanabe diagram for a $3 \mathrm{~d}^{8}$ configuration [28].

the right-hand side. For instance, it can be seen how the ground state $3 \mathrm{~F}$ splits into three energy levels in an octahedral crystal field; the ${ }^{3} \mathrm{~A}_{2 g}$ ground level and two excited levels, ${ }^{3} \mathrm{~T}_{2 g}$ and ${ }^{3} \mathrm{~T}_{1 g}$. The other excited free ion levels also split into different $\mathrm{A}, \mathrm{T}$ and $\mathrm{E}$ levels. It is also important to mention that a Sugano-Tanabe diagram is given for a particular value of $\mathrm{C} / \mathrm{B}$, which mainly depends on the specific ion and slightly on the host matrix. Among the TM free ions, the value of C/B varies from 4.19 for $\mathrm{Ti}^{2+}$ to 4.88 for $\mathrm{Ni}^{2+}$ [28]. Sugano-Tanabe diagrams, such as the one shown in Figure 2.10, allow us to deduce some useful information about the nature of the optical bands of TM ions. As can be seen in this figure, the levels, ${ }^{1} \mathrm{E}_{g}$ is almost independent of the crystal field (close to zero slopes in the diagram). Additionally, the energy of the ${ }^{1} \mathrm{~A}_{1 g}$ state is also almost constant for $\Delta_{0} / \mathrm{B}>10$, where $\Delta_{0}=10 \mathrm{D}_{q}$. Thus, the spectral positions of the transitions between the ${ }^{3} \mathrm{~A}_{2 g}$ ground level and the ${ }^{1} \mathrm{E}_{g}$ and ${ }^{1} \mathrm{~A}_{1} g$ levels are also almost independent of the crystal field strength. From the dynamic point of view, this means that the transition 
energy is practically constant with the configurational coordinate $\mathrm{Q}$. Therefore, these close to zero slope energy levels give rise to narrow optical bands, with $\mathrm{S} \approx 0$, as they have nearly the same electron-lattice coupling behaviour as the ground level $\left({ }^{3} \mathrm{~A}_{2 g}\right)$.

On the other hand, other levels, such as ${ }^{3} \mathrm{~T}_{2 g},{ }^{3} \mathrm{~T}_{1 g},{ }^{1} \mathrm{~T}_{2 g},{ }^{1} \mathrm{~T}_{1 g},{ }^{1} \mathrm{E}_{g}$ and ${ }^{1} \mathrm{~A}_{1 g}$, have a large slope in the diagram, which means that the energy separation of these levels and the ground level, ${ }^{3} \mathrm{~A}_{2 g}(3 \mathrm{~F})$, is strongly dependent on the crystal field strength, $10 \mathrm{D}_{q}$. Consequently, transitions from the ground level ${ }^{3} \mathrm{~A}_{2 g}(3 \mathrm{~F})$ up to these large-slope energy levels are crystal field dependent, and so the corresponding optical bands appear at quite different positions in different octahedral environments. In other words, this means that, for a given $3 \mathrm{~d}^{8}$ ion, these optical bands change strongly from one host to another. From the dynamic point of view, the high sensitivity of these transition energies to small displacements of the local environment (small changes in $10 \mathrm{D}_{q}$ ) indicates that the transition energy is strongly dependent on the configurational coordinate Q, and so broad absorption and emission bands are associated with these transitions (large S values). A rule of thumb for estimating relative values of $\mathrm{S}$ is that the larger the magnitude of the slope in the Sugano-Tanabe diagram, the larger is the value of $\mathrm{S}$.

\subsubsection{Neodymium oxide (Nd2O3)}

Trivalent rare earth (RE) ions most commonly used for applications as phosphors, lasers, and amplifiers are the so-called lanthanide ions. Lanthanide ions are formed by ionization of a number of atoms located in periodic table after lanthanum: from the cerium atom (atomic number 58) to the ytterbium atom (atomic number 70), which have a common electron configuration of $[\mathrm{Xe}] 4 \mathrm{f}^{n} 6 \mathrm{~s}^{2}$ or $[\mathrm{Xe}] 4 \mathrm{f}^{n-1} 5 \mathrm{~d}^{1} 6 \mathrm{~s}^{2}$, where $[\mathrm{Xe}]$ represents a Xenon core and $\mathrm{n}$ the number of electrons in the $4 \mathrm{f}$ shell of the lanthanide (i.e., lanthanum $\mathrm{n}=0$ to lutetium $\mathrm{n}=14$ ). These atoms are usually well known for their special optical properties, which result from the fact that the partially filled 4f-electrons shell are shielded from the surrounding completely filled $5 \mathrm{~s}$ and $5 \mathrm{p}$ shell, see figure 2.11 [29]. The energy levels of 4f shell have equal parity, and hence electric dipole transitions are forbidden. In a solid, slightly mixing with odd-parity wave functions makes the transitions slightly allowed. The absorption and emission cross-sections are therefore small, and the luminescence 
lifetime is quite long, ranging from microseconds to several milliseconds. The influence of the electric field around the ion removes the degeneracy of the $4 \mathrm{f}$ levels, resulting in a Stark splitting of the energy levels. The energy level splittings across the rare-earths are generally displayed in what is referred to as a Dieke diagram, as shown in figure 2.12, which was first compiled for trivalent lanthanide ions in $\mathrm{LaCl}_{3}$ [30].

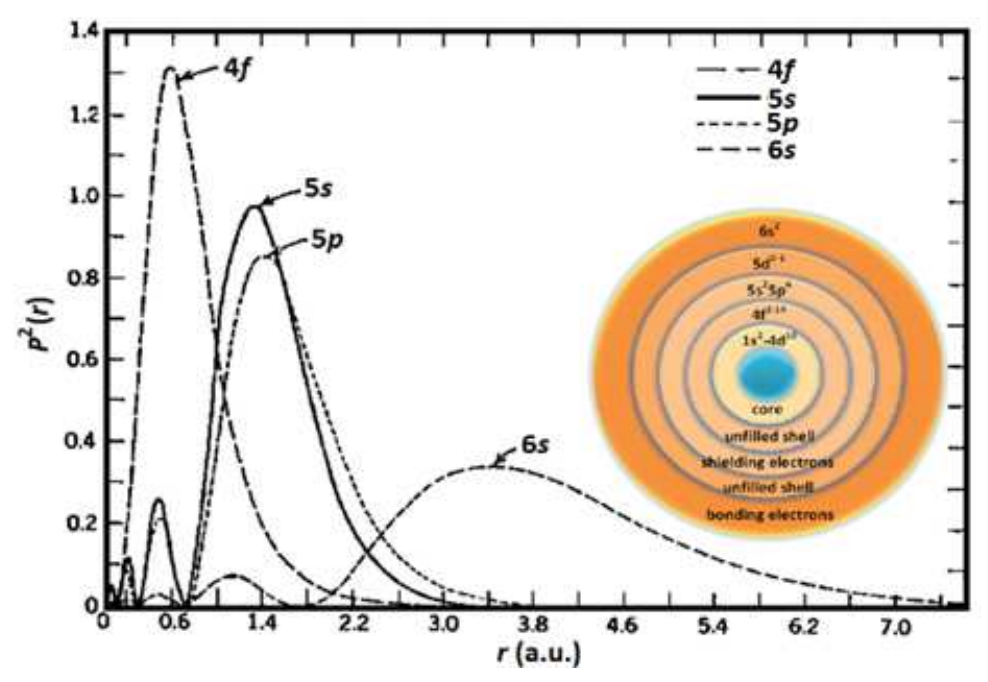

Figure 2.11: Square of the radial wavefunctions for the 4f, 5s, 5p and 6s energy levels from Hartree-Fock. It was a calculation for $\mathrm{Gd}^{3+}$ [29]. Picture inset schematically shows that the $4 \mathrm{f}$ orbital is within the $6 \mathrm{~s}, 5 \mathrm{p}$ and $5 \mathrm{~s}$ levels.

In this research work, neodymium rare earth ion is used as dopant with atomic number 60 and electronic configuration $[\mathrm{Xe}] 4 \mathrm{f}^{4} 6 \mathrm{~s}^{2}$. When it is incorporated in a glass it loses three electrons and forms the trivalent state $\mathrm{Nd}^{3+}$ with the ground electronic configuration $4 \mathrm{f}^{3}$. Energy levels for $\mathrm{Nd}^{3+}$ (see Figure 2.12) originate from the splitting of the $4 \mathrm{f}^{3}$ configuration under the effect of Coulombic $\left(\mathrm{H}_{\text {coul }}\right)$, spin-orbit coupling $\left(\mathrm{H}_{S O}\right)$ and crystal field $\left(\mathrm{H}_{C F}\right)$ interactions. Since the Hamiltonian operator $\mathrm{H}$ for the $4 \mathrm{f}$ electron could be decomposed as [31]:

$$
\mathrm{H}=\mathrm{H}_{(H-l i k e)}+\mathrm{H}_{C o u l}+\mathrm{H}_{S O}+\mathrm{H}_{C F}
$$

the first term is the sums over all $\mathrm{n}$ electrons of the individual hydrogen-like kinetic and potential energy; $\mathrm{H}_{\text {coul }}$ represents the mutual Coloumb repulsion between electrons; $\mathrm{H}_{S O}$ describes the electron-spin and orbital-angular momentum interactions and the last term, $\mathrm{H}_{C F}$, represents the electron perturbations caused by the surrounding crystal field.

In general, the magnitude of the various interactions in $\mathrm{Nd}^{3+}$ in glass can be 


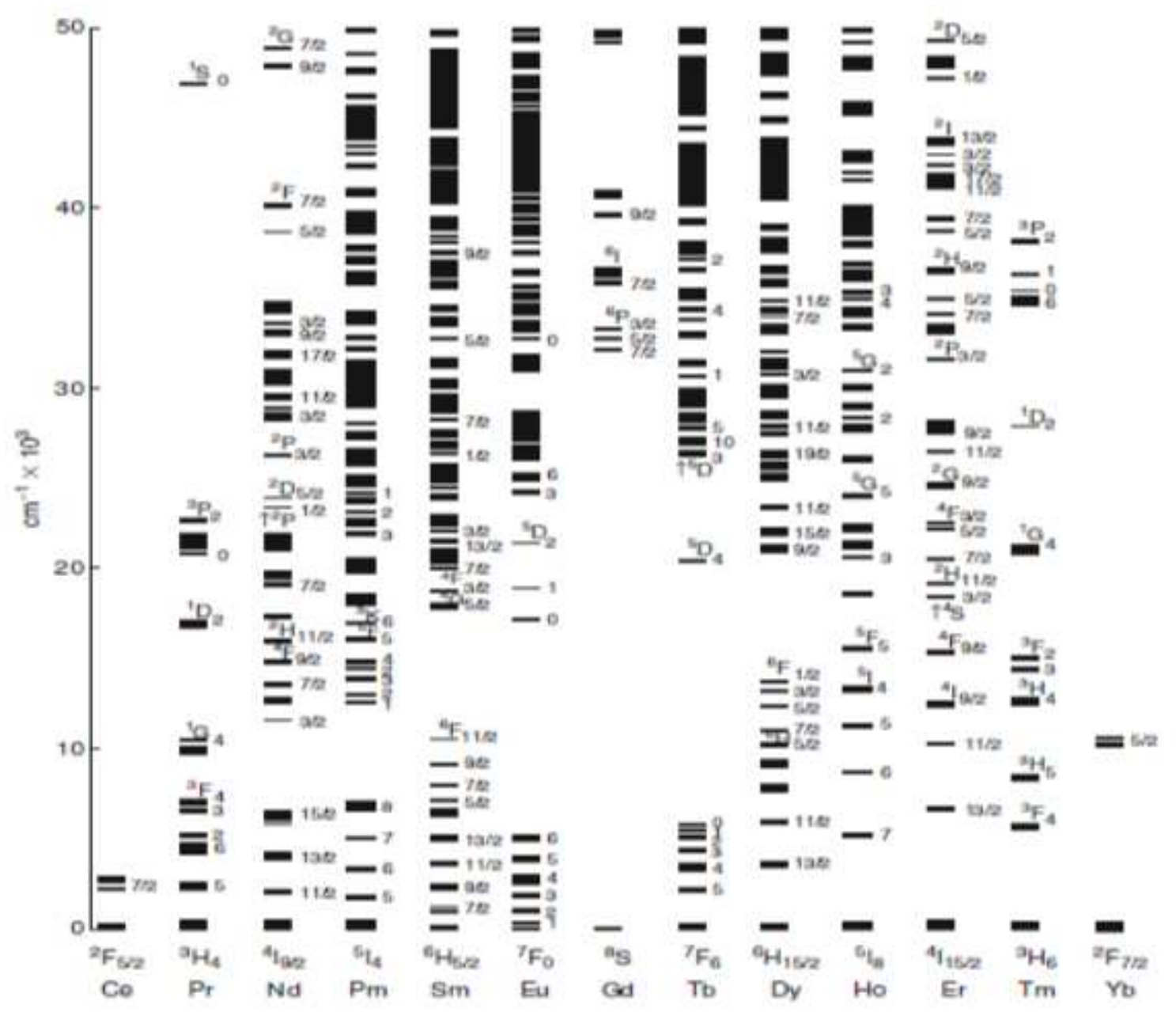

Figure 2.12: The Dieke diagram for elements of the lanthanide series in $\mathrm{LaCl}_{3}$, based on theoretical free-ion and crystal-field splittings [30].

written as,

$$
\mathrm{H}_{(H-l i k e)} \gg \mathrm{H}_{C o u l}>\mathrm{H}_{S O}>\mathrm{H}_{C F} .
$$

As can be observed in the above expression, the effect of crystal field $\left(\mathrm{H}_{C F}\right)$ is quite small compared to the other interactions, because of the shielding of $4 \mathrm{f}$ orbitals by the filled $5 \mathrm{~s}$ and $5 \mathrm{p}$ outer shells. Therefore, the $\mathrm{Nd}^{3+}$ ion energy level configuration varies only slightly from one host to another. The magnitude of the crystal field splitting is of order $100 \mathrm{~cm}^{-1}$ (Figure 2.13) and thus approximates $\mathrm{kT}$ value at ambient temperatures $\left(200 \mathrm{~cm}^{-1}\right)$. Moreover, due to the lack of symmetry in glass material, $\mathrm{Nd}^{3+}$ ions reside in sites having a slightly different crystal field interaction [31]. The result is that Stark splitting cannot be individually resolved; in Figure 2.13 they are represented as broad and shaded bands. 


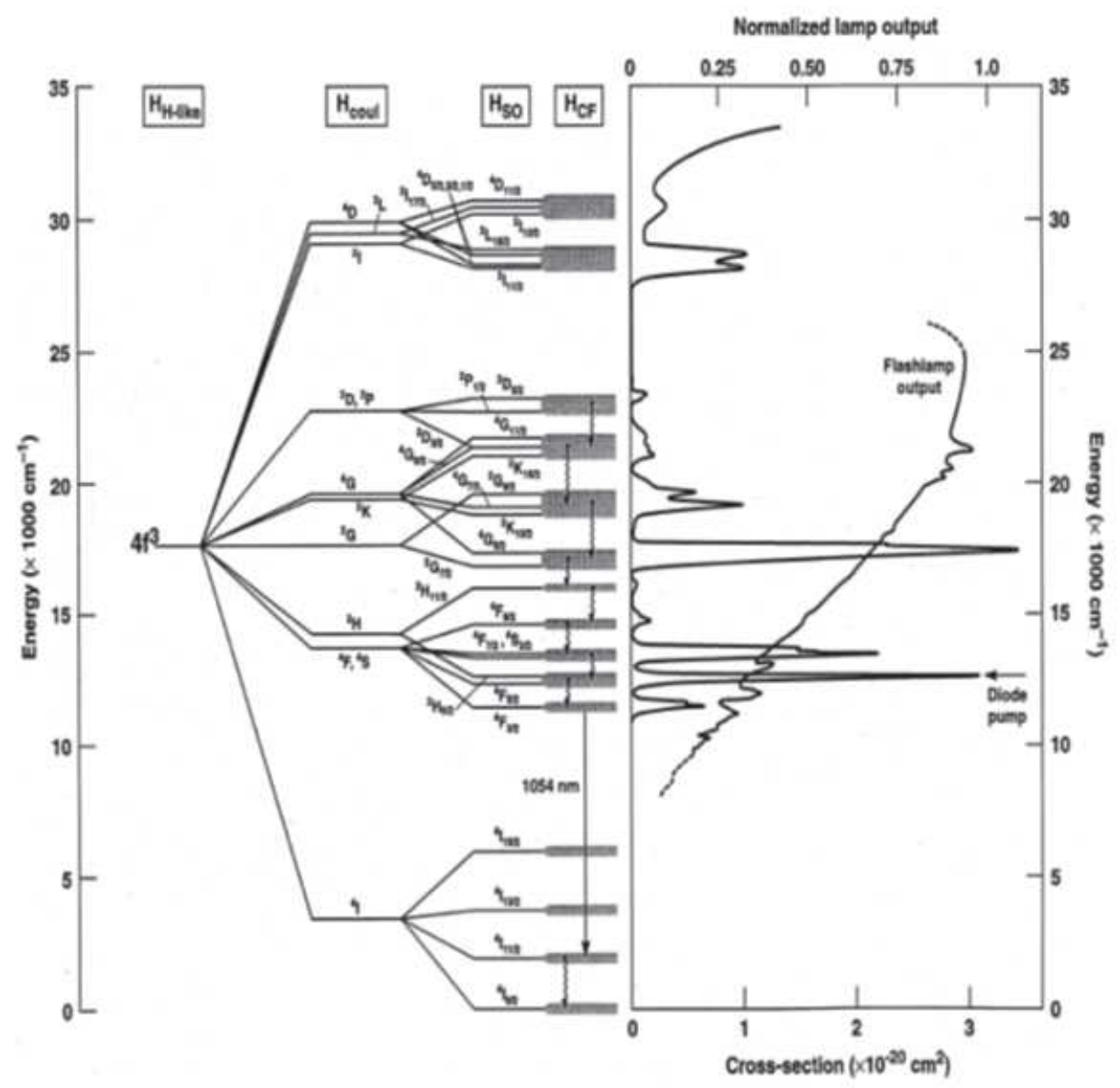

Figure 2.13: On the left: energy levels for $\mathrm{Nd}^{3+}$ originated from the splitting of the $4 \mathrm{f}^{3}$ configuration under the effect of Coulombic $\left(\mathrm{H}_{\text {coul }}\right)$, spin-orbit coupling $\left(\mathrm{H}_{S O}\right)$ and crystal field $\left(\mathrm{H}_{C F}\right)$ interactions. The laser transition of interest $(1053 \mathrm{~nm})$ is from the metastable ${ }^{4} \mathrm{~F}_{3 / 2}$ state to the ${ }^{4} \mathrm{I}_{11 / 2}$ final level. The wavy lines denote rapid non-radiative (multiphonon) transitions. On the right: typical Nd-absorption cross-section in metaphosphate glass host. Relative output intensity for a xenon flash lamp and laser diode pump source are also shown. The energies reported are relative to the ${ }^{4} \mathrm{I}_{9 / 2}$ ground state [31].

The spin-orbit interaction is quite large for $\mathrm{Nd}$ and these causes that ${ }^{4} \mathrm{I}_{11 / 2}$ state remains virtually unpopulated at ambient temperatures. This effect together with the high energy gap between the ${ }^{4} \mathrm{~F}_{3 / 2}$ state and the terminal ${ }^{4} \mathrm{I}_{J}$ states $\left(\sim 5500 \mathrm{~cm}^{-1}\right)$, is the reason why Nd-doped gain media exhibit pure four-level behaviour. The states above the ${ }^{4} \mathrm{~F}_{3 / 2}$ level are split by energies of order $1000 \mathrm{~cm}^{-1}$, for comparison, in case of phosphate glass matrix, the phonon energies of the glass are $\left(\sim 1200 \mathrm{~cm}^{-1}\right)$. Therefore electrons excited to these levels undergo non-radiatively decay to the ${ }^{4} \mathrm{~F}_{3 / 2}$ state where they accumulate. In fact the high energy gap between the ${ }^{4} \mathrm{~F}_{3 / 2}$ state and the lower-lying ${ }^{4} \mathrm{I}_{J}$ manifold prevents multiphonon decay from this level and, on the contrary, favors radiative decay. Although the radiative decay can occur to all the lower lying ${ }^{4} \mathrm{I}_{J}$ levels, 
the strongest transition is the one to the ${ }^{4} \mathrm{I}_{11 / 2}$ level that leads to the emission of light near $1053 \mathrm{~nm}$ in most glass materials.

The Judd-Ofelt $[32,33]$ theory has been well known for decades and has been used to estimate quantitatively and qualitatively optical absorption and emission bands of intra-configurational f-f transitions of several rare earth doped host materials. According to the Judd-Ofelt $(\mathrm{J}-\mathrm{O})$ theory, the oscillator strength, $\mathrm{f}_{c a l}\left[(\mathrm{~S}, \mathrm{~L}) \mathrm{J} ;\left(\mathrm{S}^{\prime}, \mathrm{L}^{\prime}\right) \mathrm{J}^{\prime}\right]$ of an electronic dipole absorption transition from the initial state $|(\mathrm{S}, \mathrm{L}) \mathrm{J}\rangle$, to the final state, $\mid\left(\mathrm{S}^{\prime}, \mathrm{L}^{\prime}\right) \mathrm{J}^{\prime}>$, depends on the three Judd-Ofelt parameters, $\Omega_{\lambda},(\lambda=2,4,6)$ as,

$$
f_{\text {cal }}\left[(S, L) J ;\left(S^{\prime}, L^{\prime}\right) J^{\prime}\right]=\frac{8 \pi^{2} m c}{3 h \lambda(2 J+1)} \frac{\left(n^{2}+1\right)}{9 n} \sum_{\lambda=2,4,6} \Omega_{\lambda}\left|<(S, L) J\left\|U^{\lambda}\right\|\left(S^{\prime}, L^{\prime}\right) J^{\prime}>\right|^{2}
$$

where $\lambda$ is the mean wavelength of the transition, $m$ is the mass of the electron, $\mathrm{c}$ the velocity of light, $\mathrm{n}$ the refractive index, $\mathrm{h}$ the Planck constant and $\left\|U^{\lambda}\right\|$ are the doubly reduced matrix elements of unit tensor operators that are considered to be independent of the host matrix. The experimental oscillator strengths $\mathrm{f}_{\text {exp }}$ of the observed absorption band are determined using the expression [34],

$$
f_{\text {exp }}=\frac{m c^{2}}{\pi e^{2} \lambda^{2} N} \times \frac{2.303}{d} \int O D(\lambda) d \lambda
$$

where $\mathrm{N}$ is the number of $\mathrm{Nd}^{3+}$ absorbing ions per unit volume, $\mathrm{d}$ is the thickness of the sample and $\mathrm{OD}(\lambda)$ is the optical density as a function of wavelength. Equating $\mathrm{f}_{\text {exp }}$ and $\mathrm{f}_{\text {cal }}$ and using the squared reduced matrix elements, the three characteristic intensity parameters, $\Omega_{2}, \Omega_{4}$ and $\Omega_{6}$ are calculated by standard least square fitting method. The quality of the fit is obtained by using magnitude of root mean square $\left(\delta_{r m s}\right)$ formula [34],

$$
\delta_{r m s}=\sqrt{\frac{\sum\left(f_{\text {exp }}-f_{c a l}\right)^{2}}{(P-3)}}
$$

where $\mathrm{P}$ are the number of existing transitions.

The Judd-Ofelt intensity parameters represent the square of the charge displacement due to the induced electric dipole transition. The advantage of $\Omega_{\lambda}$ parameters is that a set of parameters is needed for describing both the absorption and emission processes. 
The $\Omega_{\lambda}$ parameters are important for the investigation of the local structure and bonding in the vicinity of the rare earth ions. $\Omega_{2}$ parameter indicates the both asymmetry and covalency at rare earth sites. Both $\Omega_{4}$ and $\Omega_{6}$ indicates the rigidity or long range effects of glass hosts [35].

The computed Judd-Ofelt intensity parameters $\left(\Omega_{\lambda}\right)$ are used to study certain radiative properties for the principal fluorescence transitions of rare earth ions in host matrix. We can estimate (a) radiative transition probabilities or radiative lifetimes of the excited states (b) branching ratios of all the transitions from the excited states to ground state and (c) integrated absorption cross-sections. The radiative transition probability $\mathrm{A}_{\text {rad }}\left(\Psi \mathrm{J}, \Psi^{\prime} J^{\prime}\right)$ for emission from an initial excited state $\Psi \mathrm{J}$ to a final ground state $\Psi^{\prime} J^{\prime}$ is given in [34],

$$
A_{\text {rad }}\left(J \rightarrow J^{\prime}\right)=\frac{64 \pi^{4} e^{2}}{3 h(2 J+1) \lambda^{3}}\left[\frac{n\left(n^{2}+2\right)^{2}}{9} S_{e d}+n^{3} S_{m d}\right]
$$

where

$$
\begin{gathered}
S_{e d}\left(J \rightarrow J^{\prime}\right)=\sum_{\lambda=2,4,6} \Omega_{\lambda}\left|<(S, L) J\left\|U^{\lambda}\right\|\left(S^{\prime}, L^{\prime}\right) J^{\prime}>\right|^{2} \\
S_{m d}\left(J \rightarrow J^{\prime}\right)=\left(\frac{h^{2}}{16 \pi^{2} m^{2} c^{2}}\right)\left|\left\langle(S, L) J\|L+2 S\|\left(S^{\prime}, L^{\prime}\right) J^{\prime}\right\rangle\right|^{2}
\end{gathered}
$$

In case of electric dipole transition, the radiative transition probability is

$$
A_{\text {rad }}\left(J \rightarrow J^{\prime}\right)=\frac{64 \pi^{4} e^{2}}{3 h(2 J+1) \lambda^{3}}\left[\frac{n\left(n^{2}+2\right)^{2}}{9} S_{e d}\right]
$$

The factor $\frac{n\left(n^{2}+2\right)^{2}}{9}$ represents the local field correction term for the ion in a medium, $\nu$ is the energy of transition and $\mathrm{n}$ is the refractive index of the glass.

The total radiative transition probability, $\mathrm{A}_{T}(\Psi \mathrm{J})$ involving all the intermediate terms between $\Psi \mathrm{J}$ and $\Psi^{\prime} J^{\prime}$ is given by

$$
A_{T}(J)=\sum_{J} A_{\text {rad }}\left(J \rightarrow J^{\prime}\right)
$$


The radiative lifetime $\left(\tau_{R}\right)$ of an excited state $\Psi^{\prime} J^{\prime}$ is calculated from

$$
\tau_{R}(J)=\frac{1}{\sum_{J}^{\prime} A_{T}\left(J \rightarrow J^{\prime}\right)}
$$

The fluorescence branching ratio, $\beta_{R}$, predicts the relative intensity of lines from a given excited states and characterizes the lasing potency of that particular transition. In order to choose suitable lasing transition, one has to select the transition having branching ratio $>0.5$ and the energy difference of about $3000 \mathrm{~cm}^{-1}$ between the emitting level and the next lower level. The fluorescence branching ratio $\left(\beta_{R}\right)$ is given by

$$
\beta_{R}\left(J \rightarrow J^{\prime}\right)=\frac{A_{r a d}\left(J \rightarrow J^{\prime}\right)}{\sum_{J}^{\prime} A_{T}\left(J \rightarrow J^{\prime}\right)}
$$

In addition to the above radiative properties, the nonradiative transition probabilities involves the mechanisms of multiphonon relaxation as well as two ion energy transfer rates such as cross-relaxation and upconversion. These nonraditive transition probabilities must be quantified to the determination of fluorescence states lifetime. No comprehensive theory has been developed for predicting the ion energy transfer rates. However, multiphonon relaxation rates for rare earth ions in crystals and glasses follows the energy gap law by Weber and Moos [36, 37]. These multiphonon relaxation rates are significantly affected by the kind of host matrices. $\mathrm{W}_{M P R}$ are calculated from the equation,

$$
W_{M P R}=B\left(1+n_{e f f}\right) \frac{\Delta E}{\hbar \omega} \exp (\alpha \Delta E)
$$

where $\mathrm{n}_{\text {eff }}=\left[\exp \left(\frac{\hbar \omega}{k T}\right)-1\right]^{-1}$. Here, $\mathrm{n}_{\text {eff }}$ is the occupancy of the effective phonon modes and $\Delta \mathrm{E}$ the energy gap between the emitting level and adjacent lower level. Also for the phosphate matrix $\mathrm{B}=5.36 \times 10^{12} \mathrm{~s}^{-1}, \alpha=4.7 \times 10^{-3} \mathrm{~cm}$, and $\hbar \omega=1200 \mathrm{~cm}^{-1}$ (for phosphate glasses) [37]. These non-radiative multiphonon relaxation rates are determined and are reported in their respective chapters of this thesis.

Total transition probability of the state includes both radiative and non-radiative rates. In the absence of other nonradiative mechanisms such as upconversion or crossrelaxation, the non-radiative relaxation rate is simply the multiphonon relaxation rate. 
The total transition probability is the reciprocal of the fluorescence lifetime of the state and is represented as follows

$$
\tau^{-1}=\sum A+W_{M P R}
$$

where the summation is the total radiative transition probability and $\mathrm{W}_{M P R}$ is the multiphonon relaxation rate, which strongly depends on the maximum phonon energy and energy gap between two excited states. The estimated fluorescence lifetimes of the state of rare earth ions are reported in their respective chapters.

The stimulated emission cross-section is an important parameter and its value means the rate of energy extraction from the optical material. The efficiency of a laser transition is evaluated by considering the stimulated emission cross-section and it is related to the radiative transition probability. It was obtained from the emission spectra using Fuchtbauer-Ladenburg method [34],

$$
\sigma_{P}=\frac{\lambda_{P}^{4}}{8 \pi c n^{2} \Delta \lambda_{e f f}}
$$

where $\lambda_{P}$ is peak wavelength and $\lambda_{\text {eff }}$ is the effective linewidth. The effective linewidth $\lambda_{e f f}$ is obtained from

$$
\Delta \lambda_{e f f}=\int \frac{I(\lambda)}{I_{\max }} d \lambda
$$

where $\mathrm{I}(\lambda)$ is the integrated fluorescence intensity and $\mathrm{I}_{\max }$ is the peak fluorescence intensity.

Equation 2.22 implies that $\sigma_{P}$ depends on the intensity parameters $\Omega_{\lambda}$, the bandwidth, $\Delta \lambda_{\text {eff }}$ and refractive index $\mathrm{n}$. The bandwidth is a measure of the overall extent of the Stark splitting of the J manifold and inhomogeneous broadening due to site-to-site variation in the local field seen by the rare earth ions. Both $\Omega_{\lambda}$ and $\Delta \lambda_{\text {eff }}$ are affected by the compositional change in the glass matrix. 


\subsection{Host material used in this work: Phosphate glasses and their structure}

Generally, the identity of glass former components usually serves as the basis for the generic name used for the glass. The primary glass formers in commercial oxide glasses are silica $\left(\mathrm{SiO}_{2}\right)$, boric oxide $\left(\mathrm{B}_{2} \mathrm{O}_{3}\right)$ and phosphoric oxide $\left(\mathrm{P}_{2} \mathrm{O}_{5}\right)$, in addition to other compounds $\mathrm{GeO}_{2}, \mathrm{Bi}_{2} \mathrm{O}_{3}, \mathrm{As}_{2} \mathrm{O}_{3}, \mathrm{Sb}_{2} \mathrm{O}_{3}, \mathrm{TeO}_{2}, \mathrm{Al}_{2} \mathrm{O}_{3}, \mathrm{Ga}_{2} \mathrm{O}_{3}$ and $\mathrm{V}_{2} \mathrm{O}_{5}$ which act as glass formers under certain circumstances. The glass-forming oxides are sometimes classified as network modifiers or intermediate oxides, depending on their structural roles. Oxides with large coordination numbers and relatively weak bonds are called network modifiers and they alter the glass-forming network by replacing stronger bridging oxygen (BO) bonds between glass-forming polyhedra with weaker, nonbridging oxygen (NBO) bonds. The network modifiers are important constituents in most technological glasses because they lower the melting temperature and control many useful properties. The intermediate oxides have coordination numbers and bond strengths between the network formers and network modifiers and tend to have an intermediate effect on glass properties [13].

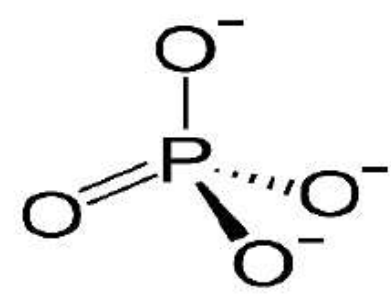

$\mathrm{PO}_{4}{ }^{3-}$

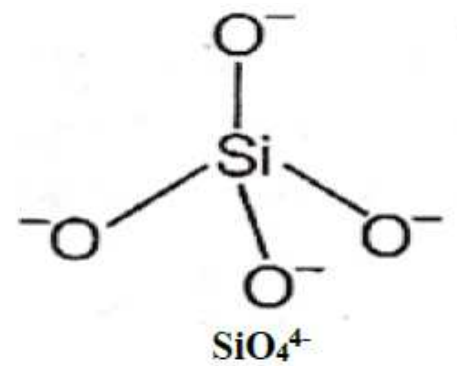

$\mathrm{SiO}_{4}{ }^{4-}$

Figure 2.14: The basic structure of tetrahedral $\mathrm{PO}_{4}^{3-}$ and $\mathrm{SiO}_{4}^{4-}$.

In this research, phosphate glasses are used as host matrices. $\mathrm{P}_{2} \mathrm{O}_{5}$ based glasses are being one of the four classic Zachariasen glass forming oxides $\left(\mathrm{SiO}_{2}, \mathrm{GeO}_{2}\right.$ and $\left.\mathrm{B}_{2} \mathrm{O}_{3}\right)$ and have been researched for over one hundred and fifty years. Van Wazer [38], Abe [39], Martin [40] and Brow [41], Knowles [42] and Abou Neel et al. [43] give an account of phosphate systems with respect to technological applications. Phosphate glasses are formed from the tetrahedral phosphate anions, $\mathrm{PO}_{4}^{3-}$, consisting of one phosphorous atom bonded to four oxygen atoms by $\mathrm{sp}^{3}$ hybridization, analogous to the $\mathrm{SiO}_{4}^{4-}$ as shown in 
figure 2.14. The main structural difference between them is the extra valency electron in the phosphorus atom which is doubly bonded to one of the oxygen atoms. The other three are singly bonded and carry one negative charge. In vitreous $\mathrm{P}_{2} \mathrm{O}_{5}$ each unit is connected to three others via bridging oxygen (BO) atoms. The fourth oxygen atom must balance the valence for the unit and is therefore unable to form connections to other tetrahedral units since phosphorus has a valence of +5 . This is known as a non-bridging oxygen (NBO). Different phosphate groups are formed by the tetrahedral linked to the covalent bridging oxygens and are classified using $\mathrm{Q}^{n}$ terminology, where $\mathrm{n}$ is the number of bridging oxygens per tetrahedron. The formation of particular Q species is dependent on cation added as a modifier content to $\mathrm{P}_{2} \mathrm{O}_{5}$. Thus, the groups starts from ultraphosphate
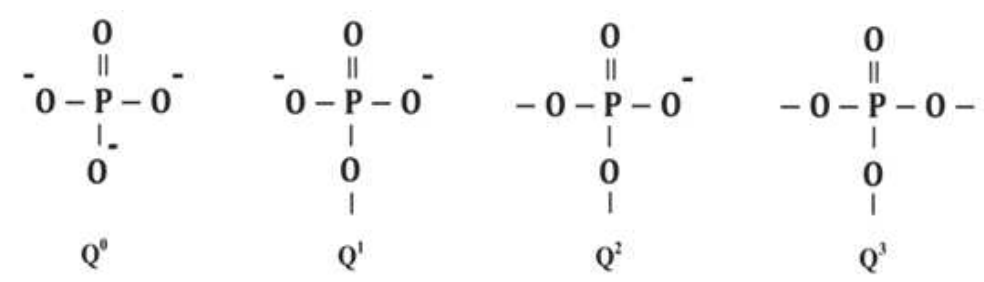

Figure 2.15: Phosphate based glass tetrahedral in $\mathrm{Q}^{n}$ terminology.

$\left(\mathrm{Q}^{3}\right)$, metaphosphate $\left(\mathrm{Q}^{2}\right)$, pyrophosphate $\left(\mathrm{Q}^{1}\right)$ and then orthophosphate $\left(\mathrm{Q}^{0}\right)$, with creating non bridging oxygens (NBOs), as shown in figure 2.15. According to overview of phosphate glass by Van Wazer [38], without any cation additions to phosphorous pentoxide, $\mathrm{Q}^{3}$ species are the only phosphate group present forming a highly cross-linked phosphate network. With addition of metal cations, so that the concentrations $\left[\mathrm{M}_{2} \mathrm{O}\right]=$ $\left[\mathrm{P}_{2} \mathrm{O}_{5}\right]$ (where $\mathrm{M}$ is any mono-valent cation, e.g. $\mathrm{Na}^{+}, \mathrm{K}^{+}$or $\mathrm{Li}^{+}$), will make $\mathrm{Q}^{2}$ the only species present, hence producing non-branched phosphate chains with infinite phosphate chain lengths which are named as metaphosphates. The addition of any more $\mathrm{M}_{2} \mathrm{O}$ will introduce terminating $\mathrm{Q}^{1}$ species, decreasing the phosphate chain length. If the concentration of $\mathrm{M}_{2} \mathrm{O}$ is twice that of $\mathrm{P}_{2} \mathrm{O}_{5}$, the terminating $\mathrm{Q}_{1}$ species is dominant that leads to producing only phosphate dimers, or pyrophosphates. If the concentration of $\mathrm{M}_{2} \mathrm{O}$ is at least three times higher than that of $\mathrm{P}_{2} \mathrm{O}_{5}$ then the non-bridging $\mathrm{Q}^{0}$ species form the dominant orthophosphate chains. In fact, concentrations of metallic cations between these limits would create a distribution of Q species, and can be diagrammatically depicted in 


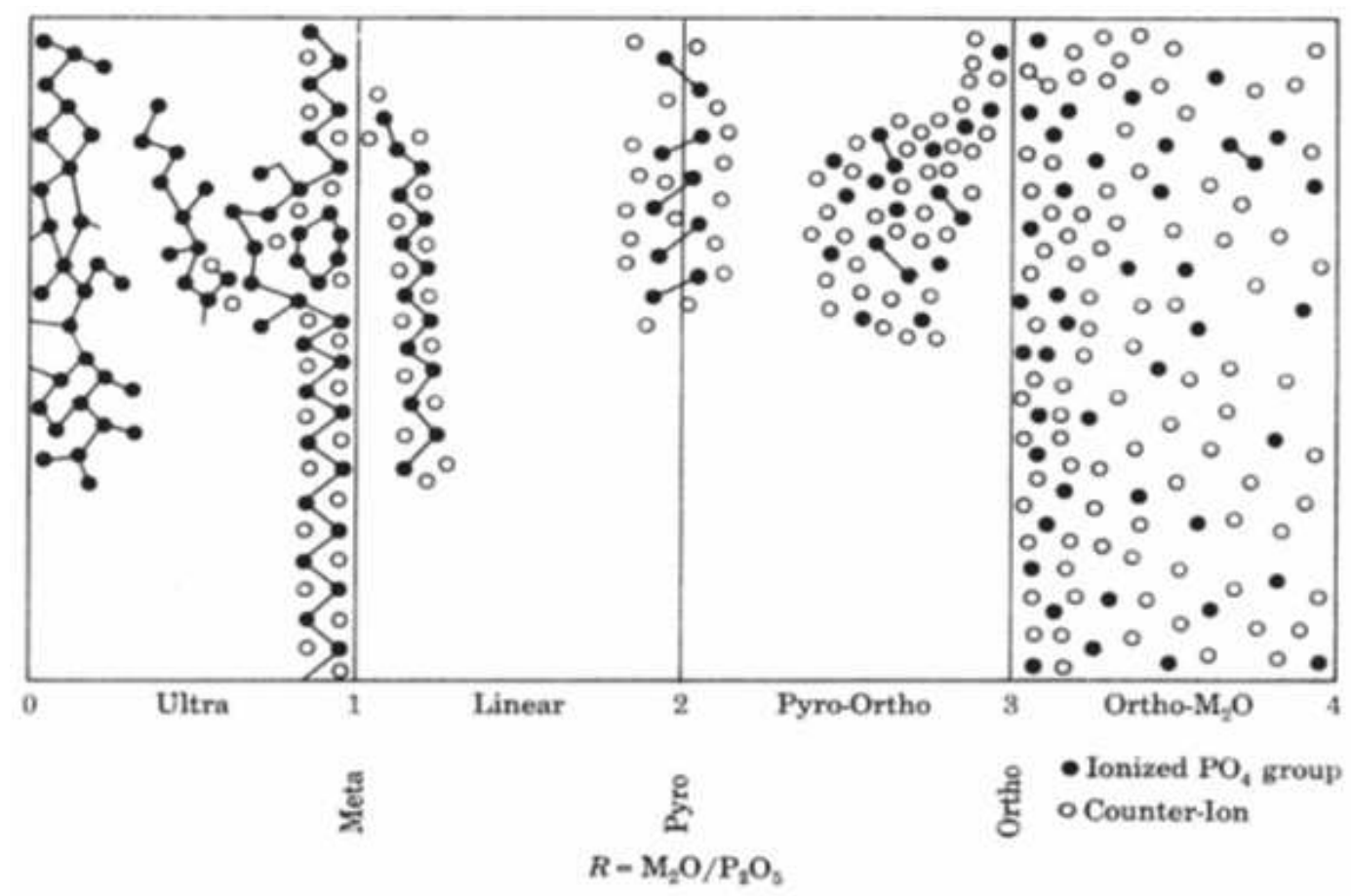

Figure 2.16: Schematic phosphate structures as a function of composition, note that linear phosphates are also known as polyphosphates [43].

figure 2.16. It is noted that phosphate polymerisation, as the number of bridging oxygens available per phosphate anion, decrease due to addition (low or higher concentration) of metal cations.

\subsection{State of the art of semiconductor nanocrystals $(\mathrm{NCs})$ in glasses}

The first evidences of semiconductor nanocrystals (NCs) doped glasses undergone through thermal annealing were given by Rocksby at about 1930's [44]. In 1964 Bret and Gires were the first to use semiconductor doped glasses (SDGs) in nonlinear optics [45]. They introduced a commercial semiconductor nanocrystals doped glass filter into a ruby laser cavity. In this way, they exploited the saturable absorption of semiconductor nanocrystals doped glasses for passive Q-switching, and nanosecond laser pulses could be obtained. The starting point of the optical study of semiconductor nanocrystals doped glasses was, however, the publication of degenerate four-wave mixing results by Jain and Lind in 1983 [46]. This was the first time that the high optical third-order nonlinearities of semiconductor 
nanocrystals doped glasses were observed. It is worth noticing that the main reason they investigated semiconductor nanocrystals doped glasses was not the search for new, highly nonlinear materials, but problems they encountered in elaborating suitable bulk semiconductor samples. In fact, at that time, it was quite difficult to grow semiconductor crystals of appropriate dimensions with the desired band edge, absorption coefficient, and overall optical quality. Bányai and Koch (1993) [47], Woggon (1997) [44], and Gaponenko (1998) [48] reported interesting results in the physical properties of semiconductor nanocrystals doped glasses, and its optical transitions of electrons in quantum confinement regime. Since the second half of 20th century, companies like Corning Glass Industries, Schott Optical Glass, Hoya, and Toshiba, have been using quantum dot-doped glasses [48].

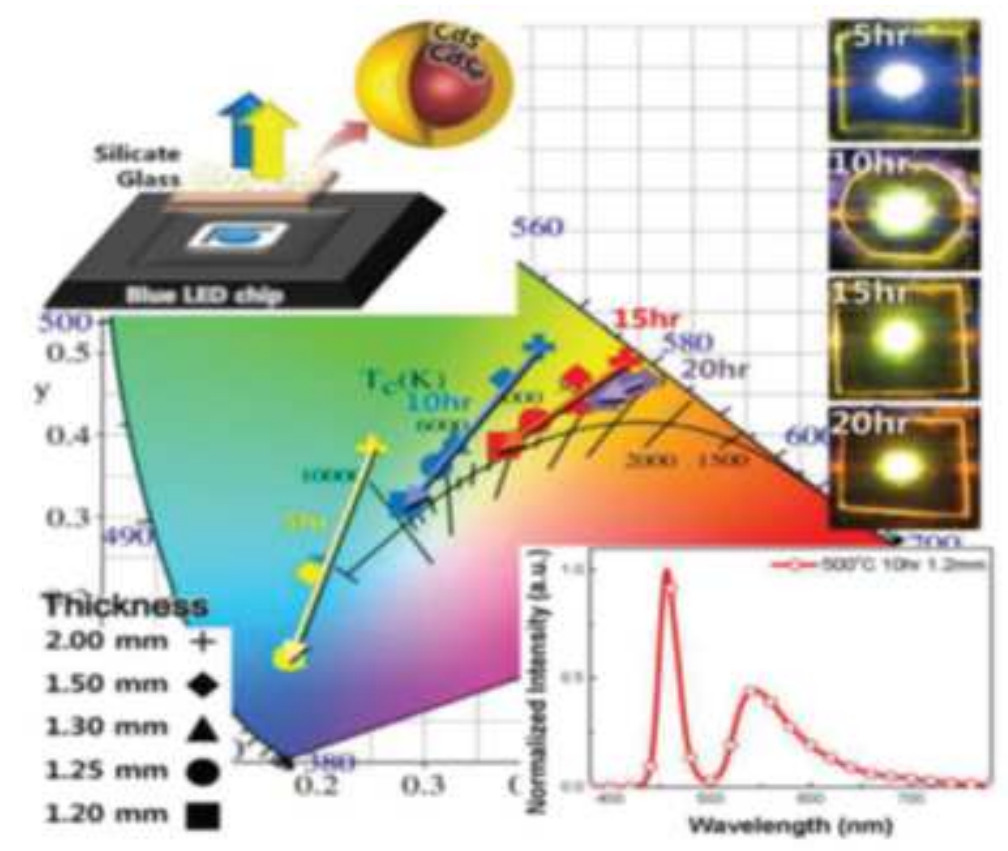

Figure 2.17: Commission Internationale de l'Eclairage (CIE) color coordinates of LEDs mounted with CdSe/CdS QDs-embedded silicate glasses of various thickness heat-treated for $5,10,15$, and $20 \mathrm{~h}$ at $500{ }^{\circ} \mathrm{C}$. The inset presents the electroluminescence and PL spectra of the wLED, which had coordinates of $(0.3277,0.3458)$ and a CRI (Color Rendering Index) of 90. Actual photos of the LEDs with CdSe/CdS QDs-embedded silicate glasses of the same thickness $(1.2 \mathrm{~mm})$ with varying heat treatment duration are presented at the right of the figure. (Adapted from Ref.[1]).

There are different growth techniques such as QD suspension in colloids, sol-gel porous glasses, rf magnetron sputtering and laser ablation, isolated or combined were developed, as well as different materials such as $\mathrm{GaAs}, \mathrm{CuCl}, \mathrm{CdTe}, \mathrm{PbTe}$, and etc., were extensively studied by several groups $[49,50,51,52,53,54]$. An optical device 
working at 250 gbits/s was demonstrated by Tsunetomo et al. [55] using a CdTe QD glass produced by rf magnetron sputtering combined with laser ablation. Recently Han et al., combining II-VI NCs-embedded glass (Yellow light emission) with a blue LED chip resulted in obtaining a composite wLED device for the first time [56]. Due to the strong nonradiative recombination loss of CdSe or CdS NCs in glasses, the photoluminescence quantum yield (PLQY) of NCs-embedded glasses is lower than 5\%, which fails to meet the application requirements. Later, they made wLED device using CdSe/CdS core-shell structural QDs-embedded glasses [1], as shown in Figure 2.17. The highest PLQY was increased to $20 \%$ profiting from the enhanced intrinsic emission of CdSe QDs.

$\mathrm{CdSe} / \mathrm{Cd}_{1-x} \mathrm{Zn}_{x}$ Se and $\mathrm{CdS} / \mathrm{Cd}_{1-x} \mathrm{Zn}_{x} \mathrm{~S}$ core-shell QDs synthesized in situ in glasses by two-step heat-treatment were studied by Xia et al. [57] and Hall et al. [58]. The defects emission can be nearly completely passivated and the highest PLQY of II-VI NCs in glass increased from $3 \%$ to more than $50 \%$. The results laid the foundation for the development of highly luminescent QDs-embedded glasses and emitting devices. It should be noted that other efforts have been made in order to enhance the luminescence of II-VI NCs-embedded glasses as well. It can be enhanced by energy transfer between the NCs and transition metal ions or rare earth ions $[2,3]$. Therefore, the advantage of NCs in glasses is their stability compared to NCs without packaging material, and the exploration of NCs-based devices become possible.

ZnTe and PbTe nanocrystals with average radii of 2.42 and $4.25 \mathrm{~nm}$, respectively, were grown in a fluorophosphate glass host by Donya and Taha [59]. They observed a strong quantum confinement effect through the blue shifted optical absorption due to the ZnTe and PbTe nanocrystals. Thermal properties of a phosphate glass matrix (PZABP) doped with $\mathrm{ZnTe}$ and co-doped with $\mathrm{Yb}^{3+}$ ions were studied by Freitas et al. [60]. Many applications focus on improving the performance of NCs after they are stabilized. Utilizing their continuously tunable absorption cutoff edges in the visible range, II-VI NCs-embedded glasses can be used in optical filters [61]. Since amplified spontaneous emission was first reported in CdSe NCs, applications of II-VI NCs-embedded glasses in the field of optical amplifiers, such as Raman amplifiers, have soon become one of the most popular studies of NCs-embedded glasses for their ultrastability [62]. In addition, 
the QDs-embedded glasses have large nonlinear optical polarizability and can produce response at the time level of picosecond under strong excitation, making them attractive for all-optical switches [63]. Meanwhile, some studies on the relationship between the nonlinear refractive index and the absorptivity of II-VI QDs-embedded glasses provided precondition for the application in nonlinear optics [64, 65].

\subsection{State of the art of metal (TM/RE) ions in glasses}

Broadly tunable lasers are useful for basic spectroscopy studies, as well as a wide range of applications from optical communications to biomedical imaging. Transition metal or rare earth-ions doped solid-state gain media are eminently suitable for generating broadband emissions due to the strong interaction of the electronic states with lattice phonons. The interaction leads to a strong homogeneous broadening of the transition and thus results in a broad gain bandwidth. The broad gain bandwidth,however, inherently exhibits small product of emission cross-section and fluorescent lifetime. As a result, one major limitation for metal ions doped lasers has been the high pump-power density required for efficient lasing.

Since the invention of laser by Maiman in 1960, among the broadly tunable laser gain media, $\mathrm{Ti}^{3+}$ : sapphire crystal was first demonstrated as a widely tunable laser gain medium at the Lincoln Laboratory [66]. The $\mathrm{Ti}^{3+}$ : sapphire crystals used in the initial experiments exhibited significant scattering and an unidentified absorption at the laser wavelength. These losses affected the efficiency of the laser, and only pulsed operation was possible. As high-quality crystals became available, a series of tunable lasers based upon $\mathrm{Ti}^{3+}$ : sapphire appeared, and a $235 \mathrm{~nm}$ tuning bandwidth was demonstrated with one mirror set [67]. For waveguide $\mathrm{Ti}^{3+}$ : sapphire lasers, continuous-wave channel waveguide lasers were demonstrated and the emission wavelength was tuned over a $170 \mathrm{~nm}$ range by using a birefringent filter in an external cavity [68].

Among all the $\mathrm{Cr}^{4+}$ doped gain media, $\mathrm{Cr}^{4+}$ : YAG has been shown high concentration of tetrahedrally coordinated $\mathrm{Cr}^{4+}$ ions and high emission cross section in fiber communication bands. $\mathrm{Cr}^{4+}$ : YAG tunable laser has been developed for thirty years, and the first operated in gain-switched mode with a tuning range from 1.35 to $1.45 \mu \mathrm{m}$ [69]. 
Then, there tunable lasers in continuous-wave mode had been demonstrated [70]. These systems used high power solid-state laser as pumping source, which was massive and high cost. Although laser diode could reduce the cost and volume, the threshold was still in the Watt level [71]. Another issue was the thermal loading in crystal with bulk structure. The lifetime suffer from the thermal loading and the thermal lensing effect in the crystal [72].To overcome the thermal problem and poor pump/signal beam overlapping in bulk crystal, a $120 \mu \mathrm{m}$ diameter $\mathrm{Cr}^{4+}$ : YAG crystal fiber was developed with a tuning range of $180 \mathrm{~nm}$ at a threshold pump power above $2 \mathrm{~W}$ [73].

Decades later, silica glass fiber has revolutionised their use in broadband optical telecommunications, due to exceptional low loss of $<1 \mathrm{~dB} / \mathrm{km}$ at $1.55 \mu \mathrm{m}$. This makes it by far the best material for long distance communication. Nevertheless, its low refractive index and the inability to transmit radiation above $2 \mu \mathrm{m}$ makes silica fiber unsuitable for active and mid infra-red (MIR) optical devices [4]. A key component for telecommunications networks, the erbium-doped fibre amplifier (EDFA) is the most widely used optical amplifier and has allowed transmission of large data volumes using a number of channels at different wavelengths through dense wavelength division multiplexing (DWDM). However, due to the limited gain bandwidth of the EDFA only a small fraction of the low-loss window of silica optical fibre is used in current telecommunication systems. Doping silica optical fibres with other rare earths could overcome this though problems associated with the vibrational structure of silica. The effective use as an amplifier medium may be reached when doping silica with ions such as praseodymium $\left(\mathrm{Pr}^{3+}\right)$, thulium $\left(\mathrm{Tm}^{3+}\right)$ and dysprosium $\left(\mathrm{Dy}^{3+}\right)[74]$. Another approach to access more of the low loss silica window is through using glasses doped with transition metals which have characteristically broad absorption and emission bands. However, the high phonon energy of silica glass results in emission being quenched and leads to low quantum efficiencies.

In recent years, phosphate glasses have demonstrated to be a promising alternative to silicate glasses as a host material, especially for high-power applications. In fact, they allow extremely high doping levels of RE ions and thus the fabrication of more compact and active devices [75]. The phosphate glasses are very well known for their suitable mechanical and chemical properties, homogeneity, good thermal stability and excellent 
optical properties. Three $\mathrm{Nd}^{3+}$ doped phosphate laser glasses, LHG-8 (Hoya), LG-7705 (Schott), and N31 (Shanghai Institute of Optics and Fine Mechanics, SIOM), have been developed for high power laser inertial confinement fusion (ICF) technology. Application of this technology is currently used by National Ignition Facility (NIF) in the United States, Laser Megajoule (LMJ) in France, and Shen Guang in China, respectively [7]. Table 2.2 summarizes the major properties of Nd: phosphate glasses from Hoya, Schott, and SIOM.

Table 2.2: Key parameters of Nd doped commercial laser glasses [7].

\begin{tabular}{|c|c|c|c|}
\hline Parameters & LHG-8 & LG-770 & N31 \\
\hline Emission cross-section $\sigma_{\text {emi }}\left(10^{-20} \mathrm{~cm}^{2}\right)$ & 3.6 & 3.9 & 3.8 \\
\hline Radiative lifetime $\tau_{\mathrm{rad}}(\mu \mathrm{s})$ & 365 & 351 & 348 \\
\hline Fluorescence effective linewidth $\Delta \lambda_{\text {eff }}(\mathrm{nm})$ & 26.5 & 25.4 & 25.5 \\
\hline Density d $\left(\mathrm{gm} / \mathrm{cm}^{3}\right)$ & 2.83 & 2.59 & 2.87 \\
\hline Refractive index $n_{d}$ & 1.5279 & 1.5067 & 1.540 \\
\hline Refractive index at $1053 \mathrm{~nm} \mathrm{n}_{1053 \mathrm{~nm}}$ & 1.5201 & 1.4991 & 1.533 \\
\hline Abbe number & 66.5 & 68.4 & 65.8 \\
\hline Nonlinear refractive index $\mathrm{n}_{2}\left(10^{-15} \mathrm{esu}\right)$ & 1.12 & 1.01 & 1.18 \\
\hline Transition temperature $\mathrm{T}_{\mathrm{g}}\left({ }^{\circ} \mathrm{C}\right)$ & 485 & 460 & 450 \\
\hline Thermal expansion coeff. $\alpha\left(10^{-7} / \mathrm{K}\right)$ & 115 & 116 & 115 \\
\hline Temp. Coeff. Refractive index dn/dT $\left(10^{-7} \mathrm{~K}\right)$ & -53 & -47 & -43 \\
\hline Temp.coeff. optical path dS/dT $\left(10^{-7} / \mathrm{K}\right)$ & 6 & 11 & 14 \\
\hline Thermal conductivity $\mathrm{K} * \mathrm{~W} / \mathrm{mK}$ ) & 0.58 & 0.57 & 0.56 \\
\hline Young;s modulus E (GPa) & 50 & 47 & 56.4 \\
\hline \multicolumn{4}{|c|}{$\begin{array}{l}\left.\left.\text { LHG: }(56-60) \mathrm{P}_{2} \mathrm{O}_{5}-(8-12) \mathrm{Al}_{2} \mathrm{O}_{3}-\right) 13-17\right) \mathrm{K}_{2} \mathrm{O}-(10-15) \mathrm{BaO}-0.2 \mathrm{Nd}_{2} \mathrm{O}_{3} \\
\text { LG-770: } \\
\mathrm{N} 31:(58-62) \mathrm{P}_{2} \mathrm{O}_{5}-(6-10) \mathrm{Al}_{2} \mathrm{O}_{3}-(20-25) \mathrm{K}_{2} \mathrm{O}-(5-10) \mathrm{MgO}-0.2 \mathrm{Nd}_{2} \mathrm{O}_{3} \text {; } \\
\end{array}$} \\
\hline
\end{tabular}

Another important feature of phosphate glasses is their thermal and mechanical strength, which allow the production of optical fibers that can be cleaved and fusionspliced with commercial optical fiber components based on silicate glasses, thus allowing an easier integration of these fibers in commercial systems [76]. Nevertheless, doping of transition metals, rare earth ions and semiconductor nanocrystals in glasses may open new kind of materials for example, Diluted Magnetic Semiconductors (DMS) in glasses. This composite may be obtained when nonmagnetic constituents of a compound semiconductor are randomly substituted by a magnetic ion. These materials may significantly enhance magneto-optic (MO) effects for MO sensors applications [77, 78, 79]. 


\section{Engineering properties of amorphous}

\section{materials}

Glass as "an amorphous solid that lacks long range crystalline structure". Since its first discovery, the key advantages of amorphous materials that makes them highly suitable for a broad range of applications are counterless. Generally, the interaction of light with matter is an interesting area in science that has led to many photo-chemical/physical processes in our daily lives. The following section focus on required engineering properties such as optical, mechanical, chemical and thermal, for glasses using literature [80, 81, 82, $83,84]$.

\section{$3.1 \quad$ Optical properties}

By virtue of electron energy band structures of glasses, they may be transparent to visible light. Therefore, not only reflection and absorption but also refraction and transmission phenomena need to be considered.

\subsubsection{Refractive index}

Light that is transmitted into the interior of materials experiences a decrease in velocity, and, as a result, is bent at the interface; this phenomenon is termed refraction. The index of refraction $(\mathrm{n})$ will depend on the wavelength of light $(\lambda \nu=c / n)$ and is proportional to the dielectric constant of a solid $(\cong \sqrt{\varepsilon})$. Generally, glass is an optically homogeneous, nonmagnetic, and isotropic material. The behavior of an electromagnetic wave propagation through glass can be described by a complex refractive index, n-ik or equivalently a complex dielectric constant, $\varepsilon^{\prime}-i \varepsilon^{\prime \prime}$, which are related through,

$$
(\mathrm{n}-\mathrm{ik})^{2}=\left(\varepsilon^{\prime}-i \varepsilon^{\prime \prime}\right)
$$

or equivalently, 
$\varepsilon^{\prime}=\mathrm{n}^{2}-\mathrm{k}^{2}$ and $\varepsilon^{\prime \prime}=2 \mathrm{nk}$
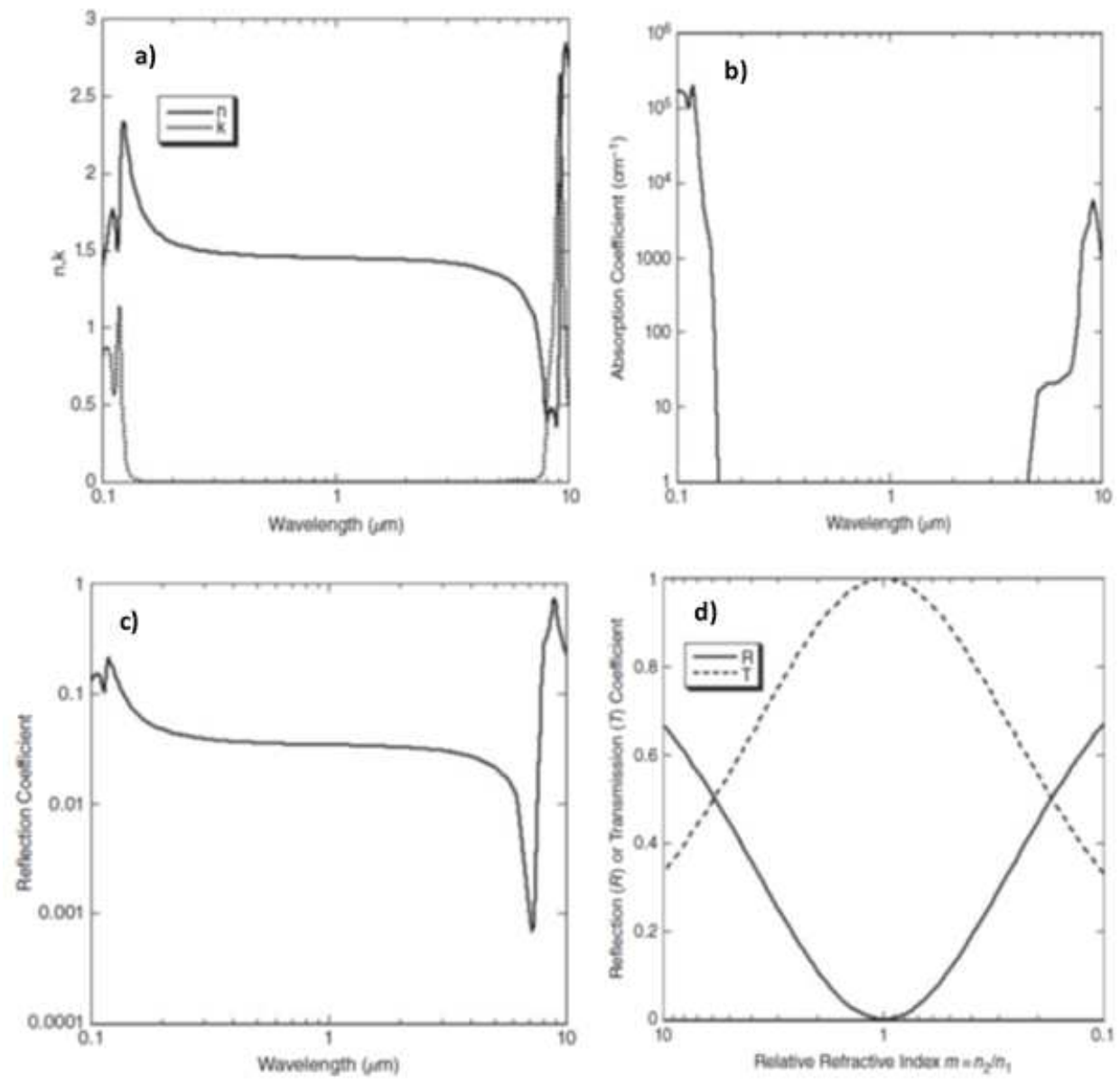

Figure 3.1: a) Complex refractive index (n, k), b) absorption coefficient, c) reflection coefficient as a function of wavelength for a silica $\mathrm{SiO}_{2}$; and d) reflection (R) and transmission (T) coefficients for a normal incidence of light from one medium to another medium as a function of the refractive index. Figures adapted from ref. [80].

Figure 3.1a shows how the refractive index beahves as a function of the wavelength for silica glass. The key features are, i) a broad region where $\mathrm{n}$ is almost (but not quite) wavelength-independent (the transmittance "window" of the glass), ii) a sharp rise in k at short wavelengths (the "uv edge"), and iii) a sharp rise in k at longer wavelengths (the IR edge). The abrupt rise in $\mathrm{k}$ at the two edges is due to the rise of absorption coefficient at that frequencies for a silica glass, as shown in figure 3.1b. The sharp rise in $\mathrm{k}$ also contributes to strong reflections from glass surfaces at the window boundaries, shown in figure 3.1c. For normal incidence, the intensity reflection coefficient from an air-glass interface is given by [81],

$$
R=\left[\frac{(n-1)^{2}+k^{2}}{(n+1)^{2}+k^{2}}\right]
$$


In the window of transparency, the complex refractive index of glasses is dominated by the real part. Thus, the reflection and transmission coefficients for normal incidence at the interface between two glass media are readily calculated from Equation 3.1 using the relative refractive index $m=n_{2} / n_{1}$ (for silicate glass, $m=1.5$ ) for the refractive indices for light in the medium of incidence $\left(\mathrm{n}_{1}\right)$ and transmission $\left(\mathrm{n}_{2}\right)$; the resultant spectra is shown in figure 3.1d. There are angles of incidence (Brewster and critical angles) at the interface of glass which play an important role in many applications. For example, most gas lasers use windows cut at the Brewster angle to eliminate reflection losses for one polarization. The critical angle is the defining parameter for the propagation of guided waves in fiber optic cables (strictly for cables whose diameter is much greater than the wavelength of light).

\subsubsection{Absorption}

The optical transparency for glasses is directly linked to the absorption of the glass for different wavelengths. The intensity of the net absorbed radiation is dependent on the character of the medium as well as the path length within. Let's consider an incident light passing through the glass. Its coefficient of absorption is given by the Lambert- Beer law as,

$$
I=I_{0} e^{-\alpha l}
$$

where $\mathrm{I}$ is the light transmitted, $I_{0}$ is the initial incident light. $\alpha$ is the absorption coefficient while 1 is the length of the sample and can written as,

$$
\alpha=-\frac{1}{l} \ln \left(\frac{I}{I_{0}}\right)
$$

In principle, when an incident light in the visible range is absorbed by the glass material, an electron is excited from the nearly filled valence band, cross the band gap, and fall into an empty state within the conduction band. Thus, a free electron in the conduction band and a hole in the valence band are created. For semiconducting materials that have band gap energies less than about $1.8 \mathrm{eV}\left(\lambda_{\max }=0.7 \mu \mathrm{m}\right)$ all visible light is absorbed resulting into a valence band to conduction band electron transitions; in this 
case the material is opaque. No visible light is absorbed by nonmetallic materials having band gap energies greater than about $3.1 \mathrm{eV}\left(\lambda_{\max }=0.4 \mu \mathrm{m}\right)$; these materials, if have high purity, will appear transparent and colorless. Only a portion of the visible spectrum is absorbed by materials having band gap energies between 1.8 and $3.1 \mathrm{eV}$; consequently, these materials appear colored.

If impurities (TM/RE ions) are present in the glass material, light radiation of specific wavelengths may be emitted as a result of electron transitions involving these levels within the band gap. The absorption spectra for the impurities (Ni or Nd ions) in amorphous materials were presented in our previous chapter. In those spectra observed electronic transition band are within the bandgap of the host material.

\subsubsection{Color}

Glasses may appear colored in transmitted light due to a variety of mechanisms, including absorption by transition metal/rare earth ions, colloidal precipitates, and band-edge cutoff. Band edge coloration simply implies that the fundamental edge for absorption has moved into the visible region of the spectrum. Many glasses based on anions other than oxygen, such as sulfur, selenium, tellurium, phosphate and etc present this property. Moreover, it is well known that the addition of metals such as $\mathrm{Cu}, \mathrm{Ag}$, and $\mathrm{Au}$ to a glass gives rise to strong coloration under certain preparation conditions. For example, "ruby glass" which is a silicate glass containing colloidal gold. The red color of ruby glass is due to a plasma resonance of gold particles in the blue-green portion of the visible spectrum.

A great number of glasses can be produced by engineering the concentration and alloying nature and size of the semiconducting particles with sharp cut-off characteristics in their transparency at a range of wavelengths. These have practical applications in the fabrication of the well-known colored edge-filters used in optical spectroscopy. Transition metal ion doping by elements from the $3 \mathrm{~d}$ series with their open valence shell electrons results in absorption bands in the visible and infrared regions arising from $3 \mathrm{~d}-3 \mathrm{~d}$ electronic transitions. In principle, rare-earth ion doping can also give rise to coloration, but the absorption per ion for the usual $4 \mathrm{f}-4 \mathrm{f}$ transitions is much weaker and narrower than that for 3d-3d transitions. 


\subsection{Chemical properties}

Chemical durability or corrosion resistance of optical glasses is a special problem. The chemical composition of many such glasses make then quite sensitive to the environment. Under certain exposure conditions, glass optical properties, chemistry and structural properties varied by different corrosion process. Generally, Corrosion occurs in one or in a combination of ways. These include: (1) leaching, which usually involves the selective removal of the soluble components of a glass by an ion exchange reaction, leaving a porous surface layer and resulting in a surface that exhibits interference effects commonly described as tarnish, stain, or aoyake; (2) etching, or total dissolution of the glass structure, continuously exposing fresh glass; and (3) deposition of insoluble materials that adhere to the surface as a result of either (1) or (2) above, sometimes referred to as shiroyake. Problems with optical devices usually involve leaching or deposition of insoluble materials $[82]$.

Leaching or etching process depend on the relative solubilities of the various glass components. In the case of silica glass, leaching occurs, but in the case of many optical glasses, etching thus dissolution occurs. High silica glasses, the normal commercial varieties used for windows, bottles, etc., are quite acid resistant. However, optical glasses which are often low in silica (or other stable glass formers) may be extremely vulnerable to acid attack.

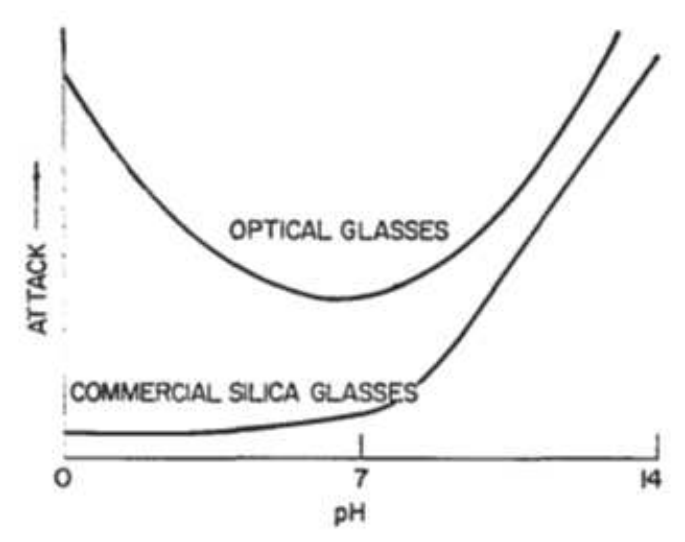

Figure 3.2: Variation of chemical resistance between commercial silicate glasses and optical glasses [81]

The primary determinant factor of chemical durability in glass is an ion-exchange 
reaction, in which alkali ions in the glass are exchanged with hydrogen atoms or hydronium ions present in atmospheric humidity or water. The alkali ions involving leaching process further react with carbon dioxide and water in the atmosphere to produce alkali carbonates and bicarbonates. These are seen as the white deposits that form on a glassy surface in dishwashing tests or after extended humidity exposure (often called weathering). It means that total glass structure is destroyed. The chemical resistance of silicate and optical glasses is shown in figure 3.2. In general, glasses that are low in alkali offer increased weathering resistance. Vitreous silica is the most resistant, but borosilicates and aluminosilicates also offer excellent weathering resistance.

On the other hand, a dissolution of the entire network may occur when glasses are attacked by caustic alkalis and by hydrofluoric, phosphoric, and chloric acids. The general approach to improve the chemical durability of glass is to make the surface as silica-rich as possible. This can be accomplished by two methods: fire polishing, a procedure that removes alkali ions by volatilization; or surface treatment with a mixture of sulfuric dioxide and steam, which extracts alkali by leaching and converting to washable alkali sulfate. Other methods of improving chemical durability involve limiting the access of water or humidity to the glass surface. Polymeric barrier coatings are effective in this way. For example, small amounts of allumina in the glass composition (on the order of 2 to $3 \%$ ) work well to improve the chemical durability of containers. Some high aluminosilicates resist even hot sodium-metal vapours.

\subsection{Mechanical properties}

\subsubsection{Elasticity}

Generally, in glasses, there is no quick and complete recovery of the shape after the stress is removed. Such permanent shape change is known as plastic deformation. In the glass there is a stress induced flow which may happen in the range of temperatures between annealing and softening. The isotropic behaviour of glass is most evident in their elastic properties, particularly, only two independent elastic moduli are normally measured: Young's modulus (E), which measures the ability of a solid to recover its 
original dimensions after being subjected to lengthwise tension or compression; and shear modulus $(\mathrm{G})$, which measures its ability to recover from transverse stress. The effect of a particular cation on the Young's modulus depends on the structural role (whether it takes network forming or interstitial positions) and the nature of the cation-oxygen bond. In the case of cations taking only interstitial positions, a proportionality has been observed between the logarithm of cation field strength and Young's modulus. For cations which take network forming as well as interstitial positions, this relation seems not to be valid.

\subsubsection{Hardness}

The hardness of a glass is measured by a diamond microindenter. Application of this instrument to a glassy surface leaves clear evidence of plastic deformation (or) a permanent change in dimension. Plastic deformation of glass (or ductility), which is generally observed in strength tests as the necking of a specimen placed under tension, is not observed generally in a glass. Whereas, instead of plastic deformation, glass failure is brittle which means the glass object fractures suddenly and completely. This behaviour can be explained by the atomic structure of a glassy solid. Since the atoms in molten glass are essentially frozen in their amorphous order upon cooling, they do not orient themselves into the sheets or planes that are typical of growing crystalline grains. The absence of such a growth pattern means that no grain boundaries arise between planes of different orientation, and therefore there are no barriers that might prevent defects such as cracks from extending quickly through the material. The absence of dislocations causes glass not to display ductility, the property of yielding and bending like metal.

Glass is exceptionally strong, much stronger than most metals, when tested in the pristine state. Under pure compression, glass may undergo a more or less reversible compression but not fracture. Its theoretical strength in tension is estimated to be 14 to 35 gigapascals (2 to 5 million pounds per square inch); glass fibres produced under very careful drawing conditions have approached 11.5 gigapascals in strength. The strength of most commercial glass products, ranges between only 14 and 175 megapascals (2,000 and 25,000 pounds per square inch), owing to the presence of scratches and microscopic flaws, generally on the surface. Apparently, surface flaws are produced in glass by abrasion 
with most solids -even by the touch of a finger and particularly by another piece of glass that rubs against it during manufacture. Flaws have a stress-concerning effect; that is, the effective stress at the tip of a flaw can be easily 100 to 1,000 times greater than that applied. Eventually, depending on the applied stress, the shape of the flaw, the temperature, and even the corrosiveness of the environment, the growth velocity of the crack approaches its terminal limit, and failure becomes imminent. Thus, under a tensile loaded condition, all glasses experiences static fatigue and eventually fails. The crack growth velocities are higher with higher magnitudes of tensile stress, sharper flaws (where the tip radius is much smaller than the length), higher temperatures, and higher humidity.

\subsection{Thermal properties}

\subsubsection{Viscosity}

As can be seen in the above Figure 3.3 , the viscosity of glass, as measured in centimetregram-second units known as poise, decreases with rising temperature. The figure also indicates the temperatures at which certain glasses reach standard viscosity reference points that are important in glassmaking. For instance, the working point, the temperature at which a gob of molten glass may be delivered to a forming machine, is equivalent to the temperature at which viscosity is $10^{4}$ poise. The softening point, at which the glass may slump under its own weight, is defined by a viscosity of $10^{7.65}$ poise, the annealing point by $10^{13}$ poise, and finally the strain point by $10^{14.5}$ poise. Upon further cooling, viscosity increases rapidly to well beyond $10^{18}$ poise, where it can no longer be measured meaningfully. The annealing point and the strain point lie in the glass transformation range shown in Figure 3.3; often, the glass transition temperature $\left(\mathrm{T}_{g}\right)$ and the annealing point are used synonymously, and the strain point marks the low-temperature end of the range. The $\mathrm{T}_{g}$ may also be considered the maximum temperature for intermittent service. It is evident from figure that the $\mathrm{T}_{g}$ of vitreous silica is the highest of the commercial glasses and that increasing the amount of alkali additions (and therefore the concentration of network modifier ions) lowers $\mathrm{T}_{g}$. Of all the various factors affecting viscosity, water, in the form of hydroxyl ions or molecular water, lowers viscosity the most. 


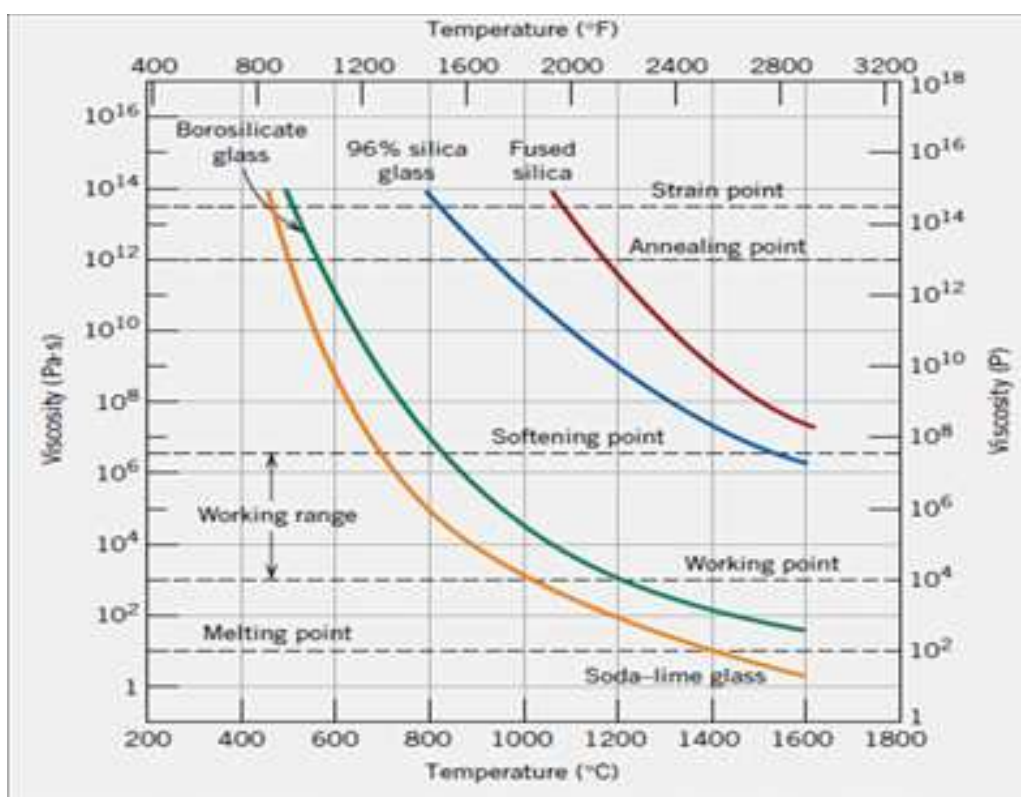

Figure 3.3: The effect of temperature on the viscosity of glass [82] - Melting point (at 10 Pa.s): At this point the glass becomes fluid enough to be considered as a liquid. Working point (at $10^{3} \mathrm{~Pa} . \mathrm{s}$ ): Glass is easily deformed at this viscosity and this is the reason why the glass fabrication operations are carried out at this point. - Softening point $\left(4 \times 10^{6}\right.$ Pa.s $)$ : Represents the maximum temperature at which a glass piece may be handled without resulting in significant dimensional changes. At this point the glass can flow under its own weight.

\subsubsection{Thermal Expansion}

The thermal expansion is defined as the relative change in size as a response to a temperature change. As is evident from the above (Figure 3.3), glass normally expands when heated and shrinks when cooled. This thermal expansion of glass is critical to its thermal shock performance, i.e., its performance when subjected suddenly to a temperature change. When a hot specimen of glass is suddenly cooled by plunging it in iced water, develop great tension in the outside layers owing to their shrinking relative to the inner layers. This tension may lead to cracking. Resistance to such thermal shock is known as the thermal endurance of a glass. Therefore, it is inversely related to the thermal- expansion coefficient and the thickness of the piece. Soda-lime-silicates and alkali-lead-silicates, which typically have high expansion coefficients, are quite susceptible to shocking. 


\subsubsection{Heat Transfer}

The thermal conductivity of oxide glass due to atomic vibrations (the so-called phonon mechanism) does not increase appreciably with temperature. On the other hand, the radiation conductivity (thermal conductivity due to photon transport) increases greatly with temperature. Radiation conductivity is also inversely proportional to the absorption coefficient of a glass for specific photon wavelengths. Thus, the rather high radiation conductivity of molten clear glass enables melting to depths of almost two meters, or five feet, in continuous glass tanks without a serious risk of frozen glass at the bottom. Coloured glasses, on the other hand, have a high photon absorption coefficient and therefore need to be melted either to shallow depths or with electric boosting from the bottom of the tank. 


\section{Materials and characterization techniques}

This chapter describes materials used in this research work and their method of preparation; and the technical details of spectroscopic experiments used for materials characterization. There is also a short theoretical discussions where relevant with respect to the techniques used.

\subsection{Preparation of glass materials}

In this work, the two set of samples used are prepared at: 1) Institute of Physics, Laboratório de Novos materias Isolantes e Semiconductores, from Federal University of Uberlândia, and 2) LPM- Laboratório de Produção de Materiais at Group of Engineering and Spectroscopy Materials (GE2M), Department of Physics - UFJF, Brazil by using melt-quenching technique. One can chose the materials compositions in mol\% (or) wt\%. Therefore, the prepared glass compositions are in mol\%. It is also worth to note that for the conversion of mol\% to wt $\%$, each calculated composition weight $(=\operatorname{mol} \% \times$ Molecular weight) is divided by the total composition of calculated weight.

\section{SET I}

Composition: $65 \mathrm{P}_{2} \mathrm{O}_{5}+14 \mathrm{ZnO}+10 \mathrm{Al}_{2} \mathrm{O}_{3}+10 \mathrm{BaO}+10 \mathrm{PbO}(\mathrm{mol} \%)(\mathrm{PZABP})$

Dopants: 5 wt $\% \mathrm{Ni}$ and $1 \mathrm{wt} \% \mathrm{Te}$ and $\mathrm{x}=0.5,0.1,5$ and $10 \mathrm{wt} \% \mathrm{Ni}$ at an expense of $\mathrm{Zn}$.

\begin{tabular}{|c|c|}
\hline Glass notation & Composition $(\mathrm{mol} \%):$ Ion dopant $(\mathrm{Wt} \%)$ \\
\hline \hline $\mathrm{G}$ & $65 \mathrm{P}_{2} \mathrm{O}_{5}+14 \mathrm{ZnO}+10 \mathrm{Al}_{2} \mathrm{O}_{3}+10 \mathrm{BaO}+10 \mathrm{PbO}: 5 \mathrm{Ni}$ \\
\hline $\mathrm{GC} 1$ & $65 \mathrm{P}_{2} \mathrm{O}_{5}+14 \mathrm{ZnO}+10 \mathrm{Al}_{2} \mathrm{O}_{3}+10 \mathrm{BaO}+10 \mathrm{PbO}: \mathrm{Zn}_{0.995} \mathrm{Ni}_{0.005} \mathrm{Te}$ \\
\hline $\mathrm{GC} 2$ & $65 \mathrm{P}_{2} \mathrm{O}_{5}+14 \mathrm{ZnO}+10 \mathrm{Al}_{2} \mathrm{O}_{3}+10 \mathrm{BaO}+10 \mathrm{PbO}: \mathrm{Zn}_{0.99} \mathrm{Ni}_{0.01} \mathrm{Te}$ \\
\hline $\mathrm{GC} 3$ & $65 \mathrm{P}_{2} \mathrm{O}_{5}+14 \mathrm{ZnO}+10 \mathrm{Al}_{2} \mathrm{O}_{3}+10 \mathrm{BaO}+10 \mathrm{PbO}: \mathrm{Zn}_{0.95} \mathrm{Ni}_{0.05} \mathrm{Te}$ \\
\hline $\mathrm{GC} 4$ & $65 \mathrm{P}_{2} \mathrm{O}_{5}+14 \mathrm{ZnO}+10 \mathrm{Al}_{2} \mathrm{O}_{3}+10 \mathrm{BaO}+10 \mathrm{PbO}: \mathrm{Zn}_{0.9} \mathrm{Ni}_{0.1} \mathrm{Te}$ \\
\hline
\end{tabular}


Composition: $29 \mathrm{P}_{2} \mathrm{O}_{5}+(60-\mathrm{x}) \mathrm{ZnO}+10 \mathrm{Na}_{2} \mathrm{O}+\mathrm{x} \mathrm{TeO}_{2}+1.0 \mathrm{Nd}_{2} \mathrm{O}_{3}(\mathrm{x}=$ $510,20,30 \& 40 \mathrm{~mol} \%)$

\begin{tabular}{|c|c|}
\hline Glass notation & Composition (mol\%) \\
\hline \hline $\mathrm{x}=5$ & $29 \mathrm{P}_{2} \mathrm{O} 5+55 \mathrm{ZnO},+10 \mathrm{Na}_{2} \mathrm{O}+5 \mathrm{TeO}_{2}+1.0 \mathrm{Nd}_{2} \mathrm{O}_{3}$ \\
\hline $\mathrm{x}=10$ & $29 \mathrm{P}_{2} \mathrm{O} 5+50 \mathrm{ZnO},+10 \mathrm{Na}_{2} \mathrm{O}+10 \mathrm{TeO}_{2}+1.0 \mathrm{Nd}_{2} \mathrm{O}_{3}$ \\
\hline $\mathrm{x}=20$ & $29 \mathrm{P}_{2} \mathrm{O} 5+40 \mathrm{ZnO},+10 \mathrm{Na}_{2} \mathrm{O}+20 \mathrm{TeO}_{2}+1.0 \mathrm{Nd}_{2} \mathrm{O}_{3}$ \\
\hline $\mathrm{x}=30$ & $29 \mathrm{P}_{2} \mathrm{O} 5+30 \mathrm{ZnO},+10 \mathrm{Na}_{2} \mathrm{O}+30 \mathrm{TeO}_{2}+1.0 \mathrm{Nd}_{2} \mathrm{O}_{3}$ \\
\hline $\mathrm{x}=40$ & $29 \mathrm{P}_{2} \mathrm{O} 5+20 \mathrm{ZnO},+10 \mathrm{Na}_{2} \mathrm{O}+40 \mathrm{TeO}_{2}+1.0 \mathrm{Nd}_{2} \mathrm{O}_{3}$ \\
\hline
\end{tabular}

The high purity of $\mathrm{P}_{2} \mathrm{O}_{5}$ (Sigma-Aldrich, 99.9\%), $\mathrm{TeO}_{2}$ (Sigma-Aldrich, 99.9\%), ZnO (Sigma-Aldrich, 99.9\%), BaO (Sigma-Aldrich, 99.9\%), PbO (Sigma-Aldrich, 99\%), $\mathrm{Al}_{2} \mathrm{O}_{3}$ (Sigma-Aldrich, 99.9\%), $\mathrm{Na}_{2} \mathrm{O}$ (Sigma-Aldrich, 99.99\%), $\mathrm{Nd}_{2} \mathrm{O}_{3}$ (Sigma-Aldrich, 99.9\%), NiO (Sigma-Aldrich, 99.9\%), and Te (Sigma-Aldrich, 99\%) of starting materials are used to prepare above glasses. About $10 \mathrm{~g}$ batches of pre-weighed specific quantities of $\mathrm{P}_{2} \mathrm{O}_{5}, \mathrm{TeO}_{2}, \mathrm{ZnO}, \mathrm{BaO}, \mathrm{PbO}, \mathrm{Al}_{2} \mathrm{O}_{3}, \mathrm{Na}_{2} \mathrm{O}$ and $\mathrm{Nd}_{2} \mathrm{O}_{3}, \mathrm{NiO}$, Te dried powders are thoroughly ground in an agate mortar to homogenize the chemical constituents. The powder mixture was melted at at $1300{ }^{\circ} \mathrm{C}$ for $30 \mathrm{~min}$ (for Set I), and at $1100{ }^{\circ} \mathrm{C}$ for $3 \mathrm{~h} 30 \mathrm{~min}$ (for Set II), with four stirring sessions, in order to reach a sufficiently good homogeneity of the final glasses, and quenched quickly into a pre heated brass mould. For Set I samples, a subsequent heat treatment was done at $500{ }^{\circ} \mathrm{C}$ for $10 \mathrm{~h}$ in order to obtain glass matrix with ZnTe nanocrystals and the diffusion of $\mathrm{Zn}^{2+}, \mathrm{Ni}^{2+}$ and $\mathrm{Te}^{2-}$ ions. For set II samples, all the samples were annealed at $400{ }^{\circ} \mathrm{C}$ below their glass transition temperature $\left(\mathrm{T}_{g}=400{ }^{\circ} \mathrm{C}\right)$ for $3 \mathrm{~h}$ in order to release the internal stresses resulting from the quenching.

\subsection{Physical parameters}

In our optical system, thickness, refractive index, density and concentration of dopant ions were varied independently to optimize the spectroscopic parameters.

\section{Thickness(l):}

The thickness (l) for all transition metal/rare earth ions doped glasses were mea- 
sured using a screw gauge of least count $0.01 \mathrm{~mm}$.

\section{Refractive index(n):}

The refractive indices were measured using an Abbe refractometer with sodium vapour lamp and using 1-monobromonapthalene as an adhesive coating with an accuracy of \pm 0.001 .

\section{$\operatorname{Density}(d)$ :}

Density measurements were carried out with an accuracy of $\pm 0.02\left(\mathrm{~g} / \mathrm{cm}^{3}\right)$ using the Archemedis principle and using the formula

$$
d\left(g / \mathrm{cm}^{3}\right)=\frac{a}{(a-b)} \times \rho
$$

where $\mathrm{a}$ is the weight of the glass sample in the air, $\mathrm{b}$ is the weight of the glass sample in the buoyant medium and $\rho$ is the density of the buoyant medium (distilled water, 1 $\left.\mathrm{g} / \mathrm{cm}^{3}\right)$.

\section{Concentration of ions $(N)$ :}

The above values are used to obtain concentration values using the formula

$$
N\left(\text { ions } / \mathrm{cm}^{3}\right)=\frac{x N_{A} d}{M}
$$

where $\mathrm{x}$ is the mole fraction of rare earth ions, $\mathrm{N}_{A}$ is the Avagadro's number, $\mathrm{d}$ is the density, and $\mathrm{M}$ is the average molecular weight. In the present work, sample thickness, refractive index, density and concentration of ions doped to the glass matrices are given in respective chapters.

\subsection{Characterization techniques and specifications}

Structural, optical, thermal and nolinear-optical properties studied in the present work are obtained using the X-ray diffraction, IR absorption, Raman, optical absorption, emission, thermal lens, thermal relaxation and z-scan spectroscopic techniques. The experimental conditions are given in this section. Results and discussions are given in their respective chapters. 


\subsubsection{X-ray diffraction spectrometer}

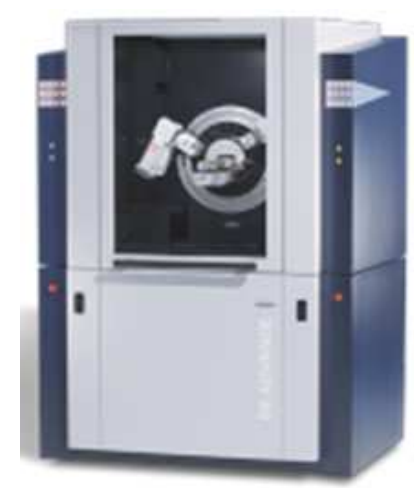

Figure 4.1: Photograph of D8 ADVANCE BRUKER x-ray diffractometer.

$\mathrm{X}$-ray diffraction (XRD) is a non-invasive method for determining many types of structural features in both crystalline and amorphous materials. XRD patterns were recorded for the solid samples with D8 ADVANCE BRUKER powder X-ray diffractometer, as shown in the photograph of Figure 4.1, operated at $40 \mathrm{kV}$ and $20 \mathrm{~mA}$, using $\mathrm{CuK} \alpha$ $(\lambda=1.5406 \AA)$ radiation source. The scan were controlled by the DIFFRAC.SUIT software module, and the data was taken in step mode with an intervals of 0.02 degrees, over a $2 \theta$ in the angular range of 15 - 60 degrees using a dwell time of 2 seconds.

\subsubsection{Fourier Transform Infrared spectrometer}

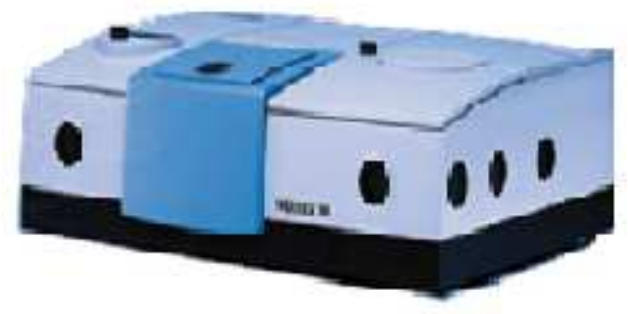

Figure 4.2: Photograph of FT-IR VERTEX 70 (BRUKER) spectrometer.

Infrared spectroscopy was performed using FTIR-ATR, VERTEX 70 (BRUKER) spectrophotometer, as shown in the photograph of Figure 4.2, operated in reflectance mode. The spectra were recorded in the region $400-1600 \mathrm{~cm}^{-1}$, with OPUS Software module and spectrophotometer submitted to 64 scans and $0.4 \mathrm{~cm}^{-1}$ of spectral resolution. 


\subsubsection{Micro-Raman spectrometer}

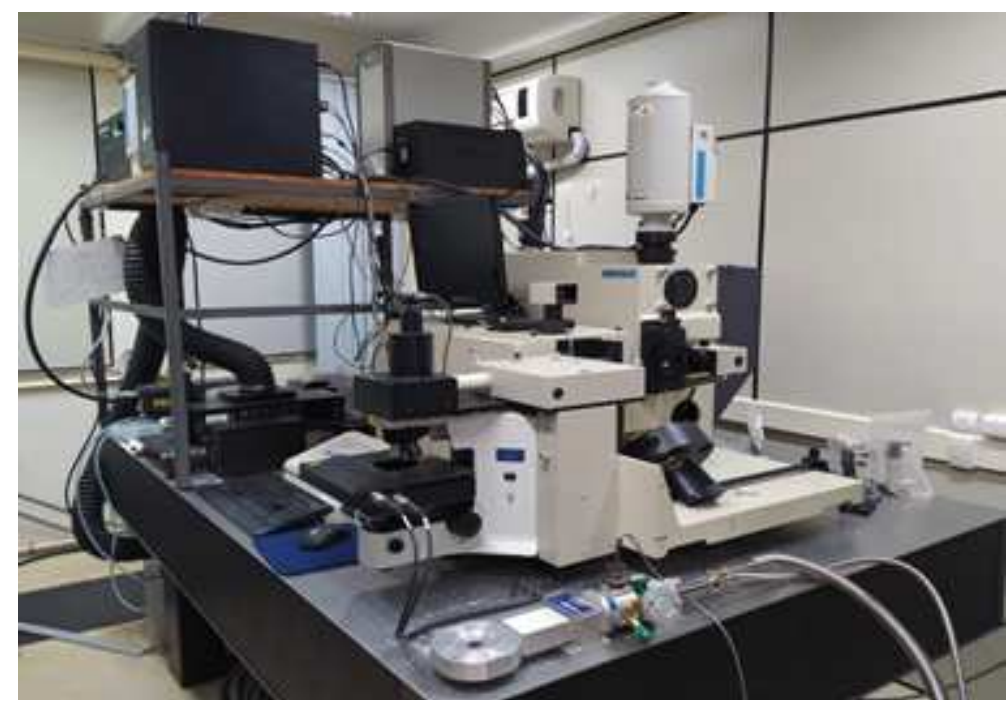

Figure 4.3: Micro-Raman HORIBA JOBIN IVON T64000 spectrometer.

Raman spectra with Stokes shift energy range from $200-1500 \mathrm{~cm}^{-1}$ were recorded at room temperature with Micro-Raman (HORIBA JOBIN IVON T64000), as shown in figure 4.3, operating in the double subtractive mode with a $488 \mathrm{~nm}$ Argon laser (Melles Griot 543-AP-01) as excitation source. The spectrometer was operated under the following adjustments: pinhole set to $300 \mu \mathrm{m}$, first slit aperture width $100 \mu \mathrm{m}$, second slit width $100 \mu \mathrm{m}$, third slit width $26.9 \mu \mathrm{m}$ and acquisition time of $120 \mathrm{~s}$ with 5 scans.

\subsubsection{UV-Vis-NIR absorption spectrometer}

Optical absorption spectra of transition metal/rare earth ions doped glass samples were recorded using double beam UV-Vis UV-2550 absorption spectrometer (SHIMADZU). The spectrophotometer is shown in left side photograph of Figure 4.4. The UV-Vis UV 2550 spectrophotometer is capable of recording the absorption/transmittance spectra in the wavelength region of 190 to $1100 \mathrm{~nm}$. The sample spectra and measurement parameters were controlled by Spectra Manager Software with \pm 0.002/0.004 sensitivity and with $0.1 \mathrm{~nm}$ of spectral resolution.

MPA FT-NIR BRUKER Multi-Purpose spectrophotometer (see Figure 4.4(Right)) is capable of recording the spectra in transmittance/reflectance mode in the wavenumber range $12500-4000 \mathrm{~cm}^{-1}$. The key advantage of these techniques is that it enables 

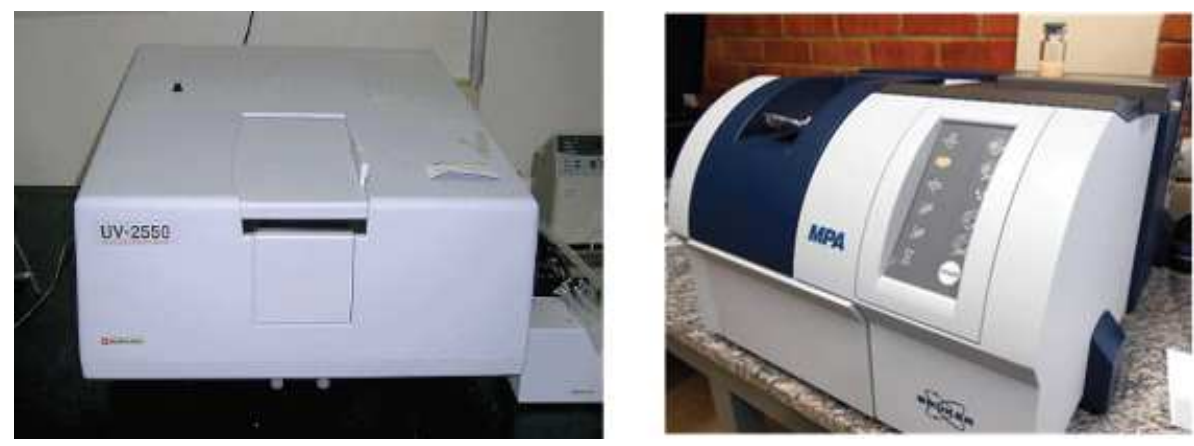

Figure 4.4: Photographs shows UV-Vis-NIR absorption spectrometers (Left: UV 2550 and Right: MPA-FT-NIR).

analysis of strongly scattering and absorbing samples unlike transmission measurements and equally has high signal intensity. Sample scanning and data acquisition were carried using OPUS LAB software version 5.5 with 32 scans and $0.4 \mathrm{~cm}^{-1}$ spectral resolution.

\subsubsection{Emission spectral analysis}

\section{UV-Visible emission measurement with FLS920 spectrofluorimeter:}

Figure 4.5 shows an FLS920 (EDINBURG PHOTONICS) spectrofluorometer. Usually, an Edinburg FLSP920 Series is a series of modular software-controlled spectrometers for the acquisition of steady state and time resolved photoluminescence. They can measure, fluorescence and phosphorescence, and their lifetime. Data can be obtained in a wide spectral range, from the ultraviolet to near-infrared, with single photon counting sensitivity. The spectrometer series combines extremely high sensitivity with high spectral and temporal resolution. FLSP920 Series of fluorescence spectrometers has at

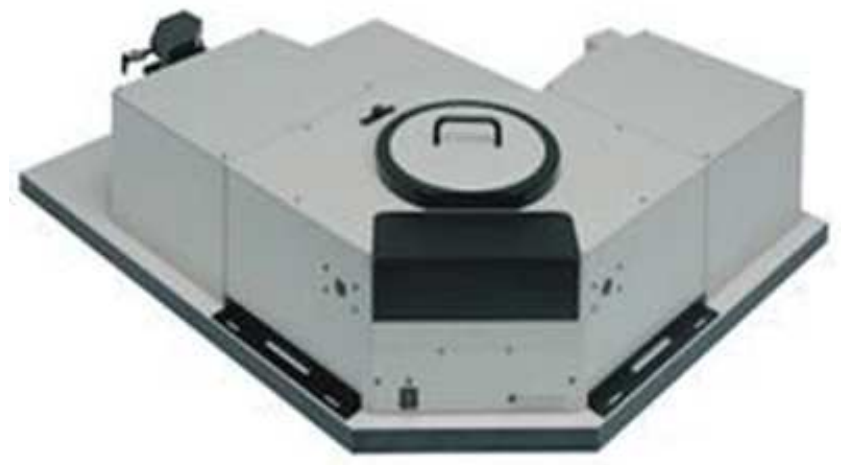

Figure 4.5: FLS920 spectrofluorimeter for visible emission with Hydrogen lamp as an excitation source (EDINBURG PHOTONICS). 
least two monochromators: an excitation monochromator and an emission monochromator. These can be either single-grating or double-grating monochromators, depending on configuration. The F900 software application controls the FLSP920 Series of Fluorescence Spectrometers. It is used to set up measurement modes and parameters, configure spectrometer components, run scans and display and manipulate scan results. It can also import and export scan data to a variety of other standard applications. In this work, the excitation, emission and decay lifetime measurements were recorded at room temperature using Edinburgh Instruments FLS920 spectrophotometer under Hydrogen lamp as an excitation source.

NIR Emission Measurements with Self-Mounted Lab Set-up:

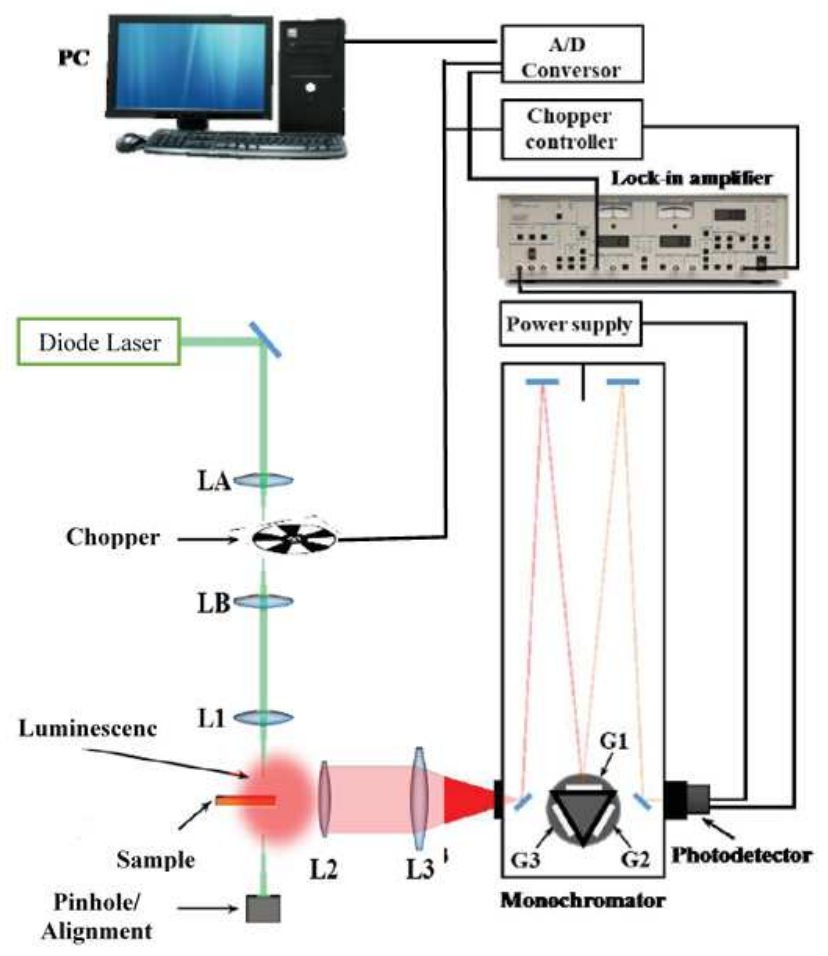

Figure 4.6: Emission experimental setup. Lens (LA, LB, L1, L2, L3); Gratings (G1, G2, G3).

Figure 4.6 shows self-mounted emission experimental set-up at LEM (Laboratório de Espectroscopia de Materiais) of GE2M, Physics Department-UFJF. NIR emission spectra were measured using an excitation source of $808 \mathrm{~nm}$ (Class 3B Laser Products) laser. The NIR luminescence signals are dispersed into a monochromator (0.5 m, DK480 Spectral Products), detected with an InGaAs detector (IGA-030-H, Electro-Optical Systems 
- USA) with a lock-in amplifier (Model SR530, Stanford Research Systems - CA). Decay curves at $1.06 \mu \mathrm{m}$ were measured by exciting the samples at $808 \mathrm{~nm}$ using optical chopper (Model SR540, Stanford Research Systems - CA), with the same single monochromator (0.5 m, DK480 spectral products) and InGaAs detector (IGA-001-H, Electro-Optical Systems - USA) and $350 \mathrm{MHz}$ preamplifier (Model SR445A, Stanford Research Systems CA). A digital oscilloscope (Minipa MFG-4201A) was used to record the decay curves.

\subsubsection{Thermal Lens (TL) Technique}

Gordon et al. [85] was the first reported thermal lens spectrometry (TLS), which can be used to measure thermal diffusivity for the very low optical absorption coefficients of transparent samples (Glasses and liquids). There are very good review papers on the subject $[86,87,88]$. Generally, it is important to know the thermo-optical properties for evaluating the figures of merit of optical glasses. Especially, the thermal diffusivity, D, and the thermal conductivity, K, related to the thermalization time within a given material. For an amorphous materials, it is well known that D and $\mathrm{K}$ are quite dependent upon the compositional and microstructural variables, as well as on the thermal processing conditions [89]. On the other hand, ds/dT describes the thermally induced distortion of a laser beam during its passing through a solid sample [90].

a)

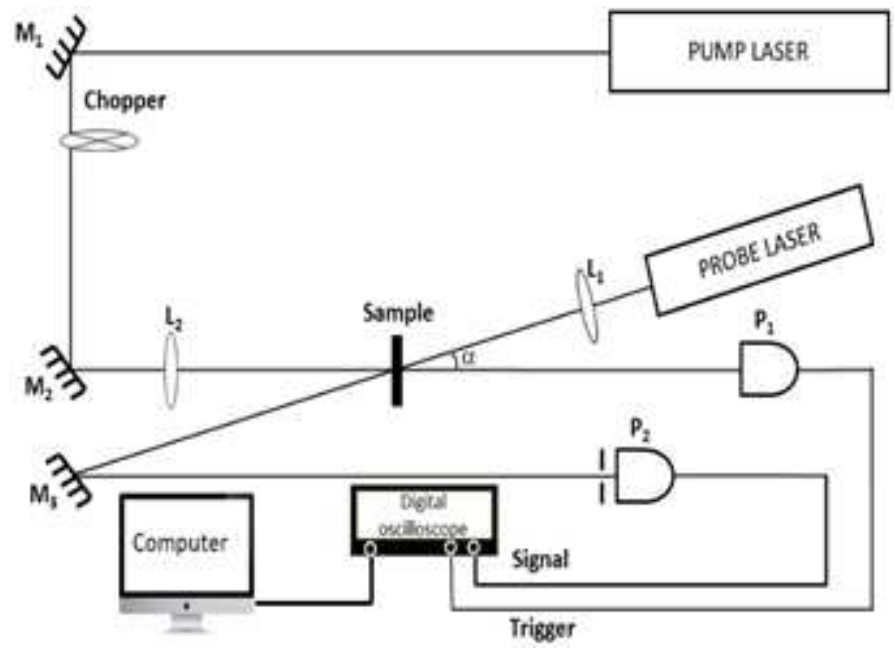

b)

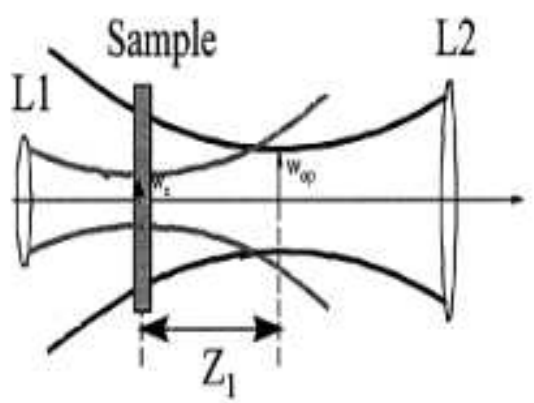

Figure 4.7: (a) Schematic diagram of the mode-mismatched thermal lens experimental apparatus, where M1, M2 and M3 are mirrors, and P1 and P2 are detectors; (b) geometric position of excitation and probe beams.

The first TL experiments were performed in the single-beam configuration or 
with two beams (excitation and probe) with the same beam waist at the sample position. It was later observed that sensitivity was improved by the mode-mismatched dual-beam configuration, where the two beams have different waists [87]. Usually, the pump or excitation beam is focused at the sample and the probe beam is arranged to be at a distance $\mathrm{Z}_{1} \sim 1.7 \mathrm{Z}_{c p}$, where $\mathrm{Z}_{c p}(\mathrm{~cm})$ is the confocal distance of the probe beam. The aberrant model was generalized for the mode-mismatched case by Shen et al. [86] and the following expression for the intensity at the detector was obtained:

$$
I(t)=I(0)\left[1-\frac{\theta}{2} \tan ^{-} 1\left(\frac{2 m V}{\left[(1+2 m)^{2}+V^{2}\right] \frac{t_{c}}{2 t}+1+2 m+V^{2}}\right)\right]^{2}
$$

where $\mathrm{I}(0$ or $\mathrm{t})$ is the intensity at time, $\mathrm{t}=0$ or $\mathrm{t} . \mathrm{m}$ is the ratio of probe-pump beam area at the sample and $\mathrm{V}$ is the ratio between the focal and confocal probe beam distance, can be written as follows,

$$
\mathrm{m}=\left(\frac{\omega_{P}}{\omega_{e}}\right)^{2} \quad \text { and } \quad \mathrm{V}=\frac{Z_{1}}{Z_{c p}}
$$

where, $\omega_{P}$ is the probe beam radius at the sample, $\mathrm{Z}_{1}(\mathrm{~cm})$ the distance between the probe beam waist and the sample, $\mathrm{Z}_{2}(\mathrm{~cm})$ the distance between the sample and the detector and $\mathrm{I}(0)=\mathrm{I}(\mathrm{t})$ when the transient time $\mathrm{t}$ or $\theta$ is 0 . The probe beam propagation results in an induced phase shift of its wave front producing a lens like effect (convergent or divergent). The intensity of the probe beam center can be expressed with the interpretation of Fresnel diffraction theory, i.e, the phase difference of the probe beam at $r=0$ and $r=\sqrt{2 \omega_{2}}$ induced by TL, is given by,

$$
\theta=-\frac{P_{a b s}}{K \lambda_{p}} \varphi \frac{d s}{d T}
$$

and

$$
t_{c}=\frac{\omega_{e}^{2}}{4 D}
$$

in which, $\theta$ is proportional to the probe beam phase shift induced by the thermal lens, $\omega_{p}$ is the probe beam wavelength and $\mathrm{P}_{a b s}$ is the absorbed pump power, $\mathrm{t}_{c}$ is the characteristic TL response time while D is the thermal diffusivity of the sample.

In the present work, an $\mathrm{Ar}^{+}$laser at $488 \mathrm{~nm}$ as excitation beam and a He-Ne laser as a probe bean at $632.8 \mathrm{~nm}$, have been used in the mode-mismatched thermal 
lens experimental setup, as shown in figure 4.7a. In a typical experimental setup the excitation beam is focused by a $20 \mathrm{~cm}$ focal length and the sample is positioned at its focal plane. A mechanical shutter or a chopper controls the exposure of the sample to the excitation beam. The probe beam is focused by a $20 \mathrm{~cm}$ focal length and it is aligned at an angle smaller than $1.5^{\circ}$ with respect to the excitation beam. An iris is put in front of the photodiode $\left(\mathrm{P}_{2}\right)$ to select only the probe beam central part. $4.7 \mathrm{~b}$ shows the sample position relative to excitation and probe beams focuses, where $\omega_{e}=40.78 \mu \mathrm{m}$; $\omega_{p}=208.87 \omega_{p} ; Z_{c}=6.08 \mathrm{~cm}, Z_{1}=9.73 \mathrm{~cm}, Z_{2} \sim 2 \mathrm{~m}$ (typical values). From these values, we obtained $\mathrm{m}=26.24$ and $\mathrm{V}=1.6$, respectively. Then, the optical absorption coefficients were determined using the same experimental configuration applied for the TL measurements. The $\mathrm{P}_{a b s}=\mathrm{P}_{e x} \mathrm{~A}_{e} \mathrm{~L}$, where $\mathrm{P}_{e x}$ is the excitation beam power, $\mathrm{L}$ is the sample thickness, and $\mathrm{A}_{e}$ is the optical absorption coefficient of the sample. The transmittance $(\mathrm{P})$ and incident $\left(\mathrm{P}_{0}\right)$ laser powers in terms of absorption coefficient can be expressed as [91], $\mathrm{P}=\mathrm{P}_{0}(1-\mathrm{R})^{2} \exp \left(-\mathrm{A}_{e} \mathrm{~L}\right)$, where $\mathrm{R}=\frac{(n-1)^{2}}{(n+1)^{2}}$ is the reflectance. The obtained experimental results for the studied systems are reported in their respective chapters.

\subsubsection{Thermal Relaxation (TR) Technique}

The temperature relaxation technique offers the advantages of an inexpensive and relatively simple experimental setup for the measurement of specific heat of solid samples at room temperature. The property of heat capacity is defined as a product of the specific heat, c, and the density, $\rho$, and expresses the amount of heat developed per mass unit in a sample of unit volume when its temperature is varied by $1 \mathrm{~K}$. Its knowledge is of great importance in solid-state physics because it provides us with a direct means to test theoretical models of a given physical system and because of its sensitivity to phase transitions, etc.

Usually, thermal relaxation method is based on first disturbing an adiabatically isolated sample from its state of equilibrium by light irradiation, and then measuring the time changes in its absolute temperature, T. If the deviation of the system from the state of equilibrium is small, the relaxation is described by the equation $\mathrm{T}(\mathrm{t})=\mathrm{T}_{0} \exp (-\mathrm{t} / \tau)$, 
where $T_{0}$ is the initial value of the temperature and $\tau$ is the relaxation time of the system which is related to the sample's specific heat.

This method was first proposed by Bachmann et al. [92] for low-temperature (1-35 K) measurements; it was later extended to measurements below 1K by Schutz [93] and successfully used, with appropriate modifications, and by several authors in higher temperature range too. Djurek and Baturic-Rubidic [94] have modified the Bachmann method for measurements above 35 K. Experiments on tungsten in the range 2400 - 3600 K were performed by Zinovev and Lebedev [95]. Hatta [96] has designed a relaxation calorimeter, employing for the first time light heating for measurements on small samples in the temperature range around room temperature. Mansanares et al. [97] have later developed Hatta's approach for simple measurements of specific heat capacity at room temperature. Recently, the temperature relaxation method, designed by the last mentioned authors as the temperature rise method under continuous illumination, has been used for characterization of different materials such as semiconductors, foods, wood, zeolites, clays, and ferroelectric ceramics, among others.

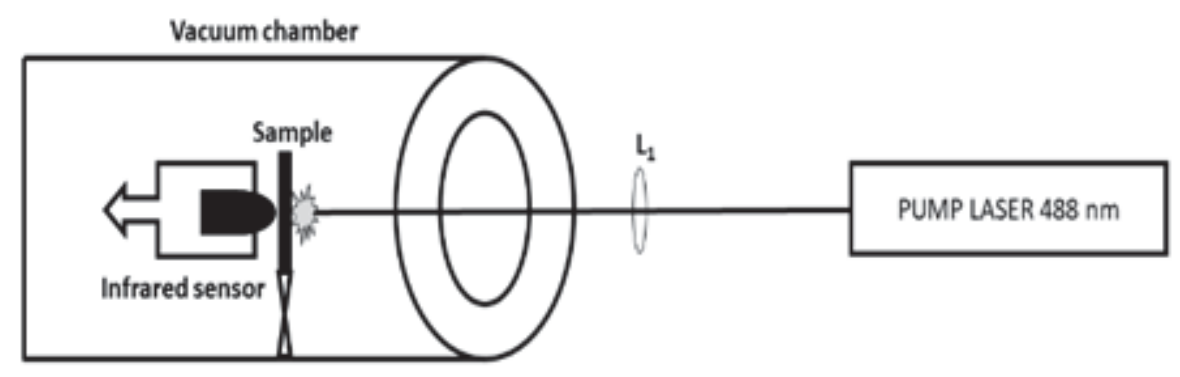

Figure 4.8: Schematic illustrations for thermal relaxation method.

In this work, the heat capacity of amorphous samples was measured by the thermal relaxation method. Figure 4.8 shows schematic representation of thermal relaxation experimental setup. This methodology records the thermal heating (thermal relaxation) of a sample over time in the presence (absence) of illumination. In the thermal equilibrium, the illuminated (front) and non-illuminated (back) faces of the samples reach saturation temperatures, $\mathrm{T}_{i, \max }$ and $\mathrm{T}_{n, \max }$. Therefore, heat capacity depends on how 
long the sample takes to heat or cool, and is expressed by the relation [98, 99],

$$
\Delta T=T_{0}-T_{m}=\frac{\left(T_{m}^{4}-T_{0}^{4}\right)}{4 T_{0}^{4}} \exp \left[1-\exp \left(\frac{t}{\tau_{d}}\right)\right]
$$

where two considerations are used: i) only radiation losses are taken into account and (ii) the temperature changes induced by the illumination are small compared to the surrounding environment temperature. In equation 4.6, $\mathrm{T}_{m}$ is the equilibrium temperature of the sample, $T_{0}$ is the initial temperature of the sample and the mean relaxation time is given by

$$
\tau_{d}=\frac{\rho c l_{s}}{8 \sigma T_{0}^{3}}
$$

where $\rho \mathrm{c}$ is the specific heat capacity, $l_{s}$ is the thickness of the sample and $\sigma$ is the Stefan-Boltzmann constant.
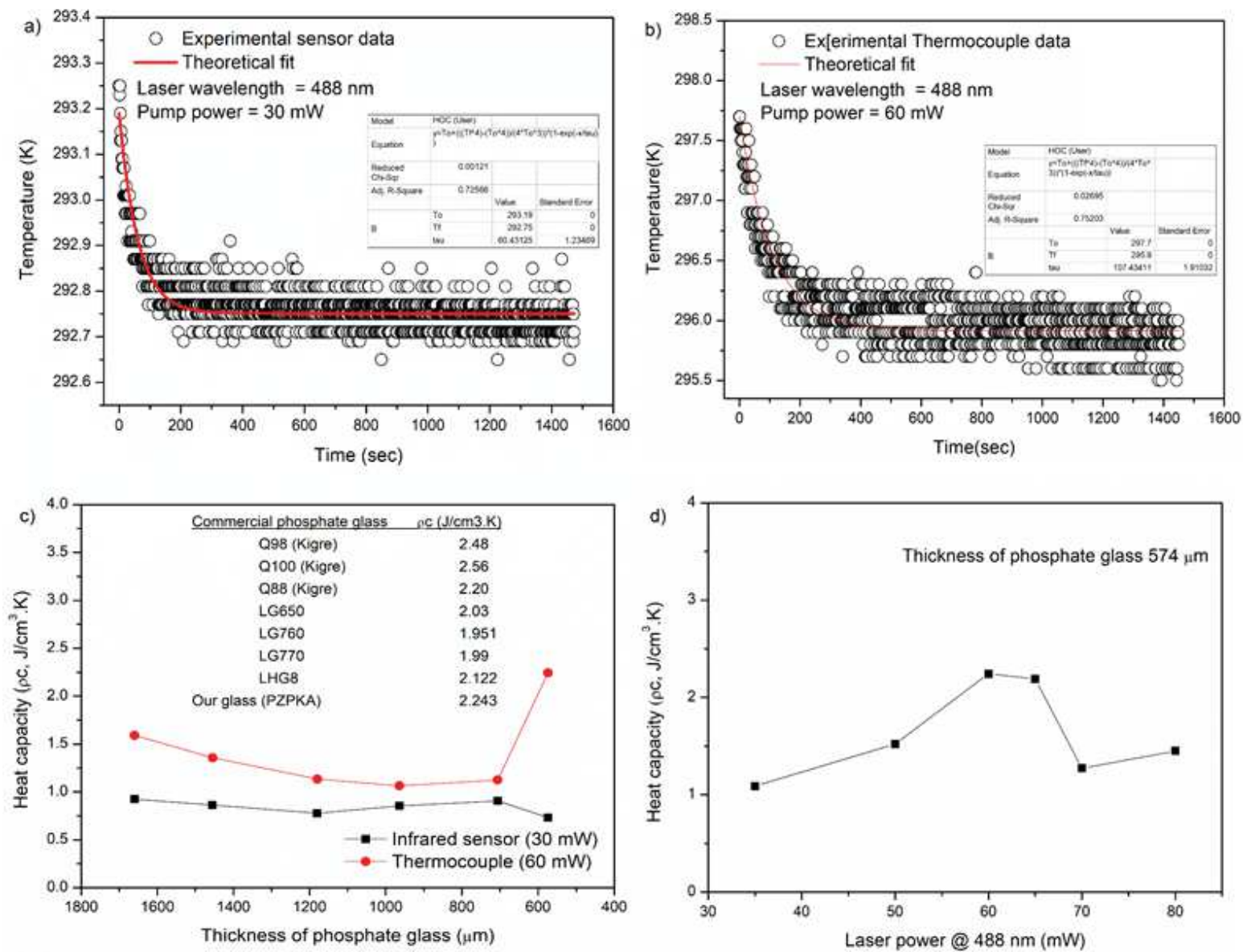

Figure 4.9: Cooling curve data for specific heat measurement using a) Sensor and b) Thermocouple as a data acquisition, c) and d) are the variation of heat capacity $(\rho c)$ as a function of thickness of sample, and laser power $(\lambda=488 \mathrm{~nm})(\mathrm{b})$. 
In order to testify the calibration accuracy of our experimental setup, different thickness of phosphate glasses chosen as reference; infrared sensor and thermocouple are used for data collection. The measurement for the each thickness of sample was performed by illuminating laser powers in between $30-80 \mathrm{~mW}$. The average heat capacity to the three laser powers as a function of sample thickness while using infrared sensor and thermocouple, is shown in Figure 4.9a. It is observed that there is no significant change in heat capacity with sample thickness while using infrared sensor, and those values are lower (average of $0.843 \mathrm{~J} / \mathrm{cm}^{3} . \mathrm{K}$ ) than those reported in phosphate glasses (average value of $\left.2.19 \mathrm{~J} / \mathrm{cm}^{3} . \mathrm{K}\right)$. Whereas, using thermocouple, the heat capacity decrease with decrease of sample thickness, but at $574 \mu \mathrm{m}$ thickness the heat capacity is around $2.243 \mathrm{~J} / \mathrm{cm}^{3} . \mathrm{K}$ which is good agreement with reported ones (average value of $2.19 \mathrm{~J} / \mathrm{cm}^{3} . \mathrm{K}$ ) are shown in Figure 4.9c. In addition, we also calibrate heat capacity with increase of power for the optimized thickness $(574 \mu \mathrm{m})$ of sample, as shown in figure $4.9 \mathrm{~b}$. It is observed that at powers $<60$ and $<65 \mathrm{~mW}$ the heat capacity value doesn't meet the standard data, but at $>60 \mathrm{~mW}$ and $>65 \mathrm{~mW}$ laser power the heat capacity of the sample is around 2.243 and $2.19 \mathrm{~J} / \mathrm{cm}^{3} . \mathrm{K}$, respectively. Therefore, we conclude that the data collecting with thermocouple, laser power operating at $60 \mathrm{~mW}$, and between $500-600 \mu \mathrm{m}$ thicknesses of glass sample is best suit conditions for the calibration of heat capacity of the glass matrices. The present studied glass samples were also used to calibrate heat capacity with the above considerations and those results are discussed in their respective chapters.

\subsubsection{Nonlinear optical spectroscopy (Z-scan)}

Since the advent of the laser in the 1960s, the nonlinear optical properties of materials has become extensively studied using different techniques. The Z-scan is amongst the simplest and most sensitive of these techniques. The basic z-scan technique has been described by Mansoor Sheik-Bahae et al. [100, 101]. In this section, we present our experimental procedure and theoretical expressions used for determine the nonlinear refraction $\left(\mathrm{n}_{2}\right)$ and nonlinear absorption $(\beta)$.

In this work, we used Z-scan experimental setup as shown in Figure 4.10. A mode-locked Ti: sapphire laser (Mai Tai) was used with 750 to $850 \mathrm{~nm}$ wavelength range 
with a repetition rate of $80 \mathrm{MHz}$. Then the laser beam is focused by lens with $15 \mathrm{~cm}$ focal length and the sample is moved along the z-axis during the measurement of transmittance (T) of light through the sample. The transmittance is performed in two ways, i) openaperture Z- scan and ii) closed-aperture Z-scan. In the case of open-aperture Z-scan, the

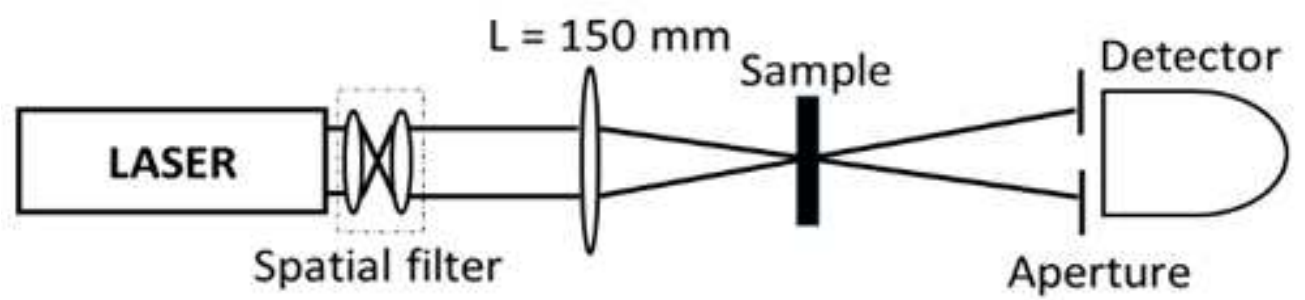

Figure 4.10: Single beam Z-scan experimental setup.

transmitted light is collected by just passing through the sample (i.e., without aperture). Whereas, in the case of closed-aperture, the transmitted light is collected after passing through a finite aperture $(\mathrm{S}=0.50)$ in the far field. The complete experimental procedure and setup is similar to our previous literature [102][96].

The third-order nonlinear properties of the samples are obtained by fitting the obtained experimental data with the following equations [100][94]:

$$
\begin{gathered}
T(Z)=1-\frac{1}{\sqrt{2\left(x^{2}+1\right)}} \Delta \Psi \quad(\text { OpenAperture }) \\
T(Z)=1+\frac{4 x}{\left(x^{2}+9\right)\left(x^{2}+1\right)} \quad \text { (CloseAperture) }
\end{gathered}
$$

where $\mathrm{x}$ is the relative distance, $\mathrm{x}=\mathrm{Z} / \mathrm{Z}_{0}=2 \mathrm{Z} /\left(\mathrm{k} \omega_{0}^{2}\right)$. In the latter equation, $\mathrm{Z}, \mathrm{Z}_{0}$, $\mathrm{k}$ and $\omega_{0}$ are the distance from the focus point, the diffraction length of the beam, the wavenumber of the light and the beam waist at the focal plane, respectively. The transmittance changes $\Delta T_{v}$ and $\Delta T_{P-v}$ can be obtained from the fitting curves by using the relationships, $\Delta T_{v}=\Delta \Psi_{0}$ and $\Delta T_{p-v}=0.406(1-\mathrm{S})^{0.25}\left|\Phi_{0}\right|$, where $\mathrm{S}$ is the closed aperture parameter. Then, nonlinear refractive index $\left(\mathrm{n}_{2}\right)$ and nonlinear absorption coefficient ( $\beta$ ) are determined from the following formulas [100],

$$
n_{2}=\frac{\lambda \Delta T_{p-v}}{I_{0} L_{e f f}}
$$




$$
\beta=\frac{2 \Delta T_{v}}{\left(x^{2}+9\right)\left(x^{2}+1\right)}
$$

where $\lambda$ is the wavelength and $\mathrm{I}_{0}$ is the power density of the pump laser. $\mathrm{L}_{\text {eff }}$ is the effective length of the sample defined as, $\mathrm{L}_{e f f}=(1-\exp (\alpha L)) / \alpha, \alpha$ is the linear absorption coefficient at a given wavelength and $\mathrm{L}$ is the thickness of the sample, respectively. The complete experimental results are presented in their respective chapters. 


\section{Results and Discussions}

This chapter details how the structural and optical properties are influenced by the variation of $\mathrm{Ni}^{2+}$ ions concentration as an interstitial dopant into ZnTe NCs present in PZABP phosphate glass/glass-ceramics; and the variation of $\mathrm{TeO}_{2}$ content in $\mathrm{Nd}^{3+}$ doped PZN phosphate glasses. The structural, optical absorption and emission spectra of all the glasses are also presented.

\subsection{ZnNiTe semiconductor NCs in PZABP phosphate glasses for optoelectronics}

As discussed in chapter 2, semiconductor materials with combination of III-V type (GaAs, InAs and SiN), II-VI type (ZnO, ZnTe, CdTe, ZnS), IV-VI type $\left(\mathrm{TiO}_{2}\right.$ and $\left.\mathrm{SnO}_{2}\right)$ and IV ( $\mathrm{Si}$, Sn and $\mathrm{Ge}$ ) have attracted much attention since they provide practical applications in the field of optoelectronics and diluted magnetic semiconductors (DMS). Concerning DMS for spintronic applications, the addition of magnetic transition metals and/or rare earth ions to the II-VI semiconductors have been extensively studied due to their greater solubility limit and lower defect concentration. The magnetic transition metal ions (for instance Nickle) incorporated into the semiconductors lead to a strong s-d interaction between the carriers and the local magnetic ions that may affect spin splitting and the spin polarization of the materials. Such modification control may lead to a promising application in spintronics. ZnTe is an important II-VI semiconductor with a wide and direct band gap of $\sim 2.26 \mathrm{eV}$ at room temperature with applications in optoelectronic and thermoelectric devices. ZnTe as well as ZnNiTe based are key materials, operating in the deep UV frequency range, which could be used, in the near future, for transparent singleelectron field-effect transistors, lithography and surface modification. In recent decades, ZnTe together with magnectic material, in various forms (bulk, thin film and nanostructured), have paid much attention in the investigation of their structural, electrical and 
magnetic behavior. It is worth to note that ZnNiTe based nanocristals synthesized by fusion in a glass template allowing control of optical, morphological and magnetic properties as a function of magnetic (Ni) ion concentration. Currently, magneto-optical properties in phosphate glasses doped with magnetic transition ions and semiconductor nanocrystals shows to be promising. Nevertheless, there are very few reports on DMSs grown in glasses and their characterization has been limited to structural and magnetic properties [103, 104, 105, 106]. Moreover, so far the thermo-optical properties of ZnTe based DMS in phosphate glass are not reported yet.

In this section, effect of $\mathrm{Ni}^{2+}$ ions in structural, optical (absorption and emission) and thermal, nonlinear properties of transparent $\mathrm{P}_{2} \mathrm{O}_{5}-\mathrm{ZnO}-\mathrm{Al}_{2} \mathrm{O}_{3}-\mathrm{BaO}-\mathrm{PbO}(\mathrm{PZABP})$ glass (G) and glass ceramic (GC) containing ZnTe semiconductor nanocrystals were studied through XRD, IR absorption and Raman spectroscopy, visible and near-infrared absorption, thermal-lens, thermal relaxation and z-scan techniques, which provides a definite contribution to the understanding of this material characteristics .

The samples are named as PZABP:5\%Ni (G), PZABP: 0.5\%ZnNiTe (GC1), PZABP: 1\% ZnNiTe (GC2), PZABP: 5\% ZnNiTe (GC3), and PZABP: 10\% ZnNiTe (GC4), respectively, and their significant physical parameters are listed in Table 5.1.

Table 5.1: Physical properties of $\mathrm{Ni}^{2+}$ ions in samples

\begin{tabular}{|c|c|c|c|c|}
\hline Sample & $\begin{array}{c}\text { Ni ions } \\
\mathrm{x} \text { wt\% }\end{array}$ & $\begin{array}{c}\text { Thickness l (mm) } \\
\mathrm{l} \pm 0.001(\mathrm{~mm})\end{array}$ & $\begin{array}{c}\text { Density } \\
\mathrm{d} \pm 0.001\left(\mathrm{~g} / \mathrm{cm}^{3}\right)\end{array}$ & $\begin{array}{c}\text { Refracrive index } \\
\mathrm{n} \pm 0.001\end{array}$ \\
\hline $\mathrm{G}$ & 5 & 1.850 & 3.178 & 1.548 \\
\hline GC1 & 0.5 & 1.847 & 3.271 & 1.541 \\
\hline GC2 & 1 & 1.858 & 3.404 & 1.545 \\
\hline GC3 & 5 & 1.887 & 3.315 & 1.534 \\
\hline GC4 & 10 & 1.881 & 3.459 & 1.539 \\
\hline
\end{tabular}

\subsubsection{Structural analysis: XRD, FT-IR, Raman spectra}

Figure 5.1a shows the XRD pattern of the $\mathrm{Ni}^{2+}$ ions doped glass $(\mathrm{G})$ and glass-ceramic (GC2) samples. It can be seen that two broad humps at around $15<2 \theta<30$ and $35<2 \theta<55$ degrees indicate the amorphous nature of the host glass. The G sample clearly exhibit glassy characteristic by the diffuse hump and absence of sharp peaks corresponding to crystalline phase. Whereas the GC2 sample exhibit not only the amorphous halo, but 
also appear sharp diffraction peaks (see figure 5.1b) that could be attributed to the growth of quantum dots (QDs) or nanocrystals (NCs). The peaks related to reflections from (111), (200), (220) and (311) planes of cubic zinc blende structure matched with the standard card of ZnTe, JCPDS: 15-0746 [103]. The additional peak at approximately 30.78 degree is related to the tetragonal structure of $\mathrm{TeO}_{2}$ (JCPDS: 11-0693) [103]; and the peaks at around 47.07 and 56.88 degrees are the hexagonal structure of ZnO (JCPDS: 36-1451) $[107,104]$. The observed crystalline phases of $\mathrm{TeO}_{2}$ and $\mathrm{ZnO}$ are formed by the ther-

a)

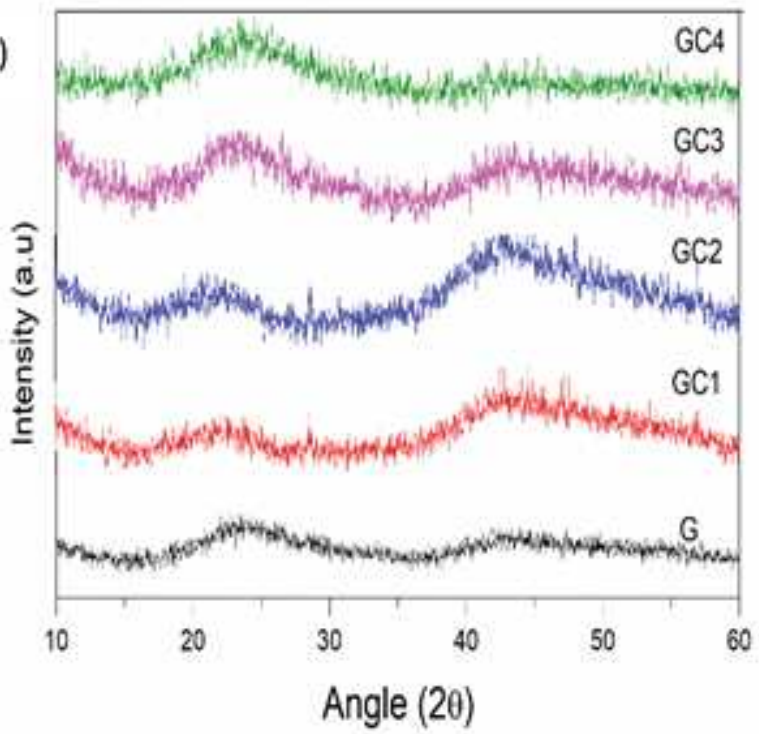

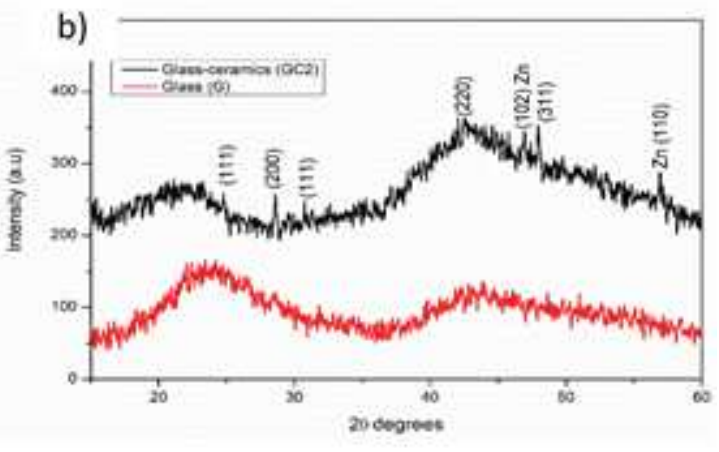

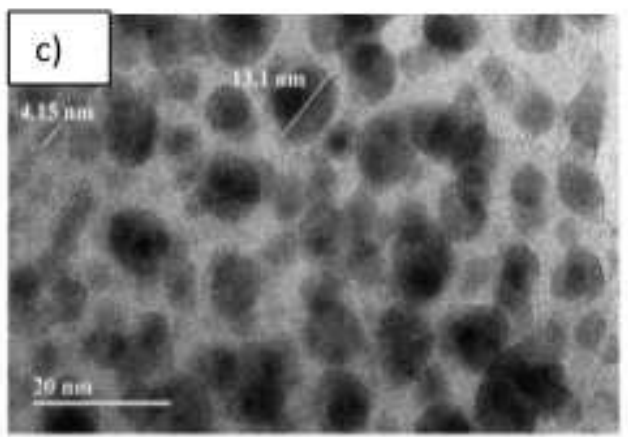

Figure 5.1: XRD pattern of samples. a) Glass (G) and glass-ceramic (GC2) samples. TEM image of sample contain ZnTe NCs, which is adapted from our collaborative research group [105].

malization processs. The phase related to the nickel oxide has not appeared due to the incorporation of $\mathrm{Ni}^{2+}$ ions into ZnTe lattice as interstitial atoms. According to the literature $[107,104,105,106,108]$, the doping of several concentrations of various transition metals (Ni, Mn and Co, etc.) into ZnTe host lattice shows constant position of phase lattices of ZnTe NCs and were confirmed by the transmission electron microscopy (TEM) [105]. The TEM image for the thermally annealed (for $10 \mathrm{~h}$ at $500{ }^{\circ} \mathrm{C}$ ) sample contain $\mathrm{Zn}_{1-x} \mathrm{Ni}_{x}$ Te NCs $(\mathrm{ZnTe}$ sample $(\mathrm{x}=0.00)$, see figure $5.1 \mathrm{~b})$ exhibit average diameter of $4.25 \mathrm{~nm}$ and $13.35 \mathrm{~nm}$ for the QD and bulk NCs, respectively. 
Due to lack of long range order in glasses, x-ray diffraction analysis is limited to analyze their structural features regarding local structure and vibrational unit arrangement of the nearest neighbors. Such structural features were determined by the use of Raman and MIR measurements in the studied samples. The observed main structural features and their assignments are listed in Table 5.2.

Table 5.2: Raman and Infrared vibrational bands with assignments.

\begin{tabular}{|c|c|c|}
\hline Raman $\left(\mathrm{cm}^{-1}\right)$ & Infrared $\left(\mathrm{cm}^{-1}\right)$ & Assignment \\
\hline 106 & & Second order TO \\
\hline 215 & & First order LO \\
\hline 326 & 446 & $\mathrm{PO}_{4}$ \\
\hline 431 & 539 & $\begin{array}{c}\text { Second order LO }(\mathrm{ZnTe}) \text { and } \\
\text { Bending of O-P-O units in } \mathrm{PO}_{4}^{3-} \text { groups }\end{array}$ \\
\hline 523 & $\begin{array}{c}\text { Cation oxygen polyhedral and } \\
\text { bending of O-P-O units in }\left(\mathrm{P}_{2} \mathrm{O}_{7}\right)^{4-} \text { groups }\end{array}$ \\
\hline & $653,669,667,688$ & Bending of $\mathrm{P}=\mathrm{O}$ bonds \\
\hline 707 & $717,735,728,785$ & $\nu_{s}(\mathrm{P}-\mathrm{O}-\mathrm{P})$ in $\mathrm{Q}^{1}$ group \\
\hline 790 & & $\nu_{a s}(\mathrm{P}-\mathrm{O}-\mathrm{P})$ in $\mathrm{Q}^{2}$ group \\
\hline & 841 & $\nu_{s}(\mathrm{P}-\mathrm{O}-\mathrm{P})$ in $\mathrm{Q}^{0}$ group \\
\hline & $989-864,918$ & $\nu_{a} s(\mathrm{P}-\mathrm{O}-\mathrm{P})$ in $\mathrm{Q}^{0}$ group \\
\hline 1080 & 1058 & $\nu_{s}\left(\mathrm{PO}_{4}^{3-}\right)$ in $\mathrm{Q}^{0}$ group \\
\hline 1165 & $1153,1203-1213$ & $\nu_{s}(\mathrm{P}-\mathrm{O}-\mathrm{P})$ nonbridging oxygen $\left(\mathrm{Q}^{1}\right)$ and \\
& & $\nu_{s}\left(\mathrm{PO}_{4}^{3-}\right)$ in $\mathrm{Q}^{0}$ group \\
\hline 1250 & 1273 & $\nu_{s}\left(\mathrm{PO}_{2}^{-}\right)$in $\mathrm{Q}^{2}$ and $\mathrm{Q}^{1}$ groups \\
\hline & & $\nu_{s}(\mathrm{P}-\mathrm{O}-\mathrm{P})$ nonbridging oxygen in $\left(\mathrm{Q}^{2}\right)$ and \\
& & $\left.\nu_{2}^{-}\right)$in $\mathrm{Q}^{1}$ groups \\
\hline
\end{tabular}

Figure 5.2 shows Raman spectra for the $\mathrm{Ni}^{2+}$ ions doped glass and glass-ceramic samples. The spectra are similar and two new narrow bands appeared in the range $90-$ $250 \mathrm{~cm}^{-1}$ and at around $430 \mathrm{~cm}^{-1}$ (except in Ni doped). Generally, characteristics of ZnTe consists of two vibrational modes such as longitudinal optical (LO) and transverse optical (TO) phonon modes. The band at $\sim 106, \sim 215 \mathrm{~cm}^{-1}$ and $\sim 430 \mathrm{~cm}^{-1}$ are attributed to the second order TO and first order LO and second order LO phonon modes [107, 109, 110]. The band between 215 and $430 \mathrm{~cm}^{-1}\left(\sim 326 \mathrm{~cm}^{-1}\right)$ is associated to the glass structure resulting from the bending of $\left(\mathrm{PO}_{4}\right)$ units. The band at $\sim 523 \mathrm{~cm}^{-1}$ is due to the bending mode related to the cation motion and chain structure. The middle frequency region bands at $\sim 707 \mathrm{~cm}^{-1}$ and $790 \mathrm{~cm}^{-1}$ are due to the symmetric stretching mode of P-O-P bending in $\mathrm{Q}^{1}$ group (from pyrophosphate) and asymmetric stretching of P-O-P bending 


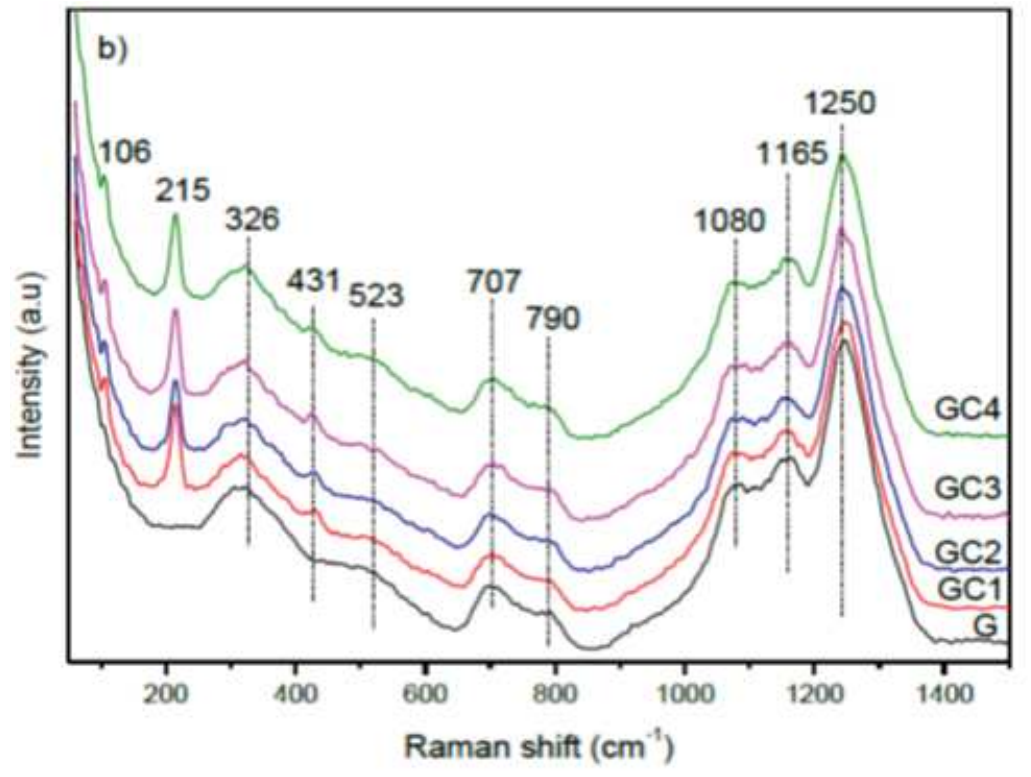

Figure 5.2: Raman spectra of $\mathrm{Ni}^{2+}$ doped glass and glass-ceramics.

in $\mathrm{Q}^{2}$ group (from metaphosphate), respectively. In the higher frequency region, $\sim 1080$ $\mathrm{cm}^{-1}$ is related to the symmetric stretching mode of P-O-P non-bridging oxygen bond in $\mathrm{Q}^{1}$ groups; $\sim 1165$ is due to the symmetric stretching mode of P-O-P non-bridging oxygen bond in $\mathrm{Q}^{2}$ groups; $\sim 1250 \mathrm{~cm}^{-1}$ is due to the asymmetric stretching of P-O-P non-bridging oxygen bond in $\mathrm{Q}^{2}$ groups [38, 39, 40, 41, 42, 43].

Figure 5.3 shows ATR-FTIR spectra for the $\mathrm{Ni}^{2+}$ ions doped glass and glassceramic samples. As seen in figure 5.3a, the IR absorption bands are broader than Raman bands (see figure 5.2) and the visually identified bands reveals the following features:

In the case of glass (G), a) A broad band between $1175 \mathrm{~cm}^{-1}$ and $1350 \mathrm{~cm}^{-1}$; b) doublets in the region between 1020 and $1175 \mathrm{~cm}^{-1}$; c) A strong intense band at $\sim 873$ $\mathrm{cm}_{-1}$; d) A weak intense band at $\sim 714 \mathrm{~cm}^{-1}$. Whereas in the case of GCs, a) A weak band at $\sim 1158 \mathrm{~cm}^{-1}$; b) An intense band at $\sim 854 \mathrm{~cm}^{-1}$; c) A broad band between 625 and $795 \mathrm{~cm}^{-1}$; and observed changes regarding intensity (decrease) and position (toward lower wavenumber side) of bands compared with G sample. The characteristic ZnTe vibrational modes at very low frequency $\left(\sim 220 \mathrm{~cm}^{-1}\right)$ region did not show due to beyond the measuring range of spectrophotometer used in this work.

In order to extract new information if the phosphate glasses contain different structural groups, a quantitative analysis was performed by the deconvolution of the IR 

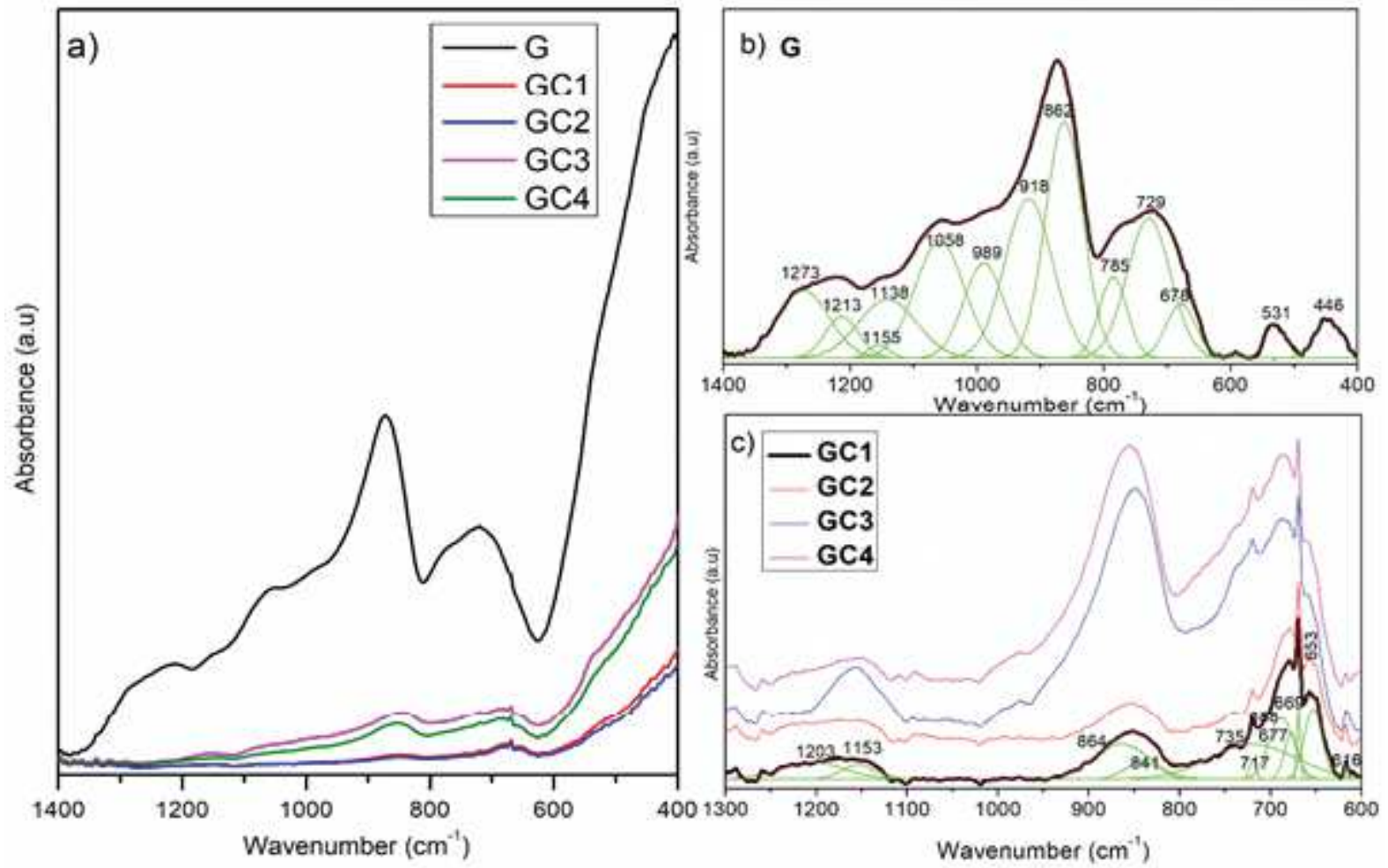

Figure 5.3: IR absorption spectra of $\mathrm{Ni}^{2+}$ doped glass and glass-ceramics.

absorption of $\mathrm{Ni}^{2+}$ doped $\mathrm{G}$ (see figure 5.3b) and GC1 (see figure 5.3c). The deconvoluted spectra reveal a number of absorption bands that are attributed to various vibrational modes of phosphate structural groups. From the figure. 5.3b (G sample), the band at 446 $\mathrm{cm}^{-1}$ is attributed to the bending vibration O-P-O units in $\mathrm{PO}_{4}^{3-}$ groups ( $\mathrm{Q}^{0}$ units) [38]. The $531 \mathrm{~cm}^{-1}$ band is related to the $\mathrm{O}-\mathrm{P}-\mathrm{O}$ bending vibrations in $\left(\mathrm{P}_{2} \mathrm{O}_{7}\right)^{4-}\left(\mathrm{Q}^{1}\right.$ units $)$. The bands 678,728 and $785 \mathrm{~cm}^{-1}$ are associated to the symmetric stretching vibration of P-O-P groups in $\mathrm{Q}^{1}$ units [28]. The $862 \mathrm{~cm}^{-1}$ and $918 \mathrm{~cm}^{-1}$ bands are related to the asymmetric stretching vibration of $\mathrm{P}-\mathrm{O}-\mathrm{P}$ units in $\mathrm{PO}_{4}^{3-}$ groups $\left(\mathrm{Q}^{0}\right.$ units). The 989 and $1058 \mathrm{~cm}^{-1}$ bands are attributed to the symmetric and asymmetric stretching vibrations of $\mathrm{PO}_{4}^{3-}$ groups $\left(\mathrm{Q}^{0}\right.$ units) [38]. The bands at 1138 and $1155 \mathrm{~cm}^{-1}$ are due to symmetric stretching vibration of $\mathrm{PO}_{3}^{2-}$ groups $\left(\mathrm{Q}^{1}\right.$ units $)$ and $\mathrm{PO}_{2}^{-}$groups $\left(\mathrm{Q}^{2}\right.$ units $)$. The bands 1213 and $1273 \mathrm{~cm}^{-1}$ are associated to symmetric and asymmetric stretching vibration of $\mathrm{PO}_{2}^{-}$groups ( $\mathrm{Q}^{1}$ units) [43].

As seen from the figure 5.3c (GC samples), the appearance of a new weak intense band at $616 \mathrm{~cm}^{-1}$ is due to a change in in-chain P-O-P groups by the effect of network modifier on phosphate glass structure [38]. The important feature of the band between 
623 and $700 \mathrm{~cm}^{-1}$ (P-O-P groups in $\mathrm{Q}^{1}$ units) is drastically changed and is resolving in to four bands. It is interesting to note that the relative area of the bands decreased from $0.12\left(688 \mathrm{~cm}^{-1}\right)-0.02\left(669 \mathrm{~cm}^{-1}\right)$, which suggested that the $653,669,677$ and $688 \mathrm{~cm}^{-1}$ bands are associated to the bending vibration of $\mathrm{P}=\mathrm{O}$ bonds, but not to the $\mathrm{P}-\mathrm{O}-\mathrm{P}$ groups [38]. The 717 and $735 \mathrm{~cm}^{-1}$ bands are related to the metaphosphate units, Q1 (P-O-P) [38]. The bands 841 and $864 \mathrm{~cm}^{-1}$ are due to the symmetric and asymmetric stretching vibration of P-O-P groups ( $\mathrm{Q}^{0}$ units) [40]. The 1153 and $1203 \mathrm{~cm}^{-1}$ bands are related to the symmetric stretching vibration of $\mathrm{PO}_{2}^{-}$groups in $\mathrm{Q}^{2}$ and $\mathrm{Q}^{1}$ units [43]. Moreover, the intensity of 717 and $737 \mathrm{~cm}^{-1}$ bands increase with the $1058 \mathrm{~cm}^{-1}$ band disappearance by varying Ni content in GCs. This means a decrease content of the pyrophosphate units with increase of metaphosphate units.

\subsubsection{Optical absorption spectra}

UV-Vis-NIR absorption spectra of $\mathrm{Ni}^{2+}$ doped glass and glass-ceramics are shown in figure 5.4a. The nature and position of the bands resembles to the $\mathrm{Ni}^{2+}$ ion octahedral symmetry and bulk-like ZnTe NCs [109][103]. According to the energy level scheme of $\mathrm{Ni}^{2+}$ ions, the observed bands around 1366, 822 and $434 \mathrm{~nm}$ are spin allowed which arise from the ground state, ${ }^{3} \mathrm{~A}_{2 g}(\mathrm{~F})$ to the excited states, ${ }^{3} \mathrm{~T}_{2 g}(\mathrm{~F}),{ }^{3} \mathrm{~T}_{1 g}(\mathrm{~F})$ and ${ }^{3} \mathrm{~T}_{1 g}(\mathrm{P})$, respectively. The absorption band of $533 \mathrm{~nm}$ is closer to the band gap of bulk ZnTe $(2.33 \mathrm{eV})$ thus the samples may exhibit Ni-doped ZnTe NCs nature in GCs (except in $\mathrm{G})$. The increasing intensity of absorption band at around $1352 \mathrm{~nm}\left({ }^{3} \mathrm{~A}_{2 g}(\mathrm{~F}) \rightarrow{ }^{3} \mathrm{~T}_{2 g}(\mathrm{~F})\right)$ in GCs with increasing $\mathrm{Ni}^{2+}$ ions are associated to the $6 \mathrm{Ni}^{2+}$ coordination, which also is an indicative of large fraction of $\mathrm{Ni}^{2+}$ ions that participate as an interstitial atom in the (ZnTe) nanocrystal GCs even though ZnTe exhibit self-intrinsic purification mechanism [6]. On the basis of color of samples one can clearly expect coordinate state of $\mathrm{Ni}^{2+}$, for instance (see inset of figure 5.1.4a), the appearance of light brown color of GC1 and GC2 samples are an indicative of $5 \mathrm{Ni}^{2+}$ and $4 \mathrm{Ni}^{2+}$ coordinate states; and the light green and blue color of GC3 and GC4 samples are related to $6 \mathrm{Ni}^{2+}$ coordination.

The crystal field $\left(\mathrm{D}_{q}\right)$ and Racah $(\mathrm{B})$ parameters were calculated based on observed absorption energies by fit to the Tanabe-Sugano diagram for $\mathrm{d}^{8}$ ions, as shown 

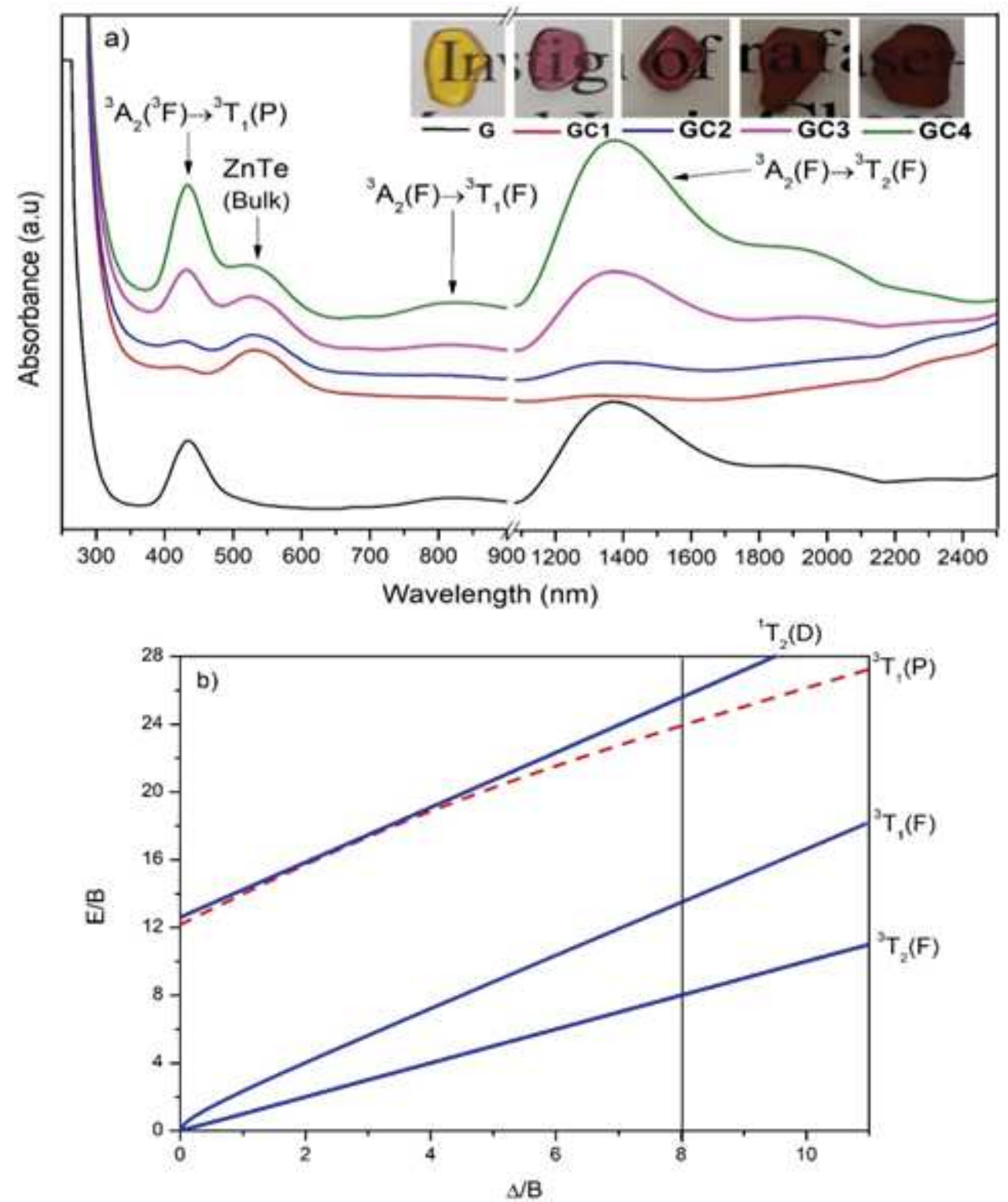

Figure 5.4: (a) Optical absorption spectra of $\mathrm{Ni}^{2+}$ ions doped glass and glass-ceramics; (b) Energy level diagram for octahedral of $\mathrm{Ni}^{2+}$ ions.

Table 5.3: Absorption band energies $(\nu)$, crystal field splitting $\left(D_{q}\right)$, Racah parameter $(\mathrm{B})$, nephelauxetic ratio $(\beta)$ and optical band gaps $\left(E_{\text {opt }}\right)$ of our glasses.

\begin{tabular}{|l|l|l|l|l|l|}
\hline Parameter & G & GC1 & GC2 & GC3 & GC4 \\
\hline Wavenumber $\left(\nu \mathrm{cm}^{-1}\right)$ & & & & & \\
\hline${ }^{3} \mathrm{~A}_{2}(\mathrm{~F}) \rightarrow{ }^{3} \mathrm{~T}_{2}(\mathrm{~F})$ & 7294 & 7289 & 7283 & 7283 & 7273 \\
\hline${ }^{3} \mathrm{~A}_{2}(\mathrm{~F}) \rightarrow{ }^{3} \mathrm{~T}_{1}(\mathrm{~F})$ & 12195 & 12255 & 12255 & 12255 & 12077 \\
\hline${ }^{3} \mathrm{~A}_{2}(\mathrm{~F}) \rightarrow{ }^{3} \mathrm{~T} 1(\mathrm{P})$ & 23041 & 23809 & 23364 & 23148 & 23041 \\
\hline $\mathrm{D}_{q}\left(\mathrm{~cm}^{-1}\right)$ & 729 & 729 & 728 & 728 & 727 \\
\hline $\mathrm{B}\left(\mathrm{cm}^{-1}\right)$ & 890 & 974 & 916 & 902 & 887 \\
\hline$\beta$ & 0.824 & 0.876 & 0.848 & 0.835 & 0.821 \\
\hline $\mathrm{E}_{\text {opt }}$ (Direct) & $4.55 \pm 0.21$ & $4.13 \pm 0.28$ & $4.15 \pm 0.35$ & $4.16 \pm 0.24$ & $4.14 \pm 0.18$ \\
\hline $\mathrm{E}_{\text {opt }}$ (Indirect) & $3.81 \pm 0.11$ & $3.75 \pm 0.24$ & $3.77 \pm 0.19$ & $3.72 \pm 0.16$ & $3.72 \pm 0.20$ \\
\hline
\end{tabular}


in figure 5.4. Table 5.3 shows band energies, $\mathrm{D}_{q}$ and $\mathrm{B}$ parameters. The splitting field strength does not change significantly with increase of $\mathrm{Ni}^{2+}$ ions in GCs suggesting that ligand field of $\mathrm{Ni}^{2+}$ ions occupy regular octahedral site of the molecules. Moreover, $\mathrm{D}_{q}$ is more sensitive to change in the metal ligand distance. Thus the distortion of the ligands induces a negligible effect on the crystal field strength of the central ion in GCs [111]. The decrease of $\mathrm{B}$ is ascribed to the decrease of interelectronic repulsion within the d-orbitals, which lead to increase of the covalent nature between metal-ligand bonds. Using the interelectronic repulsion parameter $\mathrm{B}$, the nephelauxetic ratio $\left(\beta=\mathrm{B}_{(\text {complex })} / \mathrm{B}_{(\text {freeion })}\right)$ has been also determined and found to decrease in GCs with increase of $\mathrm{Ni}^{2+}$ ions (see Table 5.3), which indicates higher delocalization effect between metals and ligands.
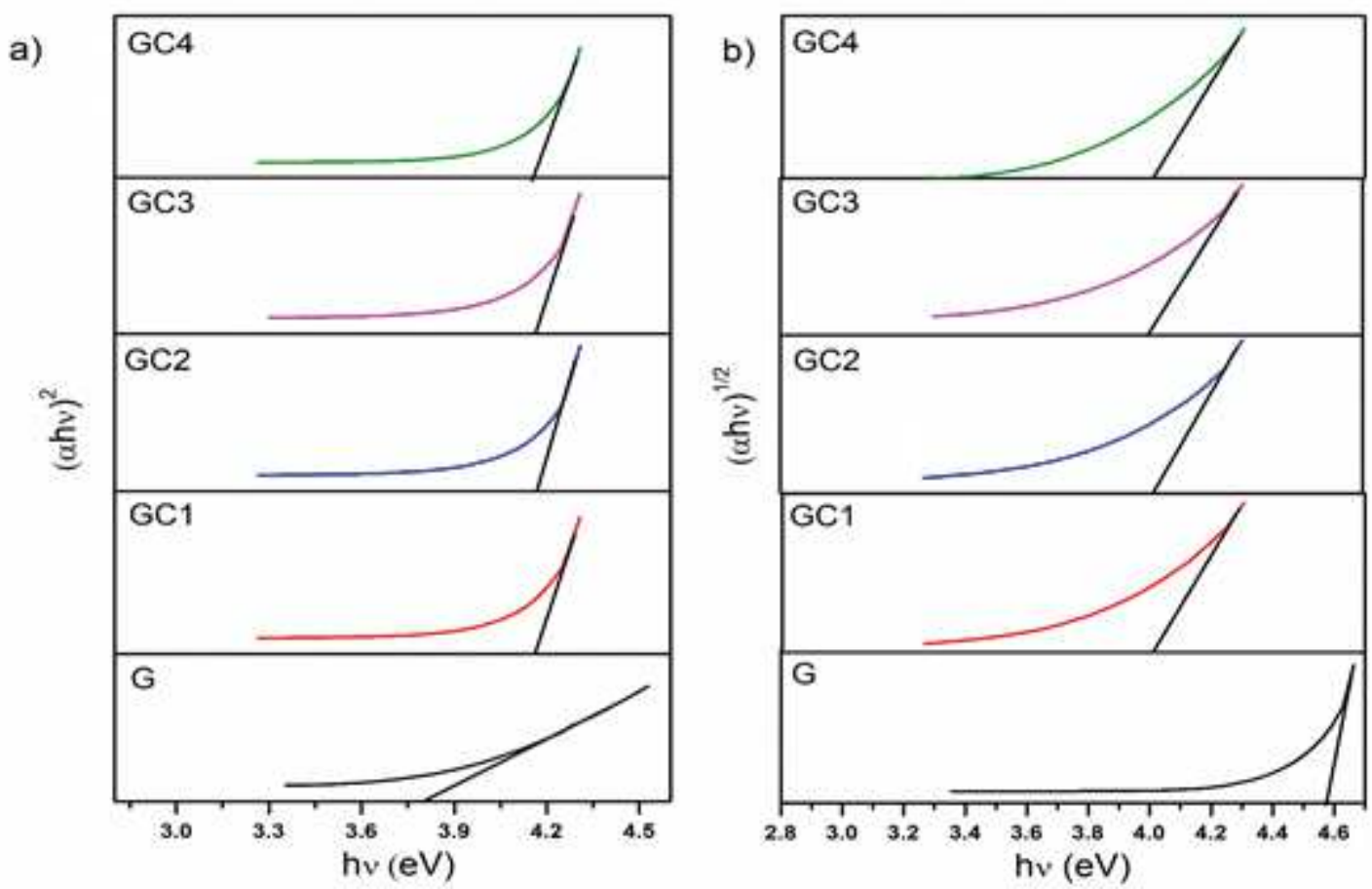

Figure 5.5: Plots of $(\alpha \mathrm{h} \nu)^{2}$ and $(\alpha \mathrm{h} \nu)^{1 / 2}$ as a function of photon energy $(\mathrm{h} \nu)$ for $\mathrm{Ni}^{2+}$ doped glass and glass-ceramics.

The fundamental absorption edge in UV region of $\mathrm{G}$ is at around $262 \mathrm{~nm}$ and is shift to longer wavelength $(\sim 300 \mathrm{~nm})$ in GCs. The optical transitions such as direct and indirect transitions occur at the fundamental absorption edges of crystalline and noncrystalline materials. According to Davis and Mott [16] theory and expressions, 2.2 and 2.3 for the direct and indirect allowed transitions, the optical band gap $\left(\mathrm{E}_{\text {opt }}\right)$ values are estimated by plotting $(\alpha \mathrm{h} \nu)^{2}$ and $(\alpha \mathrm{h} \nu)^{1 / 2}$ as a function of photon energy $(\mathrm{h} \nu)$ that are 
shown in figure $5.5 \mathrm{a}$ and figure $5.5 \mathrm{~b}$. The $\mathrm{E}_{\text {opt }}$ is obtained by a linear extrapolation of the curve to the $\mathrm{h} \nu$ axis and are reported in Table 5.3. The $\mathrm{E}_{\text {opt }}$ values are $4.55 \mathrm{eV}$ (direct) and $3.81 \mathrm{eV}$ (indirect) for G sample; whereas in the case of GCs show negligible variation in their $\mathrm{E}_{\text {opt }}$ values, $\sim 4.14 \mathrm{eV}$ (direct) and $\sim 3.74 \mathrm{eV}$ (indirect) with increasing $\mathrm{Ni}^{2+}$ ions, respectively. In addition, the decreasing of $\mathrm{E}_{\text {opt }}$ for $\mathrm{G}$ to $\mathrm{GCs}$ indicate that there is an increase of non-bridging oxygens (NBOs).

\subsubsection{Emission spectra and cross-sections}

The $\mathrm{Ni}^{2+}$ ions of excited levels are varied with the change of host glass composition and emission could be related to d-d optical transitions due to existance of octahedral and tetrahedral coordination sites within the glass matrix. The excitation and emission spectra of $5 \% \mathrm{Ni}(\mathrm{G})$ doped and GCs is shown in Figure 5.6(a). Figure 5.6(b) shows possible emission levels of $\mathrm{Ni}^{2+}$ ions in ZnTe NCs GCs samples. The excitation spectrum for the Ni doped glass was recorded by monitoring the emission at $620 \mathrm{~nm}$. Under $240 \mathrm{~nm}$ excitation, the broad emission band between $525-700 \mathrm{~nm}$ wavelength is attributed to ${ }^{1} \mathrm{~T}_{2 g}(\mathrm{D}) \rightarrow{ }^{3} \mathrm{~T}_{2 g}(\mathrm{~F})$ transition. The emission profile are similar for the $\mathrm{G}$ and GCs but the intensity has decreased with the increase of the concentration of $\mathrm{Ni}^{2+}$ ions $(\mathrm{x}=5$ and 10 wt\%) in GCs, which can be observed in figure 5.7. By introducing $\mathrm{Ni}^{2+}$ into ZnTe NCs as substitutional ions, they act as electron trapping centers, which results into non-radiative
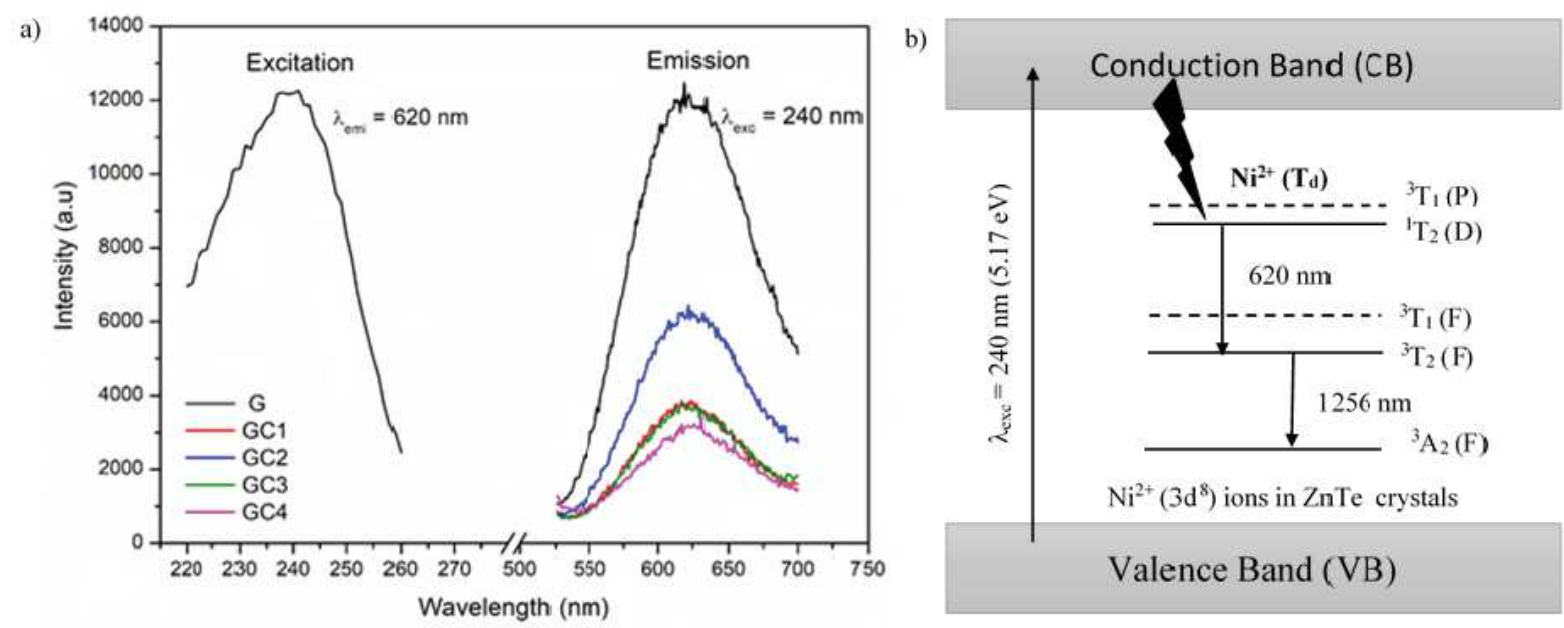

Figure 5.6: a) UV-excitation and Visible emission spectra for $\mathrm{Ni}^{2+}$ ions, and b) schematic representation of emission levels of $\mathrm{Ni}^{2+}$ ions in ZnTe NCs contain system. 
recombination. Therefore, the luminescence quenching is due to the photo-electrons that are transferred to nickel ion induced trapping centers instead of an anion vacancy defect center. However, we could not neglect the energy transfer from QDs and bulk NCs to $\mathrm{Ni}^{2+}$ ions because of the superposition of exciton emission of QDs and electron-hole recombination from bulk-NCs that occur with the substitutional incorporation of $\mathrm{Ni}^{2+}$ ions [112]. The quenching of luminescence was also observed $\mathrm{Ni}^{2+}$ and $\mathrm{Cd}^{2+}$ ions doped ZnS colloidal particles $[113,114,115]$. The full width at half maxima (FWHM) is found to be higher in GC2 (82 nm) and decreasing with increasing of Ni concentration in GCs, as shown in Figure 5.7.

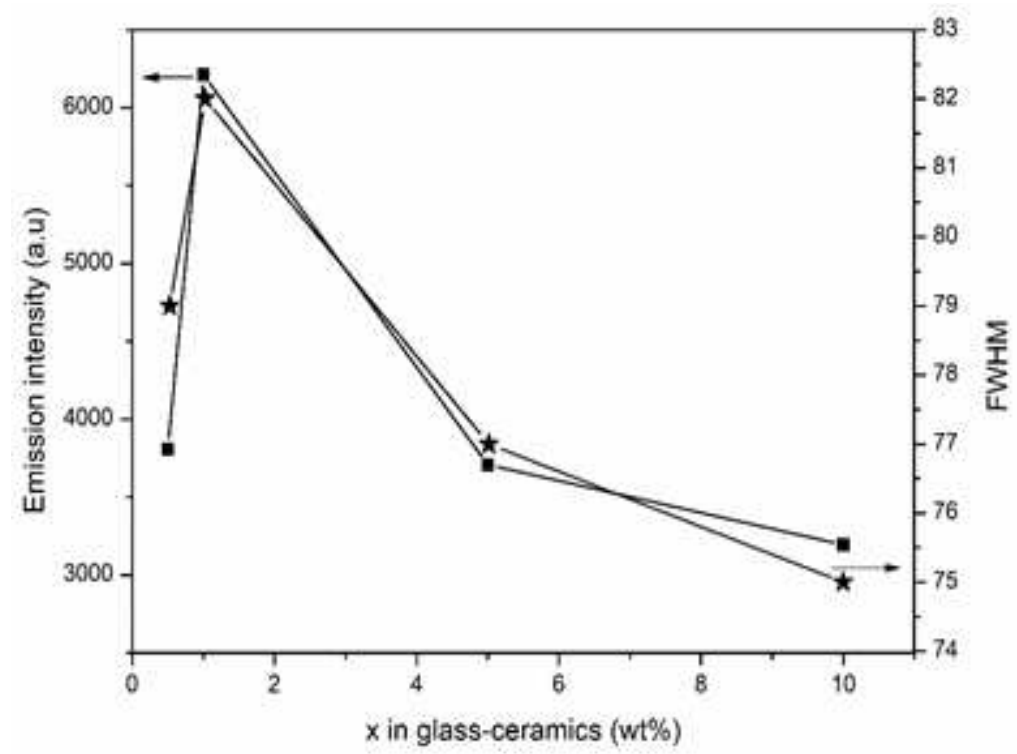

Figure 5.7: Variation of emission intensity and FWHM with $\mathrm{Ni}^{2+}$ ions in GC samples.

Figure 5.8 shows emission decay curves for the visible emission transition, ${ }^{1} \mathrm{~T}_{2 g}(\mathrm{D})$ $\rightarrow{ }^{3} \mathrm{~T}_{2 g}(\mathrm{~F})$ at $240 \mathrm{~nm}$ wavelength excitation. The curves showed good fit to bi-exponential decay (G and GC2) and tri-exponential decay (for GC1, GC3 and GC4) due to inhomogeneous distribution of doping ions in host glasses. The average lifetimes are calculated using the following expressions [116]:

$$
\langle\tau\rangle=\frac{A_{1} \tau_{1}^{2}+A_{2} \tau_{2}^{2}}{A_{1} \tau_{1}+A_{2} \tau_{2}} \quad \text { and } \quad\langle\tau\rangle=\frac{A_{1} \tau_{1}^{2}+A_{2} \tau_{2}^{2}+A_{3} \tau_{3}^{2}}{A_{1} \tau_{1}+A_{2} \tau_{2}+A_{3} \tau_{3}}
$$

Inset of Fig. 5.8 shows variation of lifetimes with Ni content in glasses. The lifetime is saturated at $1.0 \% \mathrm{Ni}^{2+}$ ions (GC2) with subsequent decrease for higher doping 


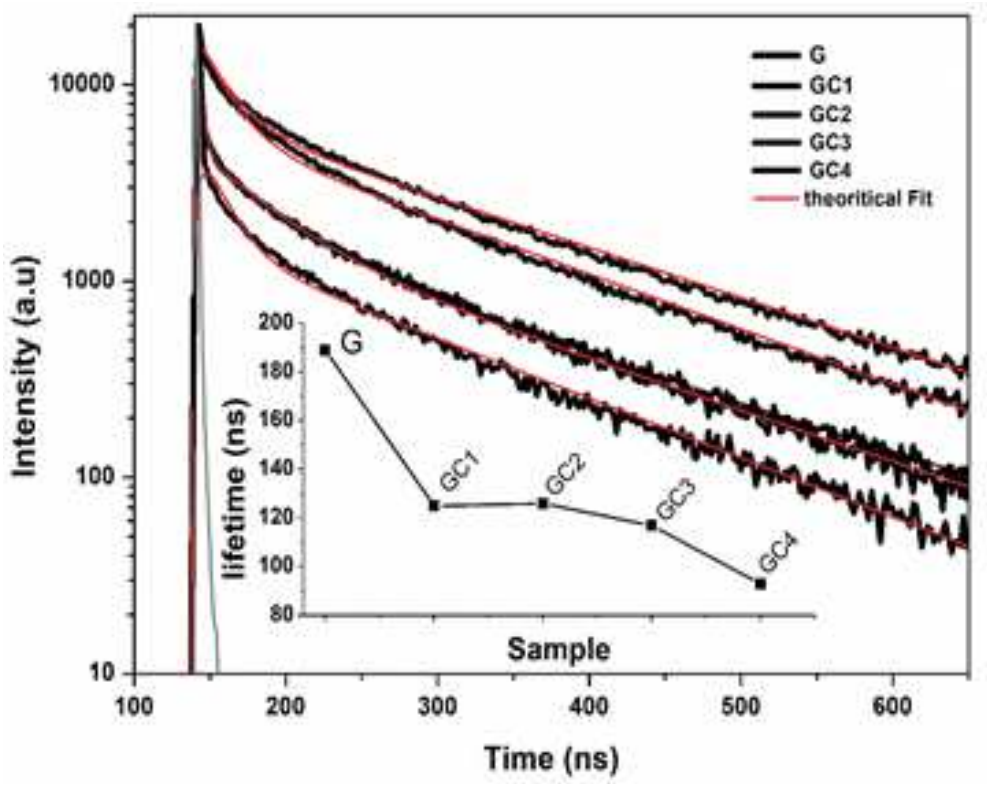

Figure 5.8: Decay curves for $\mathrm{Ni}^{2+}$ ions doped glass and glass-ceramics. Inset figure shows a variation of lifetime with $\mathrm{Ni}^{2+}$ ions.

concentration in GCs. This result could be the effects of change of environment around the $\mathrm{Ni}^{2+}$ ions or multi-polar non-radiative interactions among Ni2+ ions [117]. The lifetime for the GC3 (117 ns) has decreased compared with the G (188 ns). The variation in emission intensity, FWHM and decay lifetimes followed similar trend with increasing $\mathrm{Ni}^{2+}$ ions in GCs that are strong evidence to the change of environment surrounding $\mathrm{Ni}^{2+}$ ions in host glasses.

Table 5.4: Emission properties of samples (* from McCumber's theory).

\begin{tabular}{|c|c|c|c|c|c|c|c|}
\hline Sample & $\mathrm{n}$ & \multicolumn{6}{|c|}{${ }^{1} \mathrm{~T}_{2 g}(\mathrm{D}) \rightarrow{ }^{3} \mathrm{~T}_{2 g}(\mathrm{~F})$} \\
\hline & & $\begin{array}{c}F W H M \\
n m\end{array}$ & $\begin{array}{l}\Delta \lambda_{e f f} \\
(n m)\end{array}$ & \multicolumn{2}{|c|}{$\begin{array}{c}\tau_{\text {meas }} \\
(n s)\end{array}$} & $\begin{array}{c}\sigma_{e m i} \\
\left(\times 10^{-18} \mathrm{~cm}^{2}\right)\end{array}$ & $\begin{array}{c}\text { FOM } \\
\left(\times 10^{-25} \mathrm{~cm}^{2} \cdot \mathrm{sec}\right)\end{array}$ \\
\hline G & 1.515 & $90 \pm 1$ & $90.38 \pm 1$ & \multicolumn{2}{|c|}{$189 \pm 10$} & $5.01 \pm 1.02$ & $9.48 \pm 1.55$ \\
\hline GC1 & 1.526 & $79 \pm 1$ & $78.94 \pm 1$ & \multicolumn{2}{|c|}{$125 \pm 9$} & $8.57 \pm 0.89$ & $10.70 \pm 1.89$ \\
\hline GC2 & 1.531 & $82 \pm 1$ & $83.54 \pm 1$ & \multicolumn{2}{|c|}{$127 \pm 15$} & $7.94 \pm 0.74$ & $10.04 \pm 1.74$ \\
\hline GC3 & 1.543 & $77 \pm 1$ & $76.39 \pm 1$ & \multicolumn{2}{|c|}{$117 \pm 13$} & $9.24 \pm 0.85$ & $10.81 \pm 1.21$ \\
\hline GC4 & 1.535 & $75 \pm 1$ & $75.45 \pm 1$ & \multicolumn{2}{|c|}{$93 \pm 10$} & $11.88 \pm 1.21$ & $11.06 \pm 1.22$ \\
\hline & & Sample & \multicolumn{4}{|c|}{${ }^{1} \mathrm{~T}_{2 g}(\mathrm{D}) \rightarrow{ }^{3} \mathrm{~T}_{2 g}(\mathrm{~F})$} & \\
\hline & & & \multicolumn{2}{|c|}{ FWHM* $^{*}(\mathrm{~nm})$} & \multicolumn{2}{|c|}{$\sigma_{e m i}^{*} \times 10^{-20}\left(\mathrm{~cm}^{2}\right)$} & \\
\hline & & G & \multicolumn{2}{|c|}{$256 \pm 1$} & \multicolumn{2}{|c|}{$1.29 \pm 0.75$} & \\
\hline & & GC1 & \multicolumn{2}{|c|}{$169 \pm 1$} & \multicolumn{2}{|r|}{$0.24 \pm 0.29$} & \\
\hline & & GC2 & \multicolumn{2}{|c|}{$204 \pm 1$} & \multicolumn{2}{|r|}{$0.41 \pm 0.28$} & \\
\hline & & GC3 & \multicolumn{2}{|c|}{$252 \pm 1$} & \multicolumn{2}{|r|}{$0.75 \pm 0.15$} & \\
\hline & & GC4 & \multicolumn{2}{|c|}{$278 \pm 1$} & & $0.87 \pm 0.22$ & \\
\hline
\end{tabular}

The peak emission cross-section $\left(\sigma_{e m i}\right)$ is calculated using the equation, 2.22 , and 
are listed in table 5.4 along with $\tau_{\text {meas }}$, FWHM, $\Delta \lambda_{\text {eff }}$ parameters. The effective line width $\left(\Delta \lambda_{\text {eff }}\right)$ was estimated using equation 2.23. The emission cross-section is higher for GC4. The $\sigma_{e m i}$ of $5 \mathrm{wt} \% \mathrm{Ni}^{2+}$ doped $\mathrm{G}\left(5.01 \times 10^{-18} \mathrm{~cm}^{2}\right)$ to $\mathrm{GC}\left(9.25 \times 10^{-18}\right.$ $\left.\mathrm{cm}^{2}\right)$ is significantly improved. The figure of merit (FOM) is an important parameter to characterize the laser materials and is calculated by the product of $\sigma_{e m i}$ and $\tau_{\text {meas }}$ since it is inversely proportional to the laser threshold and proportional to the gain amplification. The FOM is higher in GC4 $\left(11.06 \times 10^{-24} \mathrm{~cm}^{2} . \mathrm{sec}\right)$ among the GCs. Finally, we expect that the GC4 sample may be useful for visible-RED emission light conversion in LED technology.

It is known that i) the near infrared emission positions of $\mathrm{Ni}^{2+}$ ions are very sensitive to the crystal field strength, which might form structurally asymmetric shape of emission; ii) the $\mathrm{Ni}^{2+}$ ions occupy regular crystal lattices with strong crystal field strength when $\mathrm{Ni}^{2+}$ is incorporated into GCs and they exhibit broad absorption and emission $\left({ }^{3} \mathrm{~A}_{2}(\mathrm{~F}) \rightarrow{ }^{3} \mathrm{~T}_{2}(\mathrm{~F})\right)$ in near infrared region with small Stokes shift. Therefore, the NIR emission of $\mathrm{Ni}^{2+}$ is reabsorbed by the neighboring $\mathrm{Ni}^{2+}$ ions. In the present work, the lower value of $\mathrm{D}_{q} / \mathrm{B}$ (see figure $5.4 \mathrm{~b}$ ) might be the result of a smaller energy interval and longer wavelength emissions. The emission cross-sections for near-infrared ${ }^{3} \mathrm{~T}_{2}(\mathrm{~F}) \rightarrow$ ${ }^{3} \mathrm{~A}_{2}(\mathrm{~F})$ emission transition has been also calculated from the absorption spectra by using McCumber's reciprocity (RE) method [118][111] and are listed in table 5.4. The FWHM and emission cross-sections $\left(\sigma_{e m i}\right)$ are found to increase with $\mathrm{Ni}^{2+}$ ions in GCs and it does not change significantly from G to GC3. The higher FWHM and $\sigma_{e m i}$ of ${ }^{3} \mathrm{~T}_{2}(\mathrm{~F}) \rightarrow{ }^{3} \mathrm{~A}_{2}(\mathrm{~F})$ emission transition in GC4 sample is most suitable for broadband optical amplification in telecommunication operating at $1.1-1.8 \mu \mathrm{m}$ region.

\subsubsection{Photo-thermal spectroscopy}

In this work, the $\mathrm{D}$ and $\mathrm{ds} / \mathrm{dT}$ of $\mathrm{Ni}^{2+}$ ions doped $\mathrm{G}$ and GCs were measured using thermal lens (TL) experiment which is based on the two-beam mismatched mode and its configuration details can be found in chapter 4. The observed excitation and probe beam radius at sample are $\omega_{e}=40.78 \mu \mathrm{m}$ and $\omega_{p}=208.87 \mu \mathrm{m}$, respectively. Figure 5.9 shows TL transient signal of the $5 \mathrm{wt} \%$ Ni-doped glass with the excitation power of $50 \mathrm{~mW}$. 
The observed shape of probe beam intensity indicates $\mathrm{dS} / \mathrm{dT}>0$. The solid line represents theoretical fit using the expression 4.3 , and it results in $\theta=-(0.0655)$ and $t_{c}=1.9652$ ms. Similar measurements were performed for the other glasses and are not presented. Using expression, 4.5 the thermal diffusivity (D) is calculated from the average of five measurements for all samples and are listed in table 5.5.

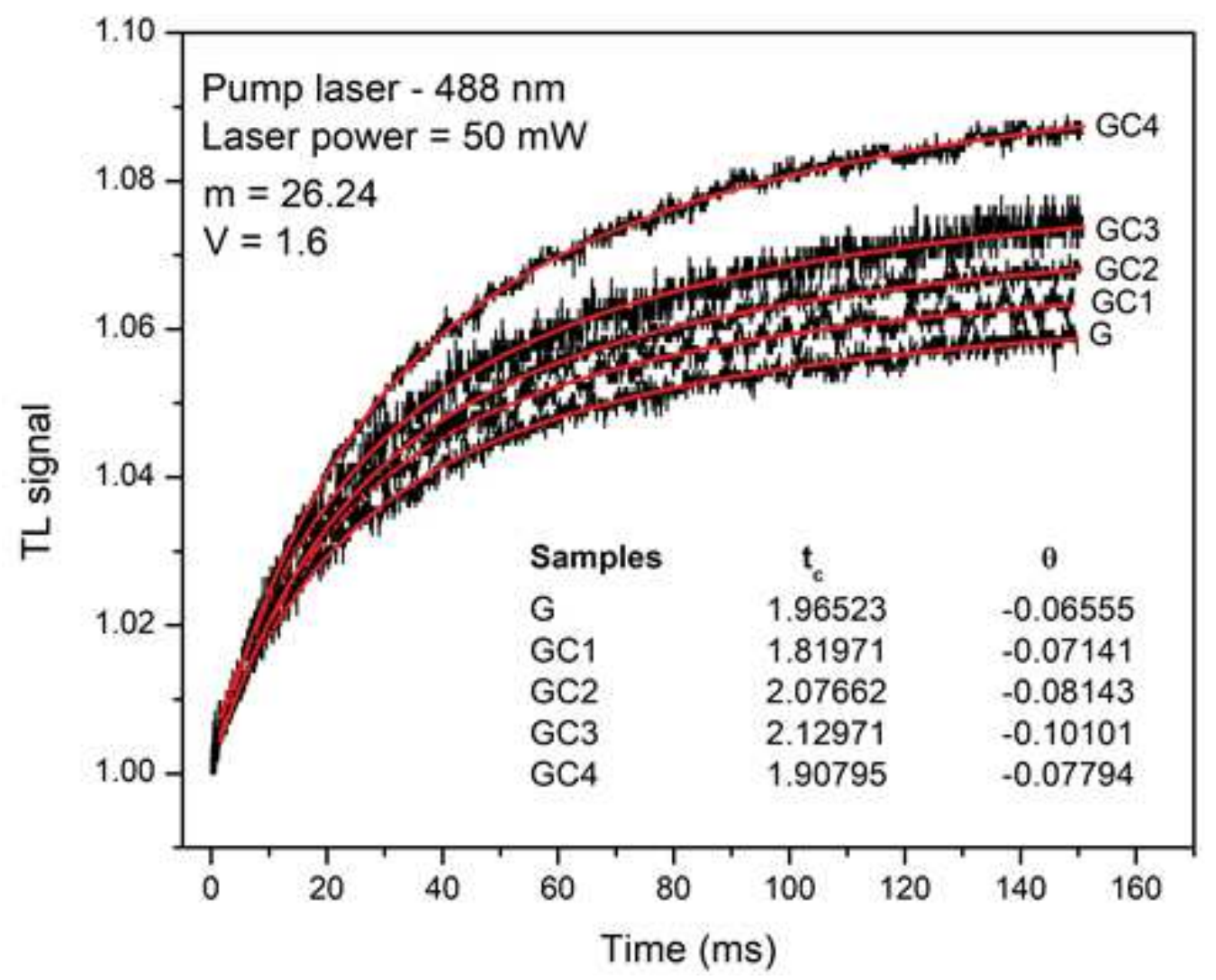

Figure 5.9: Typical normalized TL signal for ZnNiTe contain samples.

Table 5.5: Thermo-optical properties of samples.

\begin{tabular}{|l|c|c|c|c|c|c|}
\hline Sample & $\begin{array}{c}A_{e} \\
\left(\mathrm{~cm}^{-1}\right)\end{array}$ & $\begin{array}{c}t_{c} \\
(\mathrm{~ms})\end{array}$ & $\begin{array}{c}D \times 10^{-3} \\
\left(\mathrm{~cm}^{2} / \mathrm{sec}\right)\end{array}$ & $\begin{array}{c}\rho c \\
\left(\mathrm{~J} / \mathrm{cm}^{3} \cdot K\right)\end{array}$ & $\begin{array}{c}K \times 10^{-3} \\
(W / \mathrm{cm} . K)\end{array}$ & $\begin{array}{c}d S / d T \times 10^{-6} \\
K^{-1}\end{array}$ \\
\hline G & 1.16 & 1.852 & $2.267 \pm 0.2$ & $2.27 \pm 0.3$ & $5.15 \pm 0.6$ & $1.675 \pm 0.5$ \\
\hline GC1 & 2.59 & 2.067 & $2.022 \pm 0.1$ & $2.24 \pm 0.3$ & $4.53 \pm 0.6$ & $1.015 \pm 0.6$ \\
\hline GC2 & 3.07 & 2.013 & $2.069 \pm 0.3$ & $2.24 \pm 0.3$ & $4.63 \pm 0.6$ & $0.846 \pm 0.5$ \\
\hline GC3 & 3.81 & 2.042 & $2.039 \pm 0.2$ & $2.24 \pm 0.3$ & $4.57 \pm 0.6$ & $0.903 \pm 0.5$ \\
\hline GC4 & 3.28 & 1.514 & $2.754 \pm 0.4$ & $2.44 \pm 0.3$ & $6.72 \pm 0.6$ & $1.219 \pm 0.5$ \\
\hline
\end{tabular}

According to the literature $[119,120]$, the D and K of the semiconductor nanocrystals (NCs) are dependent on their crystal size. The change of crystal size in semiconductor NCs lead to an influence on thermal transport due to the effect of interface scattering in 
nanoparticles and phonon transport at the interfaces. Needless to say that the higher probability of diffusive scattering from the rougher surface can result lower the diffusivity (D) since it is very sensitive to the crystalline imperfections. As seen from the table 5.5, the D for the GCs decrease (except in GC4) when compared with the G sample which means that the host glass dominates heat transportation due to the expected low concentration of semiconductor NCs and dominating crystal imperfection in these GCs. The higher D of GC4 indicate a decrease in crystal imperfections that lead to reduce the interface and surface scatterings. In addition, the D does not change significantly with increase of $\mathrm{Ni}^{2+}$ ions in GCs $(\mathrm{x}=0.5,1.0$ and $5 \mathrm{wt} \%)$.

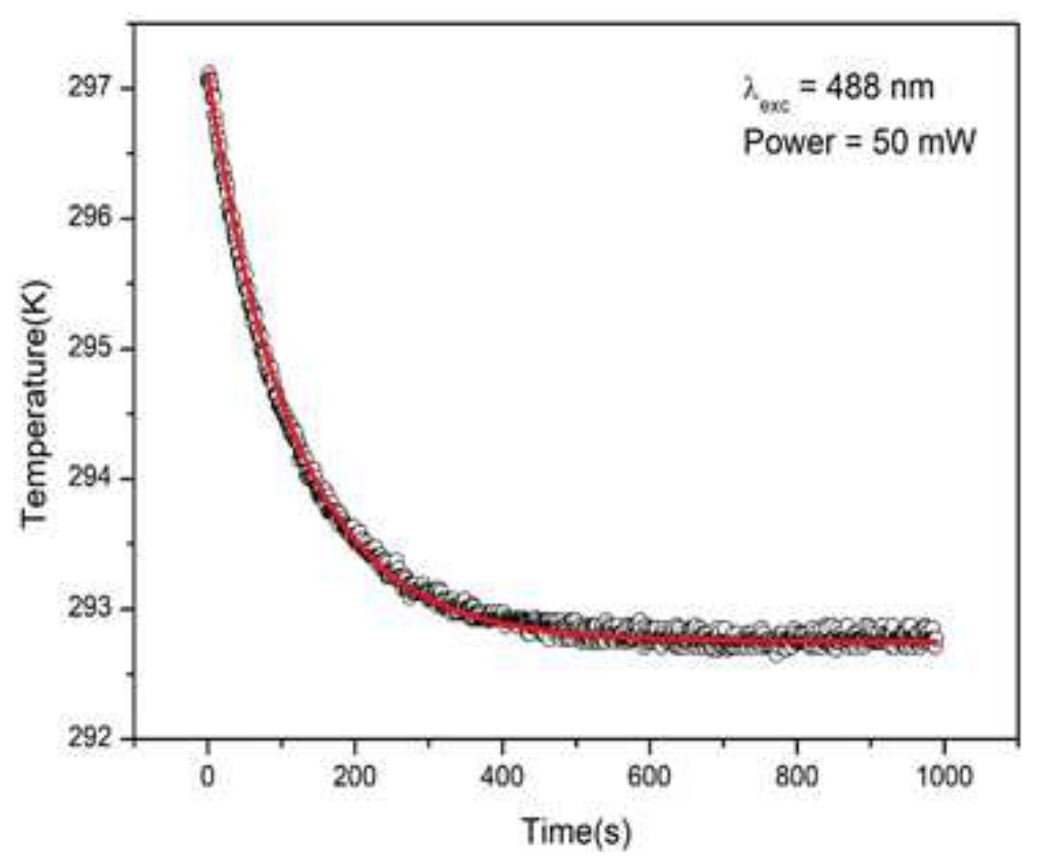

Figure 5.10: Cooling curve of the specific heat capacity measurements for for $5 \% \mathrm{Ni}$.

The relation between $\mathrm{D}$ and $\mathrm{K}$ is, $\mathrm{K}=\rho \mathrm{cD}$, where $\rho \mathrm{c}$ is the specific heat capacity. In the following, we consider that the heat transmitted in material is composed by several independent factors. In metals, heat is carried by both electrons and phonons among where phonons contributions are predominant. In the case of semiconductors and insulators, heat is transmitted entirely through phonons. Thus, the main contribution to the specific heat capacity of the solids is the amount of heat excited by the lattice vibrations, which depend on the phonon density of states. The specific heat capacity $(\rho c)$ of the samples were determined using the thermal relaxation technique [96], in which 488 $\mathrm{nm}$ of $\mathrm{Ar}+$ laser $(60 \mathrm{~mW})$ was used as heating source to the sample at a given temper- 
ature. The specific heat capacity measurement of the sample is presented in figure 5.10. We believe that the decreasing temperature experimental data is more reliable than the increasing temperature data due to the external noise that may interfere in the measurements. Therefore, the calculated specific heat values of the samples correspond to the data of the decreasing temperature experiment. As seen in figure 5.10, the solid line indicates theoretical fit to the equation 4.6, resulting thermal relaxation time, $\tau$ in seconds. Using the tau parameter, the $\rho \mathrm{c}$ is determined from equation, 4.7, and are presented in table 5.5 including thermal conductivity, $\mathrm{K}$ of all the samples.

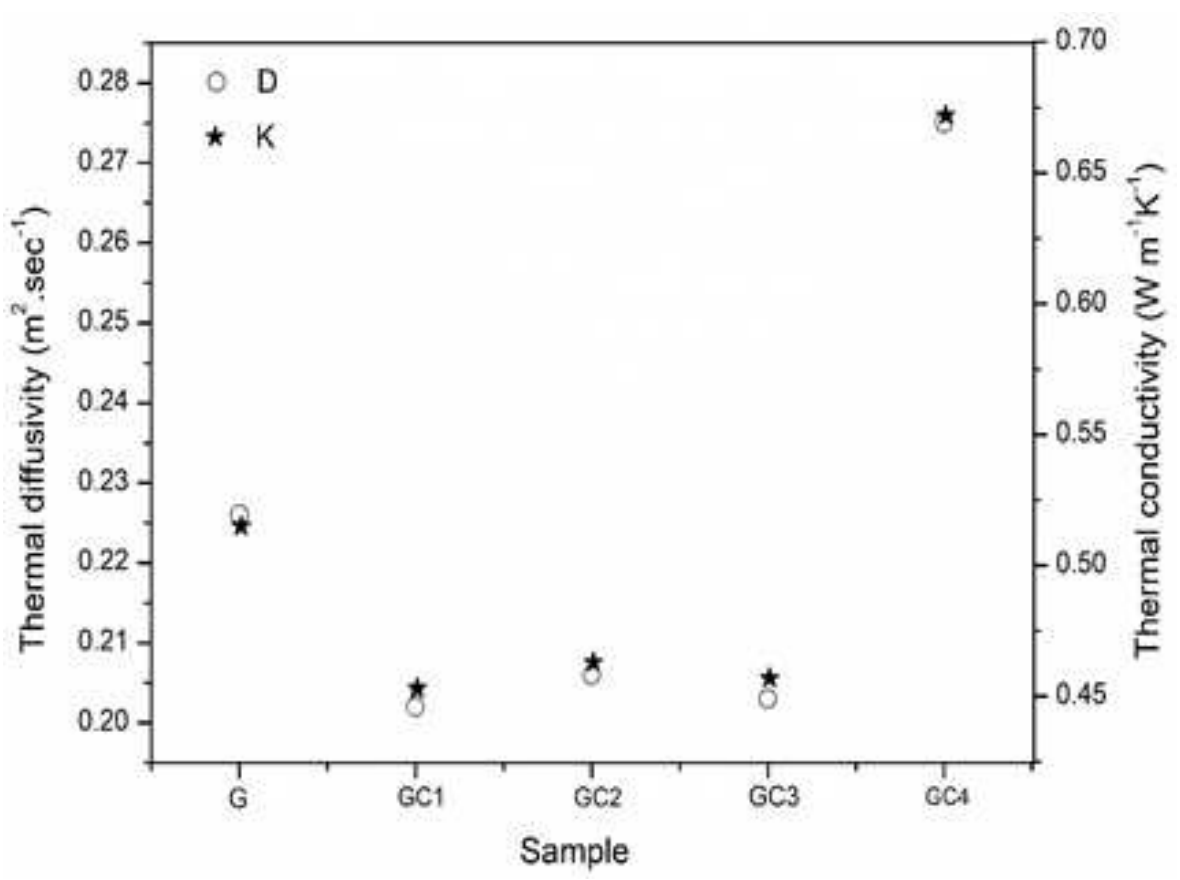

Figure 5.11: Variation of $\mathrm{D}$ and $\mathrm{K}$ with $\mathrm{Ni}^{2+}$ ions in samples

According to Ghoneim and Halawa [121], the thermal conductivity for the $\mathrm{Na}_{2} \mathrm{O}$ - $\mathrm{B}_{2} \mathrm{O}_{3}-\mathrm{SiO}_{2}$ glasses were higher and are increased with the increase of $\mathrm{B}_{2} \mathrm{O}_{3}$ and $\mathrm{SiO}_{2}$ content, indicating that the formation of a network structure consisting of $\mathrm{BO}_{4}$ and $\mathrm{SiO}_{4}$ tetrahedral units results in a longer phonon mean free path and consequently in a higher thermal conductivity. Similarly, the observed increase K (except GC3) with increase Ni content in GCs is due to the increase in the ordering of the glass network structure by the formation of $\mathrm{PO}_{4}$ tetrahedral units which results in longer phonon mean-free-path. The phonon mean free path were determined from, $\mathrm{D}=\mathrm{l} \cdot \nu_{s} / 3$, where 1 is the sample width, $\mathrm{D}$ is the thermal diffusivity at room temperature and $\nu_{s}$ is the average sound velocity 
[96]. The similar trend of D and K (see figure 5.11) shows strong evidence to the above discussions. Table 5.6 shows D and K values for some of glass hosts. From the data, one may depict that our glasses has comparable D and K of similar phosphate ones, and lower than silicate and tellurite glasses.

Table 5.6: Thermal diffusivity (D) and thermal conductivity $(\mathrm{K})$ of materials.

\begin{tabular}{|c|c|c|}
\hline Host glasses & $\mathrm{D} \times 10^{-3}\left(\mathrm{~cm}^{2} / \mathrm{sec}\right)$ & $\mathrm{K} \times 10^{-3}(\mathrm{~W} / \mathrm{cm} . \mathrm{K})$ \\
\hline \multicolumn{3}{|l|}{ Silicate $[122,123,124]$} \\
\hline Soda-lime & $4.9 \pm 5 \%$ & $10.10 \pm 10 \%$ \\
\hline LSCAS & $5.7 \pm 9 \%$ & $15.5 \pm 10 \%$ \\
\hline SCA & $5.5 \pm 0.05$ & \\
\hline SCA:Nd & $5.8 \pm 0.05$ & \\
\hline SCA: Er & $5.76 \pm 0.01$ & \\
\hline Silica & $9.0 \pm 5 \%$ & \\
\hline SNAB & 3.75 & \\
\hline SNAB: CdS & 2.5 & \\
\hline \multicolumn{3}{|l|}{ Phosphate $[60,122]$} \\
\hline LHG-8 & $2.7 \pm 5 \%$ & $5.8 \pm 10 \%$ \\
\hline LG-750 & $2.9 \pm 5 \%$ & $6.0 \pm 10 \%$ \\
\hline LG-760 & $4.3 \pm 5 \%$ & $8.4 \pm 10 \%$ \\
\hline Q-88 (Kigre) & $3.8 \pm 5 \%$ & $8.4 \pm 10 \%$ \\
\hline Q-98 (Kigre) & $2.2 \pm 5 \%$ & $5.5 \pm 10 \%$ \\
\hline Q-100 (Kigre) & $2.1 \pm 5 \%$ & $5.4 \pm 10 \%$ \\
\hline PZABP:ZnTe & $2.5 \pm 0.2 \%$ & $3.3 \pm 0.4 \%$ \\
\hline \multicolumn{3}{|l|}{ Tellurite $[91,124,125]$} \\
\hline TeLi & $2.7 \pm 0.1 \%$ & $6.4 \pm 0.5 \%$ \\
\hline TeLi-10 & $2.9 \pm 0.1 \%$ & $6.5 \pm 0.5 \%$ \\
\hline TWNN: Er & $3.1 \pm 0.2 \%$ & $8.0 \%$ \\
\hline TWNN: Tm & $3.2 \pm 0.4 \%$ & 8.4 \\
\hline TeLiNb-5 & $3.4 \pm 0.1 \%$ & $6.6 \pm 0.3 \%$ \\
\hline TeLiNb-15 & $3.1 \pm 0.1 \%$ & $6.4 \pm 0.4 \%$ \\
\hline \multicolumn{3}{|l|}{ Chalcogenide [122] } \\
\hline InSbZnGdN & $3.2 \pm 5 \%$ & $10.2 \pm 10 \%$ \\
\hline Ga:La:S & $2.7 \pm 5 \%$ & $5.9 \pm 10 \%$ \\
\hline $\mathrm{PbI}_{2}-\mathrm{Sb}_{2} \mathrm{~S}_{3}-\mathrm{As}_{2} \mathrm{~S}_{3}$ & $1.3 \pm 5 \%$ & [] \\
\hline ISZn & $3.1 \pm 5 \%$ & $9.9 \pm 10 \%$ \\
\hline
\end{tabular}

As already stated, dS/dT is the temperature dependent variation of optical path. It is another important parameter for operating devices in practical temperatures where it should be required low $\mathrm{dS} / \mathrm{dT}$. This parameter is generally difficult to control by the glass composition since $\mathrm{dS} / \mathrm{dT}=\mathrm{n} . \alpha+\mathrm{dn} / \mathrm{dT}$. From TL experiments, one can estimate dS/dT with the known TL-induced phase shift using the expression, 4.4, where $\varphi$ (the fraction of absorbed energy converted into heat) is considered to be 1, and are reported 
in table 5.5. The lower dS/dT of G and GCs is attributed to the occurrence of laser beam deviation inside the samples. It is worth mentioning that our samples are not completely homogeneous thus reported values were average of five measurements. The GC2 shows lower dS/dT among the studied glasses and it would present better working conditions in optoelectronic device applications.

\subsubsection{Nonlinear optical spectroscopy: Z-scan}

Generally, the nonlinear optical properties of the material varied by the excitation of wavelength, peak intensity, pulse width and excited state lifetime [126]. In this work, the third-order nonlinear optical (NLO) parameters such as the nonlinear refraction $\left(\mathrm{n}_{2}\right)$ (close-aperture, CA) and nonlinear absorption coefficient $(\beta)$ (open-aperture, OA) were measured using femtosecond Z-scan experiment at an excitation wavelength ranges, 750, 800 and $850 \mathrm{~nm}$.

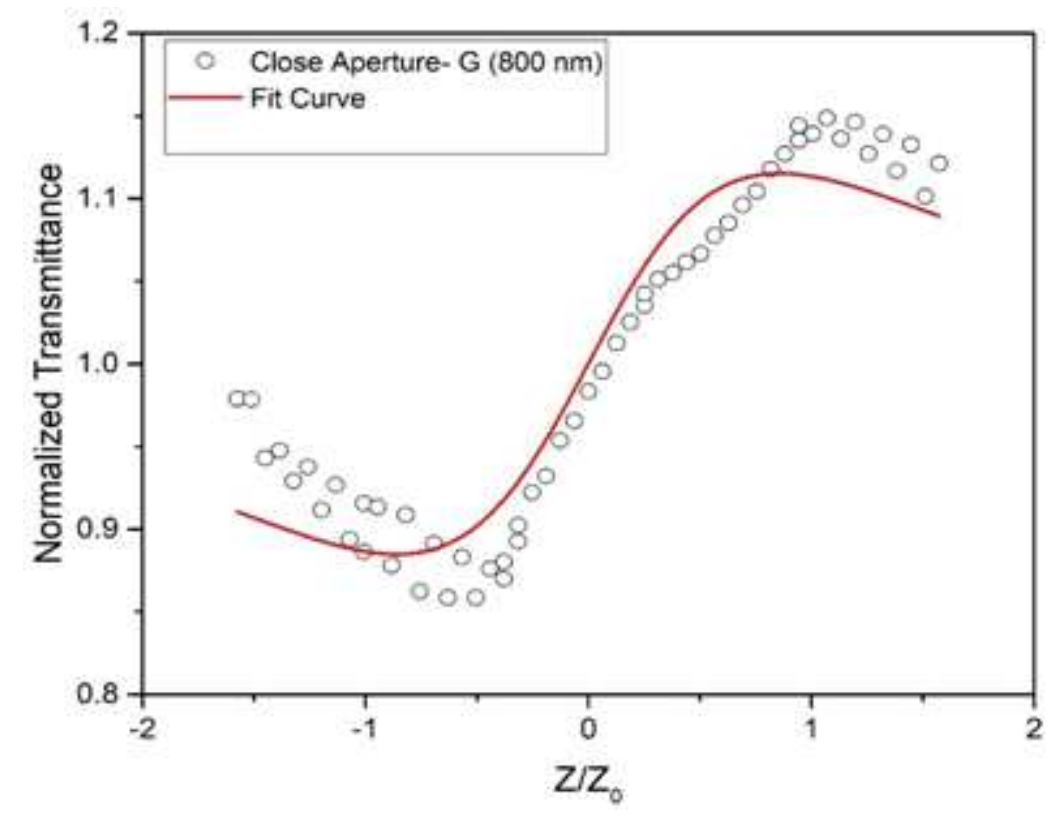

Figure 5.12: Z-scan results in the close-aperture mode for the sample 5\% Ni at $800 \mathrm{~nm}$.

Figure 5.12 shows CA traces that allowed us to find the sign and magnitude of $\mathrm{n}_{2}$ in $5 \% \mathrm{Ni}$ doped glass. It is observed that the peak following valley configuration indicates the self-focusing behavior under high laser irradiance, namely positive sign of $\mathrm{n}_{2}$ which can be calculated from the transmittance gap between the peak and valley by fitting the CA Z-scan using equations 4.9 and 4.10. The calculated $\mathrm{n}_{2}$ is $3.54 \times 10^{-14}$ 
$\mathrm{cm}^{2} / \mathrm{W}$, which is higher than borate [124-126] and tellurite glasses [127], but lower than silicate glasses containing semiconductor nanocrystals [121, 122] (see table 5.7). The measurement of $\mathrm{n}_{2}$ using CA Z-scan technique did not give detectable changes of post/pre-focal transmittance intensity within the measurement sensitivity and intensity range for the Ni doped glass-ceramics.
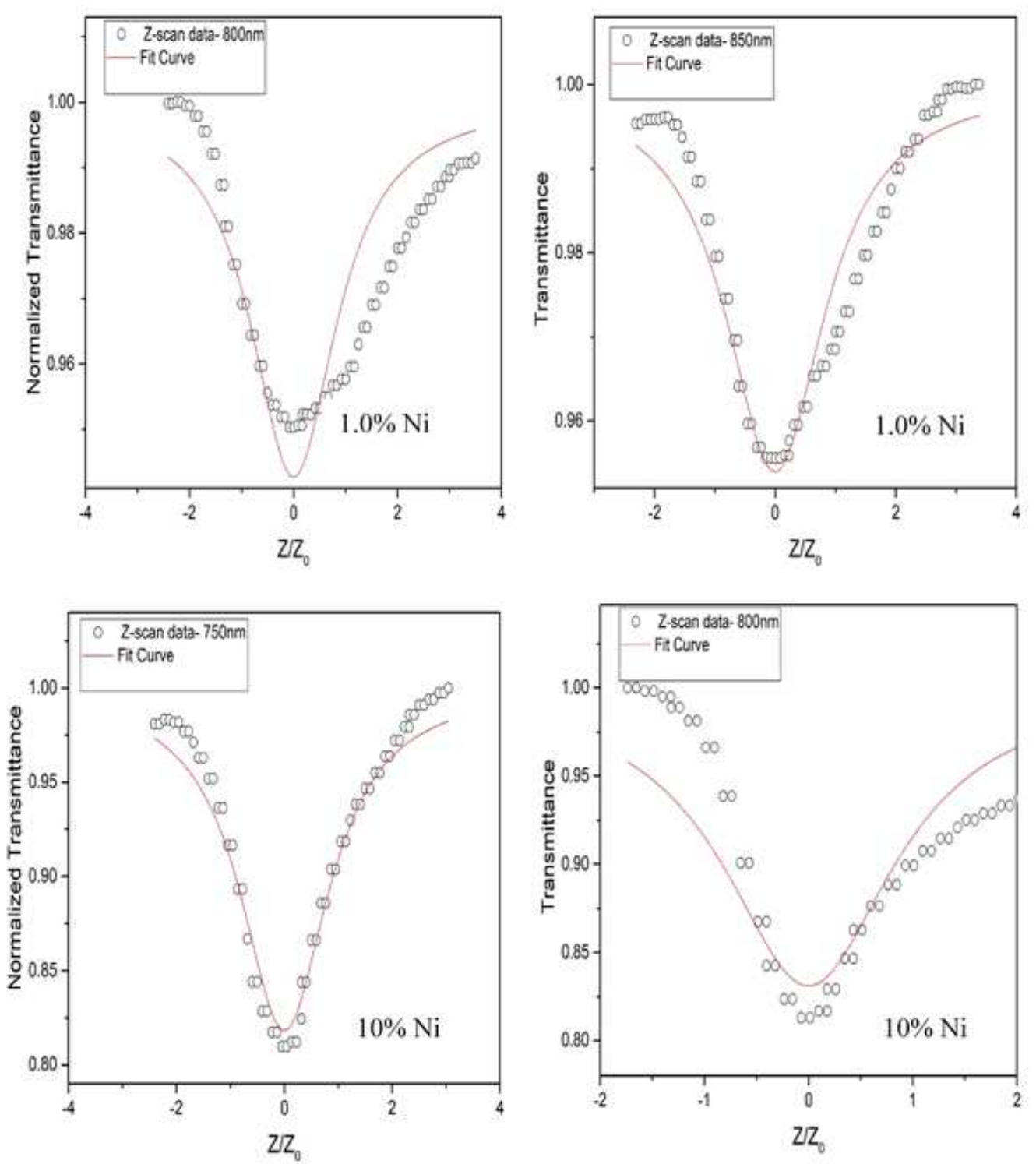

Figure 5.13: Z-scan results in the open-aperture mode for sample $1.0 \%$ and $10 \% \mathrm{Ni}$ at $750 \mathrm{~nm}, 800$ and $850 \mathrm{~nm}$.

Two glass-ceramic samples showed nonlinear absorption using OA Z-scan technique for GC2 $(1.0 \% \mathrm{Ni})$ at wavelengths $800 \& 850 \mathrm{~nm}$, and GC4 $(10.0 \% \mathrm{Ni})$ at wavelength $750 \& 800 \mathrm{~nm}$. Figure 5.13 shows OA Z-scan traces for the $1.0 \%(\lambda=800 \& 850 \mathrm{~nm})$ and $10.0 \%(\lambda=750 \& 800 \mathrm{~nm}) \mathrm{Ni}$ doped GCs. An inverted-bell shaped transmittance 
Table 5.7: Laser excitation $(\lambda)$, nolinear absorption $(\beta)$ and nolinear refractive index $\left(\mathrm{n}_{2}\right)$ in materials.

\begin{tabular}{|c|c|c|c|}
\hline Host glasses & $\lambda(\mathrm{nm})$ & $\mathrm{n}_{2}\left(\mathrm{~cm}^{2} / \mathrm{W}\right)$ & $\beta(\mathrm{cm} / \mathrm{W})$ \\
\hline PZABP: $5 \% \mathrm{Ni}(\mathrm{G})$ & 800 & $3.54 \times 10^{-14}$ & \\
\hline \multirow[t]{2}{*}{ PZABP: 1\%ZnNiTe (GC2) } & 800 & & $2.53 \times 10^{-10}$ \\
\hline & 850 & & $2.76 \times 10^{-10}$ \\
\hline \multirow[t]{2}{*}{ PZABP: 10\%ZnNiTe (GC4) } & 750 & & $7.98 \times 10^{-10}$ \\
\hline & 800 & & $7.35 \times 10^{-10}$ \\
\hline Borosilicate: CdS NCs [127] & 770 & $-2.16 \times 10^{-12}$ & $63.2 \times 10^{-10}$ \\
\hline Vycore: InP NCs [128] & 850 & $3 \times 10^{-12}$ & \\
\hline Silicate: $\mathrm{Cu}[129]$ & 770 & $5 \times 10^{-11}$ & \\
\hline Silicate: Ni [129] & 770 & $17 \times 10^{-11}$ & \\
\hline Silicate: $\mathrm{CuNi}$ [129] & 770 & $68 \times 10^{-11}$ & \\
\hline Phosphate [130] & 532 & $-9.9 \times 10^{-15}$ & $3.9 \times 10^{-10}$ \\
\hline Borate (SNBE) [131] & 700 & $0.23 \times 10^{-14}$ & $1.9 \times 10^{-10}$ \\
\hline Borate (SNBEA-31) [131] & 800 & $1.19 \times 10^{-14}$ & $0.3 \times 10^{-10}$ \\
\hline Borate (BZB) [131] & 800 & $0.15 \times 10^{-15}$ & $10.4 \times 10^{-10}$ \\
\hline Borate (BBW) [132] & 780 & $0.786 \times 10^{-14}$ & $2.54 \times 10^{-10}$ \\
\hline Borate (BBW-4) [132] & 780 & $1.099 \times 10^{-14}$ & $3.27 \times 10^{-10}$ \\
\hline Oxyfluoroborate [133] & 700 & $2.5 \times 10^{-15}$ & $0.3 \times 10^{-10}$ \\
\hline Tellurite: $5 \mathrm{Nb}_{2} \mathrm{O}_{5}[134]$ & 532 & $1.92 \times 10^{-15}$ & $6.0 \times 10^{-10}$ \\
\hline Tellurite: $5 \mathrm{CdO}$ [134] & 532 & $4.0 \times 10^{-15}$ & $8.0 \times 10^{-10}$ \\
\hline Tellurite: $5 \mathrm{WO}_{3}[134]$ & 532 & $3.23 \times 10^{-15}$ & $7.9 \times 10^{-10}$ \\
\hline Phospho-tellurite: ZnTe NCs [135] & 800 & & $0.23 \times 10^{-10}$ \\
\hline
\end{tabular}

with a minimum at focus, $\mathrm{Z}=0$ supports the reverse saturation absorption. The transmittance data was theoretically fitted to the nonlinear transmittance equation, 4.8 for the two-photon absorption (TPA) process. The calculated TPA coefficient $(\beta)$ for the GC2 is $2.53 \times 10^{-10} \mathrm{~cm} / \mathrm{W}(\lambda=800 \mathrm{~nm})$ and $2.76 \times 10^{-10} \mathrm{~cm} / \mathrm{W}(\lambda=850 \mathrm{~nm}) ;$ and for GC4 is $7.98 \times 10^{-10} \mathrm{~cm} / \mathrm{W}(\lambda=750 \mathrm{~nm})$ and $7.35 \times 10^{-10} \mathrm{~cm} / \mathrm{W}(\lambda=800 \mathrm{~nm})$, respectively. It is noted that $\beta$ does not change significantly with wavelength, but increase with $\mathrm{Ni}$ concentration due to the bound electronic effects and TPA. The laser energy $(\hbar \omega)$ used in this work meet the TPA condition, $\mathrm{E}_{g}<2 \hbar \omega<2 \mathrm{E}_{g}$, where $\mathrm{E}_{g}$ is the energy bandgap. Therefore, the small decrease of $\mathrm{E}_{g}(3.77$ to $3.72 \mathrm{eV})$ lead to significant increase of $\beta$ for samples, GC2 to GC4. This supports the Dinu's theoretical model for semiconductor glasses (i.e, $\left.\beta \propto 1 /\left(\mathrm{E}_{g}\right)^{3}\right)[136]$. However, we could not neglect the quantum confinement effects because the existence of intraband transition around $533 \mathrm{~nm}$ (see figure 5.4a) attributed to the semiconductor (ZnTe) NCs in GC2 and GC4 samples. The increase of the nonlinear absorption coefficient is the result of the increase of the oscillator strength 
caused by the confinement-induced localization of excitations. In fact, the exciton Bohr radius $\left(\mathrm{a}_{0}\right)$ decreases with the decrease of the size of ZnTe NCs thus the third-order nonlinear optical property increases proportionally to $\left(1 / \mathrm{a}_{0}\right)$ [137]. On comparison, the obtained $\beta$ values are higher than the values of zinc phospho-tellurite glass contain ZnTe quantum dots [135].

\subsubsection{Conclusions}

The structural and thermo-optical properties of glass $(\mathrm{G})$ and glass ceramics (GCs) have been studied. From XRD measurements, the G sample clearly exhibit glassy characteristic and the GC2 exhibit not only the amorphous halo, but also appeared sharp diffraction peaks that could be attributed to the growth of ZnTe quantum dots (QDs) or nanocrystals (NCs). The distribution of phosphate groups, $\mathrm{PO}_{2}^{-}, \mathrm{PO}_{3}^{2-}, \mathrm{PO}_{4}^{3-}$ and $\left(\mathrm{P}_{2} \mathrm{O}_{7}\right)^{4-}$ are determined from the infrared absorbance and Raman spectra. The observed broad infrared absorption bands of G and GCs consist of different structural groups, which are identified through deconvolution of the IR absorption spectrum of G and GC1 samples. The observed longitudinal optical (LO) and transverse optical (TO) phonon modes of ZnTe in GCs are strong evinced by the XRD pattern. The average diameter of $4.25 \mathrm{~nm}$ and $13.35 \mathrm{~nm}$ for the QD and bulk NCs were observed for the thermally annealed (for 10 h at $\left.500{ }^{\circ} \mathrm{C}\right) \mathrm{GC}$ sample (0 wt\% of $\mathrm{Ni}^{2+}$ ions doped) through TEM analysis.

The spin allowed and bulk ZnTe crystal electronic transitions were observed at around 1366, 822, $434 \mathrm{~nm}$ and $533 \mathrm{~nm}$. The crystal field splitting $\left(\mathrm{D}_{q}\right)$ and Racah (B) and the nephelauxetic ratio $(\beta)$ parameters for $\mathrm{G}$ and GCs were reported. The band gap energy $\left(\mathrm{E}_{\text {opt }}\right)$ for direct and indirect transitions were estimated from optical absorption edges. The observed decrease of $\mathrm{E}_{\text {opt }}$ for the $\mathrm{G}$ sample to GCs indicate increase of nonbridging oxygens (NBOs). Under $240 \mathrm{~nm}$ excitation, the emission and decay lifetime measurements were reported. The trend of emission intensity, FWHM and decay lifetimes were similar in GCs, which is a strong evidence to the change of environment surrounding $\mathrm{Ni}^{2+}$ ions in GCs. The $\sigma_{e m i}$ is increased with increase of $\mathrm{Ni}^{2+}$ content in GCs and it is significantly improved compared with the G sample. The higher value of FOM is observed in GC4 $\left(11.06 \times 10^{-14} \mathrm{~cm}^{2}\right.$.sec $)$ among the GCs. 
5.2 Effect of $\mathrm{TeO}_{2}$ environment in $\mathrm{Nd}^{3+}$ doped PZN phosphate glasses for high power lasers97

Time-resolved thermal lens (TL) and thermal relaxation (TR) methods have been applied to determine the thermal diffusivity (D), variation of optical path length with temperature $(\mathrm{ds} / \mathrm{dT})$ and thermal conductivity $(\mathrm{K})$ of glass samples. D for the GCs have decreased (except in $10 \% \mathrm{Ni}$ doped GC) when compared with the G sample which means that the host glass dominates heat transportation due the expectation of low fromation of semiconductor NCs and the dominating crystal imperfections in these GCs. In addition, the $\mathrm{D}$ and $\mathrm{K}$ do not change significantly with increase of $\mathrm{Ni}^{2+}(0.5-5.0$ wt\% $)$ content in GCs. Z-scan measurement shows that GC4 glass showed higher nonlinear absorption coefficient $\left(7.98 \times 10^{-10} \mathrm{~cm} / \mathrm{W}\right)$ among the studied samples. Therefore, the lower $\mathrm{dS} / \mathrm{dT}$, high emission cross-section and FOM of the GC4 sample could be useful for optoelectronic device applications.

\subsection{Effect of $\mathrm{TeO}_{2}$ environment in $\mathrm{Nd}^{3+}$ doped PZN phosphate glasses for high power lasers}

The numerous known $\mathrm{Nd}^{3+}$ doped inorganic glass systems have been deployed for solid state lasers operating around $1.06 \mu \mathrm{m}$ for several decades now. In particular, scientists have witnessed considerable efforts in the development of Nd-doped phosphate glass as laser gain medium in high power and high energy laser systems since the phosphate based compositional high power laser glass explored at Osaka University in 1967 [138]. In general, phosphate glasses have several advantageous unique characteristics over conventional silicate and borate glasses [139]. The high strength and low thermal expansion coefficient with acceptable athermal behaviour of phosphate glasses can increase the thermal loading capability that lead to limit the failure of laser action in glass [140]. However, the poor chemical durability of these systems limit their practical utilization. Thus, inclusion of metal oxides (like $\mathrm{ZnO}, \mathrm{PbO}, \mathrm{Nb}_{2} \mathrm{O}_{5}, \mathrm{TeO}_{2}, \mathrm{GeO}_{2}$, etc.) can improve the thermal stability and chemical durability. Recently, phosphotellurite glass received significant attention as a promising candidate for hybrid micro-structured optical fibers (HMOFs) with tailored dispersion [141]. In fact, the inclusion of mixed glass network formers along with network modifiers in glassy system can favours the refractive index change which is dependent on 
5.2 Effect of $\mathrm{TeO}_{2}$ environment in $\mathrm{Nd}^{3+}$ doped PZN phosphate glasses for high power lasers98 compositional adjustment [142]. The compositional dependent phosphotellurite glasses also exhibit coloration from clear to dark-red-brown that are used as optical filters [143]. Tellurite glass as a host material for rare earth ions is a favourable media for optical fiber amplifiers because of their wide transmission window, high linear and nonlinear indices, good stability and low phonon energy [118]. The low phonon energy and high refractive index of these glasses can enhance the radiative transition rates, which is an advantageous for optically functional glasses. $\mathrm{TeO}_{2}$ - rich glasses contain $\mathrm{TeO}_{4}$ trigonal bipyramids (tpb) structural units that are connected by shared corners. These structural units are converted to $\mathrm{TeO}_{3}$ trigonal pyramidal (tp) units through the formation of intermediate, $\mathrm{TeO}^{3+1}$ polyhedron units by the addition of modifiers or network glass formers.

However, $\mathrm{TeO}_{2}$ rich glasses possess large nonlinear refractive index and dispersion characteristics that could restrict their use in high-power laser systems where self-focusing is an important consideration factor [144]. Therefore, in this work, we systematically analysed optical and luminescence properties of $\mathrm{Nd}^{3+}$ ions with addition of $\mathrm{TeO}_{2}$ at an expense of $\mathrm{ZnO}$ in phosphate glasses. The glass chemical composition is, $29 \mathrm{P}_{2} \mathrm{O}_{5}+(60-\mathrm{x})$ $\mathrm{ZnO}+10 \mathrm{Na}_{2} \mathrm{O}+\mathrm{x} \mathrm{TeO}_{2}+1.0 \mathrm{Nd}_{2} \mathrm{O}_{3},(\mathrm{x}=510,20,30 \& 40 \mathrm{~mol} \%)$.

The sample are named as $\mathrm{x}=5, \mathrm{x}=10, \mathrm{x}=20, \mathrm{x}=30$, and $\mathrm{x}=40 \mathrm{~mol} \%$, respectively, and their significant physical parameters are listed in the following table.

Table 5.8: Physical properties of $\mathrm{Nd}^{3+}$ doped glasses

\begin{tabular}{|c|c|c|c|c|}
\hline Sample & $\begin{array}{c}\text { Thickness } \\
\mathrm{l} \pm 0.001(\mathrm{~mm})\end{array}$ & $\begin{array}{c}\text { Density } \\
\mathrm{d} \pm 0.001\left(\mathrm{~g} / \mathrm{cm}^{3}\right)\end{array}$ & $\begin{array}{c}\text { Refracrive index } \\
\mathrm{n} \pm 0.001\end{array}$ & $\begin{array}{c}\text { Ion concentration } \\
\mathrm{N} \pm 0.01\left(\times 10^{20} \text { ions } / \mathrm{cm}^{3}\right)\end{array}$ \\
\hline $\mathrm{x}=5$ & 1.901 & 3.232 & 2.14 & 1.855 \\
\hline $\mathrm{x}=10$ & 2.129 & 3.542 & 2.18 & 1.896 \\
\hline $\mathrm{x}=20$ & 2.344 & 3.723 & 2.23 & 1.875 \\
\hline $\mathrm{x}=30$ & 2.247 & 3.768 & 2.24 & 1.781 \\
\hline $\mathrm{x}=40$ & 2.166 & 3.894 & 2.26 & 1.734 \\
\hline
\end{tabular}

\subsubsection{Structural analysis: XRD, FT-IR and Raman spectra}

XRD pattern of $\mathrm{Nd}^{3+}$ doped glasses are presented in Figure 5.14. The observed two broad humps in the 17-35 and 35-60 degrees with an absence of crystalline peak shows that the prepared glasses are in amorphous nature.

In order to know the topology information of the studied glasses, Raman and 


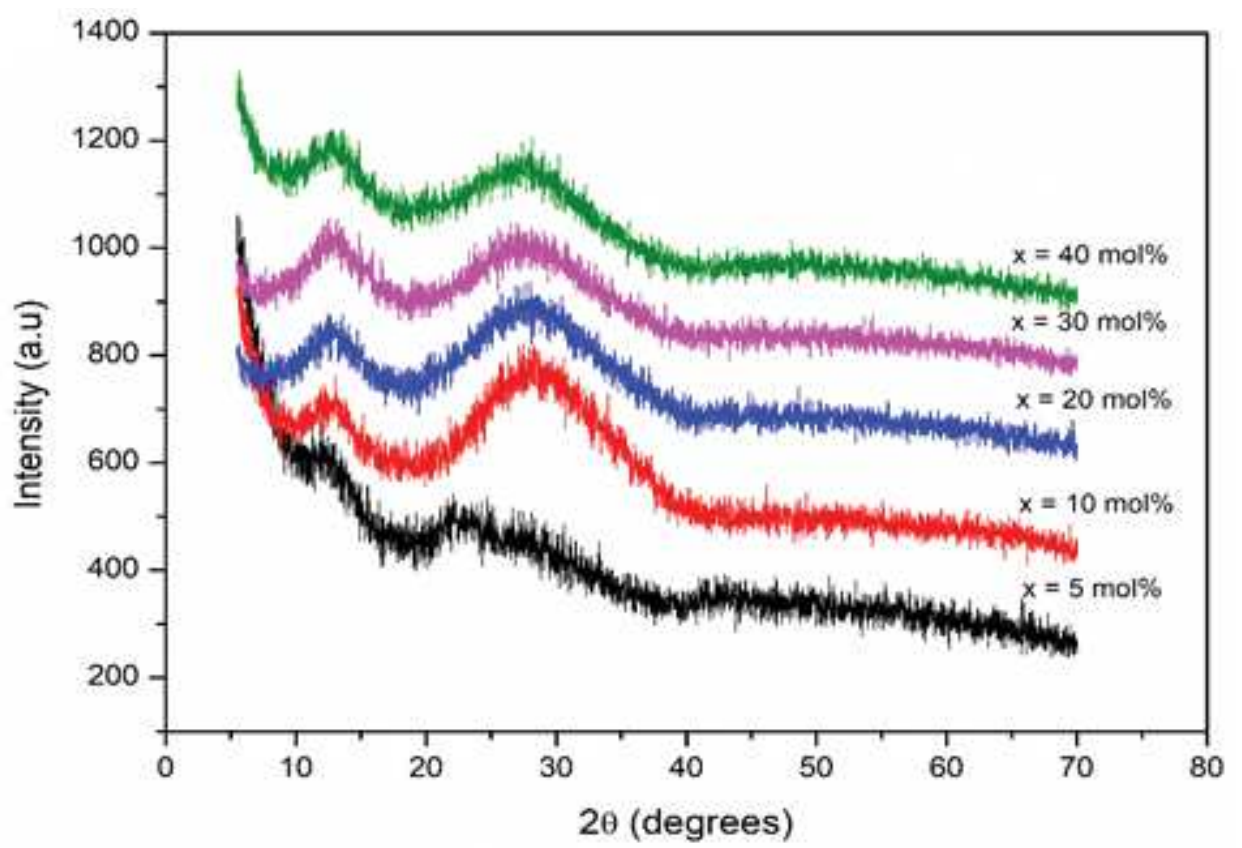

Figure 5.14: XRD patterns of $\mathrm{Nd}^{3+}$ doped glasses

infrared spectroscopic measurements are effective and its spectra are shown in figure 5.15a and 5.15b. The observed significant Raman scattering and IR absorption peak positions and their assignments are presented in Table 5.9.

Table 5.9: Raman and Infrared vibrational bands with assignments.

\begin{tabular}{|c|c|c|}
\hline $\operatorname{Raman}\left(\mathrm{cm}^{-1}\right)$ & Infrared $\left(\mathrm{cm}^{-1}\right)$ & Assignment \\
\hline 303 & & $\mathrm{PO}_{4}$ \\
\hline 478 & & O-Te-O / Te-O-Te linkages \\
\hline & 536 & $\mathrm{P}-\mathrm{O}$ bonds in IN $\mathrm{PO}_{4}$ UNITS \\
\hline 640,650 & 446 & $\begin{array}{c}\mathrm{P}-\mathrm{O} \text { bonds in } \mathrm{P}-\mathrm{O}-\mathrm{P} \text { groups } \\
\nu_{S}(\mathrm{Te}-\mathrm{O}) \text { in } \mathrm{TeO}_{4} / \mathrm{Te}-\mathrm{O}-\mathrm{Te} \text { chain }\end{array}$ \\
\hline & 539 & $\nu_{S}(\mathrm{Te}-\mathrm{O})$ in $\mathrm{TeO}_{4}$ \\
\hline 760 & 750 & $\mathrm{Te}-\mathrm{O}$ in $\mathrm{TeO}_{3}$ or $\mathrm{TeO}_{3+1}$ \\
\hline $870-1300$ & & $\nu_{s}(\mathrm{P}-\mathrm{O}-\mathrm{P})$ in $\mathrm{Q}^{0}$ group \\
\hline & 885 & $\nu_{a s}(\mathrm{P}-\mathrm{O}-\mathrm{P})$ in $\mathrm{Q}^{0}$ group \\
\hline & 1075 & $\nu_{A} s\left(\mathrm{PO}_{4}^{3}-\right)$ in $\mathrm{Q}^{0}$ group \\
\hline
\end{tabular}

Figure 5.15a shows Raman scattering spectra with $488 \mathrm{~nm}$ laser excitation, The Raman scattering peak positions and their structural groups were assigned by considering the phosphate $\left(\mathrm{P}_{2} \mathrm{O}_{5}+\mathrm{ZnO}+\mathrm{Na}_{2} \mathrm{O}\right)[138]$ and phospho-tellurite $\left(50 \mathrm{TeO}_{2}+20 \mathrm{P}_{2} \mathrm{O}_{5}+\right.$ $\left.20 \mathrm{Na}_{2} \mathrm{O}+5 \mathrm{ZnO}+5 \mathrm{ZnF}_{2}\right)[139]$ glasses. The band at low frequency $\left(\sim 400 \mathrm{~cm}^{-1}\right)$ is due to the stretching vibrations of $\mathrm{O}-\mathrm{P}-\mathrm{O}$ [138]. The band around $478 \mathrm{~cm}^{-1}$ is symmetric stretching $\mathrm{O}-\mathrm{Te}-\mathrm{O}$ or $\mathrm{Te}-\mathrm{O}-\mathrm{Te}$ linkages [139][132]. The broadband nature around 380 

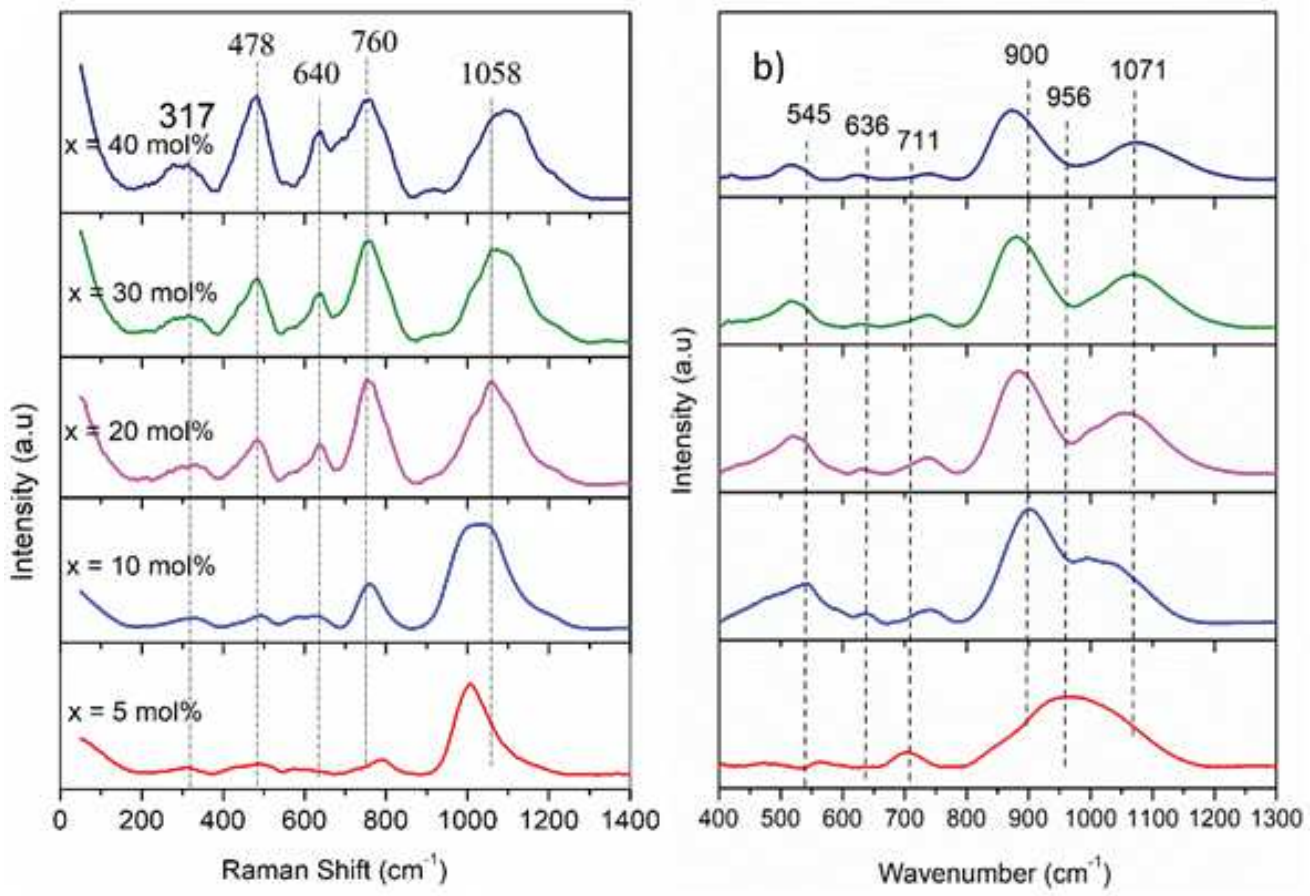

Figure 5.15: Raman and IR absorption spectra of Nd3+ doped glasses.

- $690 \mathrm{~cm}^{-1}$ is due to overlapping of symmetric stretching vibration of $\mathrm{P}-\mathrm{O}$ bonds in $\mathrm{P}-\mathrm{O}-\mathrm{P}$ linkages $\left(\mathrm{Q}^{2}\right)\left(640 \mathrm{~cm}^{-1}\right)$, and symmetric stretching of $\mathrm{Te}-\mathrm{O}$ in $\mathrm{TeO}_{4}$ trigonal bipyramidal units and/or Te-O-Te chain between two four-fold coordinated Te atoms $\left(650 \mathrm{~cm}^{-1}\right)[138,139]$. The intensity increase of bands around 485 and $638 \mathrm{~cm}^{-1}$ with $\mathrm{TeO}_{2}$ content is clear indicative of the formation of $\mathrm{P}-\mathrm{O}-\mathrm{Te}$ linkages due to the equal electronegativity of $\mathrm{P}_{2} \mathrm{O}_{5}$ (2.19) and $\mathrm{TeO}_{2}$ (2.1) thus the bonding of oxygen atoms with change of composition [3]. The $\sim 760 \mathrm{~cm}^{-1}$ is associated to the stretching vibrations of $\mathrm{Te}-\mathrm{O}$ in $\mathrm{TeO}_{3}$ trigonal pyramidal units (or $\mathrm{TeO}_{3+1}$ units) [139][139]. The broadband of higher frequency region $\left(870-1300 \mathrm{~cm}^{-1}\right)$ is ascribed to stretching vibrations $\left(\mathrm{PO}_{2}\right.$ and $\mathrm{PO}_{4}$ ) of nonbridging oxygens connected to phosphorus $(\mathrm{P}-\mathrm{O}-\mathrm{P})$ in metaphosphate groups [139]. Note that Raman scattering maxima $\left(1010-1093 \mathrm{~cm}^{-1}\right)$ is situated at lower frequency side compared with $\mathrm{P}_{2} \mathrm{O}_{5}+\mathrm{ZnO}+\mathrm{Na}_{2} \mathrm{O}$ phosphate glass $\left(1164 \mathrm{~cm}^{-1}\right)$. In general, the highest Raman scattered peak indicate the phonon energy of an optical material. For instant, the highest intensity is $\sim 1010 \mathrm{~cm}^{-1}$ for $\mathrm{x}=5$ and $10 \mathrm{~mol} \% \mathrm{TeO}_{2}$, and equal intense intensity of bands $\left(760 \mathrm{~cm}^{-1}, \mathrm{Te}-\mathrm{O}\right)$ and $\left(1063,1076\right.$ and $1098 \mathrm{~cm}^{-1}$, $\mathrm{P}-\mathrm{O}-\mathrm{P}$ ) for the $\mathrm{x}=20,30$ and $40 \mathrm{~mol} \% \mathrm{TeO}_{2}$ in glasses. In fact, increasing of $\mathrm{TeO}_{2}$ content can replace the stronger $\mathrm{P}-\mathrm{O}$ bonds by $\mathrm{Te}-\mathrm{O}$ bonds which alters significantly 
5.2 Effect of $\mathrm{TeO}_{2}$ environment in $\mathrm{Nd}^{3+}$ doped PZN phosphate glasses for high power lasers101 the phonon energy of the studied system forming a majority $\mathrm{P}-\mathrm{O}-\mathrm{Te}$ linkages beside of isolated tetrahedral $\mathrm{PO}_{4}$. The lower phonon energy and higher refractive index of the present glass systems compared with phosphate ones, indicate that these material can be efficient for enhancing Near-IR laser amplification.

Figure 5.15b shows the compositional dependence of IR absorption spectra of glasses. Generally, the absorption bands between $650-800 \mathrm{~cm}^{-1}$ wavenumbers were already reported in $\mathrm{TeO}_{2}$ containing materials and are attributed to stretching vibrations of Te-O bonds in $\mathrm{TeO}_{3+1}$ and $\mathrm{TeO}_{3}$ units respectively, suggesting a progressive conversion of $\mathrm{TeO}_{4}$ to $\mathrm{TeO}_{3}$ tellurite polyhedra in the glass network [145]. The observed absorption band between $650-780 \mathrm{~cm}^{-1}$ is shifted from $700 \mathrm{~cm}^{-1}$ to $745 \mathrm{~cm}^{-1}$ with $\mathrm{TeO}_{2}$ content (greater than $5 \mathrm{~mol} \%$ ) in phosphate glasses. In addition, an another band at $637 \mathrm{~cm}^{-1}$ is active with $\mathrm{TeO}_{2}$ content (greater than $5 \mathrm{~mol} \%$ ) in phosphate glasses, due to $\mathrm{TeO}_{2}$ units. Therefore, we suggest that the our systems exhibit both $\mathrm{TeO}_{3}$ and $\mathrm{TeO}_{4}$ units. The band between $400-600 \mathrm{~cm}^{-1}\left(\sim 536 \mathrm{~cm}^{-1}\right)$ is attributed to the deformation P-O bonds in $\mathrm{PO}_{4}$ terahedral units. A broadband is observed for high phosphate content of glass $\left(5 \mathrm{~mol} \% \mathrm{TeO}_{2}\right)$ is associated to the symmetric and asymmetric stretching modes of $\mathrm{PO}_{3}$ groups. With increasing $\mathrm{TeO}_{2}, 1075 \mathrm{~cm}^{-1}$ band is attributed to the asymmetric stretching vibration of $\mathrm{P}-\mathrm{O}-\mathrm{P}$ groups and asymmetric stretching vibration $\mathrm{P}=\mathrm{O}$ (or $\mathrm{O}-$ $\mathrm{P}-\mathrm{O})$ bond in $\mathrm{PO}_{3}$ group. The observed clear splitting and intensity variation at high frequency region is with increasing of $\mathrm{TeO}_{2}$ content, suggesting a depolymerization of the metaphosphate chains with a possible insertion of $\mathrm{TeO}_{n}$ units through $\mathrm{P}-\mathrm{O}-\mathrm{Te}$ bonds.

\subsubsection{Optical absorption spectra}

Figure 5.16 shows the room temperature UV-Visible and near-infrared absorption spectra of $\mathrm{Nd}^{3+}$ doped glasses. The absorption edges not sharply defined is an indicative of amorphous nature which is also confirmed by the occurrence of a broad diffraction halo $\left(2 \theta \cong 15-40^{\circ}\right)$ and absence of sharp Bragg peaks (Figure 5.14). The broad diffuse scattering at lower angles exemplifies the presence of short-range order in studied samples. The observed sharp peaks are associated to the ground state energies of $\mathrm{Nd}^{3+}: 4 \mathrm{f}^{3}-4 \mathrm{f}^{3}$ intra-electronic transitions, which are ${ }^{4} \mathrm{I}_{9 / 2} \rightarrow{ }^{4} \mathrm{~F}_{3 / 2},{ }^{4} \mathrm{I}_{9 / 2} \rightarrow{ }^{4} \mathrm{~F}_{5 / 2}+{ }^{2} \mathrm{H}_{9 / 2},{ }^{4} \mathrm{I}_{9 / 2} \rightarrow{ }^{4} \mathrm{~F}_{7 / 2}$ 


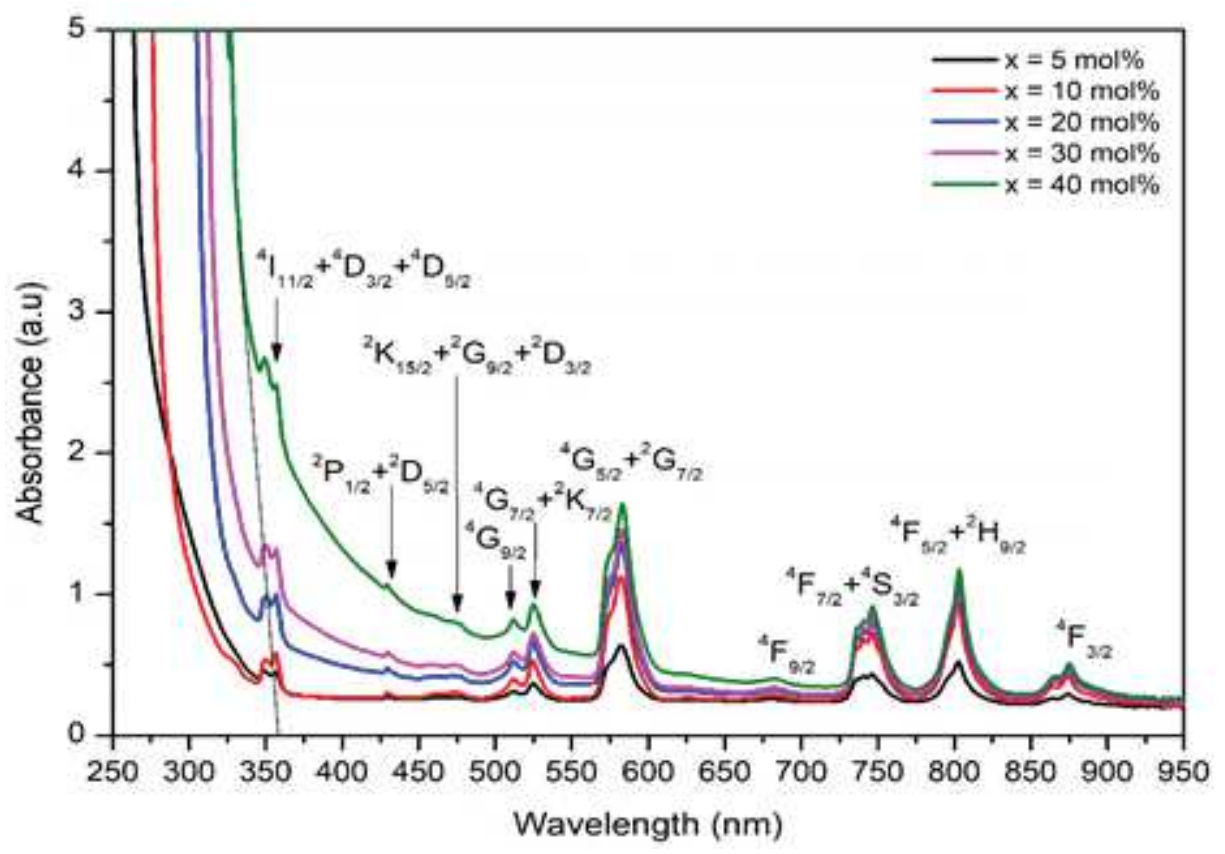

Figure 5.16: Optical absorption spectra of $\mathrm{Nd}^{3+}$ doped glasses.

$+{ }^{4} \mathrm{~S}_{3 / 2},{ }^{4} \mathrm{I}_{9 / 2} \rightarrow{ }^{4} \mathrm{~F}_{9 / 2},{ }^{4} \mathrm{I}_{9 / 2} \rightarrow{ }^{2} \mathrm{H}_{11 / 2},{ }^{4} \mathrm{I}_{9 / 2} \rightarrow{ }^{4} \mathrm{G}_{5 / 2}+{ }^{2} \mathrm{G}_{7 / 2},{ }^{4} \mathrm{I}_{9 / 2} \rightarrow{ }^{2} \mathrm{~K}_{13 / 2}+{ }^{4} \mathrm{G}_{7 / 2}$, ${ }^{4} \mathrm{I}_{9 / 2} \rightarrow{ }^{4} \mathrm{G}_{9 / 2},{ }^{4} \mathrm{I}_{9 / 2} \rightarrow{ }^{2} \mathrm{~K}_{15 / 2}+{ }^{2} \mathrm{G}_{9 / 2}+{ }^{2} \mathrm{D}_{3 / 2},{ }^{4} \mathrm{I}_{9 / 2} \rightarrow{ }^{4} \mathrm{G}_{11 / 2},{ }^{4} \mathrm{I}_{9 / 2} \rightarrow{ }^{2} \mathrm{P}_{1 / 2}$ and ${ }^{4} \mathrm{I}_{9 / 2} \rightarrow$ ${ }^{4} \mathrm{I}_{11 / 2}+{ }^{4} \mathrm{D}_{3 / 2}+{ }^{4} \mathrm{D}_{5 / 2}$, centered at $875,805,749,684,628,587,527,514,478,461,431$ $\mathrm{nm}$, respectively. The red shifted absorption edge $(300-360 \mathrm{~nm})$ with increasing $\mathrm{TeO}_{2}$ content is due to the electron transition transfer in between valance and conduction ( $\mathrm{V}$ - C) bands. The cut-off wavelength can determine the energy gap between $\mathrm{V}-\mathrm{C}$ bands, thus the optical band gap energies $\left(\mathrm{E}_{\text {opt }}\right)$ are estimated from Davis and Mott theory [16] and plots of $(\alpha \mathrm{h} \nu)^{2}$ and $(\alpha \mathrm{h} \nu)^{1 / 2}$ as a function of photon energy (h $\left.\nu\right)$ that are shown in figure 5.17a and 5.17b. According to Tauc's relation [146], the indirect allowed transitions are valid for amorphous materials because their absorption coefficients are very high in the range of $10^{4}-10^{5} \mathrm{~cm}^{-1}$. Therefore, it is observed that $\mathrm{E}_{\text {opt }}$ for the indirect allowed transitions with $\mathrm{x}$ mol\% of $\mathrm{TeO}_{2}$ decreases monotonically from 4.16 to $3.56 \mathrm{eV}$, as shown in Figure 5.18a . In general, the band gap of crystalline $\mathrm{P}_{2} \mathrm{O}_{5}$ is $\sim 8 \mathrm{eV}$. The crystalline $\mathrm{TeO}_{2}$ exhibits three crystalline polymorphs of tellurium dioxides, $\alpha-\mathrm{TeO}_{2}, \beta-\mathrm{TeO}_{2}$ and $\gamma-\mathrm{TeO}_{2}$. The $\alpha-\mathrm{TeO}_{2}$ crystalline lattice is the first to form compared with $\beta-\mathrm{TeO}_{2}$ and $\gamma-\mathrm{TeO}_{2}$ in vitreous state. The band gap of $\alpha-\mathrm{TeO}_{2}$ is $\sim 2.78-3.50 \mathrm{eV}$ [147]. In addition, $\mathrm{ZnO}$ also possess a band gap of $3.40 \mathrm{eV}$. The $\mathrm{E}_{\text {opt }}$ values of the present systems are close with crystalline $\alpha-\mathrm{TeO}_{2}$ and $\mathrm{ZnO}$. In fact, the $\mathrm{ZnO}$ and $\mathrm{TeO}_{2}$ content is about $40-60 \%$ 

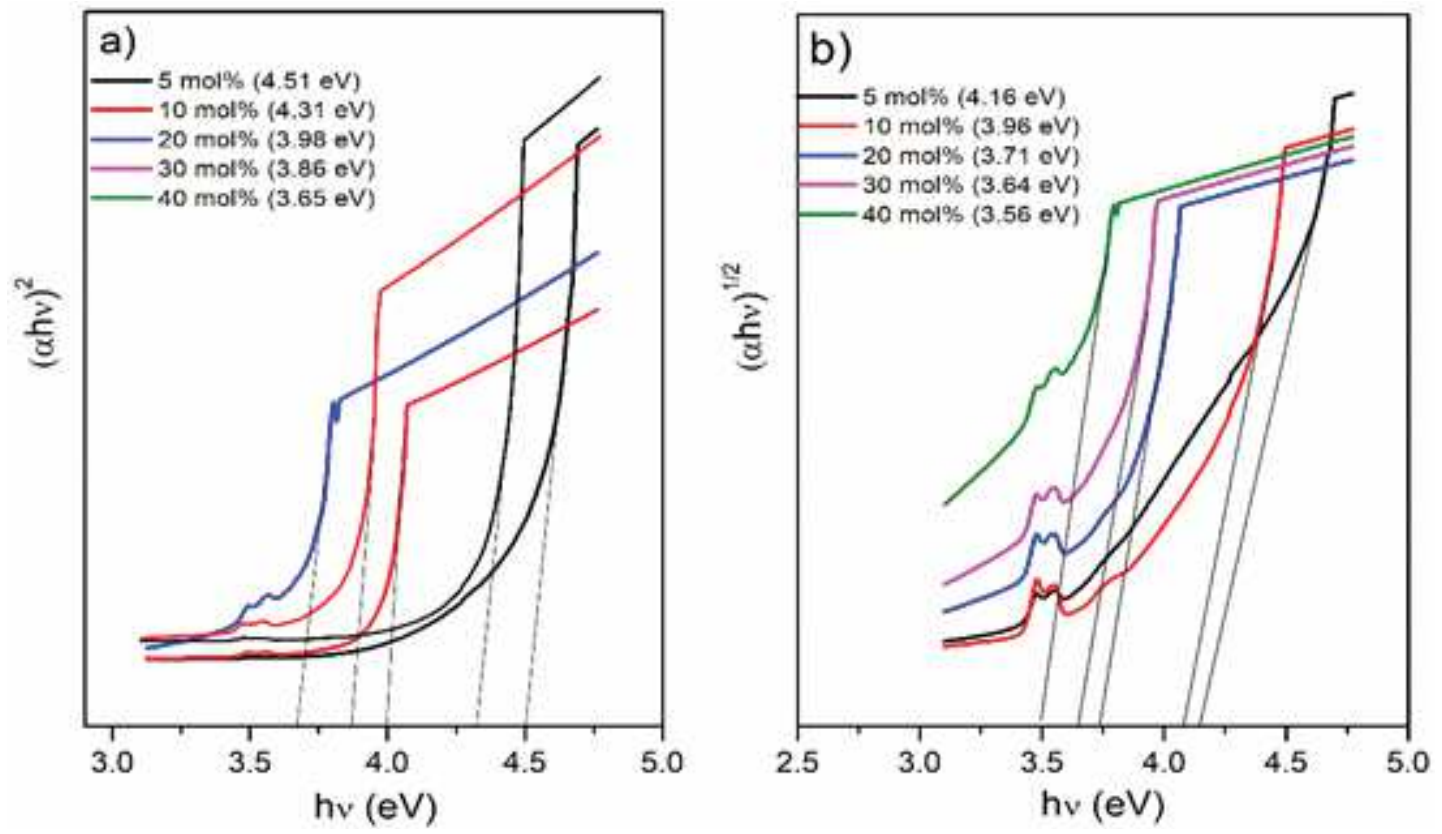

Figure 5.17: Plots of $(\alpha \mathrm{h} \nu)^{2}$ and $(\alpha \mathrm{h} \nu)^{1 / 2}$ as a function of photon energy $(\mathrm{h} \nu)$ for $\mathrm{Nd}^{3+}$ doped glasses

of the studied glass composition thus greatly influencing the electronic property of the phosphates. In $\mathrm{Nd}^{3+}: \mathrm{P}_{2} \mathrm{O}_{5}+\mathrm{ZnO}+\mathrm{Na}_{2} \mathrm{O}+\mathrm{TeO}_{2}$ glass, the fundamental transitions from the electronic bands are expected to be $2 \mathrm{p}(\mathrm{O}) \rightarrow 3 \mathrm{p}(\mathrm{P})$ in $\mathrm{P}-\mathrm{O}$ bond, $2 \mathrm{p}(\mathrm{O}) \rightarrow$ $5 \mathrm{~s}(\mathrm{Te})$ in $\mathrm{Te}-\mathrm{O}$ bond and $2 \mathrm{p}(\mathrm{O}) \rightarrow 3 \mathrm{~d}(\mathrm{Zn})$ in $\mathrm{Zn}-\mathrm{O}$ bond. Considering the band energies and separation between cation (P, Te, Zn) and oxygen $(\mathrm{O})$ states, the decrease of $\mathrm{E}_{\text {opt }}$ with increase of $\mathrm{TeO}_{2}$ content in glass can be explained as follows: the amount of non-bridging oxygens are increased with the reduction of $\mathrm{ZnO}$ content due to the increase of $2 \mathrm{p}$ oxygen energy levels. The raise of $2 \mathrm{p}$ oxygen levels shorten the separation between the $5 \mathrm{~s}(\mathrm{Te})$ and $2 \mathrm{p}(\mathrm{O})$ levels leading to the broadening of the valance band, and thus diminishing the $\mathrm{E}_{\text {opt }}$. The observed decrease trend of $\mathrm{E}_{\text {opt }}$ with increase $\mathrm{TeO}_{2}$ is in accordance with the theoretical prediction that a increase of the covalent character of the bonds causes a decrease in the absorption edge energy. A similar decrease of $\mathrm{E}_{\text {opt }}$ has been observed in lead-containing borate and silicate glasses [148]. The increase of the molar volume $\left(\mathrm{V}_{m}\right)$ with $\mathrm{x} \mathrm{mol \%}$, as shown in figure 5.18b, is an indicative of expanding network structure of the studied glasses through formation of non-bridging oxygens (NBOs).

Using $\mathrm{E}_{\text {opt }}$ values, the refractive index $(\mathrm{n})$ and electronic polarizability of oxide ions $\left(\alpha_{O^{2-}}\right)$ were determined from the following equations [149]: 

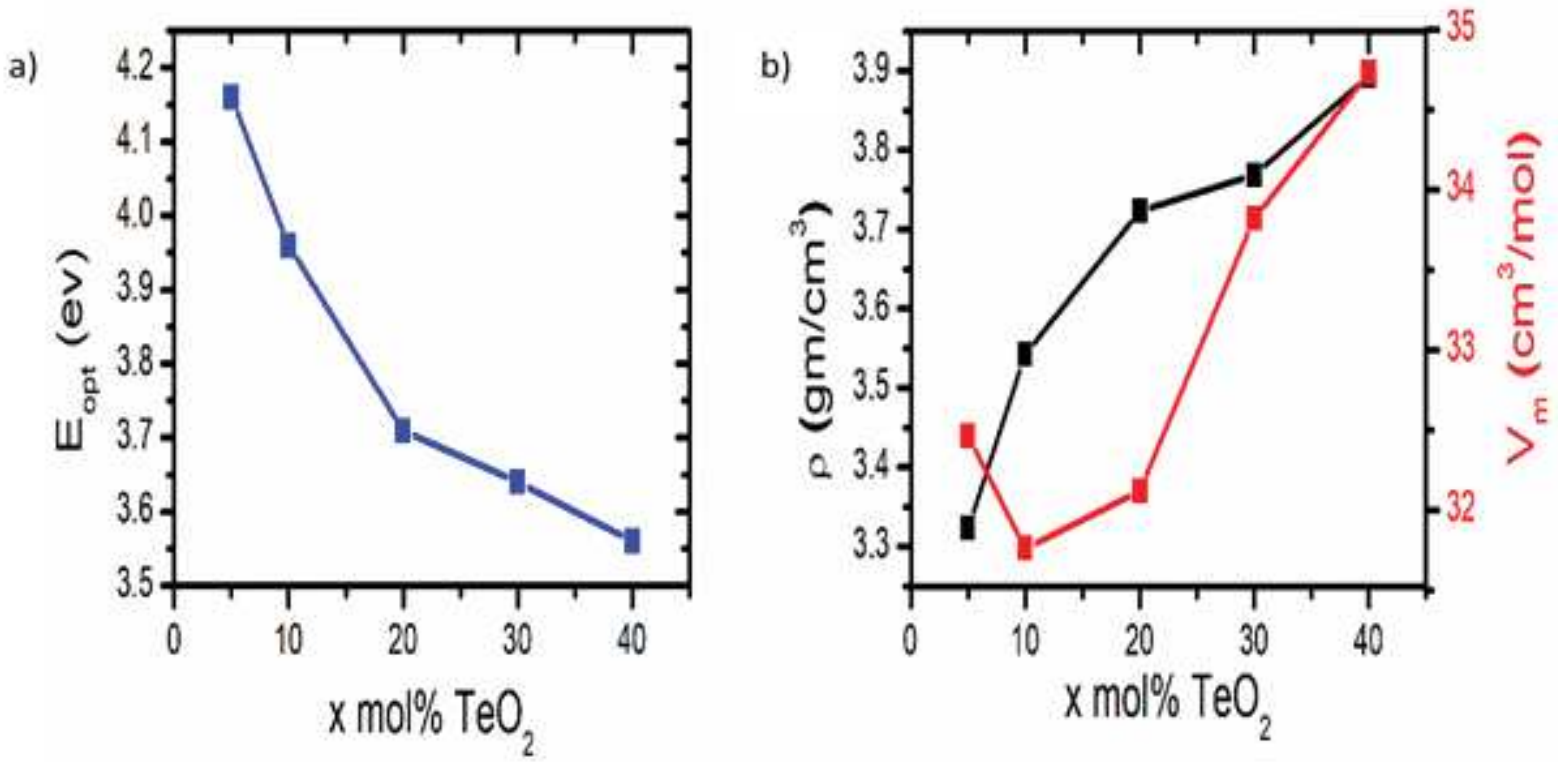

Figure 5.18: Plots of (a) optical band gap, and b) density and molar volume as a function of $\mathrm{x} \mathrm{mol} \% \mathrm{TeO}_{2}$ in glasses.

$$
\begin{gathered}
\frac{n^{2}-1}{n^{2}+1}=1-\sqrt{\frac{E_{\text {opt }}}{20}} \\
\alpha_{O^{2-}}=\left[\frac{V_{m}}{2.52}\left(1-\sqrt{\frac{E_{\text {opt }}}{20}}\right)-\sum \alpha_{\text {cat. }}\right] /\left(N_{O^{2}-}\right)
\end{gathered}
$$

where, $\mathrm{V}_{m}$ is the molar volume and $\mathrm{N}_{O^{2-}}$ is the number of oxide ions in chemical composition. $\alpha_{\text {cat }}$ is the molar cation polarizability and are $0.021,0.283,0.175,0.242$ and $1.25 \AA^{3}$ for $\mathrm{P}^{+}, \mathrm{Zn}^{+}, \mathrm{Na}^{+}, \mathrm{Te}^{6+}$ and $\mathrm{Nd}^{3+}$ ions [150, 151]. Figure 5.19a and 5.19b shows the compositional dependence of refractive index (n) and polarizability of oxide ions $\alpha_{O^{2-}}$ with $\mathrm{x}$ mol\% in glasses. $\mathrm{n}$ increased from 2.14 to 2.26 , which is consistent with molar volume. It also increases from 2.96 to 3.18 with $\mathrm{x}$. The addition of $\mathrm{TeO}_{2}$ as second network glass former to phosphate glass lead to enhancing the electron density around oxide ions. The obtained $\alpha_{O^{2-}}$ is rather large and correspond to $\mathrm{P}_{2} \mathrm{O}_{5}-\mathrm{SiO}_{2}, \mathrm{P}_{2} \mathrm{O}_{5}-\mathrm{Bi}_{2} \mathrm{O}_{3}, \mathrm{La}_{2} \mathrm{O}_{3}-$ $\mathrm{Ga}_{2} \mathrm{O}_{3}$ and $\mathrm{TeO}_{2}-\mathrm{ZnO}$ glasses $[150,152]$. The average polarizability of cations does not change which may due to nearly equal polarizabilities of $\mathrm{Te}^{6+}$ and $\mathrm{Zn}^{+}$. Nevertheless, the molecular polarization should also be increased and dominated by oxide ions in glasses because polarizability of cations are lower than those of oxide ions. The observed increase of optical basicity $\left(\Lambda=1.62\left(1-1 / \alpha_{O^{2-}}\right)\right)$ with $\mathrm{x}$ results from the increase of negative 
5.2 Effect of $\mathrm{TeO}_{2}$ environment in $\mathrm{Nd}^{3+}$ doped PZN phosphate glasses for high power lasers105
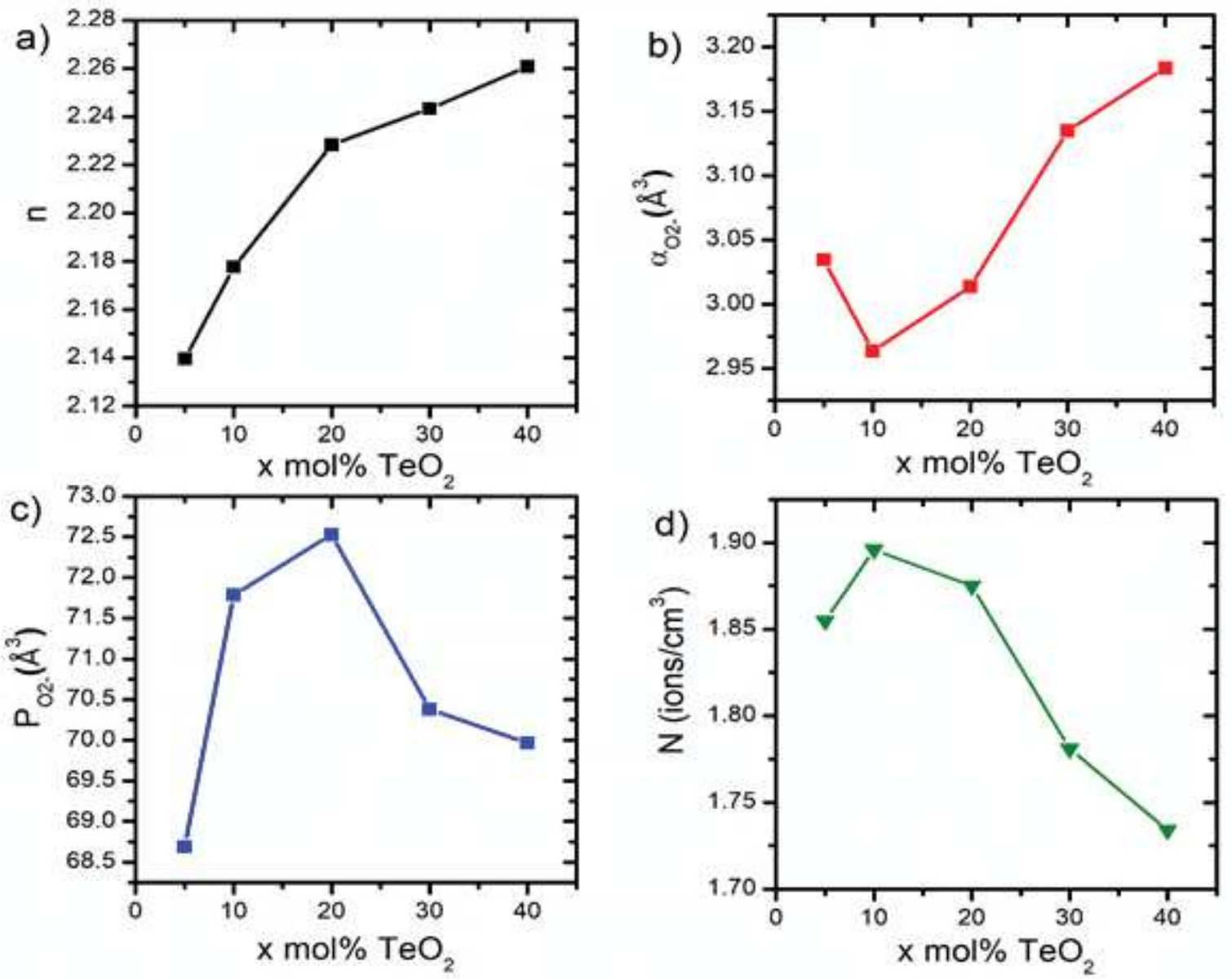

Figure 5.19: (a) Refractive index (n), (b) oxygen polarizability $\alpha_{O^{2-}}$, (c) oxygen packing density $\mathrm{P}_{O^{2-}}$ and $(\mathrm{d})$ ion concentration $(\mathrm{N})$ as a function of $\mathrm{x} \mathrm{mol} \% \mathrm{TeO}_{2}$ in glass.

Table 5.10: Molar volume, cation polarizability, $\alpha_{\text {cat. }}$, (b) number of oxide ions, $\mathrm{N}_{O^{2-}}$, (c) oxygen polarizability, $\alpha_{O^{2-}}$, (c) oxygen packing density, $\mathrm{P}_{O^{2-}}$, and optical basicity $(\Lambda)$ in glasses.

\begin{tabular}{|c|c|c|c|c|c|c|}
\hline $\begin{array}{c}\text { Glass } \\
\mathrm{mol}_{\%} \mathrm{TeO}_{2}\end{array}$ & $\begin{array}{c}\mathrm{V}_{m} \\
\left(\mathrm{~cm}^{3} / \mathrm{mol} \%\right)\end{array}$ & $\begin{array}{c}\alpha_{\text {cat. }} \\
A^{3}\end{array}$ & $\begin{array}{c}\mathrm{N}_{O^{2-}} \\
\AA^{3}\end{array}$ & $\begin{array}{c}\alpha_{O^{2-}} \\
\AA^{3}\end{array}$ & $\begin{array}{c}\mathrm{P}_{O^{2-}} \\
A^{3}\end{array}$ & $\Lambda$ \\
\hline $\mathrm{x}=5$ & $32.46 \pm 0.11$ & $0.02 \pm 0.01$ & $2.23 \pm 0.03$ & $3.03 \pm 0.01$ & $68.69 \pm 0.21$ & $1.12 \pm 0.05$ \\
\hline $\mathrm{x}=10$ & $31.46 \pm 0.25$ & $0.28 \pm 0.04$ & $2.28 \pm 0.02$ & $2.96 \pm 0.06$ & $71.79 \pm 0.28$ & $1.11 \pm 0.02$ \\
\hline $\mathrm{x}=20$ & $32.12 \pm 0.18$ & $0.18 \pm 0.02$ & $2.33 \pm 0.06$ & $3.01 \pm 0.04$ & $72.53 \pm 0.19$ & $1.12 \pm 0.04$ \\
\hline $\mathrm{x}=30$ & $33.82 \pm 0.21$ & $0.25 \pm 0.07$ & $2.38 \pm 0.04$ & $3.13 \pm 0.08$ & $70.38 \pm 0.25$ & $1.14 \pm 0.08$ \\
\hline $\mathrm{x}=40$ & $34.73 \pm 0.24$ & $1.25 \pm 0.05$ & $2.43 \pm 0.02$ & $3.18 \pm 0.05$ & $69.96 \pm 0.16$ & $1.15 \pm 0.05$ \\
\hline
\end{tabular}

charge on the oxygen atom increases the covalency between cation and oxygen bond. The oxygen packing density $\mathrm{P}_{O^{2-}}$ was determined from molar volume and number of oxide ions using the expression, $\mathrm{P}_{O^{2-}}=1000 \times \mathrm{N}_{O^{2-}} / \mathrm{V}_{m}$ [151]. Figure 5.19c shows variation of $\mathrm{P}_{O^{2-}}$ with $\mathrm{x}$. The decrease $\mathrm{P}_{\mathrm{O}^{2-}}$ at higher $\mathrm{TeO}_{2}$ content $(>\mathrm{x}=20 \mathrm{~mol} \%)$ reveals that the structure of the glass is loosely packed. The trend of rare earth ion concentration $(\mathrm{N})$ with $\mathrm{x}$ is followed with $\mathrm{P}_{O^{2-}}$ (see figure $5.19 \mathrm{~d}$ ), since it is related with $\mathrm{V}_{m}$ and $\rho$ of the 
5.2 Effect of $\mathrm{TeO}_{2}$ environment in $\mathrm{Nd}^{3+}$ doped PZN phosphate glasses for high power lasers106 glasses. The detailed estimated data is given in Table 5.10.

The radiative transitions within the $4 \mathrm{f}$ configuration of $\mathrm{Nd}^{3+}$ ions can be analysed from the Judd-Ofelt theory $[32,33]$ using absorption spectra of $\mathrm{Nd}^{3+}$ doped glasses. The experimental oscillator strengths $\left(\mathrm{f}_{\text {exp }}\right)$ for the observed absorption transitions are estimated by using the equation, 2.11, and are listed in Table 5.11 along with r.m.s (using equation 2.12) deviation. The low r.m.s $\left(0.40-1.15 \times 10^{-6}\right)$ deviation between experimental and calculated oscillator strengths indicates the validity of Judd-Ofelt theory. It worth to note the most intense absorption band at $17185 \mathrm{~cm}^{-1}$ is due to the ${ }^{4} \mathrm{I}_{9 / 2} \rightarrow$ ${ }^{4} \mathrm{G}_{5 / 2}+{ }^{2} \mathrm{G}_{7 / 2}$ hypersensitive transition (HST) and is followed by the quadrupole selection rule, $\Delta \mathrm{L} \leq 2, \Delta \mathrm{J} \leq 2, \Delta \mathrm{L} \leq 0$ [26]. It is observed that the oscillator strength of the HST is comparatively higher than other transitions of $\mathrm{Nd}^{3+}$ due to large value of $\left\|\mathrm{U}^{2}\right\|$ double reduced matrix element which indicates the high crystal field asymmetry at the sites of $\mathrm{Nd}^{3+}$ ions.

Table 5.11: The wavenumber $\left(\nu, \mathrm{cm}^{-1}\right)$ and experimental oscillator strength $\left(f_{\text {exp }} \times 10^{-6}\right)$ for the absorption transition of $\mathrm{Nd}^{3+}$.

\begin{tabular}{|c|c|c|c|c|c|c|}
\hline $\begin{array}{l}\text { Transition } \\
\text { from }{ }^{4} \mathrm{I}_{9 / 2}\end{array}$ & $\begin{array}{c}\nu \\
\left(\mathrm{cm}^{-1}\right)\end{array}$ & $\mathrm{x}=5$ & $\mathrm{x}=10$ & $\mathrm{x}=20$ & $\mathrm{x}=30$ & $\mathrm{x}=40$ \\
\hline${ }^{4} \mathrm{~F}_{3 / 2}$ & 11428 & 1.27 & 2.49 & 2.57 & 3.12 & 3.51 \\
\hline${ }^{4} \mathrm{~F}_{5 / 2}+{ }^{2} \mathrm{H}_{9 / 2}$ & 12453 & 5.63 & 11.56 & 11.78 & 13.54 & 14.71 \\
\hline${ }^{4} \mathrm{~S}_{3 / 2}+{ }^{4} \mathrm{~F}_{7 / 2}+{ }^{4} \mathrm{~F}_{7 / 2}$ & 13405 & 5.58 & 11.42 & 11.49 & 12.81 & 14.35 \\
\hline${ }^{4} \mathrm{~F}_{9 / 2}$ & 14684 & 0.53 & 1.27 & 1.02 & 1.11 & 1.34 \\
\hline${ }^{4} \mathrm{G}_{5 / 2}+{ }^{2} \mathrm{G}_{7 / 2}$ & 17182 & 15.42 & 29.57 & 32.25 & 37.48 & 41.55 \\
\hline $\begin{array}{l}{ }^{2} \mathrm{~K}_{13 / 2}+{ }^{4} \mathrm{G}_{7 / 2}+{ }^{4} \mathrm{G}_{7 / 2} \\
+{ }^{4} \mathrm{G}_{9 / 2}+{ }^{4} \mathrm{G}_{9 / 2} \\
\end{array}$ & 19048 & 5.01 & 10.15 & 11.17 & 12.52 & 13.89 \\
\hline $\begin{array}{l}{ }^{2} \mathrm{~K}_{15 / 2}+{ }^{2} \mathrm{G}_{9 / 2} \\
+{ }^{2} \mathrm{D}_{3 / 2}+{ }^{4} \mathrm{G}_{11 / 2}\end{array}$ & 21008 & 1.27 & 2.66 & 2.52 & 2.83 & 2.73 \\
\hline${ }^{2} \mathrm{P}_{1 / 2}$ & 23310 & 0.347 & 1.04 & 1.14 & 1.29 & 0.75 \\
\hline $\begin{array}{l}{ }^{4} \mathrm{D}_{3 / 2}+{ }^{4} \mathrm{D}_{5 / 2} \\
+{ }^{2} \mathrm{I}_{11 / 2}+{ }^{4} \mathrm{D}_{1 / 2}\end{array}$ & 28011 & 5.98 & 13.08 & 14.23 & 15.71 & 19.82 \\
\hline$\delta_{r m s} \times 10^{-6}$ & & \pm 0.41 & \pm 0.97 & \pm 1.16 & \pm 0.84 & \pm 1.14 \\
\hline
\end{tabular}

The best set of Judd-Ofelt intensity parameters, $\Omega_{2}, \Omega_{4}$ and $\Omega_{6}$ for the studied glasses are presented in Table 5.12 along with other hosts. $\Omega_{2}$ parameter is sensitive to the local structure, is an indicator of covalence (or ionicity) of Nd-O bond and asymmetry around the $\mathrm{Nd}^{3+}$ ion. $\Omega_{4}$ and $\Omega_{6}$ are related to the rigidity of host matrix, while $\Omega_{4} / \Omega_{6}$ determine the spectroscopic quality factor $(\chi)$ for the host glass laser materials. With increase of $\mathrm{TeO}_{2}$ at an expense of $\mathrm{ZnO}$, increase covalency bond between $\mathrm{Nd}-\mathrm{O}$ and 
5.2 Effect of $\mathrm{TeO}_{2}$ environment in $\mathrm{Nd}^{3+}$ doped PZN phosphate glasses for high power lasers107 asymmetry around $\mathrm{Nd}^{3+}$ ions which can be explained by electronegativity theory [108][42]

Table 5.12: J-O parameters $\left(\Omega_{\lambda}\right)\left(\times 10^{-20} \mathrm{~cm}^{2}\right)$ and spectroscopic quality factor $(\chi)$ in $\mathrm{Nd}^{3+}$ doped glasses.

\begin{tabular}{|l|c|c|c|c|}
\hline $\begin{array}{l}\text { Glass } \\
\text { mol\% of } \mathrm{TeO}_{2}\end{array}$ & $\Omega_{2}$ & $\Omega_{4}$ & $\Omega_{6}$ & $\chi$ \\
\hline $\mathrm{x}=5$ & $2.17 \pm 0.68$ & $2.35 \pm 0.51$ & $2.44 \pm 0.49$ & $1.07 \pm 0.22$ \\
\hline $\mathrm{x}=10$ & $3.73 \pm 0.71$ & $4.81 \pm 0.84$ & $4.80 \pm 1.05$ & $0.95 \pm 0.08$ \\
\hline $\mathrm{x}=20$ & $3.91 \pm 0.73$ & $5.07 \pm 1.08$ & $4.57 \pm 0.86$ & $1.08 \pm 0.11$ \\
\hline $\mathrm{x}=30$ & $4.59 \pm 0.42$ & $5.73 \pm 1.07$ & $5.11 \pm 1.04$ & $1.29 \pm 0.42$ \\
\hline $\mathrm{x}=40$ & $4.76 \pm 0.91$ & $6.66 \pm 1.08$ & $5.45 \pm 0.98$ & $0.58 \pm 0.02$ \\
\hline Phosphate [153] & 3.28 & 3.54 & 4.67 & 0.76 \\
\hline Tellurite $[154]$ & 2.99 & 2.82 & 2.62 & 1.07 \\
\hline Phosphotellurite [155] & 5.93 & 3.23 & 4.69 & 0.69 \\
\hline Silicate [156] & 5.01 & 2.10 & 4.54 & 0.46 \\
\hline Borotellurite [157] & 10.51 & 5.36 & 10.04 & 0.53 \\
\hline
\end{tabular}

Table 5.13: Emission properties of Nd samples.

\begin{tabular}{|l|c|c|c|c|c|}
\hline Sample & \multicolumn{5}{|c|}{${ }^{4} \mathrm{~F}_{3 / 2} \rightarrow{ }^{4} \mathrm{I}_{9 / 2}$} \\
\hline & $\begin{array}{c}\mathrm{A}_{R} \\
\left(\mathrm{~s}^{-1}\right)\end{array}$ & $\begin{array}{c}\beta_{\text {exp }} \\
\%\end{array}$ & $\begin{array}{c}\beta_{\text {cal }} \\
\%\end{array}$ & $\begin{array}{c}\Delta \lambda_{\text {eff }} \\
(\mathrm{nm}\end{array}$ & $\begin{array}{c}\sigma_{\text {emi }} \\
\left(\times 10^{-20} \mathrm{~cm}^{2}\right)\end{array}$ \\
\hline $\mathrm{x}=5$ & $1757 \pm 10$ & $19 \pm 1$ & $42 \pm 1$ & $45 \pm 1$ & $0.65 \pm 0.05$ \\
\hline $\mathrm{x}=10$ & $3830 \pm 18$ & $17 \pm 1$ & $43 \pm 1$ & $47 \pm 1$ & $1.35 \pm 0.08$ \\
\hline $\mathrm{x}=20$ & $4320 \pm 22$ & $19 \pm 1$ & $46 \pm 1$ & $44 \pm 1$ & $1.54 \pm 0.06$ \\
\hline $\mathrm{x}=30$ & $4956 \pm 18$ & $17 \pm 1$ & $45 \pm 1$ & $48 \pm 1$ & $1.62 \pm 0.04$ \\
\hline $\mathrm{x}=40$ & $5873 \pm 28$ & $19 \pm 1$ & $46 \pm 1$ & $48 \pm 1$ & $1.90 \pm 0.08$ \\
\hline \hline Sample & \multicolumn{5}{|c|}{${ }^{4} \mathrm{~F}_{3 / 2} \rightarrow{ }^{4} \mathrm{I}_{11 / 2}$} \\
\hline & $\mathrm{A}_{R}$ & $\beta_{\text {exp }}$ & $\beta_{\text {cal }}$ & $\Delta \lambda_{\text {eff }}$ & $\sigma_{\text {emi }}$ \\
& $\left(\mathrm{s}^{-1}\right)$ & $\%$ & $\%$ & $(n m$ & $\left(\times 10^{-20} \mathrm{~cm}^{2}\right)$ \\
\hline $\mathrm{x}=5$ & $1905 \pm 25$ & $58 \pm 1$ & $46 \pm 1$ & $34 \pm 1$ & $2.05 \pm 0.12$ \\
\hline $\mathrm{x}=10$ & $4068 \pm 19$ & $61 \pm 1$ & $46 \pm 1$ & $32 \pm 1$ & $4.40 \pm 0.14$ \\
\hline $\mathrm{x}=20$ & $4348 \pm 16$ & $60 \pm 1$ & $56 \pm 1$ & $32 \pm 1$ & $4.56 \pm 0.12$ \\
\hline $\mathrm{x}=30$ & $4958 \pm 20$ & $61 \pm 1$ & $45 \pm 1$ & $31 \pm 1$ & $5.27 \pm 0.19$ \\
\hline $\mathrm{x}=40$ & $5617 \pm 22$ & $58 \pm 1$ & $44 \pm 1$ & $32 \pm 1$ & $5.75 \pm 0.16$ \\
\hline \hline Sample & \multicolumn{5}{|c|}{$\mathrm{F}_{3 / 2} \rightarrow{ }^{4} \mathrm{I}_{13 / 2}$} \\
\hline & $\mathrm{A}_{R}$ & $\beta_{\text {exp }}$ & $\beta_{\text {cal }}$ & $\Delta \lambda_{\text {eff }}$ & $\sigma_{\text {emi }}$ \\
& $\left(\mathrm{s}^{-1}\right)$ & $\%$ & $\%$ & $(n m$ & $\left(\times 10^{-20} \mathrm{~cm}^{2}\right)$ \\
\hline $\mathrm{x}=5$ & $453 \pm 5$ & $23 \pm 1$ & $11 \pm 1$ & $64 \pm 1$ & $0.64 \pm 0.06$ \\
\hline $\mathrm{x}=10$ & $959 \pm 1$ & $23 \pm 1$ & $11 \pm 1$ & $59 \pm 1$ & $1.42 \pm 0.05$ \\
\hline $\mathrm{x}=20$ & $815 \pm 10$ & $22 \pm 1$ & $09 \pm 1$ & $57 \pm 1$ & $1.24 \pm 0.09$ \\
\hline $\mathrm{x}=30$ & $1132 \pm 17$ & $23 \pm 1$ & $10 \pm 1$ & $57 \pm 1$ & $1.63 \pm 0.04$ \\
\hline $\mathrm{x}=40$ & $1250 \pm 19$ & $23 \pm 1$ & $10 \pm 1$ & $59 \pm 1$ & $1.73 \pm 0.08$ \\
\hline
\end{tabular}

In fact, the electronegativity of Oxygen (O), Tellurium (Te) and Znic (Zn) are about $3.5,2.1$, and 1.65, respectively. The difference of electronegativity of Te-O bond 
5.2 Effect of $\mathrm{TeO}_{2}$ environment in $\mathrm{Nd}^{3+}$ doped PZN phosphate glasses for high power lasers108 is smaller than Zn-O bond, which means that covalence of $\mathrm{Te}-\mathrm{O}$ bond is stronger than $\mathrm{ZnO}$. Therefore, the covalency of $\mathrm{Nd}-\mathrm{O}$ bonding increase together with Te- O bonding by increasng the number of NBOs with increase of $\mathrm{TeO}_{2}$ content. This is also in agreement with increase intensity of $\mathrm{Nd}^{3+}$ intra-configurational f-f transitions (Figure 5.17). On the other hand, the bulk property $\left(\Omega_{4}\right.$ and $\left.\Omega_{6}\right)$ also increase with $\mathrm{TeO}_{2}$ content, which may have significant influence on spontaneous emission transition probabilities and branching ratios of the emission transitions originated from ${ }^{4} \mathrm{~F}_{3 / 2}$ level. Table 5.13 present emission properties of certain radiative transitions of $\mathrm{Nd}^{3+}$ ions in glasses.

\subsubsection{Emission spectra and radiative properties}

Figure 5.20a shows the measured room temperature emission spectra under $808 \mathrm{~nm}$ diode laser excitation. Upon $808 \mathrm{~nm}$ excitation wavelength, the excited Nd ions suffer a nonradiative decay from ${ }^{4} \mathrm{~F}_{5 / 2}$ to ${ }^{4} \mathrm{~F}_{3 / 2}$ level and then the populated ${ }^{4} \mathrm{~F}_{3 / 2}$ radiatively decay to the lower level emitting light around $900 \mathrm{~nm}, 1060$ and $1330 \mathrm{~nm}$ that are correspond to ${ }^{4} \mathrm{~F}_{3 / 2} \rightarrow{ }^{4} \mathrm{I}_{9 / 2},{ }^{4} \mathrm{~F}_{3 / 2} \rightarrow{ }^{4} \mathrm{I}_{11 / 2}$, and ${ }^{4} \mathrm{~F}_{3 / 2} \rightarrow{ }^{4} \mathrm{I}_{13 / 2}$ (see Figure 5.20). From Figure 5.20a, the
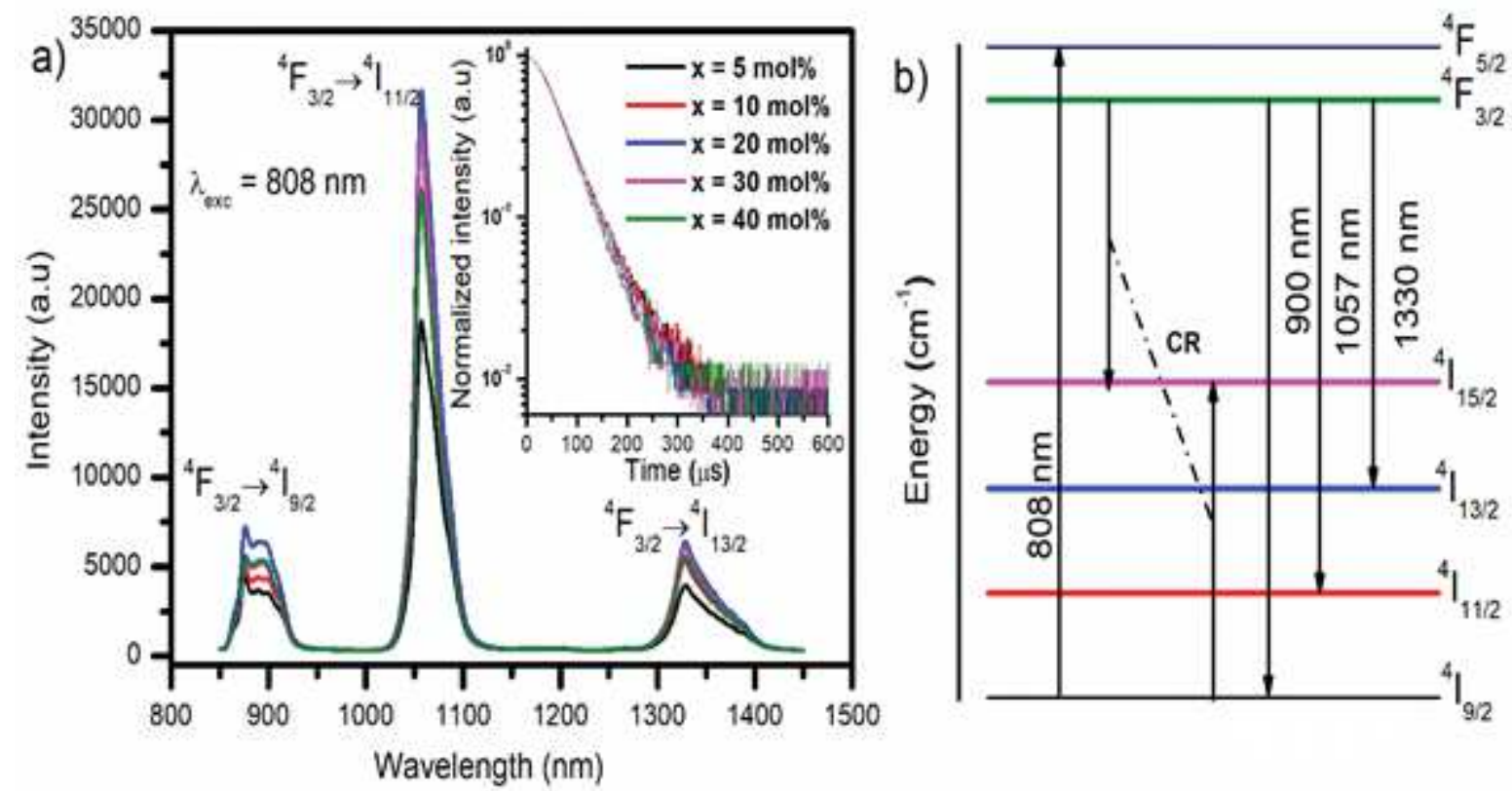

Figure 5.20: (a) Emission spectra and (b) schematic energy levels of $\mathrm{Nd}^{3+}$ ions. Inset shows decay of ${ }^{4} \mathrm{~F}_{3 / 2}$ level.

emission of ${ }^{4} \mathrm{~F}_{3 / 2} \rightarrow{ }^{4} \mathrm{I}_{11 / 2}$ transition is more intense than the ${ }^{4} \mathrm{~F}_{3 / 2} \rightarrow{ }^{4} \mathrm{I}_{9 / 2}$ and ${ }^{4} \mathrm{~F}_{3 / 2} \rightarrow$ ${ }^{4} \mathrm{I}_{13 / 2}$ transitions, and its emission intensity is maximized at $20 \mathrm{~mol} \% \mathrm{TeO}_{2}$ contain glass. 
5.2 Effect of $\mathrm{TeO}_{2}$ environment in $\mathrm{Nd}^{3+}$ doped PZN phosphate glasses for high power lasers109

The emission intensity could be explained in terms of spectroscopic quality factor $\left(\Omega_{4} / \Omega_{6}\right)$ because of the $\left\|U^{2}\right\|=0$ for the transition from ${ }^{4} \mathrm{~F}_{3 / 2}$ level. The value of $\left(\Omega_{4} / \Omega_{6}\right)$ is varied in between $0.9-1.2$ with $\mathrm{x}$, which implies good lasing performance. Nevertheless, the estimated spontaneous emission probabilities and branching ratios for the emission transitions, as shown in table 5.13 are consistent with the emission spectra.

Table 5.14: Radiative lifetime $(\tau)$, radiative energy transfer rate $\left(\mathrm{W}_{E T}\right)$ and quantum efficiency $(\eta)$ for $\mathrm{Nd}^{3+}$ doped glasses.

\begin{tabular}{|l|c|c|c|c|}
\hline $\begin{array}{l}\text { Glass } \\
\text { mol\% of } \mathrm{TeO}_{2}\end{array}$ & $\begin{array}{c}\tau_{\text {meas }} \\
(\mu \mathrm{s})\end{array}$ & $\begin{array}{c}\tau_{\exp } \\
(\mu \mathrm{s})\end{array}$ & $\begin{array}{c}\mathrm{W}_{E T} \\
\left(\mathrm{~s}^{-1}\right)\end{array}$ & $\begin{array}{c}\eta \\
(\%)\end{array}$ \\
\hline $\mathrm{x}=5$ & $65 \pm 4$ & $242 \pm 12$ & $11329 \pm 100$ & $26.70 \pm 1$ \\
\hline $\mathrm{x}=10$ & $64 \pm 5$ & $113 \pm 9$ & $6818 \pm 55$ & $56.57 \pm 1$ \\
\hline $\mathrm{x}=20$ & $63 \pm 6$ & $105 \pm 11$ & $6409 \pm 50$ & $59.82 \pm 1$ \\
\hline $\mathrm{x}=30$ & $60 \pm 2$ & $90 \pm 7$ & $5535 \pm 48$ & $66.68 \pm 1$ \\
\hline $\mathrm{x}=40$ & $59 \pm 5$ & $78 \pm 9$ & $3729 \pm 40$ & $76.25 \pm 1$ \\
\hline
\end{tabular}

We obtained decay for the ${ }^{4} \mathrm{~F}_{3 / 2}$ excited level by monitoring the $1057 \mathrm{~nm}$ emission with $808 \mathrm{~nm}$ excitation, and as illustrated in inset of figure 5.20a. The experimental lifetime for the ${ }^{4} \mathrm{~F}_{3 / 2}$ level is determined by fitting decay profile with single exponential function, and are summarized in table 5.14. It can be seen that the experimental lifetime decreases with $\mathrm{x}$ and are much smaller than the calculated lifetimes (from $\mathrm{J}-\mathrm{O}$ theory) which implies the existence of non-radiative decay from the ${ }^{4} \mathrm{~F}_{3 / 2}$ level. Usually, the measured lifetime can be expressed as [37],

$$
\frac{1}{\tau_{\text {exp }}}=\frac{1}{\tau_{c a l}}+W_{M P R}+W_{C R}
$$

where, $W_{M P R}$ is the multiphonon-relaxation rate and $W_{C R}$ is the cross-relaxation rate. In this work, the expected that the $W_{M P R}$ is around $3 \mathrm{~s}^{-1}\left(\hbar \omega \cong 5400 \mathrm{~cm}^{-1}\right)$ due to large energy gap between the ${ }^{4} \mathrm{~F}_{3 / 2}$ level to the next lower level ${ }^{4} \mathrm{I}_{15 / 2}$, and is lesser than the $A_{\text {rad }}\left({ }^{4} \mathrm{~F}_{3 / 2} \rightarrow{ }^{4} \mathrm{I}_{11 / 2}\right)$, (see Table 5.14. Therefore, we believe that the non-radiative de-excitation process from $W_{M P R}$ is negligible and may significantly attributed to the cross-relaxation rate $\left(\mathrm{W}_{C R}\right)$ in the process, $\left({ }^{4} \mathrm{~F}_{3 / 2},{ }^{4} \mathrm{I}_{9 / 2}\right) \rightarrow\left({ }^{4} \mathrm{I}_{15 / 2},{ }^{4} \mathrm{I}_{11 / 2}\right)$, as shown in Figure 5.20(b). The non-radiative relaxation rate $\left(\mathrm{W}_{N R}\right)$ owing to cross-relaxation can be written as [158],

$$
\frac{1}{\tau_{\exp }}-\frac{1}{\tau_{c a l}}=W_{N R}
$$



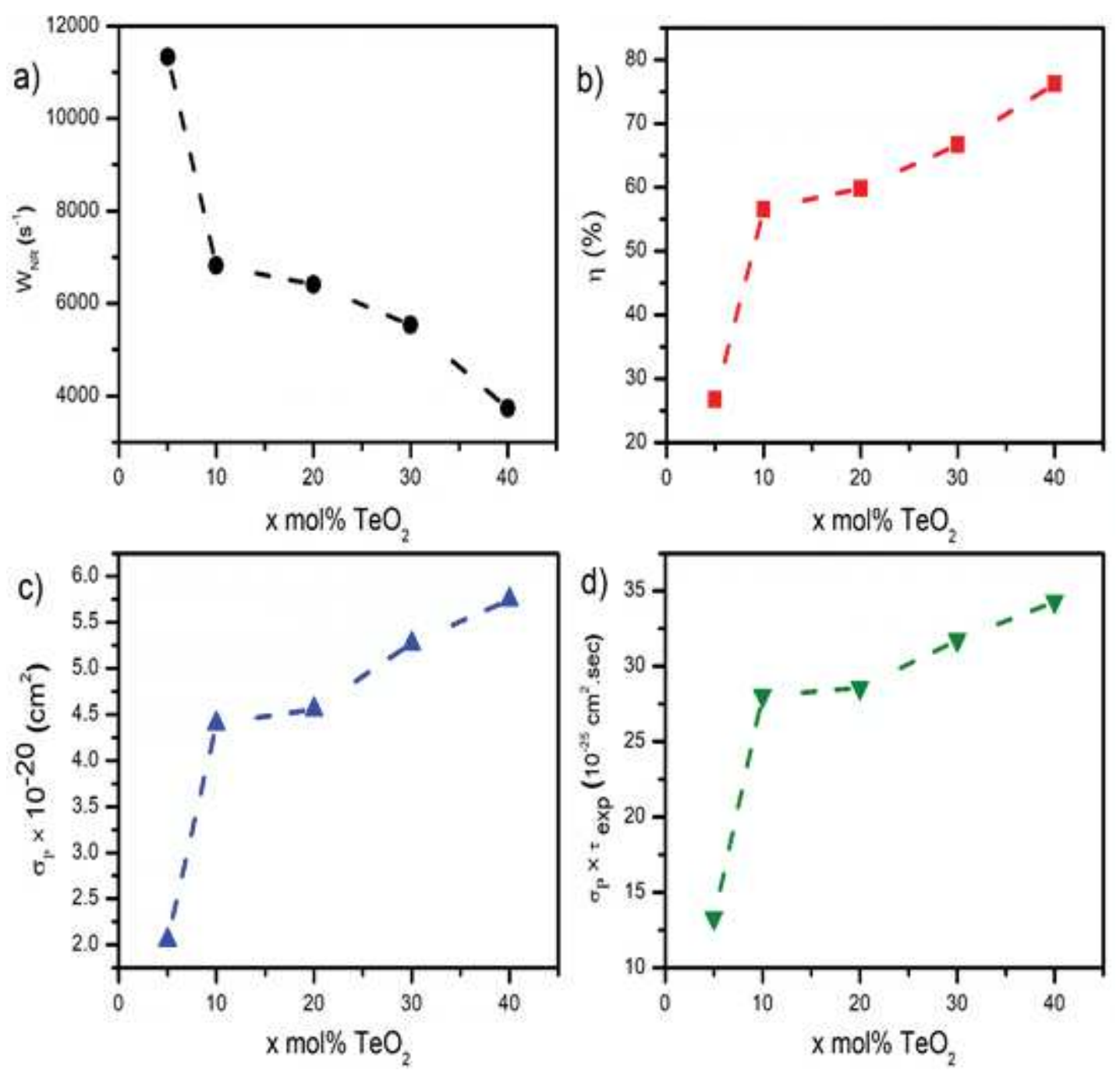

Figure 5.21: (a) Nonradiative relaxation rate $\left(\mathrm{W}_{N R}\right)$, (b) quantum efficiency $(\eta)$, (c) emission cross-section $\left(\lambda_{p} @ 1057 \mathrm{~nm}\right)$ and $(\mathrm{d})$ optical gain $\left(\lambda_{p} \times_{\text {exp }}\right.$ @ $\left.1057 \mathrm{~nm}\right)$ as a function of $\mathrm{x}$ in glass.

The decrease trend of $\mathrm{W}_{N R}$ becomes evident by a significant reduction of the emission lifetime and of the increase of the quantum efficiency for the ${ }^{4} \mathrm{~F}_{3 / 2}$ level, = $\tau_{\text {exp }} / \tau_{\text {rad }}$, as shown in Figures 5.21a and 5.21b. However, we should not neglect the $\mathrm{OH}$ hydroxyl groups in glasses which influence on spectral properties and laser glass output. In general, the coupling between $\mathrm{Nd}$ and $\mathrm{OH}$ ions is possible due to small ionic radius and high electronegativity of the $\mathrm{Nd}^{3+}$ ions. The formation of $\mathrm{Nd}-\mathrm{OH}$ bond is responsible for the structural distortion of $\mathrm{Nd}^{3+}$ sites thus significantly influencing the transfer of energy from $\mathrm{Nd}$ to $\mathrm{OH}$. The observed fluorescence quenching at higher $\mathrm{TeO}_{2}$ (30 and 40 mol\%) glasses have proven that excited energy is lost whenever it is transferred to $\mathrm{Nd}^{3+}$ ion coupled to a $\mathrm{OH}$ quenching center.

The large stimulated emission cross-section of emitting transitions are favorable 
Table 5.15: Effective linewidth $\left(\Delta \lambda_{e f f}\right)$, emission cross-section $\left(\sigma_{p}\right)$ and optical gain $\left(\sigma_{p}\right.$ $\times \tau_{\text {exp }}$ ) for the $1057 \mathrm{~nm}$ emission of $\mathrm{Nd}^{3+}$ in glasses.

\begin{tabular}{|l|c|c|c|}
\hline $\begin{array}{l}\text { Glass } \\
\mathrm{mol} \% \text { of } \mathrm{TeO}_{2}\end{array}$ & $\begin{array}{c}\Delta \lambda_{\text {eff }} \\
(\mathrm{nm})\end{array}$ & $\begin{array}{c}\sigma_{p} \times 10^{-20} \\
\left(\mathrm{~cm}^{2}\right)\end{array}$ & $\begin{array}{c}\sigma_{p} \times \tau_{\text {exp }} \\
\left(\times 10^{-25} \mathrm{~cm}^{2} . \mathrm{sec}\right)\end{array}$ \\
\hline $\mathrm{x}=5$ & $34 \pm 1$ & $2.05 \pm 0.52$ & $13.29 \pm 1.55$ \\
\hline $\mathrm{x}=10$ & $32 \pm 1$ & $4.40 \pm 0.71$ & $28.03 \pm 1.05$ \\
\hline $\mathrm{x}=20$ & $32 \pm 1$ & $4.56 \pm 0.55$ & $28.57 \pm 1.64$ \\
\hline $\mathrm{x}=30$ & $31 \pm 1$ & $5.27 \pm 0.92$ & $31.73 \pm 1.28$ \\
\hline $\mathrm{x}=40$ & $32 \pm 1$ & $5.75 \pm 0.39$ & $34.30 \pm 1.42$ \\
\hline Phosphate [147] & 29.3 & 2.78 & 119.54 \\
\hline Tellurite [148] & 28 & 2.55 & 46.15 \\
\hline Phosphotellurite $[149]$ & 35 & 3.00 & 66.30 \\
\hline Silicate [150] & 34.8 & 2.60 & 80.60 \\
\hline Borotellurite [151] & 21.6 & 8.91 & 65.04 \\
\hline
\end{tabular}

for low threshold and high gain applications that are significantly used to obtain CW lasers. The peak stimulated emission cross-section $\left(\sigma_{p}\right)$ for the ${ }^{4} \mathrm{~F}_{3 / 2} \rightarrow{ }^{4} \mathrm{I}_{9 / 2},{ }^{4} \mathrm{~F}_{3 / 2} \rightarrow$ ${ }^{4} \mathrm{I}_{11 / 2}$, and ${ }^{4} \mathrm{~F}_{3 / 2} \rightarrow{ }^{4} \mathrm{I}_{13 / 2}$ emission transitions have been estimated using equation 2.22, and are also listed in table 5.13. Figure 5.21c and 5.21d shows the increase of the peak of stimulated emission cross-section $\left(\sigma_{p}(\lambda)\right)$ and optical gain $\left(\sigma_{p} \times \tau_{\text {exp }}\right)$ for the $1057 \mathrm{~nm}$ emission with x content. The large $\lambda_{\text {eff }}$ reveals a strong electron-phonon coupling and an inhomogeneous broadening ${ }^{4} \mathrm{I}_{11 / 2}$ emission with $\sim 31-34 \mathrm{~nm}$ with $\mathrm{x}$. In fact, with increase $\mathrm{TeO}_{2}$ in glass, a strong electron-phonon coupling lead a greater $4 \mathrm{f}$ and $5 \mathrm{~d}$ opposite parity state admixture that achieves to increase the electric-dipole strengths, particularly the HST: ${ }^{4} \mathrm{I}_{9 / 2} \rightarrow{ }^{4} \mathrm{G}_{5 / 2}$ and increase asymmetry $\left(\Omega_{2}\right)$ of $\left[\mathrm{NdO}_{6}\right]$ octahedron in studied glasses. The increase of optical gain turn to decrease the saturation intensity of laser material since, $\mathrm{I}_{s}=\mathrm{hc} /\left(\lambda \sigma_{p}(\lambda) \tau_{\text {exp }}\right)[159]$. In comparison, Table 5.15 present laser parameters for the ${ }^{4} \mathrm{~F}_{3 / 2} \rightarrow{ }^{4} \mathrm{I}_{11 / 2}$ emission of $\mathrm{Nd}^{3+}$ in various glasses. The small fluorescence lifetime of ${ }^{4} \mathrm{~F}_{3 / 2}$ level compared with that of the other materials, the high stimulated emission and optical gain/bandwidths are unique among $\mathrm{Nd}^{3+}$ doped glasses. In addition, we have compared lasing wavelength $(\lambda)$, effective linewidth $\left(\Delta \lambda_{e f f}\right)$ and stimulated emission cross-section $\left(\sigma_{p}(\lambda)\right)$ of our glasses with reported commercial phosphate glasses [7], as shown in Figure 5.22. It can be seen that our glasses also provide better lasing properties, especially higher emission intensity of $\mathrm{x}=20 \mathrm{~mol} \% \mathrm{TeO}_{2}$ sample (see Figure $5.20(\mathrm{a})$ ) which is expected to perform better lasing operation at $1.06 \mu \mathrm{m}$ with low threshold power. 

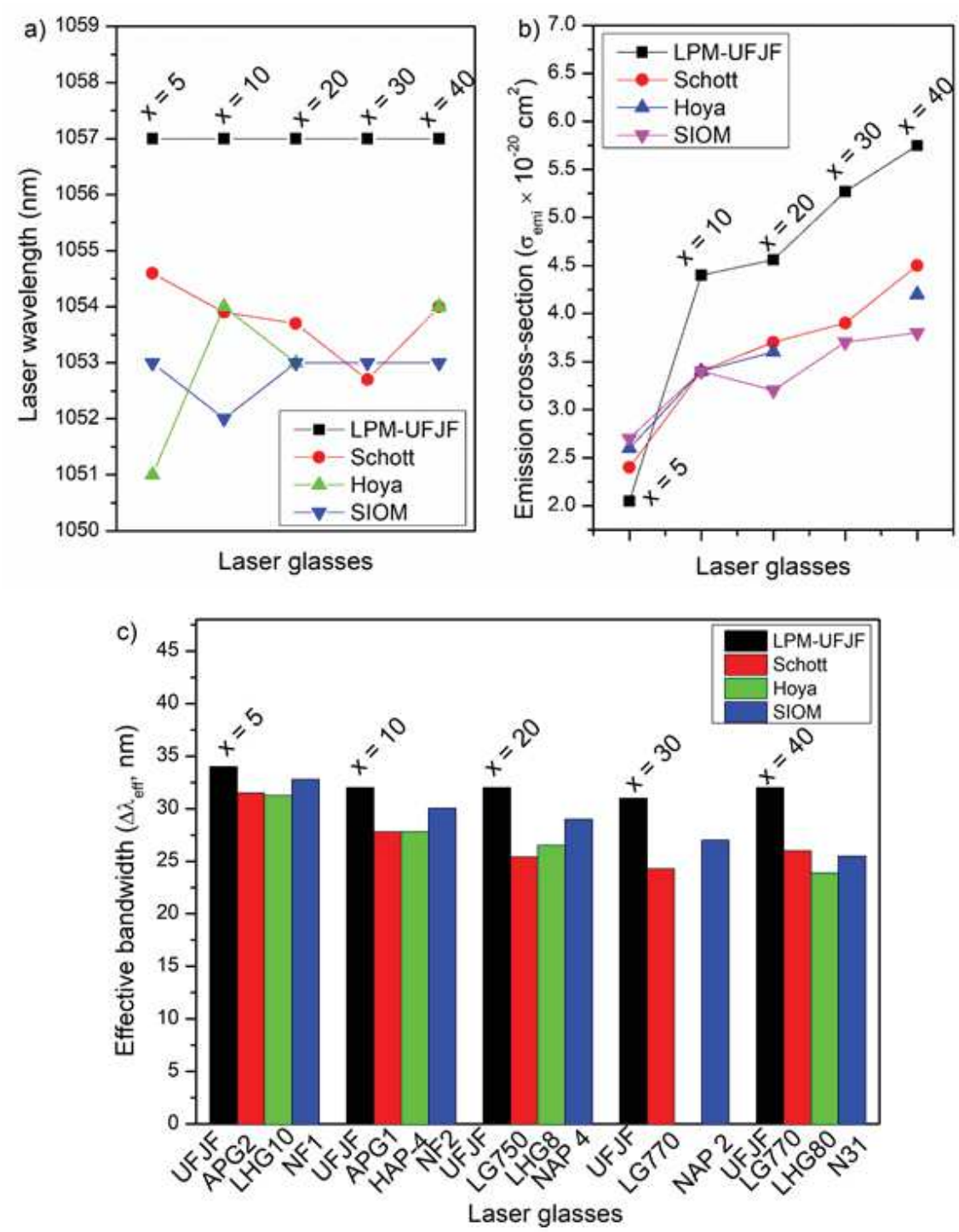

Figure 5.22: Comparative analysis of laser properties: a) Laser emission wavelength, b) stimulated emission cross-section $\left(\sigma_{p} @ 1057 \mathrm{~nm}\right)$ and $(\mathrm{c})$ effective line width $\left(\Delta \lambda_{\text {eff }} @\right.$ $1057 \mathrm{~nm})$ in glasses.

\subsubsection{Conclusions}

It was described detailed optical and luminescence properties of $\mathrm{Nd}^{3+}$ doped phosphate glass with addition of $\mathrm{TeO}_{2}$ oxide. The decrease of optical energy band gap $\left(\mathrm{E}_{\text {opt }}\right)$ with $\mathrm{x}$ at an expense of $\mathrm{ZnO}$ by increase of $2 \mathrm{p}$ oxygen levels with increase amount of non-bridging oxygens. Using Lorentz-Lorentz relation, refractive index and oxygen polarizability were estimated and are found to increase with x. The Raman scattering spectra show increase intensity of scattered peaks that confirms the decrease bridging oxygen ions and an increase of non-bridging oxygen ions due to addition of $\mathrm{TeO}_{2}$. Evaluation using Judd-Ofelt theory revealed that spectroscopic parameters and radiative transition probabilities are 
5.2 Effect of $\mathrm{TeO}_{2}$ environment in $\mathrm{Nd}^{3+}$ doped PZN phosphate glasses for high power lasers113 increased efficiently with $\mathrm{x}$. Decrease of fluorescent lifetime of ${ }^{4} \mathrm{~F}_{3 / 2}$ level with $\mathrm{TeO}_{2}$ is associated to cross-relaxation process, $\left({ }^{4} \mathrm{~F}_{3 / 2},{ }^{4} \mathrm{I}_{9 / 2}\right) \rightarrow\left({ }^{4} \mathrm{~F}_{15 / 2},{ }^{4} \mathrm{I}_{15 / 2}\right)$ since multiphonon relaxation in $\mathrm{Nd}^{3+}$ doped host matrices is negligible. Increased stimulation cross-section and optical gain for the $1057 \mathrm{~nm}$ emission laser line suggest that these materials might be potential for usage in high power laser technology. 


\section{Summary}

Doped glasses containing nanocrystals, transition metals and rare earth ions have been explored extensively in the last decade, to large extent, motivated by the new possibilities for tuning and controlling the electronic properties. The intentionally introducing dopants into semiconductor nanocrystals (NCs) glass has proven possible to manipulate photon emission of semiconductor NCs to cover the ultra-violet, visible and near-infrared spectral ranges through simply tuning their inter co-dopants. Rare earth ions, specially, $\mathrm{Nd}^{3+}$ doped glasses/fibers have a lot of potential applications, in which they could replace the solid state lasers based on crystals, high output power lasers. However, devices that generate light like LEDs, amplifiers or lasers have been perhaps the most difficult to affordably fabricate.

In this thesis, Nickle ions are intentionally introduced into ZnTe NCs phosphate glass; and addition of $\mathrm{TeO}_{2}$ into $\mathrm{Nd}^{3+}$ doped phosphate glass have been considered and studied. The reason for phosphate glass chosen as a host is due to its higher ion solubility (compared to silicate glass), higher photo-darkening threshold and lower nonlinear index. The basic concepts on semiconductors and quantum confinement effects; and significant electronic features of Nickle and Neodymium ions are described in chapter 2. We present the most useful theoretical expression based on Judd-Ofelt theory to estimate the lasing parameters of a system. Also, crystal field parameters determination using Sugano-Tanabe diagram for a $3 \mathrm{~d}^{8}$ configuration was briefly discussed. In chapter 3 , we describe required engineering conditions for an amorphous materials, such as optical properties (Refractive index, absorption and color); chemical properties (Chemical durability and corrosion resistance on optical/commertical); mechanical properties (Elasticity and hardness); and thermal properties (Viscosity, thermal expansion and thermal conductivity). A detailed method of preparation of samples and used spectroscopic instruments such as XRD, FT-IR, Raman, UV-Vis-NIR absorption spectrometers, and photoluminescence, thermal lens and thermal relaxation, and z-scan experimental set-ups to characterize the samples were used, as a part of the work of this PhD activity. 
ZnNiTe semiconductor nanocrystals in PZABP phosphate glass: All the samples investigated in this study are the phosphate glass composition: $65 \mathrm{P}_{2} \mathrm{O}_{5}+14$ $\mathrm{ZnO}+10 \mathrm{Al}_{2} \mathrm{O}_{3}+10 \mathrm{BaO}+10 \mathrm{PbO}(\mathrm{mol} \%)$ doping with $5 \mathrm{wt} \% \mathrm{Ni}^{2+}$ ions and doping of Te $(1 \mathrm{wt} \%)$ and $\mathrm{x}$-content of $\mathrm{Ni}^{2+}$ ions varying at an expense of $\mathrm{Zn}$ content $(\mathrm{x}=0.5,1,5$ and $10 \%$ ) for the formation of semiconductor nanocrystals. The prepared samples named as $\mathrm{G}$ (5 wt\% $\mathrm{Ni}^{2+}$ ions doped) for glass; GC1, GC2, GC3 and GC4 for the glass-ceramics $\left(0.5,1.0,5.0\right.$ and $10.0 \mathrm{wt} \% \mathrm{Ni}^{2+}$ ions doped), respectively. A thorough investigation of these glass and glass-ceramic samples revealed some interesting structural, optical and thermal features.

X-ray diffraction pattern of the G sample clearly exhibit glassy characteristic and glass-ceramic samples exhibit not only the amorphous halo, but also appear sharp diffraction peaks that could be attributed to the growth of quantum dots (QDs) or nanocrystals (NCs) in the present work. The ZnTe characteristic vibrational (Longitudinal optical (LO) and transverse optical (TO)) modes are observed at $\sim 106, \sim 215 \mathrm{~cm}^{-1}$ and $\sim 430 \mathrm{~cm}^{-1}$ , and frequencies in range $430-1300 \mathrm{~cm}^{-1}$ exhibiting various symmetric and asymmetric stretching of $\mathrm{P}-\mathrm{O}-\mathrm{P}$ bridging/non-bridging oxygen bonds observed in Raman spectra. Due to broadening of IR absorption bands a quantitative analysis was performed by the deconvolution of the IR absorption of glass and glass-ceramics. A detailed structural information was given with band assignments.

Optical absorption spectral nature and position of the bands resembles to the $\mathrm{Ni}^{2+}$ ion octahedral symmetry and bulk-like ZnTe NCs. The appearance of studied samples color from light brown to blue, is an indicative of coordinate states of $\mathrm{Ni}^{2+}$, like related to $6 \mathrm{Ni}^{2+}, 5 \mathrm{Ni}^{2+}$ and $4 \mathrm{Ni}^{2+}$. The crystal field $\left(\mathrm{D}_{q}\right)$ and Racah $(\mathrm{B})$ parameters were reported. The observed decrease trend of $\mathrm{B}$ is related to the decrease of interelectronic repulsion within the d-orbitals than can increase the covalent nature between metal-ligand bonds. A broad emission band between $525-700 \mathrm{~nm}\left({ }^{1} \mathrm{~T}_{2 g}(\mathrm{D}) \rightarrow{ }^{3} \mathrm{~T}_{2 g}(\mathrm{~F})\right)$ wavelength is observed up on lamp excitation at $240 \mathrm{~nm}$ wavelength. The intensity decreased with the increase of concentration of $\mathrm{Ni}^{2+}$ ions $(\mathrm{x}=5$ and $10 \mathrm{wt} \%)$ in GCs and is due to the photo-electrons transferred to nickel ion inducing trapp centers instead anion vacancy defect centers. These results are in good agreement with $\mathrm{Ni}^{2+}$ and $\mathrm{Cd}^{2+}$ ions doped $\mathrm{ZnS}$ colloidal particles. 
Decay kinetics for the visible emission and radiative properties such as emission crosssection, effective line width, full-width at half maxima and figure of merit, are reported for studied systems. The higher emission cross-section and the FOM is higher for the visible emission transition ${ }^{1} \mathrm{~T}_{2 g}(\mathrm{D}) \rightarrow{ }^{3} \mathrm{~T}_{2 g}(\mathrm{~F}) \mathrm{Ni}^{2+}$ in $\mathrm{GC} 4$ sample and it may useful for visible-RED emission light conversion in LED technology.

The time-resolved thermal lens (TL) and thermal relaxation (TR) methods have been used to testify the thermal diffusivity (D), variation of optical path length with temperature (ds/dT) and thermal conductivity $(\mathrm{K})$ of the samples. The observed decrease in D for the GCs (except in GC4) when compared with the G sample. This may be to the low formation of semiconductor NCs and the domination of crystal imperfection in these GCs than the G sample. The trend of D and $\mathrm{K}$ for the studied samples were observed. From the dS/dT analysis, the GC2 shows lower value $\left(0.846 \times 10^{-6} \mathrm{~K}^{-1}\right)$ among the studied samples and it may present better working conditions in optoelectronic to device applications.

Nonlinear optical properties are also studied using Z-scan technique. The nonlinear refraction property was observed in G sample only. Others, GC2 and GC4 present nonlinear absorption nature. The absorption coefficient, $\beta$ does not change significantly with wavelength. The increase with $\mathrm{Ni}$ concentration is due to the bound electronic effects and two-photon absorption (TPA). However, we could not neglect the quantum confinement effects because the existence of intraband transition around $533 \mathrm{~nm}$ (energy of ZnTe NCs) in GC2 and GC4 samples. The increase of nonlinear absorption coefficient is resulting from the increase of the oscillator strength caused by the confinement-induced localization of excitation. The obtained $\mathrm{n}_{2}$ and $\beta$ values are compared with host materials are also listed in tables.

Finally, we conclude that the lower dS/dT, high emission cross-section and FOM of the GC4 sample provides definite contribution in visible-RED emission light conversion in LED technology and broadband amplifiers.

Effect of $\mathrm{TeO}_{2}$ environment in $\mathrm{Nd}^{3+}$ doped PZN phosphate glass: All the samples investigated in this study are based on the chemical composition: $29 \mathrm{P}_{2} \mathrm{O}_{5}$ $+(60-\mathrm{x}) \mathrm{ZnO}+10 \mathrm{Na}_{2} \mathrm{O}+\mathrm{x} \mathrm{TeO}_{2}(\mathrm{x}=510,20,30$ and $40 \mathrm{~mol} \%)$ containing a 
$1.0 \mathrm{~mol} \% \mathrm{Nd}^{3+}$ as active ions dopant. Structural and laser properties are systematically investigated using XRD, FT-IR, Raman, UV-Vis-NIR absorption spectrometers, and photo-luminescence spectroscopic techniques.

Amorphous nature is confirmed by the observation of a broad diffraction halo $\left(2 \theta \sim 15-40^{\circ}\right)$ and absence of sharp Bragg peaks for all samples. Raman and IR absorption band positions and their structural groups were discussed and listed. In the case of Raman spectra, The intensity increase of bands around 485 and $638 \mathrm{~cm}^{-1}$ with $\mathrm{TeO}_{2}$ content is clear indicative of the formation of $\mathrm{P}-\mathrm{O}-\mathrm{Te}$ linkages due to the equal electronegativity of $\mathrm{P}_{2} \mathrm{O}_{5}$ (2.19) and $\mathrm{TeO}_{2}(2.1)$ thus the bonding of oxygen atoms with change of composition. The $\sim 760 \mathrm{~cm}^{-1}$ is associated to the stretching vibrations of $\mathrm{Te}-\mathrm{O}$ in $\mathrm{TeO}_{3}$ trigonal pyramidal units (or $\mathrm{TeO}_{3+1}$ units). The broadband of higher frequency region $\left(870-1300 \mathrm{~cm}^{-1}\right)$ is ascribed to stretching vibrations $\left(\mathrm{PO}_{2}\right.$ and $\left.\mathrm{PO}_{4}\right)$ of nonbridging oxygens connected to phosphorus $(\mathrm{P}-\mathrm{O}-\mathrm{P})$ in metaphosphate groups. We observed the stronger $\mathrm{P}-\mathrm{O}$ bonds replacement by $\mathrm{Te}-\mathrm{O}$ bonds with increasing of $\mathrm{TeO}_{2}$ content and the phonon energy of the studied system significantly altered through formation of majority $\mathrm{P}-\mathrm{O}-\mathrm{Te}$ linkages beside of isolated $\mathrm{PO}_{4}$ tetrahedral. The lower phonon energy and higher refractive index of the present glass systems compared with phosphate ones, may permit that these material could be efficient for enhancing Near-IR laser amplification. In the case of IR absorption spectra, the presented absorption bands between $650-800 \mathrm{~cm}^{-1}$ wavenumbers are attributed to stretching vibrations of Te-O bonds in $\mathrm{TeO}_{3+1}$ and $\mathrm{TeO}_{3}$ units respectively, suggesting a progressive conversion of $\mathrm{TeO}_{4}$ to $\mathrm{TeO}_{3}$ tellurite polyhedra in the glass network in the studied systems. A broadband is observed at high frequency region for high phosphate content of glass $\left(5 \mathrm{~mol}_{\mathrm{TeO}} \mathrm{Te}_{2}\right)$ is associated to the symmetric and asymmetric stretching modes of $\mathrm{PO}_{3}$ groups. With increasing $\mathrm{TeO}_{2}$ content, a clear splitting and intensity variation at high frequency region, suggests a depolymerization of the metaphosphate chains with a possible insertion of $\mathrm{TeO}_{n}$ units through $\mathrm{P}-\mathrm{O}-\mathrm{Te}$ bonds.

Absorption spectra of glasses consist of several sharp peaks that are associated to the ground state energies of $\mathrm{Nd}^{3+}: 4 \mathrm{f}^{3}-4 \mathrm{f}^{3}$ intra-electronic transitions, and their transitions identification and band centers are noted based on literature. The observed red shifted absorption edge $(300-360 \mathrm{~nm})$ with increasing $\mathrm{TeO}_{2}$ content is due to the 
electron transition transfer in between valance and conduction $(\mathrm{V}-\mathrm{C})$ bands. The optical band gap energies $\left(\mathrm{E}_{\text {opt }}\right)$ are estimated from Davis and Mott theory. $\mathrm{E}_{\text {opt }}$ for the indirect allowed transitions with $\mathrm{x}$ mol\% $\mathrm{TeO}_{2}$ is decreased monotonically from 4.16 to $3.56 \mathrm{eV}$, and are close with crystalline $\alpha-\mathrm{TeO}_{2}(\sim 2.78-3.50 \mathrm{eV})$ and $\mathrm{ZnO}(3.40 \mathrm{eV})$. In this work, the $\mathrm{ZnO}$ and $\mathrm{TeO}_{2}$ content is about $40-60 \%$ varies which could influence on electronic properties of the phosphates. Therefore, the observed decrease trend of $\mathrm{E}_{\text {opt }}$ with increase $\mathrm{TeO}_{2}$ is an accordance with the theoretical predictions that increased covalent character of the bonds causes a decrease in the absorption edge energy. These results are to the leadcontaining borate and silicate glasses. The electronic polarizability of oxide ions $\left(\alpha_{O^{2-}}\right)$ for the glasses were determined from $\mathrm{E}_{\text {opt }}$ and $\mathrm{n}$ values, are tabled. We observed enhancement in electron density around oxide ions with addition of $\mathrm{TeO}_{2}$ as second network glass former to phosphate glass. The optical basicity with $\mathrm{x}$ is increased due to increase of negative charge on the oxygen atom, and it increases the covalency between cation and oxygen bond.

Judd-Ofelt theory is used to estimate quantitatively and qualitatively assess the studied $\mathrm{Nd}^{3+}$ systems through their optical absorption and emission bands of intraconfigurational f-f transitions. The oscillator strengths (f) of transitions, Judd-Ofelt intensity $\left(\Omega_{\lambda}, \lambda=2,4\right.$ and 6$)$ parameters, radiative properties such as radiative transition probabilities $\left(\mathrm{A}_{R}\right)$, branching ratios $(\beta)$ and emission cross-sections are reported for all glasses. The covalency of $\mathrm{Nd}-\mathrm{O}$ bonding increase together with $\mathrm{Te}$ - O bonding by increase number of NBOs with increase of $\mathrm{TeO}_{2}$ content in glasses.

The room temperature emission spectra were measured under $808 \mathrm{~nm}$ diode laser excitation. We observed three emission bands around $900 \mathrm{~nm}, 1057$ and $1330 \mathrm{~nm}$ that are correspond to ${ }^{4} \mathrm{~F}_{3 / 2} \rightarrow{ }^{4} \mathrm{I}_{9 / 2},{ }^{4} \mathrm{~F}_{3 / 2} \rightarrow{ }^{4} \mathrm{I}_{11 / 2}$ and ${ }^{4} \mathrm{~F}_{3 / 2} \rightarrow{ }^{4} \mathrm{I}_{13 / 2}$ transitions. The estimated spontaneous emission probabilities and branching ratios for the emission transitions are inconsistent with the emission spectra. The large stimulated emission cross-section of emitting transitions are favorable for low threshold and high gain applications. Therefore, we calculated peak stimulated emission cross-sections and effective linewidths for an observed emission transitions which were compared with reported glasses.

Decay for the ${ }^{4} \mathrm{~F}_{3 / 2}$ excited level were measured by monitoring the $1057 \mathrm{~nm}$ emis- 
sion with $808 \mathrm{~nm}$ excitation.). The experimental lifetime for the ${ }^{4} \mathrm{~F}_{3 / 2}$ level is determined by fitting decay profile with single exponential function. The observed reduction of emission lifetime is strong evident to the decreased trend of $\mathrm{W}_{N R}$ and an increase of the quantum efficiency for the ${ }^{4} \mathrm{~F}_{3 / 2}$ level. The increase peak of stimulated emission crosssection $\left(\sigma_{p}(\lambda)\right)$ and optical gain $\left(\sigma_{p}(\lambda) \times \tau_{\text {exp }}\right)$ is forecast for the $1057 \mathrm{~nm}$ emission with $\mathrm{x}$ content.

Finally, we conclude the higher stimulated emission and optical gain/bandwidths are unique among $\mathrm{Nd}^{3+}$ doped glasses. Especially, the higher emission intensity of $\mathrm{x}=$ $20 \mathrm{~mol} \% \mathrm{TeO}_{2}$ sample which is expected to perform better lasing operation at $1.06 \mu \mathrm{m}$ with low threshold power. 
Appendices 


\section{A List of Published and submitted articles}

1. $\mathrm{Zn}_{1-x} \mathrm{Ni}_{x}$ Te semiconductor nanocrystals in transparent glass-ceramics for Optoelectronic device applications, Paper submitted to Nature Scientific Reports (April 2021).

2. Effect of $\mathrm{TeO}_{2}$ environment on optical and $1.06 \mu \mathrm{m}$ emission in $\mathrm{Nd}^{3+}$ doped phosphate glass for high power lasers, Paper submitted to Scripta Materialia (Jan, 2021).

3. H. Darabian, M. Radha, V. Anjos, M. J. V. Bell, C. Batesttin, A. S. Silva, and N. O. Dantas. Structural and thermal study of ZnTe nanocrystals doped with Cr and Mn in phosphate glasses. Journal of Non-Crystalline Solids, 561 (2021) 120745.

4. M. Seshadri, M. Radha, G.A. Mendes, M.J.V. Bell, V. Anjos. Broadband emission and energy transfer process between silver species in photo luminescent borophosphate glasses: Journal of Luminescence, 210 (2019) 444-451.

5. M. Seshadri, M. Radha, H. Darabian, L.C. Barbosa, M.J.V. Bell, V. Anjos, Thermal and nonlinear optical properties of $\mathrm{Tm}^{3+}$-doped tellurite glasses. Journal of Thermal Analysis and Calorimetry, 138 (2019) 2971 - 2978.

6. M. Seshadri, M. Radha, M.J.V. Bell, V. Anjos. Structural and spectroscopic properties of $\mathrm{Yb}^{3+}$ doped borophosphate glasses for IR laser applications. Ceramics International, 44(17) (2018) 20790-20797. 


\section{Bibliography}

1 HAN, K. et al. Complete inorganic colour converter based on quantum-dotembedded silicate glasses for white light-emitting-diodes. Chemical Communications, v. 52, p. 3564-3567, 2016.

2 LI, K. et al. Optical properties of $\mathrm{cu}$ ions-doped znse quantum dots in silicate glasses. Journal of American Ceramic Society, v. 101, p. 5080-5088, 2018.

3 DEY, C.; GOSWAMI, M.; KARMAKAR, B. White light emitting ho ${ }^{3+}$ doped cds nanocrystal ingrained glass nanocomposites. Applied Physics Letters, v. 106, p. 083106, 2015.

4 HUMBACH, H. F. O. et al. Analysis of oh absorption bands in synthetic silica. Journal of Non-Crystalline Solids, v. 203, p. 19-26, 1996.

5 WANG, C. et al. Light emission and amplification in changed cdse quantum dots. Journal of Physical Chemistry B, v. 108, p. 9027-9031, 2004.

6 CHAN, T. et al. Role of confinement on diffusion barriers in semiconductor nanocrystals. Physical Review Letters, v. 102, p. 025901, 2009.

7 ZHANG, L.; HU, L.; JIANG, S. Progress in $\mathrm{Nd}^{3+}, \mathrm{Er}^{3+}$, and $\mathrm{Yb}^{3+}$ doped laser glasses at shanghai institute of optics and fine mechanics. International Journal of Applied Glass Science, v. 9, p. 90-98, 2018.

8 BROWN, R.; SHMITT, M. A survey of energy and environmental applications of glasses. Journal of European Ceramic Society, v. 29, p. 1193-1201, 2009.

9 AXINTE, E. Glass as engineering materials: A review. Materials and Design, v. 32, p. 1717-1732, 2011.

10 ELLIOT, S. Physics of amorphous materials. [S.l.]: Harlow, Essex, England: Longman Scientific \& Technical ; New York, 1990.

11 KARASU, B. et al. The latest developments in glass science and technology. El-Cezerî Journal of Science and Engineering, v. 4(2), p. 209-233, 2017.

12 ZARZYCKI, J. Glasses and Amorphous Materials. [S.l.]: (Eds. R. W. Cahn, P. Haasen, E. J. Kramer) VCH, Weinheim, 1991.

13 SHELBY, V. J. E. Introduction to glass science and technology. [S.l.]: Royal Society of Chemistry, Cambridge, 1997.

14 W.H.ZACHARIASEN. The atomic arrangement in glass. Journal of American Chemical Society, v. 54, p. 3841-3851, 1932.

15 SMITH, D. J. et al. Atomic-scale characterization of (mostly zincblende) compound semiconductor heterostructures. Journal of Physics: Conference Series, v. 471, p. 012005, 2013. 
16 DAVIS, E. A.; MOTT, N. F. Conduction in non-crystalline systems v. conductivity, optical absorption and photoconductivity in amorphous semiconductors. Philosophical Magazine, v. 22, p. 0903-0922, 1970.

17 SAHU, S.; NANDA, K. Nanostructured semiconductors: physics and applications. Philosophical Magazine, v. 67, p. 103-130, 2001.

18 EFROS, A. L.; EFROS, A. L. Interband light absorption in semiconductor spheres. Soviet Physics-Semiconductors, v. 16, p. 772, 1982.

19 EDVINSSON, T. Optical quantum confinement and photocatalytic properties in two-, one- and zero-dimensional nanostructures. ACCOUNTS OF CHEMICAL RESEARCH, v. 43, p. 190-200, 2018.

20 SMITH, A. M.; NIE, S. Semiconductor nanocrystals: Structure, properties, and band gap engineering. ACCOUNTS OF CHEMICAL RESEARCH, v. 43, p. 190-200, 2010 .

21 MCKITTRICK, J.; SHEA-ROHWER, L. E. Review: Down conversion materials for solid-state lighting. Journal of American Ceramic Society, v. 97(5), p. 1327-1352, 2014.

22 LAFUENTE-SAMPIETRO, A. Thesis:Optical control of the spin of a magnetic atom in a semiconductor: hybrid hole-Manganese spin and Chromium spin. [S.l.]: Tsukuba University, 2018.

$23 \mathrm{LI}, \mathrm{Y}$. et al. Ultrathin $\mathrm{CO}_{3} \mathrm{O}_{4}$ nanomeshes for the oxygen evolution reaction. ACS Catalysis, v. 8, p. 1913-1920, 2018.

24 FLEUR, S.; NICHOLAS. Four New Names Officially Added to the Periodic Table of Elements. [S.1.]: New York Times, USA, 2017.

25 REDDY, S. L.; ENDO, T.; REDDY, G. S. Book: Atomic and Molecular Low-n Rydberg States in Near Critical Point Fluids - Chapeter 1:Electronic (Absorption) Spectra of 3d Transition Metal Complexes. [S.l.]: INTECH, UK, 2012.

26 WENGER, O.; BéNARD, S.; GüDEL, H. Crystal field effects on the optical absorption and luminescence properties of $\mathrm{ni}^{2+}$ doped chlorides and bromides: Crossover in the emitting higher excited states. Inorganic Chemistry, v. 41, p. 5968-5977, 2002.

27 HENDERSON, B.; IMBUSCH, G. F. Optical Spectroscopy of Inorganic Solids. [S.1.]: Oxford Science Publications, Oxford, 1989.

28 SUGANO, S.; TANABE, Y.; KAMIMURA, H. Multiplets of Transition Metal Ions in Crystals. [S.l.]: Academic Press, New York, 1970.

29 FREEMAN, A.; WATSON, R. Theoretical investigation of some magnetic and spectroscopic properties of rare earth ions. Physical Review, v. 127, p. 2058-2075, 1962.

30 DIEKE, G. H.; CROSSWHITE, H. Spectra and energy levels of rare earth ions in crystals. Interscience Publishers, 1968.

31 CAMPBELL, J.; SURATWALA, T. Nd-doped phosphate glasses for highenergy/high-peak-power lasers. Journal of Non-Crystalline Solids, v. 54, p. 318-341, 2000 . 
32 JUDD, B. Optical absorption intensities of rare earth ions. Physical Review, v. 127, p. $750,1962$.

33 OFELT, G. Optical absorption intensities of rare earth ions. Journal of Chemical Physics, v. 37(3), p. 511, 1962.

34 SESHADRI, M.; BARBOSA, L.; RADHA, M. Study on structural, optical and gain properties of 1.2 and $2.0 \mu \mathrm{m}$ emission transitions in $\mathrm{ho}^{3+}$ doped tellurite glasses. Journal of Non-Crystalline Solids, v. 40, p. 62-74, 2014.

35 REISFELD, R.; JORGENSEN, C. Lasers and Excited states of Rare Earths. [S.l.]: Springer, Berlin, 1977.

36 WEBER, M. Multiphonon relaxation of rare earth ions in yttrium orthoaluminate. Physical Review B, v. 8, p. K54, 1973.

37 MOOS, H. Spectroscopic relaxation processes of rare earth ions in crystals. Journal of Luminescence, v. 11, p. 106, 1979.

38 WAZER, J. V. Phosphorus and its compounds. [S.l.]: Interscience, New York, 1958.

39 ABE, Y. Topics in Phosphorus Chemistry. [S.1.]: Wiley, New York, 1983.

40 MARTIN, S. W. Ionic conduction in phosphate glasses. Journal of American Ceramic Society, v. 74, p. 1767-1784, 1991.

41 BROW, R. K. The structure of simple phosphate glasses. Journal of Non-Crystalline Solids, v. 74, p. 1767-1784, 2000.

42 KNOWLES, J. C. Phosphate based glasses for biomedical applications. Journal of Materials Chemistry, v. 13, p. 2395-2401, 2003.

43 NEEL, E. A. A. et al. Bioactive functional materials: a perspective on phosphate based glasses. Journal of Materials Chemistry, v. 19, p. 690-701, 2009.

44 WOGGON, U. Optical Properties of Semiconductor Quantum Dots. [S.1.]: Springer Verlag, Berlin, 1997.

45 BRET, G.; GIRES, F. Giant-pulse laser and light amplifier using variable transmission coefficient glasses as light switches. Applied Physics Letters, v. 4, p. 175, 1964.

46 JAIN, R.; LIND, R. Degenerate four-wave mixing in semiconductor doped glasses. Journal of Optical Society of America, v. 73, p. 647-653, 1983.

47 BáNYAI, L.; KOCH, S. W. Semiconductor Quantum Dots. [S.l.]: World Scientific Publishing Co. Pte. Ltd., Singapore, 1993.

48 GAPONEnKO, S. V. Optical Properties of Semiconductor Nanocrystals. [S.l.]: Cambridge University Press, Cambridge, 1998.

49 BARBOSA, L. et al. Cdte quantum dots by melting heat treatement in borosilacate glasses. Journal of Optical Society of America, v. 219, p. 205-211, 1997.

50 AliviSATOS, A. et al. in: Physical Phenomena in Granular Materials. [S.1.]: Materials Research Society, Pittsburg, 1990. 
51 RIGHINI, G. Glass integrated optics: advances and perspectives. Proc. SPIE: Optics for Science and New Technology, v. 2778, 1996.

52 NASU, H. et al. Preparation and magnetooptical properties of $\operatorname{cd}_{1-x} \mathrm{mn}_{x}$ te microcrystal doped $\mathrm{sio}_{2}$ glass thin films. Journal of Applied Physics, v. 35, p. L440, 1995.

53 NETO, J. M. et al. Desenvolvimento e caracterização de nanoestuturas do tipo cdte ${ }_{x} \mathrm{~s}_{1-x}$ em vidro borosilicatos. Proc. 2nd International Ceramic Science and Technology:Ceramic Transfer, v. 20, p. 161, 1991.

54 REYNOSO, V. et al. Pbte quantum dot doped glasses with absorption edge in the $1.5 \mu \mathrm{m}$ wavelength region. Electronic Letters, v. 31, p. 1013, 1995.

55 TSUNETOMO, K. et al. Nonlinear optical properties in semiconductor ncs glasses. Nonlinear Optics, v. 13, p. 109, 1995.

56 HAN, K.; HEO, S. Y.; CHUNG, W. J. Cds and cdse quantum dot embedded silicate glasses for led color converter. CInte. Journal of Applied Glass Science, v. 6, p. 103-108, 2015 .

57 XIA, M. et al. Effect of $\mathrm{al}_{2} \mathrm{O}_{3}$ on the formation of color centers and cdse/cd ${ }_{1-x} \mathrm{Zn}_{x} \mathrm{se}$ quantum dots in $\mathrm{sio}_{2}+\mathrm{na}_{2} \mathrm{O}+\mathrm{zno}$ glasses. Journal of American Ceramic Society, v. 10, p. 1726-1733, 2018.

58 HALL, D. W.; BORRELLI, N. F. Absorption saturation in commercial and quantum-confine cdse ${ }_{x} \mathrm{~s}_{1-x}$ doped glasses. Journal of Optical Society of America B, v. 5, p. $1650-1654,1988$.

59 DONYA, H.; TAHA, T. A. Preparation, structure and optical properties of znte and pbte nanocrystals grown in fluorophosphate glass. Journal of Material Science: Materials in Electronics, v. 29, p. 8610-8616, 2018.

60 FREITAS, A. et al. Thermal analyzas of phosphate glassed doped znte and $\mathrm{yb}^{3+}$ ions. Journal of Luminescence, v. 169, p. 353-358, 2016.

61 HU, Z. et al. Co-doping of ag into mn:znse quantum dots: Giving optical filtering effect with improved monochromaticity. Scientific Reports, v. 5, p. 14817, 2015.

62 KLIMOV, V. I. et al. Optical gain and stimulated emission in nanocrystal quantum dots. Science, v. 290, p. 314-317, 2000.

63 MALý, P.; MIYOSHI, T. Effect of photodarkening on photoluminescence dynamics in cds doped glasses. Journal of Luminescence, v. 90, p. 129-134, 2000.

64 WAN, X. et al. The third order optical nonlinear character of znse nanocrystals doped silica glasses. Journal of Electroceramics, v. 21, p. 737-740, 2008.

65 THANTU, N. Second harmonic generation and two-photon luminescence upconversion in glasses doped with znse nanocrystalline quantum dots. Journal of Luminescence, v. 111, p. 17-24, 2005.

66 MOULTON, P. Ti-doped sapphire:tunable solid-state laser. Journal of Optics News, v. 8(6), p. 9, 1982. 
67 IZAWA, T.; MATSUI, S.; MAEDA, M. Broad-band tunable,compact,low-threshold ti: sapphire laser using a single set of extremely broad-band optics. CLEO, CtuL27, 1996.

68 GRIVAS, C.; CORBAR, C.; VRAMBILLA, G. Tunable,continuous-wave ti:sapphire channel waveguide lasers written by femtosecond and picosecond laser pulses. Journal of Optics Letters, v. 3722, p. 4630-4632, 2012.

69 ANGERT, N. B.; BORODIN, N. I.; GARMASH, V. M. Lasing due to impurity color centers in yttrium aluminum garnet crystals at wavelengths in the range $1.35-1.45 \mu \mathrm{m}$. J. Soviet Journal of Quantum Electronics, v. 18(1), p. 73-74, 2012.

70 EILERS, H.; DENNIS, W. M.; YEN, W. M. Performance of a cr:yag laser. J. IEEE Journal of Quantum Electronics, v. 29(9), p. 2508-2512, 1993.

71 SOROKINA, I. T.; NAUMOV, S.; SOROKIN, E. Directly diode-pumped tunable continuous-wave roomtemperature $\mathrm{cr}^{4+}$ : Yag laser. Journal of Optics Letters, v. 24(22), p. $1578-1580,1999$.

72 SENNAROGLU, A. Broadly tunable $\mathrm{cr}^{4+}$ doped solid-state lasers in the near infrared and visible. Journal of Progress in Quantum Electronics, v. 26(6), p. 287-352, 2002.

73 ISHIBASHI, S.; NAGANUMA, K. Cr ${ }^{4+}$ : Yag single-crystal fiber laser widely tunable using birefringent filter. Journal of Progress in Quantum Electronics, CLEO, JW2A, 2012 .

74 ARONSONN, J. Thesis. [S.1.]: University of Southampton, UK, 2003.

75 LEE, Y. W. et al. $20 \mathrm{w}$ single-mode $\mathrm{yb}^{3+}$-doped phosphate fiber laser. Optics Letters, v. 31, p. 3255-3257, 2006.

76 ZHU, X. et al. $976 \mathrm{~nm}$ single-frequency distributed bragg reflector fiber laser. Optics Letters, v. 37, p. 4167-4169, 2012.

77 KUMARI, S.; CHAKRABORTY, S. Study of different magneto-optic materials for current sensing applications. Journal of Sensors and Sensor Systems, v. 7, p. 421-431, 2018.

78 KUMAR, G. et al. Magneto-optic characteristics of ferric oxide quantum-dotphosphate glass nanocomposite. Applied Physics A, v. 98, p. 531-535, 2010.

79 FURDYNA, J. K.; SAMRTH, N. Magnetic properties of diluted magnetic semiconductors: A review. Journal of Applied Physics, v. 61(8), p. 3526-3532, 1987.

80 EDGAR, A. Optical Properties of Materials and Their Applications. [S.1.]: JohnWiley \& Sons Ltd., 2020.

81 WALTERS, H. V.; ADAMS, P. B. The chemical durability of optical glass. Journal of Applied Optics, v. 7, p. 845-848, 1968.

82 CALLISTER, W.; RETHWISCH, D. Materials science and engineering: an introduction. [S.l.]: John Wiley \& Sons, Inc., 2009.

83 VARSHNEYA, A. K. Fundamentals of Inorganic Glasses. [S.l.]: Alden Group Limited, 2006. 
84 VARSHNEYA, A. K. Industrial Glasses. [S.l.]: Encyclopedia Britannica, 2016.

85 GORDON, J. P. et al. Longtransient effects in lasers with inserted liquid samples. Journal of Applied Physics, v. 36, p. 3, 1965.

86 SHEN, J.; LOWE, R. D.; SNOOK, R. D. A modle for cw laser incudced mode-mismatched dual-beam thermal lens spectroscopy. Chemical Physics, v. 165, p. 385-396, 19925.

87 SNOOK, R. D.; LOWE, R. D. Thermal lens spectroscopy: A review. Analyst, v. 120, p. 2051-2068, 1995.

88 JANSEN, K. L. Thermal lens measurements of optical computation of the laser beam spot size. Analytical Chemistry, v. 57, p. 1698-1703, 1985.

89 TOUlOUKIAN, Y. S. et al. Thermal Di€usivity. [S.l.]: Plenum, New York, 1973.

90 BAESSO, M. L.; SHEN, J.; SNOOK, R. D. Mode-mismatched thermal lens determination of temperature coefficient of optical path length in soda lime glass at different wavelengths. Journal of Applied Physics, v. 75, p. 3733-3737, 1994.

91 LIMA, S. M. et al. Mode-mismatched thermal lens determination of temperature coefficient of optical path length in soda lime glass at different wavelengths. Journal of Non-Crystalline Solidss, v. 352, p. 3603-3607, 2006.

92 BACHMANN, R. et al. Heat capacity measurements on small samples at low temperature. Review of Scientific Instruments, v. 43, p. 205, 1972.

93 SHUTZ, R. J. Thermal relaxation calorimetry below 1k. Review of Scientific Instruments, v. 45, p. 548, 1974.

94 DJUREK, D.; BATURIC, J. Simple specific heat measurements at low temperature. Journal of Physics E: Scientific Instruments, v. 5, p. 424, 1972.

95 ZINOVEV, O. S.; LEBEDEV, S. V. Specific heat of tungsten at low temperature. High Temperature, v. 14, p. 73, 1976.

96 HATTA, I. Heat capacity measurements by means of thermal relaxation method in medium temperature range. Review of Scientific Instruments, v. 50, p. 292, 1979.

97 MANSANARES, A. M. et al. Photoacoustic measurement of the thermal properties of two-layer systems. Physical Review B, v. 42, p. 4477, 1990.

98 PINHEIRO, A. S. et al. Thermal characterization of glasses prepared from simulated composition of lunar soil jsc-1a. Journal of Non-Crystalline Solids, v. 359, p. 56-59, 2013.

99 PINHEIRO, A. S. et al. Thermal characterization of iron phosphate glasses for nuclear waste disposal. Optical Materials, v. 33, p. 1975-1979, 2011.

100 SHEIK-BAHAE, M. et al. Sensitive measurement of optical nonlinearities using a single beam. IEEE Journal of Quantum Electronics, v. 26(4), p. 760-768, 1990.

101 SHEIK-BAHAE, M.; SAID, A. A.; STRYLAND, E. W. V. High sensitivity single beam n2 measurements. Optics Letters, v. 14(7), p. 955-957, 1989. 
102 MOREIRA, L. et al. The effect of excitation intensity variation and silver nanoparticle co-doping on nonlinear optical properties of mixed tellurite and zinc oxide glass doped with $\mathrm{nd}_{2} \mathrm{O}_{3}$ studied through ultrafast z-scan spectroscopy. Optical Materials, v. 79 , p. 397-402, 2018.

103 SILVA, A. S. et al. Solubility limit of $\mathrm{mn}^{2+}$ ions in znmnte nanocrystals grown within an ultraviolet-transparent glass template. Journal of Nanoparticle Research, v. 18(125), p. 1-9, 2016.

104 SILVA, A. et al. Paramagnetic behavior at room temperature of $\mathrm{zn}_{1-x} \mathrm{mn}_{x}$ te nanocrystals grown in a phosphate glass matrix by the fusion method. Journal of Alloys and Compounds, v. 647, p. 637-643, 2015.

105 SILVA, A. S. et al. Effects of $\mathrm{cu}^{2+}$ ion incorporation into znte nanocrystals dispersed within a glass matrix. Journal of Alloys and Compounds, v. 749, p. 681-686, 2018.

106 DANTAS, N. O. et al. Dilute magnetism in $\mathrm{zn}_{1-x} \mathrm{mn}_{x}$ te nanocrystals grown in a glass template. Chemical Physics Letters, v. 541, p. 44-48, 2012.

107 WOJNAROWICZ, J. et al. Effect of water content in ethylene glycol solvent on the size of zno nanoparticles prepared using microwave solvothermal synthesis. Journal of Nanomaterials, Article ID 2789871), 2016.

108 DANTAS, N. O. et al. Evidence of $\mathrm{cd}_{1-x} \mathrm{mn}_{x} \mathrm{~s}$ nanocrystal growth in a glass matrix by the fusion method. Applied Physics Letters, v. 93, p. 193115-193118, 2008.

109 HAYASHI, S. et al. Resonant raman scattering from znte microcrystals: Evidence for quantum size effects. Physical Review B, v. 40, p. 5544, 1989.

110 VINOGRADOV, V. S. et al. Raman spectra of structures with cdte, znte, and cdse based quantum dots and their relation to the fabrication technology. Physics of the Solid State, v. 50, p. 164-167, 2008.

111 ZHOU, S. et al. Intense infrared luminescence in transparent glass-ceramics containing $\beta$-ga $\mathrm{O}_{3}: \mathrm{ni}^{2+}$ nanocrystals. Journal of Physical Chemistry C, v. 111, p. 7335-7338, 2007.

112 SILVA, A. S. et al. Effect of co co-doping on the optical properties of znte:mn nanocrystals. Journal of Physical Chemistry Chemical physics, v. 19, p. 1158-1166, 2017.

113 BORSE, P. et al. Luminescence quenching in zns nanoparticles due to fe and ni doping. Journal of Material Science, v. 34, p. 6087-6093, 1999.

114 KAUR, M. S. J.; PANDEY, O. P. Photoluminescence and photocatalytic studies of metal ions (mn and ni) doped zns nanoparticles. Optical Materials, v. 47, p. 7-17, 2015.

115 IGARASHI, T.; ISOBE, T.; SANNA, M. Epr study of $\mathrm{mn}^{2+}$ electronic states for the nanosized zns:mn powder modified by acrylic acid. Physical Review B, v. 56, p. 6444, 1997.

116 DUTTA, S.; SOM, S.; SHARMA, S. K. Excitation spectra and luminescence decay analysis of $\mathrm{k}^{+}$compensated $\mathrm{dy}^{3+}$ doped camoo $_{4}$ phosphors. RSC Advances, v. 5, p. 7380-7387, 2015. 
117 SUZUKI, T.; OHISHI, Y. Broadband $1400 \mathrm{~nm}$ emission from ni ${ }^{2+}$ in zinc-aluminosilicate glass. Applied Physics Letters, v. 84, p. 3804-3806, 2004.

118 SESHADRI, M. et al. Doped tellurite glasses: Extending near-infrared emission for near $2.0 \mu \mathrm{m}$ amplifiers. International Journal of Applied Glass Science, v. 8(2), p. 216-225, 2017.

119 WAN, C. et al. Ultralow thermal conductivity in highly anion-defective aluminates. Physical Review Letters, v. 101, p. 085901, 2008.

120 YANG, C. et al. Determinants of thermal conductivity and diffusivity in nanostructural semiconductors. Journal of Physical Chemistry B, v. 112(5), p. 1482-1486, 2008.

121 GHONEIM, N. A.; HALAWA, M. M. Effect of boron oxide on the thermal conductivity of some sodium silicate glasses. Thermochimica Acta, v. 83, p. 341-345, 1982 .

122 JACINTO, C. et al. Thermal lens and z-scan measurements: Thermal and optical properties of laser glasses - a review. Journal of Non=Crystalline Solids, v. 352, p. 3582-3597, 2006.

123 BAESSO, M. L. et al. Neodymium concentration dependence of thermos-optical properties of low silica calcium aluminate glasses. Journal of Non=Crystalline Solids, v. 219, p. 165-169, 1997.

124 PILLA, V. et al. Thermal-lens study of thermo-optical properties of tellurite glasses. Journal of Materials Science, v. 42, p. 2304-2308, 2007.

125 MORAES, J. C. S. et al. Relation among optical, thermal and thermo-optical properties and niobium concentration in tellurite glasses. Journal of Non-Crystalline Solids, v. 356, p. 2146-2150, 2010.

126 PRAKASH, G. V. et al. Nonlinear optical properties of silicon nanocrystals grown by plasma-enhanced chemical vapor deposition. Journal of Applied Physics, v. 91(7), p. $4607,2002$.

127 YANG, X. et al. Third-order optical nonlinearity of cds nanocrystals embedded in sodium borosilicate glass studied by the z-scan technique. Journal of Materials Research, v. 25, p. 491-499, 2010.

128 JUSTUS, B. L. et al. Optical limiting in semiconductor nanocrystals in glass. Optical Communications, v. 103, p. 405-409, 1993.

129 FALCONIERI, M. et al. Large third-order optical nonlinearity of nanocluster-doped glass formed by ion implantation of copper and nickel in silica. Appled Physics Letters, v. 73, p. 288, 1998.

130 HASHIMOTO, T. et al. Optical nonlinearity of tio2 containing glasses measured by z-scan technique. Journal of Non-Crystalline Solids, v. 253, p. 30-36, 1999.

131 JAGANNATH, G. et al. Influence of gold nanoparticles on the nonlinear optical and photoluminescence properties of $\mathrm{eu}_{2} \mathrm{O}_{3}$ doped alkali borate glasses. Physical Chemistry Chemical Physics, v. 22, p. 2019-2032, 2020. 
132 JIANLIANG, Z. et al. Nonlinear optical properties in bismuth based glasses. ournal of Wuhan University of Technology-Mater. Sci. Ed., v. 26, p. 61-64, 2011.

133 ALMEIDA, J. M. P. et al. Third-order nonlinear spectra and optical limiting of lead oxifluoroborate glasses. Optical Express, v. 19, p. 17220-17225, 2011.

134 MIEDZINSKI, R. et al. Z-scan measurements of the third-order optical nonlinearities and linear optical properties of $70 \mathrm{teo}_{2}-5 \mathrm{~m} 10 \mathrm{p}_{2} \mathrm{O}_{5}-10 \mathrm{zno}-5 \mathrm{pbf}_{2}$ glasses doped with $\mathrm{er}^{3+}$ ions modified by transition metals. Optical Materials, v. 85, p. 48-54, 2018 .

135 DU, X. et al. Coloration and nonlinear optical properties of znte quantum dots in zno - teo $2-\mathrm{p}_{2} \mathrm{O}_{5}$ glasses. Journal of American Ceramic Society, v. 97(1), p. 185-188, 2014.

136 WANG, T. et al. Systematic z-scan measurements of the third order nonlinearity of chalcogenide glasses. Optical Materials Express, v. 4(5), p. 1011-1022, 2014.

137 LAKSHMI, S. V.; GEORGE, M. A.; GREBEL, H. Nonlinear optical properties of silicon nanoclusters. Applied Physics Letters, v. 70, p. 708, 1997.

138 DeUtSchBein, O. K.; PAUTRAT, C. C.; M, S. I. Phosphate glasses: new laser materials. Review of Physics Applied, v. 2, p. 29-37, 1967.

139 SESHADRI, M. et al. Effect of zno on spectroscopic properties of $\mathrm{sm}^{3+}$ doped zinc phosphate glasses. Physica B: Condensed Mater, v. 459, p. 79-87, 2015.

140 MYERS, J. D.; JIANG, S. Athermal laser glasses compositions with high thermal loading capacity. US Patent No.5 322, v. 820, 1994.

141 DUAN, Z. et al. New phosphor-tellurite glasses with optimization of transition temperature and refractive index for hybrid microstructured optical fibers. Optical Materials, v. 35, p. 2473-2479, 2013.

142 EL-MALLAWANY. Tellurite Glasses Handbook: Physical Properties and Data. [S.l.]: CRC Press, 2011.

$143 \mathrm{KONISHI}, \mathrm{T}$. et al. Investigation of glass formation and color properties in the $\mathrm{p}_{2} \mathrm{O}_{5}$ - teo ${ }_{2}$ - zno system. Journal of Non-Crystalline Solids, v. 324, p. 58-66, 2003.

144 WEBER, M. J.; MYERS, J. D.; BLACKBURN, D. H. Investigation of glass formation and color properties in the $\mathrm{p}_{2} \mathrm{O}_{5}-\mathrm{teO}_{2}$-zno system. Journal of Applied Physics, v. 52(4), p. 2944-2949, 1981.

145 MOSNER, P. et al. Structure and properties of zno- $\mathrm{b}_{2} \mathrm{O}_{3}-\mathrm{p}_{2} \mathrm{O}_{5}-\mathrm{teo}_{2}$ glasses. Materials Chemistry and Physics, v. 24, p. 732-737, 2010.

146 WANG, Y. et al. Physical properties and optical band gap of new tellurite glasses within the $\mathrm{teO}_{2}-\mathrm{nb}_{2} \mathrm{O}_{5}-\mathrm{bi}_{2} \mathrm{O}_{3}$ system. Materials Chemistry and Physics, v. 113, p. 407-411, 2009 .

147 LI, Y. et al. Structural, electronic, and optical properties of $\alpha, \beta$ and - $\mathrm{teo}_{2}$. Journal of Applied Physics, v. 107, p. 093506, 2010.

148 DimitROV, V. et al. Third harmonic generation in pbo $-\mathrm{sio}_{2}$ and pbo $-\mathrm{b}_{2} \mathrm{O}_{3}$ glasses. Journal of Ceramic Society of Japan, v. 101, p. 59-63, 1993. 
149 DIMITROV, V.; SAKKA, S. Linear and nonlinear optical properties of simple oxides ii. Journal of Applied Physics, v. 79, p. 1741, 1996.

150 DIMITROV, V.; KOMATSU, T. An interpretation of optical properties of oxides and oxide glasses in terms of the electronic ion polarizability and average single bond strength (review). Journal of the University of Chemical Technology and Metallurgy, v. 45, p. 219-250, 2010.

151 ALGRADEE, M. A. et al. Electronic polarizability, optical basicity and interaction parameter for $\mathrm{nd}_{2} \mathrm{O}_{3}$ doped lithium-zinc-phosphate glasses. Journal of Applied Physics A, v. 123, p. 524, 2017.

152 YOSHIMOTO, K. et al. Low phonon energies and wideband optical windows of $\mathrm{la}_{2} \mathrm{O}_{3}-\mathrm{ga}_{2} \mathrm{O}_{3}$ glasses prepared using an aerodynamics levitation technique. Scientific Reports, v. 7, p. 45600, 2017.

153 AJROUD, M. et al. Investigation of the spectroscopic properties of $\mathrm{nd}^{3+}$ doped phosphate glasses. Journal of Physics: Condensed Matter, v. 12, p. 3181, 2000.

154 SESHADRI, M.; ANJOS, V.; BELL, M. J. V. Energy transfer process and radiative properties of $1.06 \mu \mathrm{m}$ emission in $\mathrm{nd}^{3+}$ doped teo $2-$ zno $-\mathrm{na}_{2} \mathrm{O}$ glasses. Journal of Luminescence, v. 196, p. 399-405, 2018.

155 LINGANNA, K. et al. Effect of $\mathrm{p}_{2} \mathrm{O}_{5}$ addition on structural and luminescence properties of $\mathrm{nd}^{3+}$ doped tellurite glasses. Journal of Alloys and Compounds, v. 684, p. 322-327, 2016.

156 JIANG, Z.; YANG, J.; DAI, S. Optical spectroscopy and gain properties of nd ${ }^{3+}$ doped oxide glasses. Journal of Optical Society of America B, v. 21, p. 739-743, 2004.

157 MADHU, A. et al. $\mathrm{Nd}^{3+}$ doped lanthanum lead boro-tellurite glass for lasing and amplification applications. Optical Materials, v. 75, p. 357-366, 2018.

158 NOSTRAND, M. C. et al. Optical properties of $\mathrm{dy}^{3+}$ and $\mathrm{nd}^{3+}$-doped $\mathrm{kpb}_{2} \mathrm{cl}_{5}$. Journal of Optical Society of America B, v. 18(3), p. 264-276, 2001.

159 BABU, S. S. et al. Optical properties of $\mathrm{dy}^{3+}$ and $\mathrm{nd}^{3+}$-doped $\mathrm{kpb}_{2} \mathrm{cl}_{5}$. Journal of Luminescence, v. 130, p. 1021-1025, 2010. 